Chemical Technology Division

Chemical Technology Division

Chemical Technology Division

Chemical Technology Division

Chemical Technology Division

Chemical Technology Division

Chemical Technology Division

Chemical Technology

Division

Chemical Technology Division

Chemical Technology Division Chemical Technology Division Chemical Technology Division Chemical Technology Division Chemical Technology Division Chemical Technology Division Chemical Technology Division Chemical Technology

Division

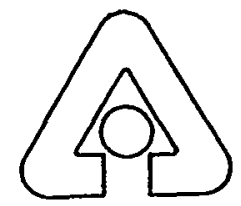

Argonne National Laboratory, Argonne, Illinois 60439 operated by The University of Chicago

for the United States Department of Energy under Contract W-31-109-Eng-38

Chemical Technology

Division

Chemical Technology

Division

Chemical Technology

Division

Chemical Technology

Division by J. S. Luo, T. A. Abrajano, Jr., and W. L. Ebert 
Argonne National Laboratory, with facilities in the states of Illinois and Idaho, is owned by the United States government, and operated by The University of Chicago under the provisions of a contract with the Department of Energy.

\section{DISCLAIMER}

This report was prepared as an account of work sponsored by an agency of the United States Government. Neither the United States Government nor any agency thereof, nor any of their employees, makes any warranty, express or implied, or assumes any legal liability or responsibility for the accuracy, completeness, or usefulness of any information, apparatus, product, or process disclosed, or represents that its use would not infringe privately owned rights. Reference herein to any specific commercial product, process, or service by trade name, trademark, manufacturer, or otherwise, does not necessarily constitute or imply its endorsement, recommendation, or favoring by the United States Government or any agency thereof. The views and opinions of authors expressed herein do not necessarily state or reflect those of the United States Government or any agency thereof.

Reproduced from the best available copy.

Available to DOE and DOE contractors from the Office of Scientific and Technical Information P.O. Box 62

Oak Ridge, TN 37831

Prices available from (423) 576-8401

Available to the public from the National Technical Information Service

U.S. Department of Commerce 5285 Port Royal Road

Springfield, VA 22161 


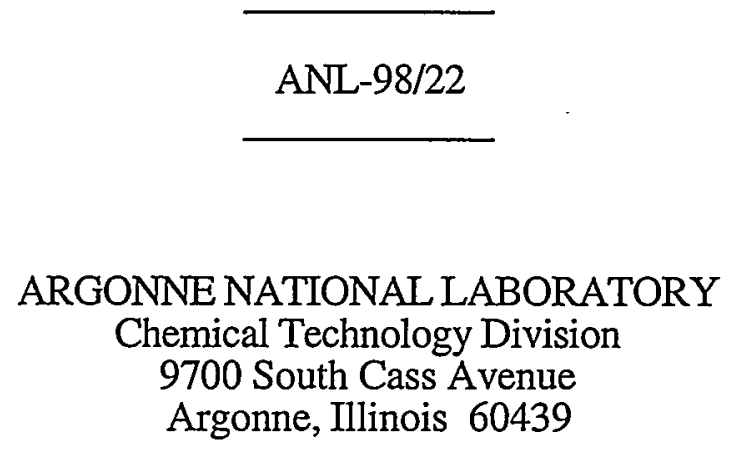

NATURAL ANALOGUES OF NUCLEAR WASTE GLASS CORROSION by

J. S. Luo, T. A. Abrajano, Jr., * and W. L. Ebert

September 1998

*Rensselaer Polytechnic Institute, Troy, NY 12180 



\section{DISCLAIMER}

Portions of this document may be illegible in electronic image products. Images are produced from the best available original document. 


\section{TABLE OF CONTENTS}

Abstract

I. Introduction.

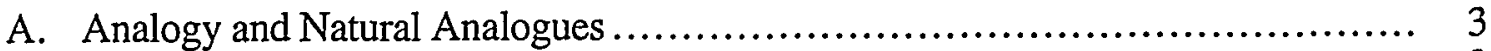

B. Natural Glasses ............................................................. 3

C. Previous Reviews of Natural Analogues ....................................... 4

D. High-Level Radioactive Waste Glasses..................................... 4

II. Mechanism and Rate Expression for Waste Glass Dissolution................... 6

III. Tektite Glasses ....................................................... 9

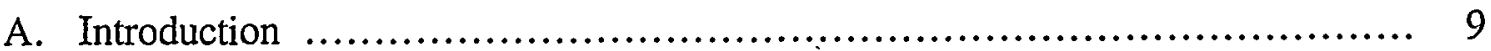

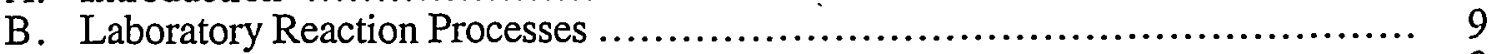

1. Reaction in Liquid Water............................................ 9

2. Hydration in Saturated Water Vapor....................................... 10

3. Laboratory Reaction Rates ............................................ 11

C. Natural Alteration of Tektites................................................ 12

1. Tektites from Australasian Field........................................... 12

2. Cretaceous/Tertiary Boundary Tektites................................... 14

3. Bottle-Green Microtektites ............................................ 17

4. Tektite Reaction Rates in Natural Environments ......................... 17

IV. Rhyolitic Glasses...................................................... 19

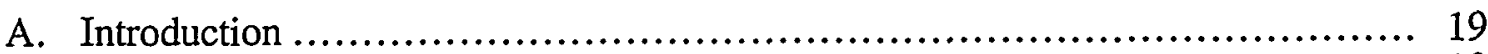

B. Laboratory Reaction Processes .............................................. 19

1. Reaction in Liquid Water............................................... 19

2. Hydration in Saturated Water Vapor........................................ 21

3. Laboratory Reaction Rates ............................................ 22

C. Natural Alteration of Obsidian .................................................. 25

1. Subaerial Alteration ...................................................... 25

2. Alteration in Liquid Water............................................. 26

3. Obsidian Reaction Rates in Natural Environment .......................... 28

V. Basaltic Glasses .......................................................... 31

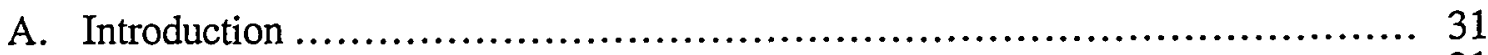

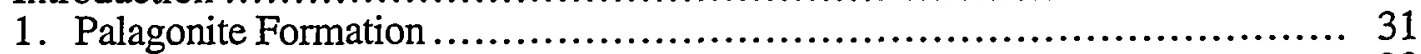

2. Formation of Secondary Minerals...................................... 32

B. Laboratory Reaction Processes ............................................... 32

1. Reaction in Liquid Water................................................ 32

2. Hydration in Saturated Water Vapor.......................................... 34

3. Laboratory Reaction Rates .................................................. 36

C. Natural Alteration of Basaltic Glasses.......................................... 39

1. Seawater Alteration ......................................................... 39

2. Subglacial Alteration.......................................................... 45

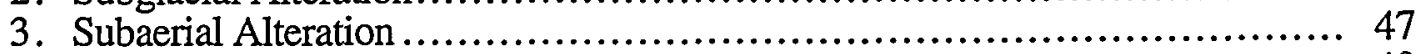

4. Hydrothermal Alteration................................................ 49 
TABLE OF CONTENTS (Contd.)

$\underline{\text { Page }}$

5. Reaction Rates.......................................................... 51

VI. Implications to Nuclear Waste Glasses ....................................... 56

A. Introduction ............................................................ 56

B. Lessons from Natural Glass Alteration ....................................... 56

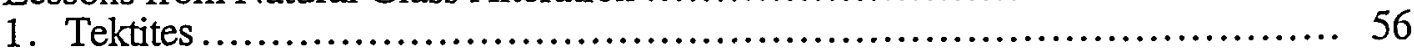

2. Rhyolitic Glasses....................................................... 57

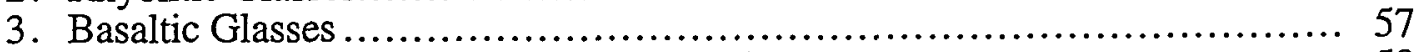

C. Natural Glasses as Nuclear Waste Glass Analogues ............................... 58

1. Are Natural Glasses Good Analogues of Nuclear Waste Glasses? ............ 58

2. Mechanism and Rate Expression for Palagonitization ........................ 60

3. Long-Term Kinetics .................................................. 62

VII. Conclusions..................................................................... 65

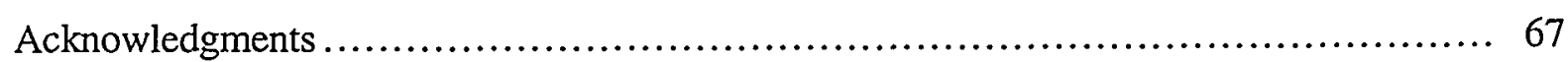

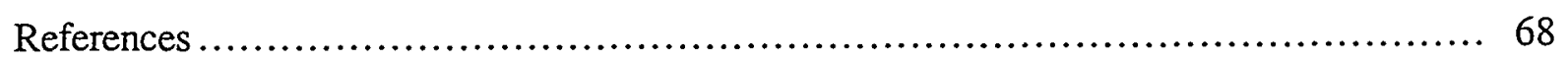

Appendix: Laboratory Testing and Characterization of Natural Analogue and

Waste Glasses....................................................................... 81 


\section{LIST OF FIGURES}

$\underline{\text { Page }}$

III-1. (a) Thickness of altered layers increases linearly with $t^{1 / 2}$ for tektites hydrated at various temperatures, suggesting a diffusion-controlled reaction. (b) The temperature dependence of the hydration process shows Arrhenius behavior with an activation energy of $91 \mathrm{~kJ} / \mathrm{mol}$.

III-2. Scanning electron micrographs showing tektites from various strewn fields exhibiting characteristic surfaces with no evidence of forming alteration layers at surface

III-3. Scanning electron micrographs of glass spherules recovered from the $\mathrm{K} / \mathrm{T}$ boundary at Beloc, Haiti, showing the formation of alteration layer at outer surfaces of tektites

IV-1. (a) The hydrated rind of an obsidian artifact shows a sharp interface between the hydrated and nonhydrated glass. (b) The same sample shows a bright contrast under crossed Nicol prisms because it is under strain

IV-2. The effects of the intrinsic water content of Snake River obsidian on (a) the hydration rate at $160^{\circ} \mathrm{C}$ and (b) the activation energy of hydration prociess

IV-3. Sorption isotherm collected at room temperature for a Snake River obsidian

IV-4. Depth profiles of $\mathrm{H}, \mathrm{Na}, \mathrm{K}, \mathrm{Li}, \mathrm{Ca}, \mathrm{Mg}, \mathrm{Si}$, and $\mathrm{Al}$ in an obsidian artifact from Kaminaljuyu, Guatemala, plotted as the number of photon counts versus the sputtering time and depth

IV-5. The square of hydration rim thickness versus age of Mummy Cave obsidian samples showing a linear time dependence

$\mathrm{V}$-1. Normalized mass loss for $\mathrm{Si}, \mathrm{Na}, \mathrm{Al}, \mathrm{Ca}$, and $\mathrm{Mg}$ as a function of time for Hawaiian basalt glass hydrothermally leached at $150^{\circ} \mathrm{C}$ in deionized water.

$\mathrm{V}-2$. Scanning electron micrographs of Hawaiian basalt glass and borosilicate waste glass reacted in saturated synthetic $\mathrm{NaCl}$ solution at $200^{\circ} \mathrm{C}$ for 30 days

$\mathrm{V}-3$. Decrease of the Li-spiked glass dissolution rate in neutral feed solutions as a function of time

V-4. Growth rate of palagonite observed from alkali basaltic glass reacted at $20,43,70$, and $90^{\circ} \mathrm{C}$ in deionized water

V-5. Scanning electron micrographs of palagonite formed on a deep sea-altered basaltic glass from the Mid-Atlantic Ridge.

V-6. Compositional variations between glass and palagonite of basaltic glasses altered under various conditions. 


\section{LIST OF FIGURES (Contd.)}

Page

V-7. Iron and titantium contents versus distance from glass core to palagonite layer....... 43

V-8. Commonly observed secondary phases formed on the surface of seawater-altered basaltic glasses ............................................................... 45

V-9. Optical images of the surfaces of naturally altered Hawaiian basaltic glasses showing spallation taking place in many samples due to dry/precipitation cycling .... 48

V-10. Formation of alteration phases as a function of temperature for glassy and crystalline basalts from the East Pacific Rise, California.......................... 50

$\mathrm{V}-11$. The relationship between the rates of palagonite rind formation and the forward and final rates of reaction 


\section{LIST OF TABLES}

Page

III-1. Average compositions of bottle-green microtektites ............................. 16

III-2. Average, standard deviation, and range of composition for 11 black impact glasses from Haiti ..................................................... 17

III-3. Average values of dissolution rates and $\mathrm{SiO}_{2}$ content ......................... 18

IV-1. Chemical analyses of typical obsidian samples from various locations .............. 20

IV-2. Published hydration depth vs. time formulas to determine age of volcanic glasses grouped in the order of faster penetration reading downward............... 30

V-1. Chemical formulae of common minerals in glass alteration layer .................... 32

$\mathrm{V}-2$. Average composition of glass and corresponding palagonite rinds in deep sea

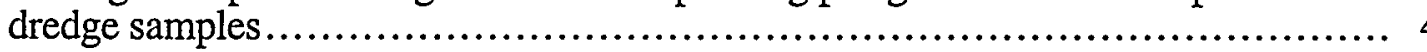

V-3. Summary of reaction rates of basalt glass in aqueous environments at approximately $3^{\circ} \mathrm{C}$, as calculated from age and palagonite rind thickness............ 52

V-4. TRZ calculated for subglacial hyaloclastites and other samples from Iceland ......... 55 


\title{
NATURAL ANALOGUES OF NUCLEAR WASTE GLASS CORROSION
}

by

\author{
J. S. Luo, T. A. Abrajano, Jr., and W. L. Ebert
}

\begin{abstract}
This report reviews and summarizes studies performed to characterize the products and processes involved in the corrosion of natural glasses. Studies are also reviewed and evaluated on how well the corrosion of natural glasses in natural environments serves as an analogue for the corrosion of high-level radioactive waste glasses in an engineered geologic disposal system. A wide range of natural and experimental corrosion studies has been performed on three major groups of natural glasses: tektite, obsidian, and basalt. Studies of the corrosion of natural glass attempt to characterize both the nature of alteration products and the reaction kinetics. Information available on natural glass was then compared to corresponding information on the corrosion of nuclear waste glasses, specifically to resolve two key questions: (1) whether one or more natural glasses behave similarly to nuclear waste glasses in laboratory tests, and (2) how these similarities can be used to support projections of the long-term corrosion of nuclear waste glasses. The corrosion behavior of basaltic glasses was most similar to that of nuclear waste glasses, but the corrosion of tektite and obsidian glasses involves certain processes that also occur during the corrosion of nuclear waste glasses. The reactions and processes that control basalt glass dissolution are similar to those that are important in nuclear waste glass dissolution. The key reaction of the overall corrosion mechanism is network hydrolysis, which eventually breaks down the glass network structure that remains after the initial ion-exchange and diffusion processes. This review also highlights some unresolved issues related to the application of an analogue approach to predicting long-term behavior of nuclear waste glass corrosion, such as discrepancies between experimental and field-based estimates of kinetic parameters for basaltic glasses.
\end{abstract}




\section{INTRODUCTION}

In this report, we critically review studies performed to characterize the products and processes involved in the corrosion of natural glasses and evaluate how well the corrosion of natural glasses in natural environments serves as an analogue for the corrosion of high-level radioactive waste glasses in an engineered geologic disposal system. By critical review, we mean, primarily, that we assess the work with regard to possible sampling and experimental artifacts, interpretation of data, and consistency with other studies. This report is not meant to be a comprehensive review of natural glass weathering. In selecting and synthesizing the many observations that workers have made previously regarding the weathering of natural glasses for the present report, our paramount concern was the specific relevance of the observations to nuclear waste glass corrosion in geologic repositories.

The use of analogue materials has been suggested as a means of enhancing confidence in the validity of long-term predictions made with mechanistic models, as well as assisting in the development of those models [ASTM-1991]. By studying the alteration of natural materials that has occurred over thousands to billions of years.through weathering in various terrestrial environments, insight may be gained into the corrosion behavior of glasses made to immobilize radioactive wastes over long times in an engineered geologic repository environment. Two types of analogue studies are considered, which serve related, but distinct, purposes. The first involves examination and characterization of the altered natural analogue glasses, usually for archeological or geological interest. These studies provide the nuclear waste community an inventory of alteration products that form over long reaction times and clues regarding the processes involved in the glass corrosion mechanism. The second type of study involves performing laboratory tests with natural glass materials (or synthetic homologues). Some tests are conducted to study the corrosion mechanism and dissolution kinetics, and others are conducted to simulate long-term corrosion within a controlled laboratory setting. Combining these types of studies provides a means of confirming that laboratory tests can reproduce alteration that occurs over geologic time periods in nature. If the same alteration modes control the long-term corrosion of natural glasses and nuclear waste glasses, then the same laboratory experiments that accelerate the corrosion of natural glasses can be used with confidence to accelerate the corrosion of nuclear waste glasses.

In this report we consider in detail three ways in which the corrosion behavior of natural analogues is commonly used to better understand the corrosion of nuclear waste glass:

- Comparison of alteration products generated during long-term corrosion of natural glasses with those generated in accelerated ${ }^{*}$ laboratory tests to verify experimental methods of accelerating glass corrosion,

- Study of specific reaction products and processes in the laboratory that are important for both natural and nuclear waste glass corrosion, and

- Study of the relationship between the kinetics of natural glass corrosion measured in short-term laboratory tests and the observed long-term weathering of the glass to verify the appropriate reactions and processes that could also be important for nuclear waste glasses.

Brief summaries of the method of analogy, high-level waste glasses, and the mechanistic model of waste glass corrosion are presented first to provide a background for the use of natural

\footnotetext{
*In the context of the present report, "accelerated" is used to imply formation of alteration products normally produced over long periods of time in a shorter experimental time frame. This is achieved by using experimental conditions (e.g., temperature, water/glass ratio) that increase the rates of corrosion processes and reveal aspects of advanced stages of corrosion progress.
} 
analogues. Literature relevant to the alteration of tektite, obsidian, and basalt glasses in nature and in laboratory tests is then critically evaluated to assess how this information can be utilized for waste management. An appendix provides detailed results of microscopic examinations performed at Argonne National Laboratory of naturally reacted basalt glass and experimentally reacted obsidian, basalt, and several high-level waste glasses. Finally, conclusions based on review of the literature and our own experiments are discussed to summarize the usefulness and limitations of natural analogues in nuclear waste management.

\section{A. Analogy and Natural Analogues}

Analogy is a proven scientific method that uses inference from certain resemblances to imply a probable further similarity [EWING-1987; PETIT-1992B]. Analogy is useful for situations in which direct demonstration and model verification are impossible. For example, it is impossible to carry out experiments over the very long periods of time for which the corrosion behavior of nuclear waste glasses must be predicted. The method of analogy allows us to test the veracity of chemical models or determine the range of conditions under which a particular model is applicable [MILLER-1994; MULER-1995].

The term "natural analogue" has been used in the nuclear waste community to refer to an occurrence of materials or processes that resemble those expected in a proposed geological waste repository [CÔME-1986]. The term also refers to the methodology used to study and assess such materials and processes [IAEA-1989]. In the case of using natural glasses as analogues for nuclear waste glasses, the analogues should ideally provide confirmation of thermodynamic and kinetic models used to calculate the long-term corrosion behavior of nuclear waste glasses [EWING-1979; EWING-1987]. Information regarding important alteration processes is commonly inferred by characterizing the alteration products of naturally reacted glasses recovered from a wide range of geologic environments and by studying the reaction kinetics under carefully controlled laboratory conditions. If the alteration products formed by natural processes over long times can be reproduced in laboratory experiments with the natural materials and the same experimental method produces similar alteration of waste glass, then similar processes are likely to determine the long-term corrosion of waste glass. The mechanisms of these processes can be studied and models developed with laboratory tests. If the models describe the long-term alteration observed with natural analogues, then they can be applied to calculate the long-term alteration of waste glasses with confidence. The level of confidence provided by analogue studies will necessarily depend on the degree of similarity between natural glasses that were altered experimentally and over long times in the field, and the similarity between the alteration mechanisms of natural and nuclear waste glasses.

\section{B. Natural Glasses}

Natural glasses that have been studied as natural analogues for high-level waste (HLW) glasses are tektites [BARKATT-1984; BARKATT-1986], rhyolitic (obsidian) glasses [MALOW-1984; DICKIN-1981], and basaltic glasses [EWING-1979; BATES-1982A; BATES-1982B, MALOW-1984]. The samples of these glasses that have been studied range in age from very young to millions of years old, and cover a wide compositional range. These glasses are studied as analogues because (1) they occur in the natural environment, where they are exposed to the weathering action of water, and (2) because they are alumino-silicate glasses that contain some of the same components as nuclear waste glasses. Basaltic glasses have been studied most extensively because they have silica contents similar to those of $\mathrm{HLW}$ glasses, or about 50 $\mathrm{wt} \% \mathrm{SiO}_{2}$. Most tektites and rhyolitic glasses have silica contents greater than $70 \mathrm{wt} \%$ and have been used as analogues of glasses with the high silica contents and low alkali metal contents that were once proposed to encapsulate wastes [DICKIN-1981]. Man-made archeological glasses have also been studied as analogues for waste glasses [RYAN-1993]. Although basaltic glasses have been studied the most as analogues for waste glasses, examination of a wide range of natural glass 
compositions provides useful insight to the effects of glass composition on weathering processes and the reaction products formed.

\section{Previous Reviews of Natural Analogues}

Ewing and others were first to suggest using natural glasses as analogues for nuclear waste glasses [EWING-1979]. They reviewed the natural analogue literature with regard to alteration analysis, field studies, modeling, etc. [EWING-1987]. They also discussed the applications and limitations of the "proof by analogy" method. Other reviews on the development and application of natural analogues have also been given by Adams [ADAMS-1984], Malow [MALOW-1984], Jercinovic [JERCINOVIC-1992], Ewing [EWING-1992], Mazer [MAZER1994], Petit [PETIT-1992A], and McKenzie [McKENZIE-1990].

Chapman [CHAPMAN-1984] published the first major assessment of natural analogue studies. Most of those were directly relevant to the Swiss high-level waste and the Swedish spent fuel repository concepts. Sites being studied for European repositories are all below the water table. Therefore, scenarios in which waste is contacted by liquid water are most probable. In contrast, the Yucca Mountain site being studied by the U.S. Department of Energy lies hundreds of meters above the water table in a hydrologically unsaturated zone. Scenarios in which waste is contacted by water vapor and small volumes of transient water are more likely than those involving contact by a large volume of liquid water. Clearly, the conditions under which analogue materials have weathered will affect how applicable they are to a particular disposal system.

More recently, the first book on natural analogue studies has been published [MILLER-1994]. This book provides a comprehensive review of studies of many physicochemical processes (including the corrosion of glasses) that control the release of radionuclides from the waste package and their subsequent transport in the geosphere. Because of the broad coverage of this book, the discussion of glass analogues was not exhaustive, and many important studies were not discussed in detail.

In this report, our focus is on the similarities that exist between alteration phases formed during natural weathering of natural glasses and the accelerated weathering induced by laboratory experiments, the similarities between the processes that control the weathering of natural glasses and those that control corrosion of nuclear waste glasses, and the use of natural analogue materials to confirm the accelerating aspects of laboratory tests that have been applied to waste glasses. A brief description of the current model for waste glass corrosion behavior is presented below to identify the reaction processes of natural glasses that are of greatest interest.

\section{High-Level Radioactive Waste Glasses}

Borosilicate glass is being used to immobilize high-level radioactive wastes stored at various U.S. Department of Energy (DOE) sites. Waste glasses will eventually be disposed in a Federal repository. A hydrologically unsaturated site at Yucca Mountain, NV, is currently being evaluated as a possible disposal site. The proposed horizon lies several hundred meters below the surface and several hundred meters above the water table in an unsaturated zone. It is anticipated that the thermal load of emplaced waste due to the decay of radionuclides in the waste will drive water from the immediate vicinity initially. Under these conditions, waste packages can most likely only be contacted by water vapor and, perhaps, small amounts of liquid water. Liquid water may return as the temperature drops below the local boiling point (which is about $96^{\circ} \mathrm{C}$ ). Corrosion of engineered barriers (e.g., the metal container and pour canister containing the waste glass) will allow water to contact and corrode the waste glass. Corrosion of the glass will allow radionuclides to enter the groundwater and be transported from the repository into the surrounding 
environment. The durability of glass that has reacted with water vapor will probably be diminished relative to the original glass.

Regulations promulgated by the U.S. Nuclear Regulatory Commission (NRC) require that the release of radionuclides from the engineered barrier system (EBS) following the initial 300-1000 y containment period (during which no material may be released from the repository) shall not exceed 1 part in $10^{5}$ per year of the inventory at 1000 y [10 Code of Federal Regulations (CFR)60.113(a)]. That this regulation will likely be met must be demonstrated by means of performance assessment (PA) calculations conducted for the entire disposal system. While the release of radionuclides from the glass waste forms is not specifically regulated, glass corrosion provides the source term for radionuclides that is needed for the PA calculations. Therefore, an understanding of the corrosion behavior of waste glasses over long time periods in repository-relevant environments is necessary to calculate the performance of a disposal system over its very long service life.

The requirement that the behavior of a material be calculated over the tens of thousands of years service life of a repository is unprecedented. Most engineering materials are designed to have a service life of tens or perhaps a few hundred years. The behavior of most materials, including high-level waste glasses, is too complex to allow simple extrapolation of short-term behavior to long times. Instead, a mechanistic model describing the corrosion behavior of waste glasses must be developed that takes into account the effects of environmental parameters, which may change over time. Our confidence in the applicability of such a mechanistic model can be vastly enhanced if observations of long-term glass alteration can be compared with model predictions, or at least those of the fundamental processes that comprise the model. Since observation of the long-term corrosion behavior of nuclear waste glasses is clearly not possible, our next best approach is to use insight from the observations of natural analogues. This is done by first identifying alteration modes that are common to both natural and nuclear waste glasses. Models can be developed for these processes and model parameters measured with laboratory tests. Our understanding and modeling of these individual processes that contribute to the longterm corrosion of both natural glass materials and nuclear waste glasses can be validated by comparing model predictions with observations made on natural samples that have been weathered for long periods of time. These same models can then be applied to nuclear waste glasses to predict their long-term corrosion behaviors.

In this report, we summarize what is known regarding the mechanism, corrosion behavior, and alteration phases formed during the weathering of natural glasses in various natural environments and compare that behavior to the behavior of nuclear waste glasses. We begin by summarizing the mechanistic model of nuclear waste glass corrosion that has emerged over the past 15 years (Sec. II). This is done to identify the processes for which natural analogues are needed. We then review studies of natural glass degradation (Sec. III, IV, and V) to elucidate the long-term corrosion behavior of glass in natural systems. The reviews are not intended to be exhaustive; rather, our intent is to identify aspects of natural glass corrosion that bear on the issue of long-term corrosion of nuclear waste glasses. Our initial emphases in these reviews is on corrosion of natural glasses experimental systems over short test durations. The review of the long-term alteration of natural glasses is presented with the intent of evaluating (1) whether similar processes control the corrosion behaviors of these natural glasses and nuclear waste glasses in short-term laboratory tests, and (2) whether the models formulated for these processes that are important to the long-term corrosion of nuclear waste glasses and natural glasses. In addition, sufficient details of the characteristics of glasses as they were found and the environmental conditions that prevailed during their alteration are discussed to allow a full appreciation of how these conditions are similar or dissimilar to those that may be expected in geologic repositories. 


\section{MECHANISM AND RATE EXPRIESSION FOR WASTE GLASS DISSOLUTION}

Over many years of testing borosilicate glasses for waste immobilization, a mechanistic and kinetic understanding of the corrosion processes has emerged [BOURCIER-1991, BOURCIER1994A; BOURCIER-1994B; STRACHAN-1994; CUNNANE-1995; EBERT-1996]. The corrosion process is summarized below as a basis for evaluating whether similar mechanisms or processes control the corrosion of natural glasses. If the mechanistic models used to describe corrosion of nuclear waste glasses can be shown to adequately describe similar processes affecting natural glasses, including long-term behavior in the latter, then indirect validation of long-term nuclear waste glass behavior will have been achieved "by analogy."

Glass is thermodynamically unstable with respect to an assemblage of alteration phases, and the stability of a glass is due to the kinetic inhibition of direct transformation. However, when glass is contacted by water, the transformation of the glass to thermodynamically more stable alteration phases can occur via a dissolution/reprecipitation mechanism. The processes leading to dissolution of silicate glasses in water include mass transport, ion exchange, and hydrolysis. The relative importance of each process to glass dissolution changes in response to changes in the solution chemistry and glass surface as corrosion proceeds. Although these three processes can occur simultaneously, they do not proceed independently. Ion exchange is the fastest process that occurs. This leads to the formation of a dealkalized layer forms at the outer surface of the glass through which water must diffuse to access alkali metal ions within the glass. The release rates of alkali metal depend both on the kinetics of the ion-exchange reactions and water diffusion, and will decrease as this layer becomes thicker. Concurrently with the dealkalization reactions, the outer surface of the glass (of the dealkalized layer) dissolves via hydrolysis reactions. The alkalidepleted layer is maintained at a nearly constant thickness as the outer surface dissolves and ion exchange occurs beneath the layer. Therefore, the rate of the coupled ion-exchange/diffusion process can become limited by the rate at which the outer surface is etched via hydrolysis reactions.

Because Si-O bonds are the most abundant, their hydrolysis at the surface is taken to be the rate-controlling reaction for long-term corrosion. Although the hydrolysis reaction can occur with either water or hydroxide as the nucleophile, it is usually written with water as

$$
\mathrm{R}-\mathrm{Si}-\mathrm{O}-\mathrm{Si}(\mathrm{OH})_{3}+\mathrm{H}_{2} \mathrm{O} \leftrightarrow \mathrm{R}-\mathrm{Si}-\mathrm{OH}+\mathrm{H}_{4} \mathrm{SiO}_{4}
$$

where $\mathrm{R}$ represents the rest of the solid material. A rate expression for this reaction was derived by using nonequilibrium thermodynamics to describe silicate mineral dissolution [AAGAARD-1982]. In this expression, the net rate is given by the product of the forward (dissolution) rate of the glass and an affinity term representing the deviation of the solution from saturation with respect to the dissolving solid phase. The net rate can be expressed as

$$
\text { net rate }=\mathrm{k}_{\mathrm{f}}(1-\mathrm{Q} / \mathrm{K})
$$

where $\mathrm{k}_{\mathrm{f}}$ is the forward rate in Eq. $\Pi-1, \mathrm{Q}$ is the ion activity product of the solution and $\mathrm{K}$ is the equilibrium constant for the dissolving solid. From Eq. $\mathrm{I}-1$, orthosilicic acid $\left(\mathrm{H}_{4} \mathrm{SiO}_{4}\right)$ is the only species that contributes to $\mathrm{Q}$ and $\mathrm{K}$; the solid reactant and product species in Eq. $\Pi-1$ are assumed to be at unit activity. 
The same rate expression has been applied to glass dissolution [GRAMBOW-1985]. This expression represents an approximation of the actual reaction that is observed for glasses, which is a type of irreversible dissolution reaction. This requires some explanation. Because glass is thermodynamically unstable, it cannot equilibrate with an aqueous solution and an equilibrium constant cannot be defined. However, experiments show that the glass dissolution rate may become immeasurably low as the solution approaches and apparent maximum silicon concentration, which depends on the temperature and solution $\mathrm{pH}$, and perhaps the concentrations of other solutes. The reaction can be thought of as attaining what has been referred to as a pseudoequilibrium [McGRAIL-1995], where the apparent equilibrium is due to very slow kinetics rather than thermodynamic stability. A value for $\mathrm{K} 1 *$, the pseudo-equilibrium constant, can be defined that corresponds with the maximum silicon concentration. Because glass cannot be formed by the reverse reaction, it is assumed that only the silica network forms in the reverse reaction. Therefore, the glass is modeled to dissolve in the forward reaction; but only the O-Si bonds form in the reverse reaction, and these determine the pseudo-equilibrium conditions. Because the maximum silicon concentrations measured in dissolution experiments are often similar to the solubility limits for amorphous silica, the "rate-controlling phase" formed by the reverse reaction is modeled to be a thermodynamically stable surrogate phase, such as chalcedony $\left(\mathrm{SiO}_{2}\right)$. The value of the equilibrium constant for that phase is used for $\mathrm{K}^{*}$.

According to the Grambow model for glass dissolution, $\mathrm{Q}$ and $\mathrm{K}$ only include the orthosilicic acid activities in the solution and at equilibrium, respectively. We note that the thermodynamic instability of the glass precludes $\mathrm{Q}$ and $\mathrm{K}$ from ever becoming exactly equal.

The glass dissolution rate is known to depend on the glass composition, the $\mathrm{pH}$, the temperature, and the orthosilicic acid activity. Based on the experimentally determined dependencies, the net reaction rate can be written as [McGRAL-1995]

$$
\text { net rate }=\mathrm{k}_{0} 10^{\mathrm{h} p \mathrm{pH}} \exp \left(-\mathrm{E}_{\mathrm{a}} / \mathrm{RT}\right)\left[1-(\mathrm{Q} / \mathrm{K})^{\mathrm{s}}\right]
$$

where $\mathrm{k}_{0}$ is the intrinsic dissolution rate of the glass, $\mathrm{h}$ is the power coefficient of the $\mathrm{pH}$ dependence, $\mathrm{E}_{\mathrm{a}}$ is the activation energy, and $\mathrm{Q}$ and $\mathrm{K}$ are the orthosilicic acid activities in the solution and at saturation (pseudo-equilibrium), respectively, and s is the net reaction order, which is assumed to be unity. The $\mathrm{pH}$ dependence in the rate equation is consistent with hydroxide being the dominant nucleophile. The reverse reaction is assumed to form a pure silica phase, such as chalcedony, and the equilibrium constant of this pure silica phase is used as $\mathrm{K}$. This expression quantifies how the glass composition, $\mathrm{pH}$, temperature, and silicic acid concentration affect the glass dissolution rate.

The dependence of the rate on the glass composition is included in $\mathrm{k}_{\mathrm{o}}$, the value of which is usually determined experimentally. The terms giving the $\mathrm{pH}$ and temperature dependencies $\mathrm{h}$ and $E_{a}$, respectively) are also determined experimentally. The value of $h$ has been measured to be about 0.4 for several glasses having different compositions, including a simple five-component glass [KNAUSS-1990], R7T7 glass [ADVOCAT-1991], and the LD6-5412 glass [McGRAIL-1997]. The activation energies for dissolution of these glasses have been measured to be 80,60 , and $75 \mathrm{~kJ} / \mathrm{mol}$, respectively, under conditions in which the affinity term was nearly one.

Under static or nearly static conditions, the activity of orthosilicic acid will increase as the glass dissolves. Two limiting conditions exist for the rate expression: (1) glass dissolves at a maximum rate when $\mathrm{Q}$ is zero and $(1-\mathrm{Q} / \mathrm{K})$ is one, and (2) glass dissolves at a minimum rate near 
zero when $\mathrm{Q}$ is at the saturation value of chalcedony and $(1-\mathrm{Q} / \mathrm{K})$ is near zero. These rates are usually referred to as the forward and residual rates, respectively. The residual rate will always be slightly greater than zero because of the thermodynamic instability of glass.

Glass is thermodynamically unstable with respect to an assemblage of mineral phases that corresponds with the glass and leachant compositions. The formation of these phases during the corrosion of radioactive waste glasses will affect the disposition of released radionuclides and the dissolution rate of the glass. Radionuclides may become immobilized by incorporation into precipitated phases or mobilized by association with colloids. The effect of alteration phase formation on the glass dissolution rate is taken into account in model calculations by the changes in the values of $\mathrm{Q}$ and the $\mathrm{pH}$. Phases that consume silicon as they form have the greatest influence on the glass dissolution rate because they remove orthosilicic acid from the solution. The decrease in $\mathrm{Q}$ as orthosilicic acid is consumed by phase formation usually results in an increase in the dissolution rate in laboratory experiments.

In comparing the corrosion behaviors of natural glasses and nuclear waste glasses, we can look at the relative importance of water diffusion, ion exchange, and hydrolysis reactions as corrosion proceeds. Tests and analyses conducted previously, some of which will be discussed in detail in the following sections, have shown that these same processes are important during the weathering of tektites, rhyolic, and basaltic glasses, although the relative importance of each process varies with the glass and the weathering environment. In addition to providing insight into the long-term effects of individual processes on the weathering of these glasses, studies of the natural glasses provide insight into the importance of each process in various environments.

The alteration phases formed as glasses corrode provide a convenient means of comparing the corrosion of glasses that occurs in natural environments with corrosion in laboratory tests. That is, the formation of the same alteration phases in nature and in laboratory experiments provides evidence that the reaction path is likely the same in both cases, and that the techniques used to accelerate the glass corrosion in the laboratory tests did not affect the mechanism. This is because the phases that form first as a glass corrodes are kinetically favored, but not necessarily thermodynamically favored. That the same kinetically favored phases form implies that the evolution of the solution chemistry is also the same. Thus, the occurrence of a particular phase on a weathered analogue glass reveals the stability of that phase relative to other phases that may be thermodynamically more stable. In other cases, the replacement of phases formed initially by more stable phases can be observed either through remnants of the dissolving phase or by examination of sample of varying age. 


\section{TEKTITE GLASSES}

\section{A. Introduction}

Tektite glasses are formed when rock, sand, or soil is melted by meteoritic impact. Most tektites were formed millions of years ago and have weathered in a wide range of geological environments. The unaltered glass is blackish or translucent green in color [O'KEEFE-1994; O'KEEFE-1984; GLASS-1984B]. Depending on the impact location, a wide range of compositions have been found for tektites. For example, Libyan tektite are pure silica glasses formed by bolide impact on sand [BARNES-1990]. Tektites were deposited in both deep sea environments and land areas following impact and subsequent scattering. Most tektites occur as splash forms that are about one centimeter in diameter. Tektites with diameters less than $1 \mathrm{~mm}$ are called microteketites and are generally found in deep sea sediment [MELOSH-1991; GLASS-1984B].

Tektites are found in several areas called strewn fields. Strewn fields of various ages have been recognized worldwide. The major fields are the Australian ( 0.7 million years old, both land and sea), Ivory Coast ( 1 million years old, land), Czechoslovakian (14.8 million years old, land), and North American (35 million years old, land) [BARNES-1990; GLASS-1984B]. Recently, tektites have been found at the cretaceous/tertiary $(\mathrm{K} / \mathrm{T})$ boundary, having been formed more than 65 million years ago [SIGURDSSON-1991; MARGOLIS-1991; IZETT-1991]. They have been offered as evidence that meteorites were responsible for the extinction of large dinosaurs.

\section{B. Laboratory Reaction Processes}

\section{Reaction in Liquid Water}

Barkatt and others [BARKATT-1984] conducted dissolution experiments with two types of tektites, australites and indochinites, at $90^{\circ} \mathrm{C}$ in deionized water under highdilution conditions (at a glass surface area/solution volume, or $\mathrm{S} / \mathrm{V}$, ratio of $15 \mathrm{~m}^{-1}$ ) for durations up to five years. Analysis of solution compositions showed that selective leaching of the alkali elements $\mathrm{Na}$ and $\mathrm{K}$ occurred during the first few hours of reaction, but that the corrosion at longer times was dominated by congruent dissolution [BARKATT-1984]. They also reacted the glasses at several $\mathrm{S} / \mathrm{V}$ ratios $\left(15-3500 \mathrm{~m}^{-1}\right)$ and temperatures $\left(25\right.$ to $\left.90^{\circ} \mathrm{C}\right)$ and found that tektites reacted by the same congruent dissolution process under all these conditions. LaMarche and others [LaMARCHE-1984] reported formation of surface etching pits and stoichiometric dissolution of an indochinite glass that was reacted in deionized water at $90^{\circ} \mathrm{C}$. Measurement of the hydrogen concentration versus depth using nuclear reaction technique revealed that the hydrated surface layer was $<0.1 \mu \mathrm{m}$ thick, confirming that the dominant reaction process is dissolution.

These studies demonstrate that congruent dissolution controlled by reactions analogous to Eq. II-1 dominate the corrosion process of tektite glasses in laboratory dissolution tests, and that selective leaching occurs only for very short times, if at all. This would therefore imply that a rate equation similar to Eq. II-2 could be used to describe the net glass dissolution rate of tektites.

Barkatt and others [BARKATT-1986] also compared the leaching behavior of synthetic microtektites in deionized water and seawater. They reported that tektites dissolved congruently in both solutions, but the glass dissolved much faster in deionized water than in seawater. Surface analysis with electron microprobe spectroscopy showed the formation of a magnesium-rich layer on the surface of seawater-reacted samples, which may have slowed the glass dissolution process. However, the exact nature of this layer has not been established: it 
could result either from sorption of $\mathrm{Mg}^{2+}$ or from the formation of magnesium-silicates, such as sepiolite $\left[\mathrm{Mg}_{4}(\mathrm{OH})_{2} \mathrm{Si}_{6} \mathrm{O}_{15} \mathrm{H}_{2} \mathrm{O}\right]$.

\section{Hydration in Saturated Water Vapor}

When reaction occurs in water vapor or in a small amount of liquid water, glass alteration occurs by water incorporation into the glass (i.e., hydration) rather than glass dissolution. Mazer and others [MAZER-1991A, -1992A] reacted indochinite tektites at temperatures ranging from 125 to $250^{\circ} \mathrm{C}$ in saturated water vapor and observed the formation of optically visible birefringent layers. The layer thickness increases with time as a function of $\mathrm{t}^{1 / 2}$ (see Fig. III-1), which is characteristic of a diffusion-controlled process [MAZER-1991A, -1992A]. Rauch and others [RAUCH-1992] also reported evidence of water diffusion in indochinite tektites at a temperature range of 125 to $200^{\circ} \mathrm{C}$ obtained by profiling hydrogen concentration by using resonant nuclear reaction technique.
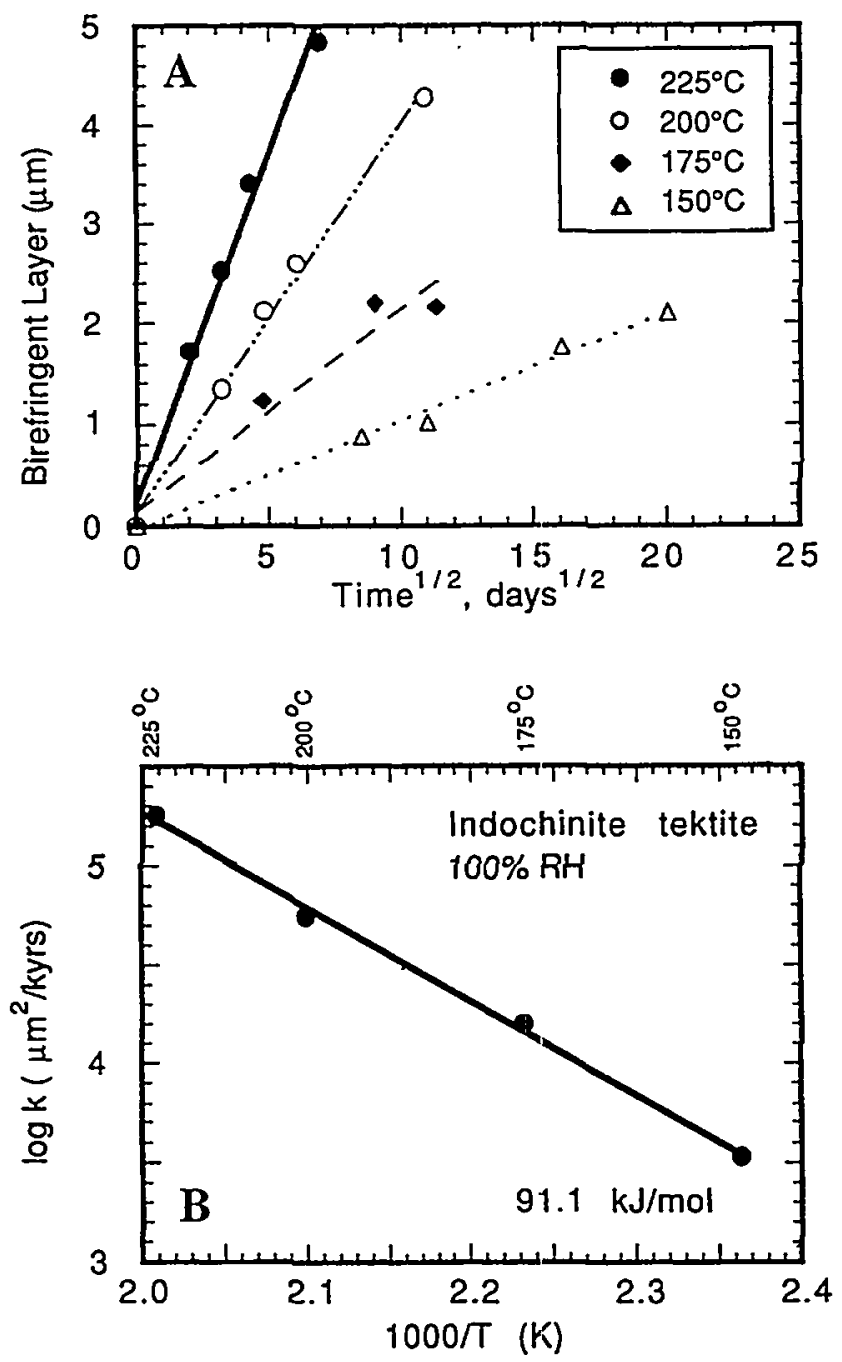

Fig. III-1. (a) Thickness of altered layers increases linearly with $t^{1 / 2}$ for tektites hydrated at various temperatures, suggesting a diffusion-controlled reaction. (b) The temperature dependence of the hydration process shows Arrhenius behavior with an activation energy of $91 \mathrm{~kJ} / \mathrm{mol}$ [MAZER-1991A]. 
We note that the aforementioned experiments were conducted at temperatures of $125-200^{\circ} \mathrm{C}$ and at $100 \%$ relative humidity ( $\left.\mathrm{RH}\right)$. The water vapor pressure in these experiments may be as high as $\mathrm{kPa}(14 \mathrm{~atm})$, while ambient pressures in terrestrial sites are limited to about $\mathrm{kPa}(1 \mathrm{~atm})$. These test conditions are clearly much more aggressive than conditions that could occur in natural environments.

\section{Laboratory Reaction Rates}

\section{a. $\quad$ Rates of Dissolution}

After a slight decrease during first hours of reaction, the rate of tektite glass dissolution in static (i.e., nonflowing) liquid water has a linear time/dependence (BARKATT-1984; LaMARCHE-1984). Barkatt and others [BARKATT-1984] measured the rate of glass dissolution to be $2.3 \mu \mathrm{m} / 1000$ y at $23^{\circ} \mathrm{C}$ and estimated an activation energy of $\sim 80 \mathrm{~kJ} / \mathrm{mol}$ for indochinite and australite tektite in deionized water. LaMarche and others [LaMARCHE-1984] measured a rate of $2.8 \times 10^{4} \mu \mathrm{m} / 1000 \mathrm{y}$ in $90^{\circ} \mathrm{C}$ distilled water. This can be extrapolated to a value of $6.9 \mu \mathrm{m} / 1000 \mathrm{y}$ at room temperature by using an activation energy of $80 \mathrm{~kJ} / \mathrm{mol}$, close to the rate obtained by Barkatt and others [BARKATT-1984].

The dissolution rate is affected by the chemistry of the solution to which the glass is exposed. The dissolution rate in seawater was reported to be about two orders of magnitude lower than in deionized water [BARKATT-1986]. Such a difference in the reaction rates has also been observed in field studies of tektites that had reacted in either seawater or meteoric water [GLASS-1984A]. The dissolution rate in seawater will be affected by the solubility of silica as well as the presence of other dissolved components. Seawater has a dissolved silica content of $\sim 3 \mathrm{mg} / \mathrm{L} \mathrm{Si}$ in the open sea and $10-25 \mathrm{mg} / \mathrm{L}$ Si in the interstitial waters of marine sediments. The higher silicon contents in the interstitial waters decrease the glass dissolution rate. Additionally, Barkatt and others [BARKATT-1986] suggested that the formation of an insoluble magnesium-rich layer might protect the glass surface from further dissolution, based on a microprobe investigation of a indochinite tektite that had been needed in seawater. Such "protective coating" was also once thought to be important during nuclear waste glass dissolution [WALLACE-1983]. However, detailed examination of current reacted HLW glasses have shown it to be unlikely that such layers are physically able to perform this role [e.g., ABRAJANO-1990].

The dissolution rate obtained in laboratory tests has been showed to be in good agreement with those inferred from field observations. Barkatt and others [BARKATT-1984] compared the laboratory leach test data to the actual geological observations on land australite tektites. The corrosion of the glass was assumed to occur only when the glass was exposed to rain water flux. During the dry periods, the dissolution process was assumed to stop because either the surface would be dry or the remaining film of water would become saturated. By assuming that the effective temperature and humidity are not very different from present-day climatological data, they calculated that the $7 \times 10^{5}$ years old australites were exposed to water for approximately $1.37 \times 10^{5}$ years at effective average temperature of $13^{\circ} \mathrm{C}$. This exposure would then result in a dissolution rate of $0.88 \mu \mathrm{m} / 1000$ y for the observed total extent of corrosion of $0.12 \mathrm{~mm}$ in australites, which is in excellent agreement with the laboratory dissolution rate, 0.93 $\mu \mathrm{m} / 1000 \mathrm{y}$, extrapolated to $13^{\circ} \mathrm{C}$ from the data obtained with deionized water at $90^{\circ} \mathrm{C}$ using the Arrhenius relation. These results indicate that the long-term corrosion of tektites by rapid rain flux can be reproduced with accelerated short-term laboratory experiments in high dilution. Although this study involved a relatively simple dissolution process, such study is an important step in 
establishing the validity of laboratory tests as a basis for the development of models and predictions concerning long-term durability.

\section{b. $\quad$ Hydration Rates}

Mazer and others [MAZER-1991A, -1992A] performed vapor hydration tests between 75 and $230^{\circ} \mathrm{C}$ for up to 400 days. Reaction progress was monitored by measuring thickness of the birefringent hydration layer. The hydration layer is visible due to the strain caused by water in glass. They reported that the rate of glass hydration is linear with $\mathrm{t}^{1 / 2}$ (see Fig. III-1) and calculated the diffusion coefficient to be approximately $2 \times 10^{-24} \mathrm{~m}^{2} / \mathrm{s}$ at room temperature. The hydration rate of indochinite tektites was calculated to be $\sim 0.2 \mu \mathrm{m} / \mathrm{y}^{1 / 2}$ at $90^{\circ} \mathrm{C}$ with an activation energy of $91 \mathrm{~kJ} / \mathrm{mol}$. The hydration process for tektites seems to be much less aggressive than dissolution [MAZER-1991A; LaMARCHE-1984; BARKATT-1984]. For example, it will take about $25 \times 10^{4}$ years of hydration at $90^{\circ} \mathrm{C}$ to form a $100-\mu \mathrm{m}$-thick birefringent layer in an indochinite tektit, whereas it takes only about 4 years of dissolution in deionized water at same temperature. Water diffusion-controlled growth of hydration layer is also well known in nuclear waste glasses [DOREMUS-1973]. It should be noted that tektite hydration in vapor seems different in that pronounced dealkalization does not take place. Instead, water diffusion is accompanied only by hydrolysis and subsequent restructuring of the hydrated surface into secondary alteration phases. This difference will be seen again in rhyolitic glasses (Sec. IV), which, like tektites, generally have higher $\mathrm{SiO}_{2}$ content than nuclear waste glass formulations.

\section{Natural Alteration of Tektites}

Given the observation that short-term corrosion of tektites and nuclear waste glasses seem to exhibit similarities (e.g., rate law governing dissolution) and differences (e.g., products of vapor hydration), it is now instructive to examine some detailed accounts of the occurrence and alteration of tektites over long periods of time in natural environments.

\section{Tektites from Australasian Field}

\section{a. Glass Compositions, Alteration Environments, and Ages}

The work that has been done suggests that two dominant processes occur during aqueous corrosion of tektites: dissolution and water diffusion. The rate-controlling process for tektite corrosion depends on the weathering conditions. Corrosion in an unsaturated environment is dominated by water diffusion, while corrosion in hydrothermal conditions is dominated by matrix dissolution. Tests conducted in the laboratory with tektites allow these processes to be isolated from ion-exchange reactions to study the effects of accelerating conditions on each process. By comparing the reaction observed for natural samples, and for those reacted in the laboratory, confidence can be gained in the accelerated test methods. The tektites recovered from the Australasian field have been studied extensively [GLASS-1984A; BARNES-1990, CHALMERS-1979]. The Australasian field includes Australia, Indonesia (Borneo, Java, Belitung Island), Malaysia, Indochina, Thailand, South China, and the Philippines. Tektites from this part of the world have similar chemistries, with characteristic compositions that are rich in $\mathrm{SiO}_{2}$ $(>65 \mathrm{wt} \%)$ and $\mathrm{Al}_{2} \mathrm{O}_{3}\left(\mathrm{SiO}_{2}+\mathrm{Al}_{2} \mathrm{O}_{3}>80 \mathrm{wt} \%\right)$, deficient in $\mathrm{K}_{2} \mathrm{O}$ and $\mathrm{Na}_{2} \mathrm{O}\left(\mathrm{K}_{2} \mathrm{O}+\mathrm{Na}_{2} \mathrm{O}<5 \mathrm{wt} \%\right)$ relative to waste glasses, and nearly free of $\mathrm{H}_{2} \mathrm{O}(<0.01 \mathrm{wt} \%)$ [GLASS-1984A]. The tektites are found in both deep sea environments ( 3000 to $5000 \mathrm{~m}$ below sea level) and land areas, with similar ages of approximately 0.7 million years [GLASS-1984A]. Deep sea tektites are altered by 
interstitial pore water present in seabed sediments, whereas the land tektites have been exposed to water in the form of precipitation, moisture, and surface runoff [GLASS-1984A].

\section{b. Deep Sea Alteration}

Tektites from various deep sea cores from the Australasian field have been extensively studied [GLASS-1984A; O'KEEFE-1986]. Glass and others [GLASS-1984A] examined 53 tektites recovered from 21 deep sea cores from the Indian Ocean, the Philippine Sea, and the western Pacific Ocean. These glasses were found in a wide range of sediment types, including calcareous and siliceous oozes, calcareous and siliceous lutites, red clay and hemipelagic sediments. The tektites typically exhibited shiny surfaces (Fig. III-2c), sometimes with silica-rich protrusions. However, there was no evidence of alteration or hydration associated with these glasses. The tektites from the Australasian field ( 0.7 million years) are also compared to the older tektites from Ivory Coast (1 million years) and North America (35 million years). Despite the older ages of these glasses, they exhibit similar surface features and show no alteration products (see Fig. III-2). Prasad and Rao [PRASAD-1990] recovered a flanged australite from sediment of the Central Indian Basin. The tektite showed a well-preserved schlieren structure on the core and smooth texture on the flange, without forming alteration layers.

These studies seem to indicate that the tektites underwent a congruent dissolution process. However, since we see only the end product of deep sea corrosion, we have no way of knowing the reaction processes or products that may have formed at the early stages of reaction. In fact, some alteration products have been observed to be associated with tektites. Koeberl reported that tektite fragments from the deep sea sometimes have rims of hydrated glass [KOEBERL-1988]. Zeolites have also been reported to form on tektite surfaces, but there is no direct proof that they are tektite alteration products and not separate sediment deposits [KOEBERL-1992].

\section{c. Subaerial Alteration}

Fewer tektites have been found to survive terrestrial alteration than deep sea environments, and the general consensus is that tektites react much faster under terrestrial conditions than in the deep sea [GLASS-1984A]. Examination of land tektites with optical and scanning electron microscopy (SEM) reveals surface features on land samples that are similar to those observed on samples recovered from the sea (i.e., shiny glaze and protrusions). This suggests that the glass may react by the same process (i.e., dissolution) in both environments [GLASS-1984A; BARNES-1990].

Nuclear reaction techniques and high-resolution transmission electron microscopy (TEM) have also been applied to study tektite alteration. Lee and others [LEE-1974] examined with a nuclear reaction technique a $10^{6}$-year-old tektite recovered from laterite soils in Southeast Asia and measured hydration layers less than $20 \mathrm{~nm}$. Their results supported the hypothesis that the dissolution process dominates during the course of the subaerial alteration of tektite. Mazer and others examined the exposed surface of a land indochinite tektite with high-resolution TEM [MAZER-1992A]. They found that although the tektite had a rather smooth appearance under optical microscopic and scanning electron microscopic examinations, an alteration layer had actually formed. The layer was $\sim 0.1 \mu \mathrm{m}$ thick and contained nanometer-sized clay and iron-rich particles. In all these cases, the alteration or hydration layers were very thin. 
These results support the thesis that the dissolution process is much faster than other processes, such as ion exchange and hydration, that may have also taken place.
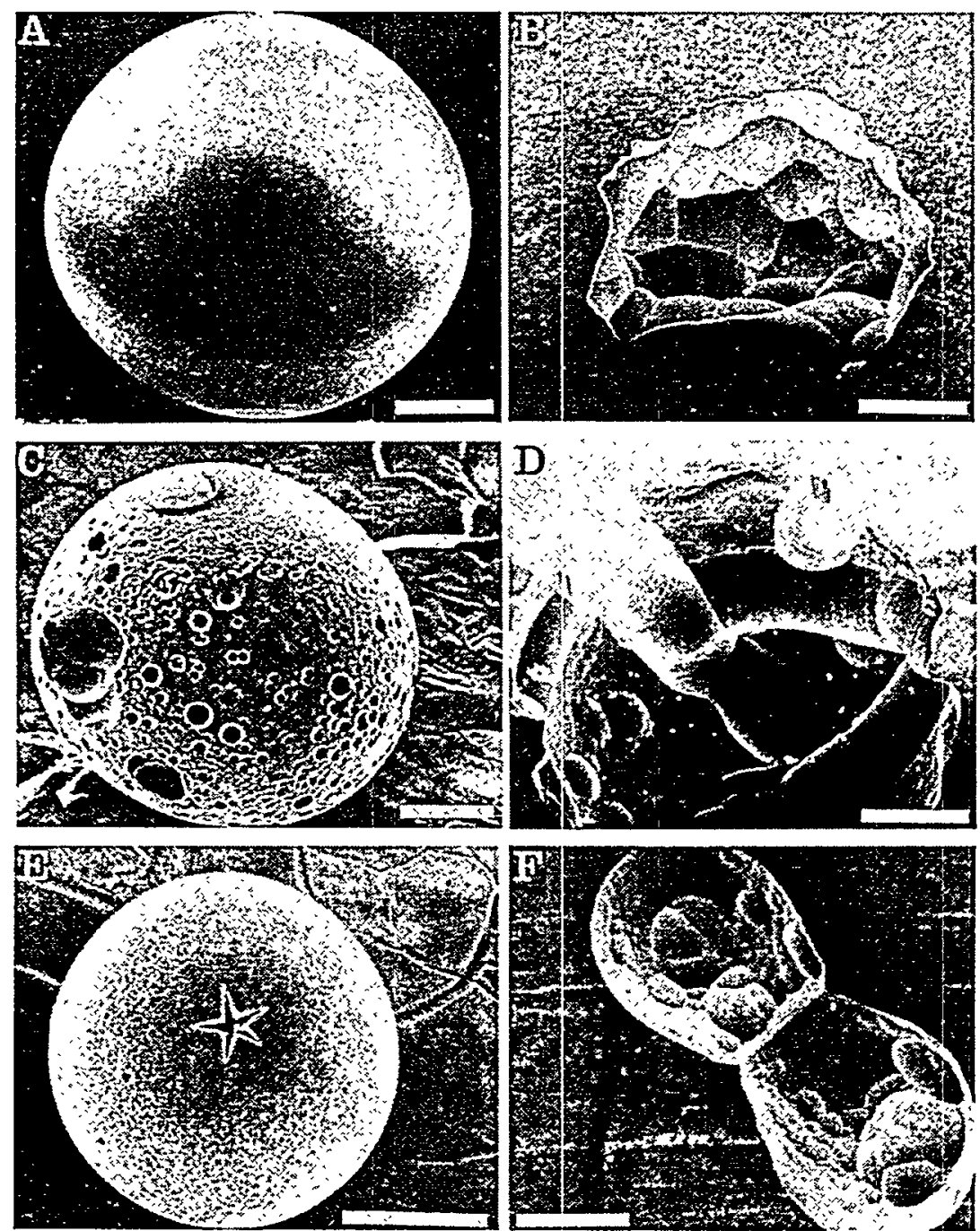

Fig. III-2. Scanning electron micrographs showing tektites from various strewn fields exhibiting characteristic surfaces with no evidence of forming alteration layers at surface: (a) and (e) North America; (b, d, f) Ivory Coast; (c) Australia. Scale bars for (b-f) equal $100 \mu \mathrm{m}$ and for (a) $40 \mu \mathrm{m}$. Note the presence of etching pits but absence of alteration phases on most surfaces [GLASS-1984B].

\section{Cretaceous/Tertiary Boundary Tektites}

\section{a. Glass Compositions, Alteration Environments, and Ages}

The $\mathrm{K} / \mathrm{T}$ boundary is marked by signs of a worldwide catastrophe that may have been the result of a giant asteroid or comet hitting the Earth about 65 million years ago [ALVAREZ-1980]. Tektite glasses that may have resulted from the shock melting induced by the bolide impact have been discovered in a section of the $\mathrm{K} / \mathrm{T}$ boundary exposed in Haiti [SIGURDSSON-1991; POLLASTRO-1987; IZETT-1991; MARGOLIS-1991; KOEBERL-1992; 
KRING-1991]. These glasses have compositions that are grossly similar to most previously described tektite glasses but slightly enriched in calcium and depleted in silicon [SIGURDSSON-1991; POLLASTRO-1987; IZETT-1991; MARGOLIS-1991; KRING-1991].

Such a composition is believed to show that the $\mathrm{K} / \mathrm{T}$ target contained more carbonate and anhydrite rock and fewer silicate units than the targets from which the Australasian tektites were produced [KRING-1991; GLASS-1984A]. Analysis of Haitian tektites with an electron microprobe indicated that the glass is nearly free of water and does not contain significant concentrations of iron [KRING-1991]. The Haitian tektites have been exposed to terrestrial conditions and found in a marl bed $0.5 \mathrm{~m}$ thick that marks the paleotologic K/T boundary [POLLASTRO-1987].

\section{b. $\quad$ Alteration of Cretaceous/Tertiary Tektite}

The $\mathrm{K} / \mathrm{T}$ boundary tektites have attained various extents of hydration and alteration [SIGURDSSON-1991; POLLASTRO-1987; IZETT-1991; MARGOLIS-1991; ALVAREZ-1995; KOEBERL-1992; KRING-1991]. Sigurdsson and others [SIGURDSSON-1991] found samples from Beloc, Haiti, in which as much as $25 \%$ of the sediment consisted of partially altered spherules with glass cores in which a smooth outer shell ( $>1 \mathrm{~mm}$ thick) of light gray to brownish smectite clay encased unaltered glasses 1 to $6 \mathrm{~mm}$ in diameter (see Fig. II-3). The surfaces of these glasses are pocked with smooth-walled pits, similar to those seen in Australasian tektites. The altered layer consists predominantly of montmorillonite clay, although rare occurrences of zeolites (mainly heulandite and barium-rich harmotome) were also observed [SIGURDSSON-1991; POLLASTRO-1987; IZETT-1991; MARGOLIS-1991; KOEBERL-1992; KRING-1991]. Calcite sometimes occurs in the altered layer, but it is not clear whether it formed in situ or precipitated from solution [KRING-1991].

It is clear that the $\mathrm{K} / \mathrm{T}$ boundary tektites have reacted differently than the tektites recovered from the other fields, which simply dissolved and generally did not produce any alteration products. Differences in the compositions of the glasses could be an important factor - the Haitian tektites are generally slightly Si-poor and Ca-rich compared with most of the other tektites (compare Tables II-1 and 2). However, a few Australasian tektites, such as bottle-green microtektites, have silica contents much lower than Haitian tektites and show no apparent evidence of alteration. The most important factor is probably the environment to which the glass has been exposed. The K/T boundary tektites have been recovered predominantly from acidic terrestrial environments, whereas the tektites from other fields are mainly found in deep sea environments. When glass dissolves into a limited amount of water, such as in humid environments, the cations released from the glass remain in a thin film of water at the glass surface and can become incorporated into alteration products when the solubility limits of alteration phases are reached. Dissolution of glass into a large volume of water is not likely to result in saturation of the solution or formation of alteration phases. Also, the $\mathrm{K} / \mathrm{T}$ boundary tektites are much older than the Australasian tektites and have had more time for the alteration phases to nucleate and grow. Given all these considerations, it is likely that chemical composition, age, and environment all affect the alteration of the $\mathrm{K} / \mathrm{T}$ tektites. 

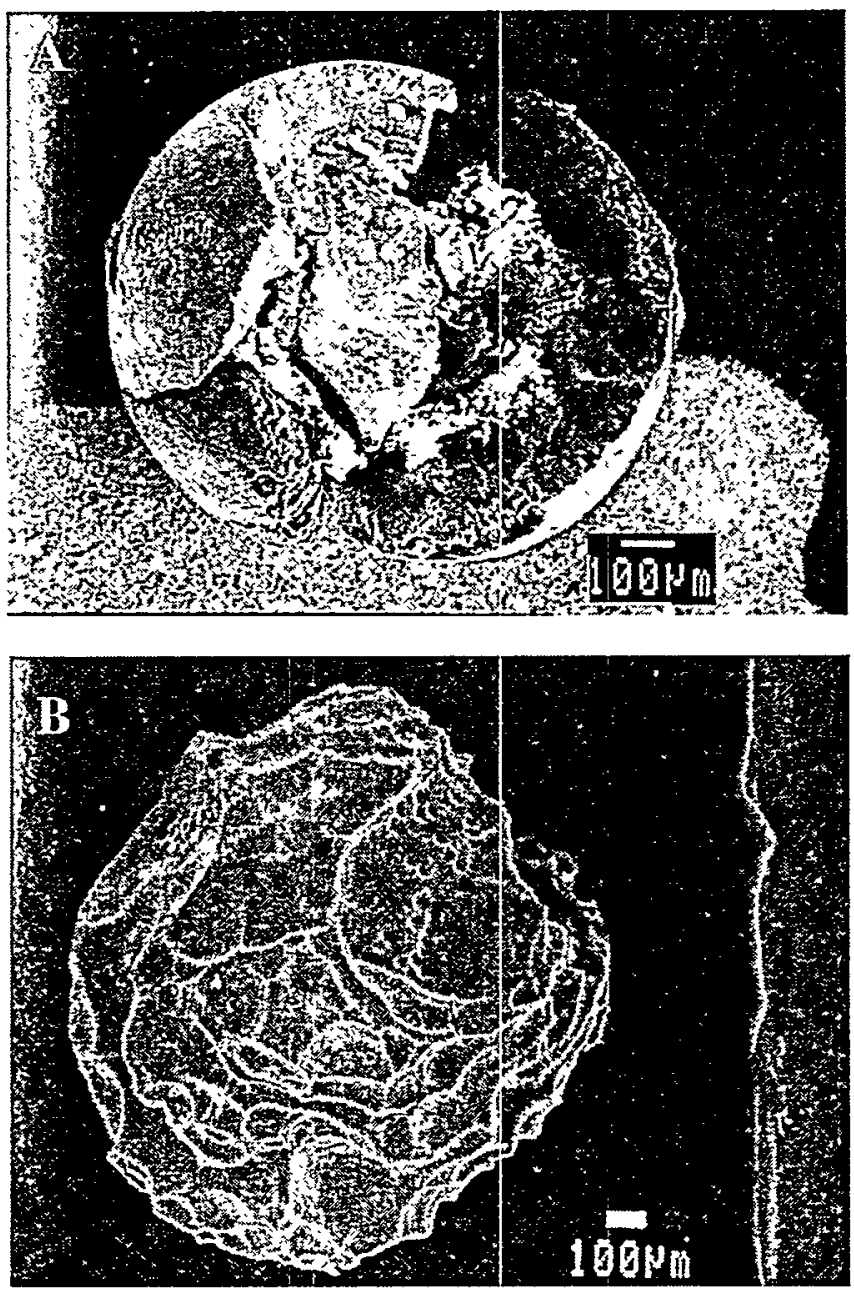

Fig. III-3. Scanning electron micrographs of glass spherules recovered from the $\mathrm{K} / \mathrm{T}$ boundary at Beloc, Haiti, showing the formation of alteration layer at outer surfaces of tektites: (a) smooth smectite shell enclosing the glass and (b) glass spherule after removal of the smectite layer [SIGURDSSON-1991].

Table III-1. Average compositions of bottle-green microtektites (after [GLASS-1972])

\begin{tabular}{ccc}
\hline & Australasian & Ivory Coast \\
\cline { 2 - 3 } & Average of 7 Samples & Average of 10 Samples \\
\hline $\mathrm{SiO}_{2}$ & 50.5 & 51.8 \\
$\mathrm{TiO}_{2}$ & 0.86 & 0.61 \\
$\mathrm{Al}_{2} \mathrm{O}_{3}$ & 16.7 & 15.7 \\
$\mathrm{FeO}$ & 4.53 & 9.53 \\
$\mathrm{MnO}$ & 0.11 & 0.13 \\
$\mathrm{MgO}$ & 20.7 & 18.1 \\
$\mathrm{CaO}$ & 4.81 & 3.27 \\
$\mathrm{Na}$ & 0.05 & 0.52 \\
$\mathrm{~K}_{2} \mathrm{O}$ & 0.04 & 0.23 \\
$\mathrm{Cr}_{2} \mathrm{O}_{3}$ & 0.21 & Below Detection \\
\hline
\end{tabular}




\section{Bottle-Green Microtektites}

One class of tektites particularly analogous to nuclear waste glass is the bottle-green microtektites, some of which have silica contents as low as $~ 50 \mathrm{wt} \%$ (Table III-1), a value similar to the silica content of waste glasses. These glasses are transparent pale green and are typically less than $0.5 \mathrm{~mm}$ in size. They have been found only in deep sea sediments (3000 to $5000 \mathrm{~m}$ below sea level) from the Australasian ( 0.7 million years old) and Ivory Coast ( 1 million years old) strewn fields, and have been altered by interstitial pore water in seabed sediments [GLASS-1972; BARKATT-1986].

Table III-2. Average, standard deviation, and range of composition for 11 black impact glasses from Haiti (after [KOEBERL-1992])

\begin{tabular}{ccccc}
\hline & Average of 11 Samples & Std. Dev. & Minimum & Maximum \\
\hline & & & & \\
$\mathrm{SiO}_{2}$ & 63.29 & 1.09 & 61.42 & 65.45 \\
$\mathrm{TiO}_{2}$ & 0.68 & 0.03 & 0.62 & 0.71 \\
$\mathrm{Al}_{2} \mathrm{O}_{3}$ & 15.33 & 0.20 & 15.05 & 15.71 \\
$\mathrm{FeO}$ & 5.27 & 0.17 & 4.87 & 5.44 \\
$\mathrm{MnO}$ & 0.17 & 0.01 & 0.15 & 0.19 \\
$\mathrm{MgO}$ & 2.55 & 0.16 & 2.28 & 2.77 \\
$\mathrm{CaO}$ & 7.21 & 0.82 & 5.65 & 8.39 \\
$\mathrm{Na}$ & 3.72 & 0.33 & 2.79 & 4.09 \\
$\mathrm{~K}_{2} \mathrm{O}$ & 1.62 & 0.09 & 1.50 & 1.78 \\
$\mathrm{P}_{2} \mathrm{O}_{3}$ & 0.07 & 0.02 & 0.02 & 0.10 \\
$\mathrm{~S}$ & 0.002 & 0.001 & 0.001 & 0.004 \\
$\mathrm{Total}$ & 99.91 & & & \\
\hline
\end{tabular}

No systematic studies of the corrosion of bottle-green tektites have been reported in the literature partly due to the lack of availability. Glass and others [GLASS-1981, -1984A, -1997] reported the discovery and physical and chemical characteristics of these glasses, but did not investigate their corrosion behavior in depth. The bottle-green microtektites generally have a deeply corroded surface while the normal seawater-altered tektites had smooth to pitted and grooved surfaces. The more extensive corrosion of bottle-green microtektites may be due to their lower silica contents. However, alteration layers have been observed on these glasses, which suggests that the dominant reaction process was dissolution followed by precipitation [GLASS-1997].

\section{Tektite Reaction Rates in Natural Environments}

When the tektites dissolve in deep sea environments, the amount of glass that dissolves depends on the time during which water has access to the glass, the temperature, and the solution chemistry. The dissolution rates can be calculated based on the extent of alteration and the age of the glass. However, these rates should be considered as lower bounds to the actual rates because the true exposure time will be less than or equal to the age of the samples.

Glass and others [GLASS-1984A] estimated the amount of glass that had dissolved by analyzing the width of cracks that penetrate into the glass the height of inclusions that protrude above the tektite surface (as a result of differential dissolution between glass and less 
soluble silica-rich inclusions). They examined more than 170 natural tektites recovered from two land sites and thirty-four deep sea sites from the Australasian, Ivory Coast, and North American strewn fields. The measured thickness of dissolved glass ranged from 0.2 to $28 \mu \mathrm{m}$, depending the site and age of glass, and the calculated dissolution rates ranged from $9 \times 10^{-5}$ to

$2.1 \times 10^{-2} \mu \mathrm{m} / 1000$ y (see Table III-3).

Table MI-3. Average values of dissolution rates and $\mathrm{SiO}_{2}$ content (after [GLASS-1984A] and [KRING-1991])

\begin{tabular}{|c|c|c|c|c|}
\hline & $\begin{array}{c}\text { Age, } \\
\text { million } \\
\text { years }\end{array}$ & Environment & $\begin{array}{c}\text { Dissolution } \\
\text { Rate, } \mu \mathrm{m} / 1000 \mathrm{y}\end{array}$ & $\begin{array}{c}\text { Average } \mathrm{SiO}_{2} \\
\text { Content, wt\% }\end{array}$ \\
\hline Australasian microtektites & 0.7 & deep sea & $10.2 \times 10^{-3}$ & 64.0 \\
\hline Ivory Coast microtektites & -1 & deep sea & $9.7 \times 10^{-3}$ & 67.3 \\
\hline North American microtektites & 35 & deep sea & $0.12 \times 10^{-3}$ & 64.9 \\
\hline Irghizites & $\sim 1$ & continental & $20.7 \times 10^{-3}$ & 63.3 \\
\hline Barbados microtektites & 35 & $\begin{array}{l}\text { originally deep } \\
\text { sea, but presently } \\
\text { continental }\end{array}$ & $0.35 \times 10^{-3}$ & 77.5 \\
\hline $\mathrm{K} / \mathrm{T}$ boundary tektites & 65 & continental & $15 \times 10^{3}$ & 63.3 \\
\hline
\end{tabular}

Of the rates calculated for the tektites from different fields, the dissolution rates for the 35 million-year-old North American tektites, $9 \times 10^{-5}$ to $1.4 \times 10^{-4} \mu \mathrm{m} / 1000 \mathrm{y}$, are systematically two orders of magnitudes lower than the rates $\left(1.0 \times 10^{-2}\right.$ to $\left.2.1 \times 10^{-2} \mu \mathrm{m} / 1000 \mathrm{y}\right)$ for tektites from the younger (0.7-1 million years.) strewn fields (i.e., Australasian and Ivory Coast fields), despite their similar composition and deep sea environment. One possible explanation is that glass dissolution slows down drastically or even ceases shortly after glasses are buried under accumulating sediments [GLASS-1984A.]. When glass is buried by pelagic sediments, which eventually envelop the glass, the pores become saturated with silica and other elements dissolved from the glass and as a result reaction slows. On the other hand, the rates inferred for the irghizite tektites, which are similar in ages and compositions to the Australasian tektites but are found in a terrestrial environment, generally are two to three times higher than the Australasian tektites (see Table III-3) [GLASS-1984A]. Likewise, the North American tektites found on Barbados, which was originally a deep sea environment but is presently continental, generally show higher rates than the North American tektites recovered from deep sea sites [GLASS-1984A].

Reaction rates have also been calculated for $\mathrm{K} / \mathrm{T}$ boundary glasses, which had been exposed to a terrestrial environments and buried in sediments [KRING-1991]. The existence of completely altered spherules that are $1-10 \mathrm{~mm}$ in diameter suggests that glass particles of similar size have been reacted [KRING-1991]. However, since the glass was preserved in some cases, the rates must be considered to be the maximum rates. Interestingly, the inferred reaction rate for $\mathrm{K} / \mathrm{T}$ tektites, which is $1.5 \times 10^{-2}$ to $15 \times 10^{-2} \mu \mathrm{m} / 1000 \mathrm{y}$, is similar to the rates calculated for younger microtektites, but two orders of magnitude lower than the rates calculated for the 35 million-year-old North American tektites (see Table III-3). This suggests that the sedimentation that occurs in a terrestrial setting does not seal the glass as effectively as sedimentation in deep sea environments. 


\section{RHYOLITIC GLASSES}

\section{A. Introduction}

When magmas of rhyolitic composition erupt onto the earth's surface as viscous fluids, the exteriors of these flows or domes cool rapidly to form a glass, which is called rhyolitic glass or obsidian [FRIEDMAN-1978, -1984; ERICSON-1976]. Most of the early studies of the interaction of water and natural glass were performed on rhyolitic (i.e., high-silica) glasses or obsidian samples that have survived for millions of years in a wide range of geological environments. Archeologists and geologists have studied the hydration of rhyolitic glasses to develop a technique for dating obsidian artifacts. Collectively, these studies have demonstrated that the rate of obsidian corrosion is controlled by a water diffusion process in humid environments and that the hydration of obsidian that occurs in nature can be reproduced reasonably well in the laboratory.

Obsidian occurs in almost all lava flows of rhyolitic composition and is distributed throughout the volcanic belts that circle the Earth. Obsidian may be black, pinkish, gray-green, brown, red, or colorless. Samples are usually transparent in thin pieces but may appear opaque because of the presence of microscopic crystalline inclusions of various minerals. Obsidian is basically an aluminosilicate material ( $>66 \mathrm{wt} \% \mathrm{SiO}_{2}$ and $>10 \mathrm{wt} \% \mathrm{Al}_{2} \mathrm{O}_{3}$ ) with minor amounts (usually less than $4 \%$ ) of $\mathrm{Na}, \mathrm{K}, \mathrm{Fe}$, and $\mathrm{Ca}$ in addition to variable trace elements in ppm range. (See Table IV-1 for compositions of typical obsidians.)

Obsidian artifacts were much sought after and widely traded in the prehistoric age as cutting tools. The presence of obsidian artifacts in many environments provides an important record of the natural degradation of obsidian, since some artifacts have survived for more than 30,000 years. Areas in which obsidian was heavily used include the Pacific Rim area of New Zealand, Australia, Japan, North and South America, as well as large areas in east Africa and the Near East. The extent of hydration of the glass has been used to develop a chronometer to date both geologic events, such as volcanic activity, and archeological artifacts manufactured from obsidian.

\section{B. Laboratory Reaction Processes}

\section{Reaction in Liquid Water}

Laboratory reaction of obsidian submerged in liquid water reveals that a combination of fundamental reactions could occur simultaneously during aqueous corrosion of this glass. For example, hydration is found to take place at least at the early stage of reaction and at low temperatures [ALLNATT-1983; YANG-1990; KARKHANIS-1980; McGRAIL-1988]. Laursen and others [LAURSEN-1978] reacted obsidian samples in distilled water at $90^{\circ} \mathrm{C}$ for up to $348 \mathrm{~h}$ and then measured the hydrogen concentration profiles using the ${ }^{15} \mathrm{~N}$ resonance nuclear reaction technique. The shape of the hydrogen profiles was found to be consistent with that predicted by an ion-exchange model, according to which hydration involves interdiffusion of hydronium $\left(\mathrm{H}_{3} \mathrm{O}^{+}\right)$and alkali ions.

White and others [WHITE-1983] analyzed the solutions from tests in which obsidian samples were reacted in deionized water at $25^{\circ} \mathrm{C}$ for up to 3 months. They found a preferential release of $\mathrm{Na}$ and $\mathrm{K}$ into the solution that seemed to be controlled by a diffusion process, as the release exhibited a parabolic rate. Working with secondary ion mass spectrometry profiling, McGrail and others [McGRAIL-1988] observed sodium-depleted layers in obsidian samples reacted in deionized water at $90^{\circ} \mathrm{C}$ for 28 days. Working with nuclear magnetic 
Table IV-1. Chemical analyses of typical obsidian samples from various locations. Chemical components are expressed as weight percentages (after [Friedman-1976[).

\begin{tabular}{|c|c|c|c|c|c|c|c|c|c|c|c|c|}
\hline \multirow[b]{2}{*}{$\begin{array}{l}\text { Chemical } \\
\text { Components }\end{array}$} & \multicolumn{11}{|c|}{ Locality } & \multirow[b]{2}{*}{ Xalpasquillo } \\
\hline & $\begin{array}{l}\text { East } \\
\text { Lake } \\
\text { Flow } \\
\end{array}$ & $\begin{array}{c}\text { Big } \\
\text { Obsidian } \\
\text { Flow }\end{array}$ & $\begin{array}{l}\text { Obsidian } \\
\text { Cliff }\end{array}$ & $\begin{array}{l}\text { Grassy } \\
\text { Lake }\end{array}$ & $\begin{array}{l}\text { Love } \\
\text { Quarry }\end{array}$ & $\begin{array}{l}\text { American } \\
\text { Falls }\end{array}$ & $\begin{array}{c}\text { Cosco } \\
\text { Hot } \\
\text { Springs }\end{array}$ & $\begin{array}{l}\text { Clear } \\
\text { Lake }\end{array}$ & $\begin{array}{l}\text { Medicine } \\
\text { Lake }\end{array}$ & $\begin{array}{l}\text { Panum } \\
\text { Dome }\end{array}$ & Kerlingerfjoll & \\
\hline $\mathrm{SiO}_{2}$ & 73.2 & 72.2 & 76.7 & 76.3 & 74.5 & 76.3 & 76.9 & 75.2 & 73.7 & 75.8 & 73.2 & 74.5 \\
\hline $\mathrm{Al}_{2} \mathrm{O}_{3}$ & 14.3 & 14.6 & 12.5 & 12.7 & 14.4 & 12.4 & 13.2 & 13.4 & 14.0 & 12.9 & 13.8 & 14.4 \\
\hline $\mathrm{Fe}_{2} \mathrm{O}_{3}$ & 0.55 & 0.72 & 0.43 & 0.59 & 0.29 & 0.52 & 0.16 & 0.19 & 0.57 & 0.36 & 0.84 & 0.00 \\
\hline $\mathrm{FeO}$ & 1.5 & 1.7 & 0.88 & 1.1 & 0.92 & 0.80 & 0.76 & 1.1 & 1.3 & 0.76 & 1.6 & 0.68 \\
\hline $\mathrm{MgO}$ & 0.28 & 0.32 & 0.09 & 0.09 & 0.18 & 0.10 & 0.02 & 0.18 & 0.32 & 0.07 & 0.13 & 0.07 \\
\hline $\mathrm{CaO}$ & 1.0 & 0.92 & 0.48 & 0.58 & 1.3 & 0.52 & 0.45 & 1.0 & 1.2 & 0.60 & 0.99 & 0.50 \\
\hline $\mathrm{Na}_{2} \mathrm{O}$ & 4.5 & 5.3 & 3.3 & 3.4 & 3.9 & 3.2 & 4.0 & 3.3 & 4.0 & 3.9 & 4.7 & 4.2 \\
\hline $\mathrm{K}_{2} \mathrm{O}$ & 3.8 & 4.0 & 4.6 & 4.6 & 3.5 & 4.6 & 3.9 & 4.3 & 3.8 & 4.2 & 3.5 & 3.7 \\
\hline $\mathrm{H}_{2} \mathrm{O}$ & 0.60 & 0.33 & 0.30 & 0.17 & 0.43 & 0.33 & 0.40 & 0.27 & 0.27 & 0.33 & 0.17 & 1.00 \\
\hline $\mathrm{TiO}_{2}$ & 0.24 & 0.21 & 0.07 & 0.14 & 0.07 & 0.22 & 0.05 & 0.25 & 0.28 & 0.06 & 0.19 & 0.02 \\
\hline $\mathrm{P}_{2} \mathrm{O}_{5}$ & 0.04 & 0.06 & 0.00 & 0.00 & 0.03 & 0.02 & 0.00 & 0.03 & 0.04 & 0.00 & 0.02 & 0.04 \\
\hline IĨnO & 0.05 & 0.06 & 0.03 & 0.04 & 0.07 & 0.05 & 0.04 & 0.03 & 0.04 & 0.05 & 0.07 & 0.13 \\
\hline $\mathrm{CO}_{2}$ & $<0.05$ & 0.01 & $<0.05$ & $<0.05$ & $<0.05$ & $<0.05$ & $<0.05$ & $<0.05$ & $<0.05$ & $<0.05$ & $\leq 0.05$ & $<0.05$ \\
\hline Sum & 100 & 100 & 99 & 100 & 100 & 99 & 100 & 99 & 100 & 99 & 99 & 99 \\
\hline
\end{tabular}


resonsance (NMR), Yang and others [YANG-1990] detected molecular water but not hydronium in a hydrated glass sample that had been reacted at $250^{\circ} \mathrm{C}$ in a pH-buffered solution.

These studies demonstrate that, under such hydrothermal reaction conditions, (1) hydration occurs in obsidian, (2) this hydration involves water diffusion, and (3) ion exchange takes place between relatively mobile alkali ions and water or hydronium. However, the results of studies carried out under hydrothermal conditions may not be directly applied to the hydration of obsidian in natural terrestrial environments. In a terrestrial environment, the amount of water that can contact obsidian is small and the release of alkali ions may be suppressed due to rapid saturation of alkali elements in the solution. Therefore, the results derived from vapor reactions are more applicable to the alteration of obsidian by natural processes than the results of hydrothermal tests with regard to the volume of water that may contact the glass.

Obsidian is also reported to congruently dissolve into the solution when reacted at high temperatures [KARKHANIS-1980; LaMARCHE-1984]. Karkhanis and others [KARKHANIS-1980] reacted obsidian in distilled water at temperatures higher than $200^{\circ} \mathrm{C}$ and observed formation of etching pits on the reacted surface followed by precipitation of a crystalline product, muscovite $\left[\mathrm{KAl}_{3} \mathrm{Si}_{3} \mathrm{O}_{19}(\mathrm{OH})_{2}\right]$, as identified by $\mathrm{X}$-ray diffraction. Allnatt and others [ALLNATT-1983] conducted a series of static tests with synthetic obsidian glasses in deionized water and analyzed the solution compositions. They observed the dominant reaction process to depend on the reaction temperature: at temperatures above $200^{\circ} \mathrm{C}$, the reaction was dominated by congruent dissolution and reprecipitation of alteration phases. These phases were identified as muscovite, sodium calcium silicates $\left[\mathrm{NaAl}_{3} \mathrm{Si}_{3} \mathrm{O}_{10}(\mathrm{OH})_{2}\right.$ and $\left.\mathrm{Na}_{2} \mathrm{Ca}_{2} \mathrm{Si}_{2} \mathrm{O}_{7} \cdot \mathrm{H}_{2} \mathrm{O}\right]$, truscottite $\left[\mathrm{CaSi}_{2} \mathrm{O}_{5} \cdot 1 / 2 \mathrm{H}_{2} \mathrm{O}\right]$, albite $\left[\mathrm{NaAlSi}_{3} \mathrm{O}_{8}\right]$, and quartz $\left[\mathrm{SiO}_{2}\right]$. At temperatures below $100^{\circ} \mathrm{C}$, however, the reaction was dominated by selective leaching of $\mathrm{Na}$ and $\mathrm{K}$. However, since their longest tests at low temperatures only lasted for about 20 days, it is not clear from these studies if the reaction mechanism is temperature dependent. The observations at high temperatures may reflect a greater reaction progress that will eventually occur in tests at low temperatures.

\section{Hydration in Saturated Water Vapor}

The rate of hydration of obsidian at ambient temperatures is too slow to be studied easily in laboratory experiments. To accelerate the hydration process in laboratory tests, Friedman and others [FRIEDMAN-1966; FRIEDMAN-1976] exposed pieces of obsidian to water vapor at $100^{\circ} \mathrm{C}$ and $100 \mathrm{kPa}$ for times up to four years. They observed the formation of birefringent layers similar to those that occur in samples of naturally altered obsidian (see Fig. IV-1). Mazer and others [MAZER-1992B] reacted Snake River obsidian at temperatures between 75 to $230^{\circ} \mathrm{C}$ for up to 400 days at $100 \%$ relative humidity. They found that birefringent layers formed on samples in all tests. Similarly, Michels and others [MMCHELS-1983] were able to hydrate obsidian and form birefringent layers by reacting glass in water vapor at temperatures as high as $250^{\circ} \mathrm{C}$ and pressures up to $4,000 \mathrm{kPa}$. These results show that the hydration of obsidian that occurs in nature can be reproduced by experiments in water vapor at high temperatures in the laboratory. However, Tremaine and others [TREMAINE-1988] noticed that the hydration rim became increasingly diffuse at temperatures greater than $180^{\circ} \mathrm{C}$, and that the surface of obsidian began to dissolve at temperatures exceeding $225^{\circ} \mathrm{C}$. 

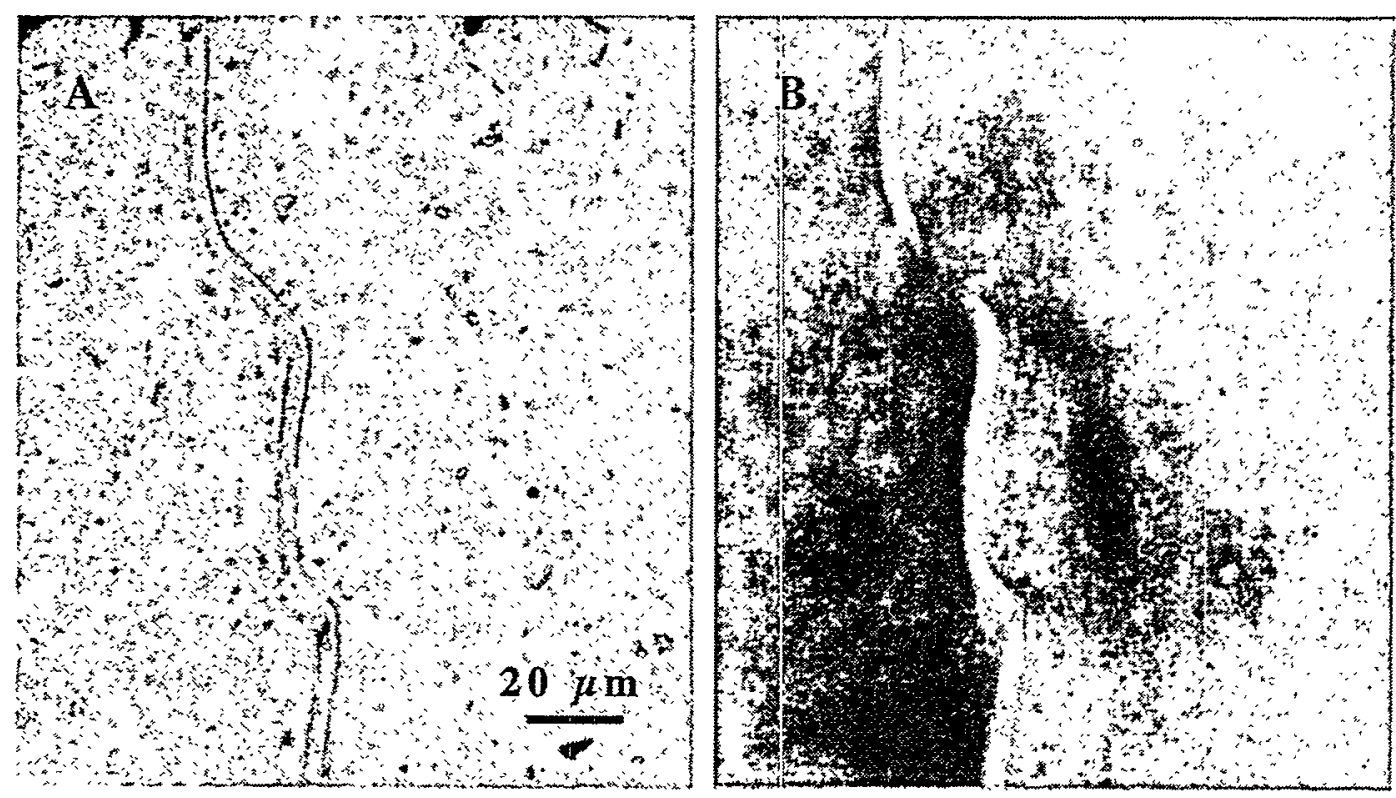

Fig. IV-1. (a) The hydrated rind of an obsidian artifact shows a sharp interface between the hydrated and nonhydrated glass. (b) The same sample shows a bright contrast under crossed Nicol prisms because it is under strain [FRIEDMAN-1978].

\section{Laboratory Reaction Rates}

On the basis of solution analyses of leached glass constituents, Karkhanis [KARKHANIS-1980] measured the dissolution rate of a California obsidian to be $3.6 \times 10^{-5} \mathrm{~g} /\left(\mathrm{m}^{2} \bullet \mathrm{d}\right)$ at $100^{\circ} \mathrm{C}$ with an activation energy of $\sim 50 \mathrm{~kJ} / \mathrm{mol}$ in deionized water. Allnatt and others [ALLNATT-1983] measured the weight loss as a function of time and observed that the weight loss is nearly immeasurable at $100^{\circ} \mathrm{C}$, but becomes more significant at $200^{\circ} \mathrm{C}$ with a rate of $4.9 \times 10^{-5} \mathrm{~g} /\left(\mathrm{m}^{2} \bullet \mathrm{d}\right)$. However, because obsidian reacts to form alteration layers that incorporate many of the cations released from glass, measurement of the dissolution rate by weight loss is invalid in many cases because of precipitation of secondary phases on the sample surface. Hence, the rate measured by Allnatt is not the dissolution rate, but a combination of dissolution and precipitation.

The hydration rate has been well established to be proportional to the square root of time [FRIEDMAN-1976; ERICSON-1980; MICHELS-1983; TREMAINE-1988; MAZER-1992B], which suggests that the reaction is diffusion controlled. Friedman and others [FRIEDMAN-1966, -1976] reacted 12 obsidian samples at $95^{\circ} \mathrm{C}$ to $245^{\circ} \mathrm{C}$ in water vapor at $100 \%$ relative humidity for up to four years. They measured the thickness of birefringent layers as a function of time to determine the hydration rate. In all the cases, the layer thicknesses increased in proportion to the square root of time. The rate at $10^{\circ} \mathrm{C}$ was calculated by extrapolation of hightemperature results to be $4.7 \mu \mathrm{m}^{2} / 1000$ y [FRIEDMAN-1966, -1976]. An activation energy of $80 \mathrm{~kJ} / \mathrm{mol}$ is calculated from the Arrhenius plot by Friedman [FRIEDMAN-1978]. However, activation energies for the hydration of obsidian are commonly found to vary as a function of glass composition and range from 68 to $91 \mathrm{~kJ} / \mathrm{mol}$ [FRIEDMAN-1976; MAZER-1992B].

The results of early hydration experiments with obsidian conducted by Friedman and others [FRIEDMAN-1966, -1976, -1978] suggest that the hydration rate may be intrinsically affected only by the chemical composition of obsidian. By comparing the chemical 
characteristics of various samples, Friedman and others [FRIEDMAN-1976] concluded that the increase in hydration rate could be correlated with the increase in $\mathrm{SiO}_{2}$ content and a decrease in the $\mathrm{CaO}, \mathrm{MgO}$, and $\mathrm{H}_{2} \mathrm{O}$ contents. Other elements in glass, such as $\mathrm{Al}_{2} \mathrm{O}_{3}, \mathrm{FeO}, \mathrm{Na}_{2} \mathrm{O}$, and $\mathrm{K}_{2} \mathrm{O}$, appeared to have little effect on the rate. However, recent studies indicate that there is a strong correlation between a single compositional parameter, the logarithm of the bulk intrinsic water content (measured by total $\mathrm{OH}^{-}$and $\mathrm{H}_{2} \mathrm{O}$ species), and the obsidian hydration rate [MAZER-1991B; TOMOZAWA-1984; STEVENSON-1993]. Mazer [MAZER-1992B] showed that the hydration rate is strongly affected by the initial water content of the glass, and that the hydration rate at $160^{\circ} \mathrm{C}$ can be expressed as

$$
\text { hydration rate }\left(\mu \mathrm{m} / \text { day }^{1 / 2}\right)=2.11+0.96\left(\log \mathrm{H}_{2} \mathrm{O} \text { wt\% }\right)
$$

With increased water content, the hydration rate increases (see Fig. IV-2a) and the activation energy of hydration decreases (see Fig. IV-2b). The reason for this dependence is not completely understood, but it may be related to the depolymerizing effect of intrinsic water on the structure. In fact, the extremely low water contents of glasses such as tektites, which have silica and alumina contents similar to obsidian, are often considered to be one of the main reasons for their high durabilities [BARKATT-1984]. The initial total water content of nuclear waste glasses produced at bench scale was reported to be 0.05 to $0.1 \mathrm{wt} \%$ [MAZER-1992B], which is lower than that of most obsidians. Consequently, the hydration of nuclear waste glasses should proceed more slowly than hydration of obsidian, based on their lower water contents.

The hydration rate is also affected by the water vapor pressure or relative humidity (RH) in the environment [YAPER-1931; AMBROSE-1976; MAZER-1991B; EBERT-1991B]. In a vapor environment, the water vapor pressure controls both the amount of water available and the driving force for subsequent reaction with the glass, such as diffusion into the glass. Ebert and others [EBERT-1991B] showed that the isotherms for water sorbed on obsidian were dominated by the condensation of water above about $95 \%$ RH. Mazer and others [MAZER-1991B] reported that water sorption had a nonlinear dependence on relative humidity and that sorption occurs mainly between $90 \%$ and $100 \%$ RH (see Fig. IV-3). The hydration of obsidian was measured to proceed at a rate of $5 \mu \mathrm{m}^{2} / 1000$ y at $84 \% \mathrm{RH}$, but only at about $3 \mu \mathrm{m}^{2} / 1000 \mathrm{y}$ at $58 \% \mathrm{RH}$ [EBERT-1991B], and the rate of hydration could be increased by as much as $70 \%$ between 60 and 100\% RH [MAZER-1991B]. These results demonstrate that the influence of the relative humidity in both the laboratory and terrestrial environments must be accounted for before experimentally determined reaction rates can be projected backward to date obsidian artifacts or forward to project long-term waste glass durability. 

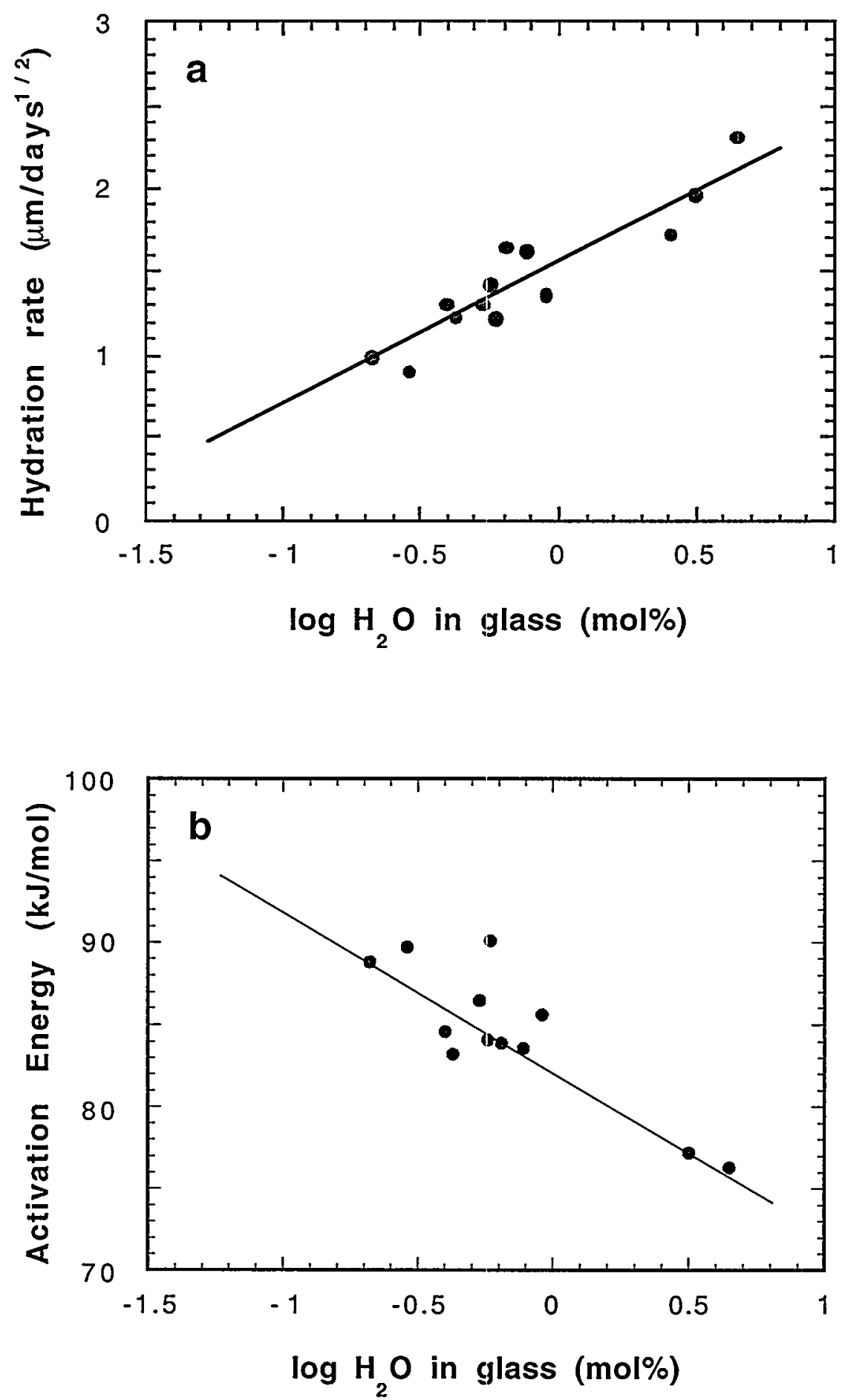

Fig. IV-2. The effects of the intrinsic water content of Snake River obsidian on (a) the hydration rate at $160^{\circ} \mathrm{C}$ and (b) the activation energy of hydration process [MAZER1992B]. 


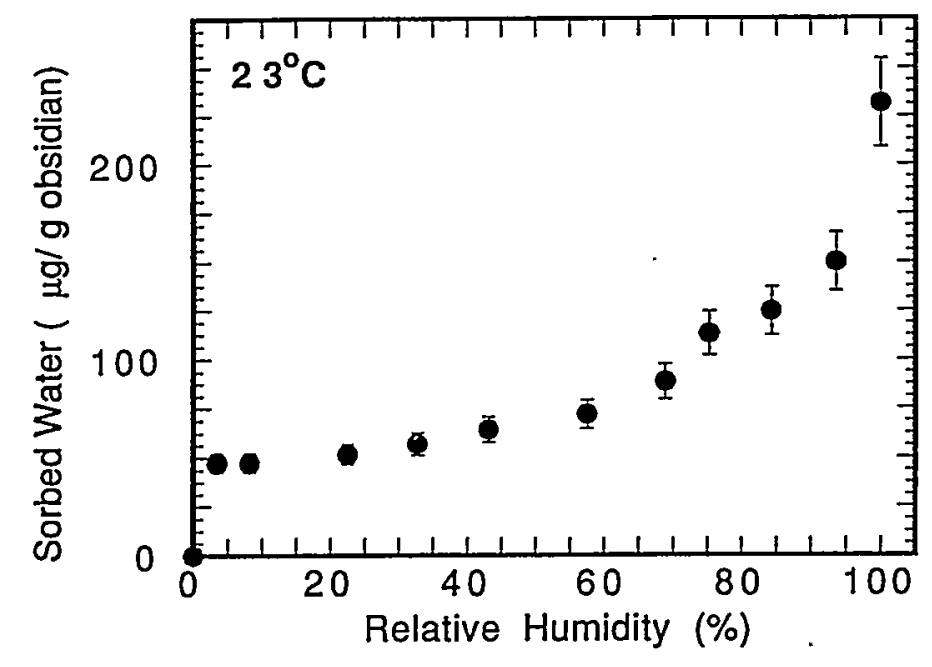

Fig. IV-3. Sorption isotherm collected at room temperature for a Snake River obsidian [MAZER-1991B].

Finally, although the hydration rate can be measured in laboratory experiments, these rates may not be directly applied to naturally reacted obsidian samples, with only a few exceptions. Friedman and others [FRIEDMAN-1976] compared the results of laboratory vapor hydration experiments with field observations on Obsidian Cliff obsidian glass. The experimental hydration rate, $4 \mu \mathrm{m}^{2} / 1000 \mathrm{y}$, obtained from a synthetic glass having the same composition as the Obsidian Cliff sample, was found to be in good agreement with the reaction rates in nature, which were 4 to $4.5 \mu \mathrm{m}^{2} / 1000 \mathrm{y}$, measured from the ${ }^{14} \mathrm{C}$-dated field samples. However, Ericson and others [ERICSON-1980] studied the rates of both natural and laboratory hydration of numerous obsidian samples from 14 localities and concluded that the rates of laboratory reaction tended to be much lower (by as much as two orders of magnitude) than those observed for natural hydration. Their results suggest that obsidians are more stable in laboratory tests suggested by study of natural samples. This is because laboratory experiments can not take into account variations of environmental conditions over time, such as temperature, humidity, and exposure time. In particular, small increases in temperature can lead to large changes in the hydration rate because of high activation energies for the hydration process. In addition, the water diffusion process that controls hydration rates in laboratory experiments may be coupled with other processes in natural corrosion, such as leaching and dissolution. Such coupled reactions could exhibit more rapid kinetics than a single water diffusion process and could lead to a lower hydration rates than are observed in the field.

\section{Natural Alteration of Obsidian}

\section{Subaerial Alteration}

Under terrestrial exposure conditions, obsidian is contacted by water in the form of precipitation, surface runoff, and ambient humidity. In nature, the glass is also contacted by organic and inorganic materials, which result in higher moisture levels at the glass surface than in the surrounding air. The humidity is an important factor in the hydration of obsidian because it 
is related to the driving force for molecular water diffusion into obsidian. Field measurements of the relative humidity of soil at 25 sites and at depths between 0.01 and $2 \mathrm{~m}$ below ground show that the relative humidity is nearly constant at $100 \%$ below about $0.25 \mathrm{~m}$ [FRIEDMAN-1994].

Friedman and others [FRIEDMAN-1978] examined more than 85 obsidian glasses that were collected from various surface sites or buried at shallow depths (typically $<1 \mathrm{~m}$ ). In all cases, the surfaces of samples were found to have altered to a hydrated form known as perlite, which is observed as a strain birefringence layer with a polarized light microscope (see Fig. IV-1) [FRIEDMAN-1966, -1976, -1978, -1984]. The thicknesses of the perlite layers that formed on different samples ranged from less than $1 \mu \mathrm{m}$ to over $50 \mu \mathrm{m}$, depending on the site and age of the sample. Ericson and others [ERICSON-1980] observed similar hydration rims on 28 rhyolitic obsidian samples recovered in California, western Nevada, and southern Oregon. Consistent with others, they noticed that, unlike altered basaltic glasses (see Sec. IV), there is no evidence for the formation of secondary minerals during corrosion of obsidian samples in terrestrial environments [FRIEDMAN-1966, -1976, -1978, -1984; AMBROSE-1976]. The formation of perlite apparently results from the diffusion of water into the glass [FRIEDMAN-1976; ERICSON-1980].

Lee and others [LEE-1974] profiled the hydrated layers of several obsidian samples recovered from Nayarit, Mexico, and Borax Lake, California, with a resonant nuclear reaction technique. They found that the general shape of the hydration profiles could be characterized by a plateau at the outer surface that represents a saturated hydrated layer, followed by a steep diffusion front into the glass. The $\mathrm{H}_{2} \mathrm{O}$ content of the saturated layer was calculated by comparing the measured hydrogen counts with a calibration sample of known hydrogen content. The layer was found to contain about 2 to $3 \mathrm{wt} \%$ water, compared with an intrinsic water content of $\sim 0.3 \mathrm{wt} \%$ in unaltered obsidian. Lanford and others [LANFORD-1977] also profiled the hydrogen concentrations in a number of obsidian glass objects of known ages and confirmed that the hydrogen profiles are characteristic of a diffusion process.

These results show that the perlite forms by a process dominated by diffusion of water. There is also evidence that the formation of perlite may involve other processes. Tsong and others [TSONG-1978] employed a sputter-induced optical emission method to simultaneously determine the variations of concentrations of not only hydrogen but nearly all elements in an obsidian artifact excavated from Kaminaljuyu, Guatemala. They found that, in addition to the characteristic enrichment of hydrogen, the outer surface was enriched also in $\mathrm{Ca}$ and $\mathrm{Mg}$ and depleted in $\mathrm{Na}, \mathrm{K}$, and $\mathrm{Li}$, relative to the bulk glass (Fig. IV-4). The enrichment of $\mathrm{Ca}$ and $\mathrm{Mg}$ at the surface may be due to the incorporation of these elements from groundwater, while the surface depletion in alkali metals $(\mathrm{Na}, \mathrm{Li}$, and $\mathrm{K}$ ) appeared to result from a dealkalization process in which they leached out from glass. The count rates for $\mathrm{Si}$ and $\mathrm{Al}$ show no variation with depth, suggesting that the silicate network remains intact.

\section{2. $\quad$ Alteration in Liquid Water}

There are only a few studies of obsidian glasses that have been altered in lake or seawaters, partly due to the limited availability of such samples. Unlike terrestrial alteration, in which obsidian transforms results to perlite, the alteration of obsidian glasses exposed to aqueous solutions resulted in the formation of various alteration phases, the identities of which may depend on the environmental conditions. Magonthier and others [MAGONTHIER-1992] studied a 52,000-year-old sample of rhyolitic glass that had been altered at low temperatures $\left(<10^{\circ} \mathrm{C}\right)$ by a subaerial flow of rain and subglacial melt waters. Interestingly, the perlitic texture, which is characteristic of the obsidian glasses that are altered in terrestrial conditions, was not 

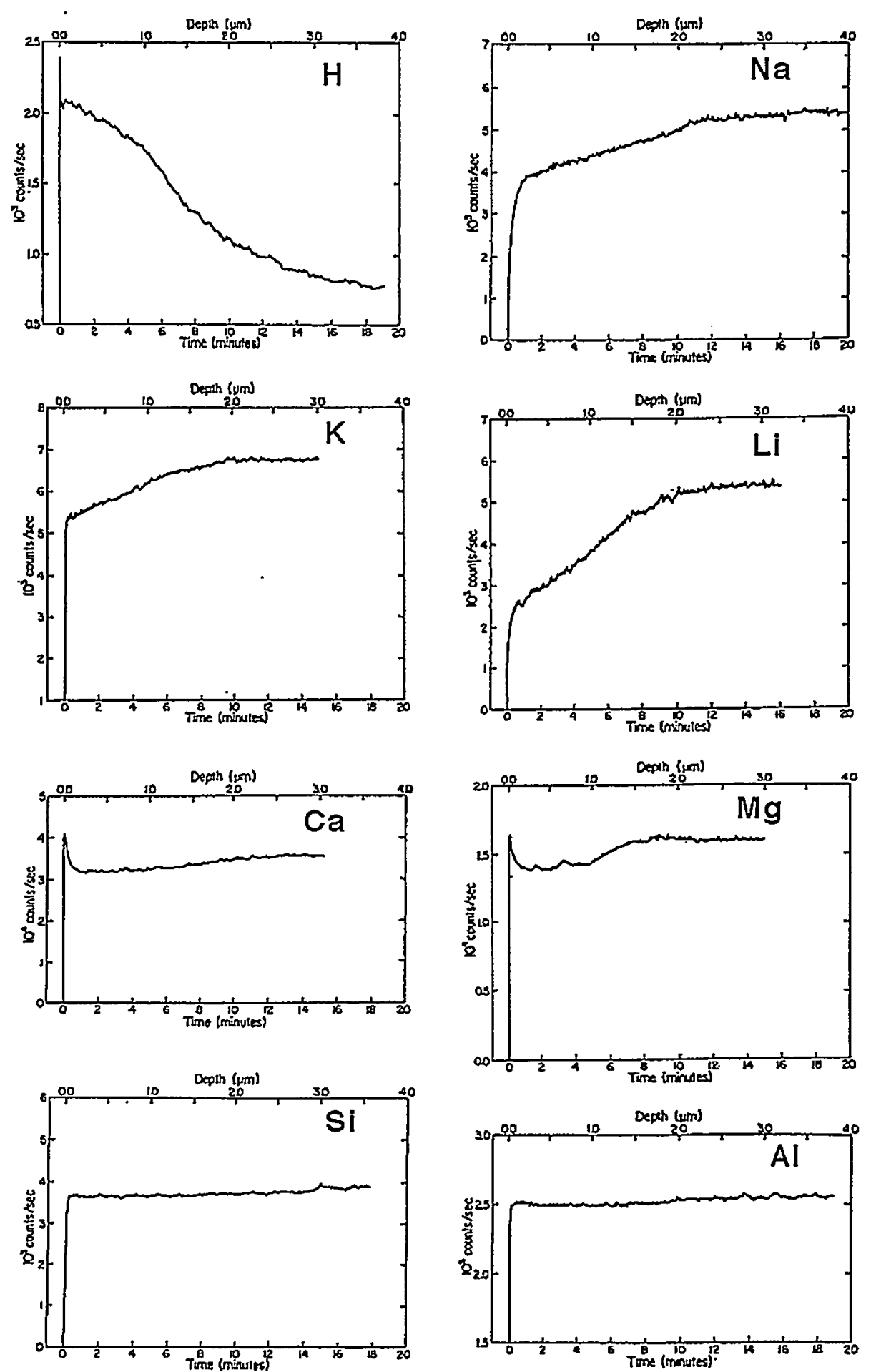

Fig. IV-4. Depth profiles of $\mathrm{H}, \mathrm{Na}, \mathrm{K}, \mathrm{Li}, \mathrm{Ca}, \mathrm{Mg}, \mathrm{Si}$, and $\mathrm{Al}$ in an obsidian artifact from Kaminaljuyu, Guatemala, plotted as the number of photon counts versus the sputtering time and depth [TSONG-1978]. 
observed in the obsidian glass reacted with water solutions. Instead, a honey-colored alteration layer depletion of alkali was found at surface. The alteration layer consisted of amorphous iron-rich aluminosilicate and crystallized aluminum trihydroxide. Similarly, Dickin and others [DICKIN-1981] reported the formation of alkali-feldspar and epidote in a 200,000-year-old rhyolite glass that had been exposed to $400^{\circ} \mathrm{C}$ seawater that had been heated in a conduct in the Theriary hydrothermal system near Scotland.

These results clearly show that the processes dominating the hydrothermal alteration of obsidian differ significantly from those of terrestrial alteration. Although the corrosion of silicate glasses involves molecular water diffusion, ion exchange, dissolution, and formation of alteration phases in all environments, some processes may be suppressed due to the effects of limited amounts of water in some environments. In terrestrial environments, in which only small amounts of water contact glass, dissolution does not occur to a significant extent, and alteration reflects only diffusion of water into the glass. In a hydrothermal environment in which a large volume of water contacts glass, the glass may simply dissolve without the formation of an alteration layer.

\section{Obsidian Reaction Rates in Natural Environment}

The rate of alteration of obsidian in humid air has been measured based on the thickness of the birefringent layer [FRIEDMAN-1966, -1976, -1978, -1984]. Friedman and others [FRIEDMAN-1976] analyzed the birefringent layers of obsidian from the Mummy Cave rock shelter, Wyoming. Samples ranged in age from several hundred to more than $10,000 \mathrm{y}$, based on ${ }^{14} \mathrm{C}$ dating. They found that the squares of the thickness of hydration rims were linear with the age of the sample (Fig. IV-5). Such a fit yields a hydration rate between 4 and $4.5 \mu \mathrm{m}^{2} / 1000$ y for the Mummy Cave obsidian, in good agreement with the rate derived from experiments on obsidian of similar composition. Similar time dependence has been reported for many naturally occurring obsidians from around the world. The actual hydration rates range from 1 to $70 \mu \mathrm{m}^{2} / 1000 \mathrm{y}$ depending on the locality and composition of obsidian [FRIEDMAN-1976; ERICSON-1980; STEVENSON-1993]. Friedman and others [FRIEDMAN-1976] expressed the hydration thickness, $\mathrm{D}$, in terms of a general diffusion equation as follows:

$$
\mathrm{D}=\mathrm{k} \cdot \mathrm{t}^{1 / 2}
$$

where $t$ is time and $\mathrm{k}$ is the hydration rate. The hydration rate has a temperature dependence that is expressed by the Arrhenius equation

$$
\mathrm{k}=\mathrm{A} \exp (-\mathrm{E} / \mathrm{RT})
$$

where $A$ is a constant, $E$ is the activation energy of the hydration process, $R$ is the gas constant, and $\mathrm{T}$ is absolute temperature. (For convenience, $\mathrm{k}$ is usually expressed in terms of thickness ${ }^{2}$ $\left(\mu \mathrm{m}^{2}\right) /$ time $(1000 \mathrm{y}$.) Both $\mathrm{A}$ and $\mathrm{E}$ have been showed to be sample dependent [FRIEDMAN-1976]. 


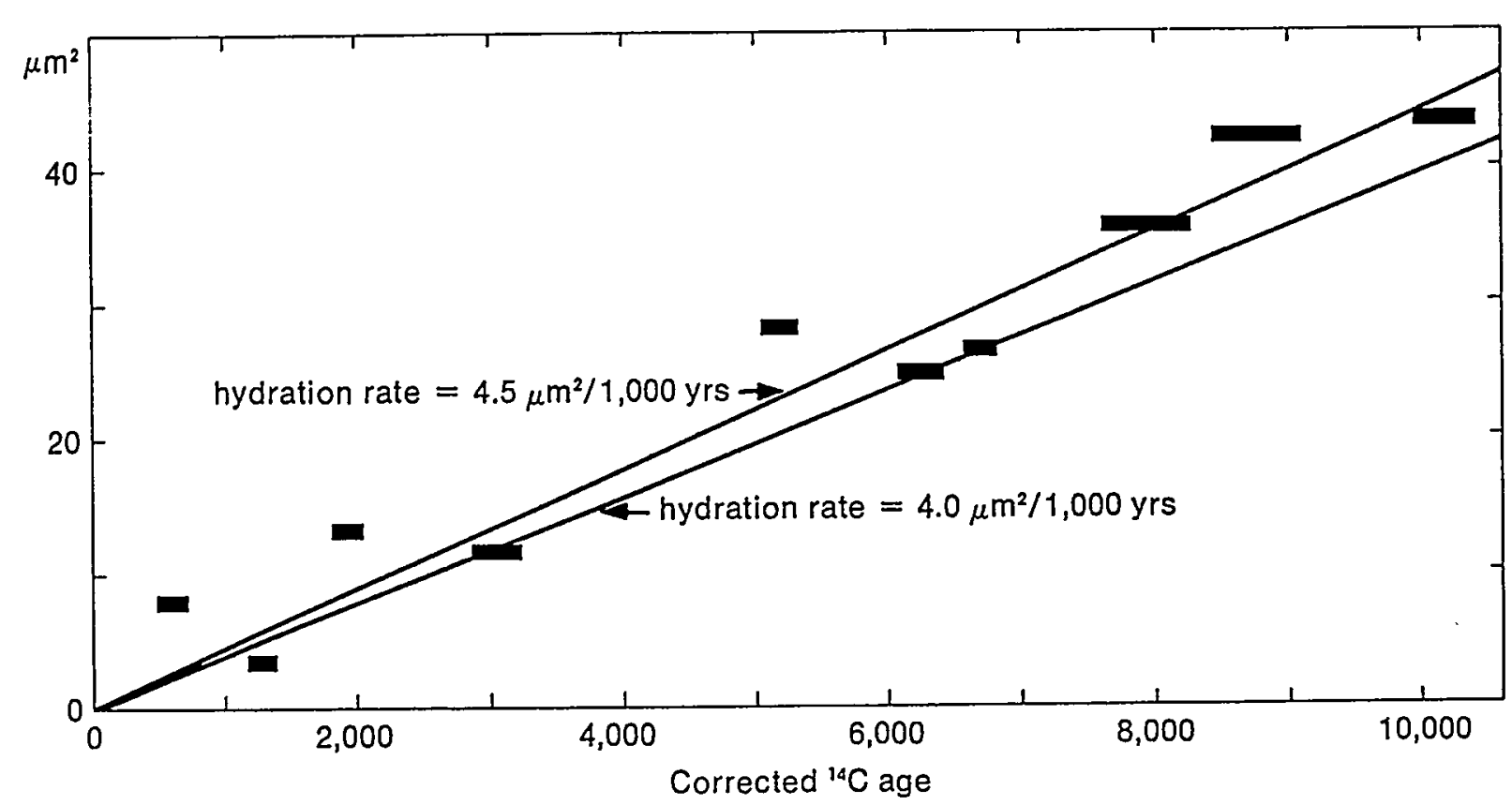

Fig. IV-5. The square of hydration rim thickness versus age of Mummy Cave obsidian samples showing a linear time dependence. The hydration rates given by the solid lines are 4$4.5 \mu \mathrm{m}^{2} / 1,000$ years. The divergencies of the field data from the solid line are attributed to the temperature variations at different sites [FRIEDMAN-1978].

Actual hydration rates differ among samples from different locations [ERICSON-1988; FRIEDMAN-1966, -1976, -1978; STEVENSON-1993]. Ericson and others reported [ERICSON-1988] a hydration rate of $4.5 \mu \mathrm{m}^{2} / 1000$ y for coastal Malibu, California, obsidian samples, but $3.3 \mu \mathrm{m}^{2} / 1000$ y for coastal Orange County obsidian samples, even though glasses from the two areas had reacted in similar environments at about the same temperature. Similar cases have also been seen in mountain areas: a hydration rate of $5.3 \mu \mathrm{m}^{2} / 1000$ y was reported in the El Paso mountains and $2.4 \mu \mathrm{m}^{2} / 1000 \mathrm{y}$ in the Scodie Mountains [ERICSON-1988]. These studies suggest that the hydration rates must be affected by the chemical composition of a glass according to Eq. IV-3, although the direct correlation between hydration rates and chemical composition has not been made for field studies. Several authors have suggested that relationships exist between the rate and the silica, alumina, and alkali contents and between the rate and the ratio of potash to alumina [SUZUKI-1973]. However, these relationships are not consistent and often have not been observed by others [FRIEDMAN-1976]. Stevenson and others [STEVENSON1993] suggested that intrinsic water content in obsidian is a critical parameter that affects the hydration rate. They noticed that a wide range of hydration rates $\left(18\right.$ to $\left.65 \mu \mathrm{m}^{2} / 1000 \mathrm{y}\right)$ can be correlated with the variation (0.3-1.3 wt\%) in water content for obsidian samples found in the Coso Volcanic Field, which have similar chemical compositions (except for water content) and have reacted at same temperature.

Although many field observations seem to be consistent with the general diffusion equation described above, other time dependencies have also been determined empirically from different data sets. These are summarized in Table IV-2. The general expression was written as

$$
\mathrm{D}=\mathrm{k} \cdot \mathrm{t}^{\mathrm{n}}
$$


where $\mathrm{n}$ has been shown to vary from $1 / 3$ to 2 , depending on samples and locations. While these results may indicate that the alteration of obsidian in nature could be more complicated than a continuous reaction dominated by a single diffusional process, it is likely that changes in the values of environmental parameters, such as relative humidity, solution composition, and effective temperature, over the course of alteration could also affect the apparent time dependence of hydration.

Table IV-2. Published hydration depth vs. time formulas to determine age of volcanic glasses (obsidian except as noted) grouped in the order of faster penetration reading downward (after [FRIEDMAN-1978])

\begin{tabular}{|c|c|}
\hline Formula Type & Investigators \\
\hline depth $=\mathrm{k} \cdot \operatorname{time}^{1 / 3}$ & Kimberlin (1976) \\
\hline depth $=k \cdot \operatorname{time} e^{1 / 2}$ & $\begin{array}{l}\text { Friedman and Smith (1960) } \\
\text { Friedman et al. (1966) } \\
\text { Michels (1967) } \\
\text { Johnson (1969) } \\
\text { Suzuki (1973) } \\
\text { Friedman and Long (1976) }\end{array}$ \\
\hline depth $=\mathrm{k} \cdot \operatorname{time}^{\mathrm{I} / 2}+\mathrm{K}^{\prime}$ & Findlow et al. (1975) \\
\hline $\operatorname{depth}=\mathrm{k} \cdot \operatorname{time}^{3 / 4}$ & Clark (1961) \\
\hline depth $=\mathrm{k} \bullet$ time & $\begin{array}{l}\text { Meighan (1976) } \\
\text { Layton (1972) } \\
\text { Ericson (1975) }\end{array}$ \\
\hline \multicolumn{2}{|c|}{$\begin{array}{l}\text { J. Kimberlin, "Obsidian Hydration Rate Determination on Chemically Characterized Samples," } \\
\text { in Advances in Obsidian Glass Studies, R. E. Taylor, ed., Noyes Press (1976). } \\
\text { I. Friedman and R. L. Smith, "A New Dating Method Using Obsidian, Part 1: The Development } \\
\text { of the Method," Amer. Antiq. } 25,476-493 \text { (1960). } \\
\text { I. Friedman, R. L. Smith, and W. Long, "Hydration of Natural Glass and the Formation of } \\
\text { Perlite," Bull. Geol. Soc. of Amer. } 77,323-328 \text { (1966). } \\
\text { J. W. Michels, "Archaeology and Dating by Hydration of Obsidian," Science } 158,211-214 \text { (1967). } \\
\text { L. Johnson, Jr., "Obsidian Hydration Rate for the Klamath Basin of California and Oregon," } \\
\text { Science } 165,1354-1356 \text { (1969). } \\
\text { M. Suzuki, "Chronology of Prehistoric Human Activity in Kanto, Japan," J. of the Faculty of } \\
\text { Science, University of Tokyo } 4(5), 241-318 \text { (1973). } \\
\text { I. Friedman and W. Long, "Hydration Rate of Obsidian," Science 191, 347-352 (1976). } \\
\text { F. J. Findlow, V. Bennett, J. Ericson, and S. De Atley, "A New Obsidian Hydration Rate for } \\
\text { Certain Obsidians in the American Southwest," Amer. Antiq. } 40,344-348 \text { (1975). } \\
\text { D. Clark, "The Application of the Obsidian Dating Method to the Archaeology of Central } \\
\text { California," Stanford University Dissertation (1961). } \\
\text { C. W. Meighan, "Empirical Determination of Obsidian Hydration Rates from Archaeological } \\
\text { Evidence," in Advances in Obsidian Glass Studies, R. E. Taylor, ed., Noyes Press (1976). } \\
\text { T. N. Layton, "Lithic Chronology in the Fort Rock Valley, Oregon," Tebiwa 15(2), 1-20 (1972). } \\
\text { J. E. Ericson, "New Results in Obsidian Hydration Dating," World Archeology } 7(2), 151-159 \\
\text { (1975). }\end{array}$} \\
\hline
\end{tabular}




\section{BASALTIC GLASSES}

\section{A. Introduction}

Basaltic glasses are of volcanic origin and occur on the outer surface of volcanic flows when basaltic magmas come into contact with air or water. The latter includes eruptions into sea, lakes, streams, groundwater, and glaciers. In addition, basalt glasses also occur as ash particles, which are often fibrous or teardrop-shaped [O'KEEFE-1984]. They have variable color, ranging from black, through pinkish, gray-green, brown, and red, or are colorless.

Basaltic glasses have silica contents that are similar to most current formulations of nuclear waste glass (silica contents for basaltic glasses are commonly in the range of 45 to $50 \mathrm{wt} \%$ ). For this reason, basaltic glasses are considered by many as the best natural analogues for borosilicate glass waste forms. Many studies have been conducted to elucidate the mechanism and kinetics of the alteration of basalt glasses in both natural and laboratory environments. These studies reveal that the aqueous alteration of basaltic glasses generally results in the formation of alteration phases referred to collectively as palagonites. The physical characteristics of these alteration products have been summarized in an extensive review by Honnorez [HONNOREZ-1978], who noted that the term palagonite has been historically applied to "a mixture, in variable proportions, of altered, hydrated, and oxidized glass ... with authigenic minerals such as clays, zeolites, and chlorite."

The variability of the chemical and mineralogical composition of palagonites reflects differences in the conditions and extent of water-glass reaction. Basalt glasses have been found in a wide range of alteration environments, including [EWING-1979]

- $\quad$ mid-ocean ridge environments, where glass reacts with seawater at temperatures less than $4^{\circ} \mathrm{C}$;

- $\quad$ subglacial environments, where glass reacts with glacial melt water at $\sim 0^{\circ} \mathrm{C}$;

- $\quad$ volcanic ash flows, where glass reacts with rain water at ambient temperatures; and

- $\quad$ active geothermal environments, where glass reacts with hot water or vapor.

The physical and chemical nature of basalt alteration in these environments has been investigated extensively [JERCINOVIC-1987; ALLEN-1981; McKENZIE-1990; FURNES-1984; STAUDIGEL-1983; STOKES-1971]. In all cases, the alteration of basaltic glass results in the formation of palogonite.

\section{Palagonite Formation}

The term "palagonite" was first used by W. Sartorius von Waltershausen in 1845 to describe a brown material in the ground mass of a tuff from Palagonia in Sicily. It has since been adapted to describe the yellow-brown, gel-like material that is the alteration product of basalt glass. Jercinovic and Ewing [JERCINOVIC-1987] listed the following general chemical characteristics of palagonite after extensively reviewing the published data in the literature:

- palagonitization is a non-isochemical alteration process and not simple hydration;

- the composition of palagonite commonly differs from one sample to another; and

- chemically different palagonites can originate from chemically and physically similar glasses, indicating the importance of the alteration environment (e.g., solution composition, temperatures, and flow rate). 


\section{Formation of Secondary Minerals}

Secondary mineral phases have been frequently observed to form on the outer surface of the alteration layer appearing in the later stages of palagonitization. Table V-1 lists the commonly formed secondary minerals and their chemical formulae. Because secondary mineral phases precipitate only after the solution becomes saturated, the sequence of minerals that are formed reflects the chemical evolution of the environment and the progress of corrosion. Many of the same phases have been observed in laboratory tests with basaltic glasses and naturally occurring glasses [EWING-1987]. The observation of similar phases indicates that the natural corrosion of basalt can be reproduced in accelerated laboratory tests without altering the fundamental reaction processes. This provides confidence that the accelerated test methods can be used to study the long-term corrosion behavior of waste glasses.

Table V-1. Chemical formulae of common minerals in glass alteration layer

\begin{tabular}{|c|c|}
\hline Mineral & Formula \\
\hline Smectite & $(1 / 2 \mathrm{Ca}, \mathrm{Na})_{0.7}(\mathrm{Al}, \mathrm{Mg}, \mathrm{Fe})_{4}\left[(\mathrm{Si}, \mathrm{Al})_{8} \mathrm{O}_{26}\right](\mathrm{OH})_{4} \bullet \mathrm{nH}_{2} \mathrm{O}$ \\
\hline Hydrotalcite & $\mathrm{Mg}_{6} \mathrm{Al}_{2} \mathrm{CO}_{3}(\mathrm{OH})_{16} \bullet 4 \mathrm{H}_{2} \mathrm{O}$ \\
\hline Analcime & $\mathrm{Na}\left[\mathrm{AlSi}_{2} \mathrm{O}_{6}\right] \cdot \mathrm{H}_{2} \mathrm{O}$ \\
\hline Phillipsite & $(1 / 2 \mathrm{Ca}, \mathrm{Na}, \mathrm{K})_{3}\left[\mathrm{Al}_{3} \mathrm{Si}_{5} \mathrm{O}_{16}\right] \bullet 6 \mathrm{H}_{2} \mathrm{O}$ \\
\hline Thomsonite & $\mathrm{NaCa}_{2}\left[(\mathrm{Al}, \mathrm{Si})_{5} \mathrm{O}_{10}\right]_{2} \cdot 6 \mathrm{H}_{2} \mathrm{O}$ \\
\hline Chabazite & $\mathrm{Ca}\left[\mathrm{Al}_{2} \mathrm{Si}_{4} \mathrm{O}_{12}\right] \bullet 6 \mathrm{H}_{2} \mathrm{O}$ \\
\hline Garronite & $\mathrm{NaCa}_{2.5}\left[\mathrm{Al}_{6} \mathrm{Si}_{10} \mathrm{O}_{32}\right] \cdot 13.5 \mathrm{H}_{2} \mathrm{O}$ \\
\hline Tobermorite & $\mathrm{Ca}_{5}(\mathrm{OH})_{2} \mathrm{Si}_{6} \mathrm{O}_{16} \bullet 4 \mathrm{H}_{2} \mathrm{O}$ \\
\hline Gyrolite & $\mathrm{Ca}_{4} \mathrm{Si}_{6} \mathrm{O}_{15}(\mathrm{OH})_{2} \bullet 3 \mathrm{H}_{2} \mathrm{O}$ \\
\hline Opal & $\mathrm{SiO}_{2} \cdot \mathrm{nH}_{2} \mathrm{O}$ \\
\hline Calcite & $\mathrm{CaCO}_{3}$ \\
\hline Gibbsite & $\mathrm{Al}(\mathrm{OH})_{3}$ \\
\hline Kaolinite & $\mathrm{Al}_{4}\left[\mathrm{Si}_{4} \mathrm{O}_{10}\right](\mathrm{OH})_{8}$ \\
\hline Lizardite & $\mathrm{Mg}_{3}\left[\mathrm{Si}_{2} \mathrm{O}_{5}\right](\mathrm{OH})_{4}$ \\
\hline Aragonite & $\mathrm{CaCO}_{3}$ \\
\hline Peyerite & $(\mathrm{Na}, \mathrm{K})_{2} \mathrm{Ca}_{14} \mathrm{Al}_{2} \mathrm{Si}_{22} \mathrm{O}_{5}(\mathrm{OH})_{8} \bullet 6 \mathrm{H}_{2} \mathrm{O}$ \\
\hline
\end{tabular}

\section{B. Laboratory Reaction Processes}

Natural basaltic glasses have been reacted in laboratory tests to study the mechanisms that control glass reaction and to develop methods to simulate the alteration that is observed in naturally altered samples. High temperature and high S/V conditions are employed to accelerate the reaction progress such that alteration of glass will take place in a relatively short time. Similarities between the alteration of glasses reacted in nature for geologic times and the alteration in laboratory tests under accelerating conditions lend confidence that the glass in the accelerated tests reacts via the same mechanism as the naturally altered glass.

\section{1. $\quad$ Reaction in Liquid Water}

The laboratory alteration of basalt glass in liquid water has been performed under different experimental conditions by various groups [BYERS-1986; SEYFRIED-1979; ABRAJANO-1986; MALOW-1984; GISLASON-1993; CROVISIER-1987]. In these experiments, the reaction behavior is quantified by analyzing the chemistry of aqueous solutions. Crovisier and others [CROVISIER-1987] reacted a synthetic tholeiitic basalt glass in synthetic seawater at temperatures between 3 and $60^{\circ} \mathrm{C}$ for up to 595 days. Analyses of the solutions 
revealed a linear time dependence of silica concentrations in solution that is consistent with a reaction that is dominated by a dissolution process. Examination of the altered surface with an electron microprobe revealed that hydrotalcite, which is a structural precursor of sheet silicates, and a microcrystalline iron hydroxide comprised the altered layer. The layer was about $1.5-\mu \mathrm{m}$ thick after reacting for 2 years at $60^{\circ} \mathrm{C}$. The observation that the altered phase always formed a sharp interface with the unreacted glass was interpreted by the authors as evidence of congruent dissolution. However, electron microscopy may not distinguish a leached glass from an unreacted glass based on imaging contrast, in particular when the glass structure (network) still remains intact upon leaching. Indeed, Ghiara and others [GHIARA-1993] reported that the dissolution of basalt glass is incongruent during the first hours of reaction. This was demonstrated by the solution concentrations of all the major cations, which exhibited a nonlinear time dependence for a basaltic glass reacted in either deionized water or natural seawater.

Byers and others [BYERS-1986] reacted a synthetic Hawaiian basalt glass in deionized water at temperatures ranging from 90 to $187^{\circ} \mathrm{C}$ for times up to 546 days. The release of individual cations from the glass as a function of time typically proceeded at a nonlinear rate initially, but at a linear rate after 15 to 91 days of reaction. Figure V-1 shows the concentrations of cations released from glass reacted at $150^{\circ} \mathrm{C}$ in deionized water. The release to solution was not stoichiometric but decreased in the order $\mathrm{Na}>\mathrm{Si} \sim \mathrm{Ca}>\mathrm{Al}>\mathrm{Mg}$.

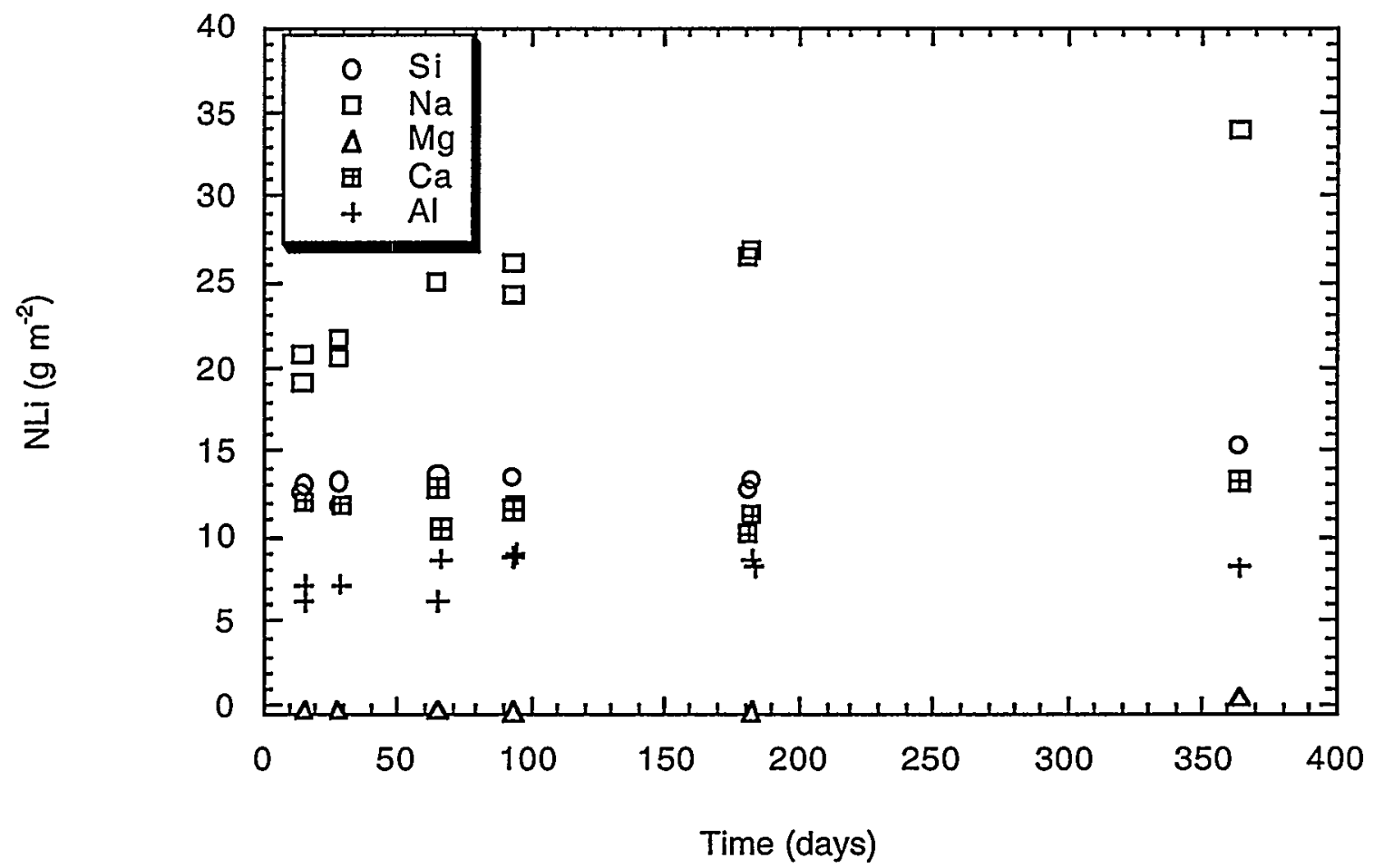

Fig. V-1. Normalized mass loss for $\mathrm{Si}, \mathrm{Na}, \mathrm{Al}, \mathrm{Ca}$, and $\mathrm{Mg}$ as a function of time for Hawaiian basalt glass hydrothermally leached at $150^{\circ} \mathrm{C}$ in deionized water [BYERS-1986].

Gislason and others reacted a basalt glass with meteoric water at temperatures of $45^{\circ} \mathrm{C}$ and $70^{\circ} \mathrm{C}$ [GISLASON-1993]. They found that the solution concentrations of $\mathrm{Ca}, \mathrm{Mg}$, and $\mathrm{Si}$ became constant after alteration phases containing these elements began to precipitate at the glass surface. Their results suggest that the continued dissolution of basalt may 
be balanced by precipitation of alteration products that incorporate elements that are released as the glass dissolves.

The identity and order of appearance of the alteration phases reflect both the solution chemistry and glass composition. Byers and others [BYERS-1986] observed that a honeycombed, net-like appearance developed at the surface on basaltic glasses leached in deionized water at temperatures between 90 and $187^{\circ} \mathrm{C}$. This honeycombed texture is typical of smectite-type clay. Murakami and others [MURAKAMI-1988] also reacted a synthetic basalt glass with deionized water for 301 days at $70^{\circ} \mathrm{C}$. The sample formed a discontinuous irregular layer that ranged in thickness from 0 to $3 \mu \mathrm{m}$. The layer, which was characterized with AEM, formed a sharp interface with the parent glass and was described as being composed of two distinct zones. The zone nearest the bulk glass contained an iron-rich crystalline phase, and the zone nearest the solution had a composition that was similar to the crystals of the inner zone but also contained gibbsite $\left[\mathrm{Al}(\mathrm{OH})_{3}\right]$.

Lutze and others [LUTZE-1985] performed experiments that directly compared the alteration layers formed at the surfaces of synthetic Hawaiian basalt glasses that were reacted in the laboratory to those that formed on a dredge sample of basalt glass that had corroded in seawater (Fig. V-2). A repetitive sheet-like structure formed on the synthetic basalt after reaction in a saturated $\mathrm{NaCl}$ solution at $200^{\circ} \mathrm{C}$ for 30 clays. This structure was similar to the palagonite layer that had formed in seawater-altered basalt glass at $3^{\circ} \mathrm{C}$ after a long period of time. Microprobe analyses revealed that relative to the basaltic glass, $\mathrm{Si}$ and $\mathrm{Ca}$ were depleted and $\mathrm{Ti}, \mathrm{Fe}$, $\mathrm{Mn}$, and $\mathrm{Na}$ were enriched in the alteration layers on both the laboratory-altered and naturally reacted samples. These results illustrate that the alteration of basalt glass that occurs in short-term laboratory experiments matches that observed in naturally reacted basalt glasses of much greater ages. Lutze et al. also reacted a borosilicate nuclear waste glass under the same conditions (saturated $\mathrm{NaCl}$ at $200^{\circ} \mathrm{C}$ ) and observed the formation of alteration products that were similar in microstructure to the laboratory-reacted basalt (Fig. V- 2 c,d). The similarity of the alteration phases suggests that the basalt and waste glasses react by similar processes, thus establishing an analogue relationship between two glasses, at least under these reaction conditions.

\section{Hydration in Saturated Water Vapor}

Reaction of glasses in water vapor accelerates the formation of secondary minerals because of the high S/V ratios and elevated temperatures used in these experiments [BATES-1982]. Such tests can be used to determine the identities and order of appearance of alteration phases within a relatively short test period.

Byers and others [BYERS-1986] studied the reaction of a synthetic Hawaiian glass in a saturated vapor environment over a temperature range of 122 to $240^{\circ} \mathrm{C}$ for reaction times up to 91 days. Increasing the reaction temperature resulted in higher reaction rates and a greater variety of alteration products on the surface. Smectite clay typically formed at the early stage of the reaction in tests conducted at all temperatures. As identified by XRD, other phases that precipitated at these temperatures included analcime, gyrolite, thomsonite, aragonite, and reyerite. These phases were found on the outer surface of the clay layer, in contact with the vapor phase. There is a good correlation between the alteration minerals formed on naturally altered basalt glass and those observed in vapor-reacted samples. For example, smectite, analcime, thomsonite, and aragonite have all been observed in naturally altered basalt glasses that have undergone palagonitization [FURNES-1984]. Garronite is similar to naturally occurring phillipsite, and gyrolite has been associated with palagonite formation with weathering of basalt in both submarine and subaerial conditions [HONNOREZ-1978]. Reyerite, which is a phyllosilicate similar in structure and composition to gyrolite, has not been observed as a natural alteration product of basalt. 

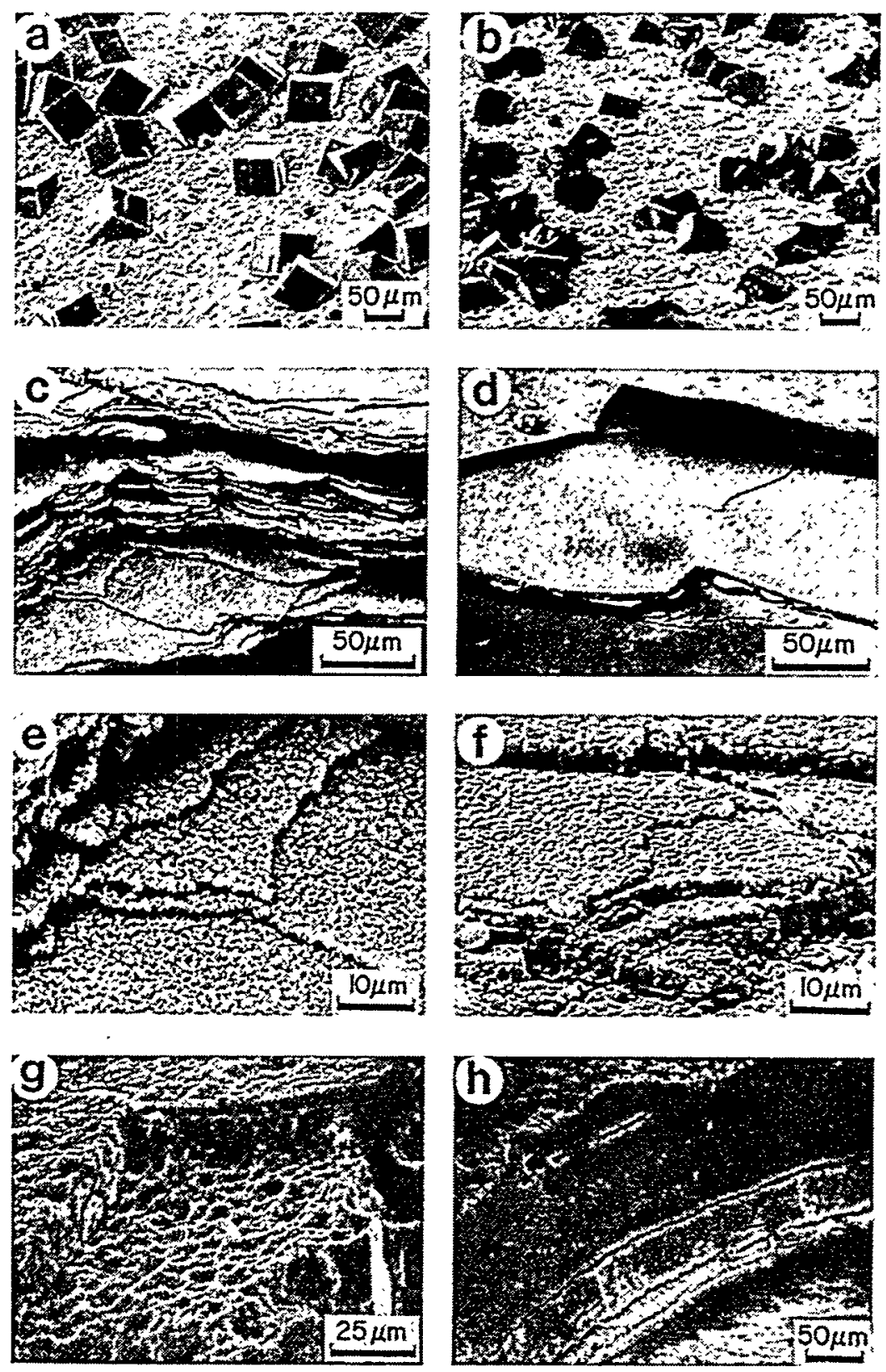

Fig. V-2. Scanning electron micrographs of Hawaiian basalt glass $(a, c, e)$ and borosilicate waste glass $(b, d, f)$ reacted in saturated synthetic $\mathrm{NaCl}$ solution at $200^{\circ} \mathrm{C}$ for 30 days. A repetitive sheet-like structure formed on synthetic basalt after reacted in a saturated $\mathrm{NaCl}$ solution at $200^{\circ} \mathrm{C}$ for 30 days, which was comparable to the palagonite formed in seawater-altered basalt glass at $3^{\circ} \mathrm{C}$ for long periods of time. Similar microstructure was also found on a naturally basaltic glass altered in seawater at $3^{\circ} \mathrm{C}(\mathrm{g}, \mathrm{h})$ [LUTZE-1985].

Byers and others [BYERS-1986] also studied the corrosion reaction of nuclear waste glass SRL 165 in (saturated water vapor at $240^{\circ} \mathrm{C}$ ). They found that many of the reaction products formed on SRL 165 were similar to those formed on basalt glass. These phases included a layer of smectite, which formed a sharp interface with the glass surface, and analcime and gyrolite crystals overlaying the outer surface of the smectite. Abrajano and others [ABRAJANO-1989] studied the reaction of several nuclear waste glasses in vapor environments. They noted that despite the differences in compositions of the nuclear waste glasses, common alteration phases, such as smectite clay, analcime, gyrolite, and tobermorite, were often produced 
when glasses were reacted under similar conditions. These results indicate that the same alteration reactions occur in the vapor hydration experiments as occur during the natural alteration of basalt glasses.

\section{Laboratory Reaction Rates}

The rate of glass dissolution can be calculated based on the analysis of dissolved components of the glass in solution. Crovisier and others [CROVISIER-1987] reported a linear increase in silica concentration as a function of time during experiments with a basalt glass in seawater; the dissolution rate was $1.16 \times 10^{-6} \mathrm{~g} /\left(\mathrm{m}^{2} . \mathrm{s}\right)$ at $60^{\circ} \mathrm{C}$. The rate exhibited an Arrhenius dependence on temperature with an activation energy of $\sim 65 \mathrm{~kJ} / \mathrm{mol}$.

In most cases, however, the calculation of dissolution rates through solution analyses may not be straightforward. This is because the formation of alteration products removes dissolved glass components from solution, so that their solution concentrations do not represent the amount of the glass dissolved. Byers and others [BYERS-1986] found that the release rates of cations from a synthetic Hawaiian basalt decreased with the reaction time in tests at $187^{\circ} \mathrm{C}$, with only a slight increase in normalized mass loss occurring after reaction for 56 days. It seemed that steady-state concentrations were established at this stage, because the rate of release of the elements from the glass and the rate of consumption of elements by precipitating alteration products were nearly equal. This has also been observed during the reaction of basalt glass and hydrothermal solutions by other investigators [GLASON-1993; GHIARA-1993].

Berger and others [BERGER-1994] studied the dissolution of an Li-spiked synthetic tholeiitic glass. The authors had demonstrated in their earlier studies [BERGER-1988] that the amount of $\mathrm{Li}$ incorporated into the alteration phases was negligible under hydrothermal conditions and that the Li release from a basalt glass was stoichiometric with silica [BERGER1988]. The glass network dissolution rates could then be calculated from Li release data. During the first stage of alteration before the formation of a continuous alteration layer at the surface, a socalled "initial rate" was measured in solutions that were undersaturated with respect to amorphous silica. Typical rates measured in a fresh water were $9.32,25.7$, and $260 \times 10^{-6} \mathrm{~g} \mathrm{Si} /\left(\mathrm{m}^{2} \cdot \mathrm{s}\right)$ at 150 , 200 , and $300^{\circ} \mathrm{C}$, respectively. The tholeiitic glass had a $\mathrm{SiO}_{2}$ content of 48.3 , so the normalized dissolution rates were $19.3,53.2,53.8 \mathrm{~g} /\left(\mathrm{m}^{2} \bullet \mathrm{s}\right)$. The initial rate was found to be controlled by the silica concentration in solution when the $\mathrm{pH}$ of the solution was fixed around neutral. When the glass was reacted in a solution that was saturated with respect to amorphous silica, the measured reaction rate was about 20 times lower than the rate in silica-free solutions.

Interestingly, when an alteration layer began to form and grow in tests conducted in deionized water, the dissolution rate also began to decrease. Even though the silica concentration did not exceed $10 \%$ of the amorphous silica solubility, the dissolution rates in tests in which alteration layers formed were similar to those measured in saturated solution (see Fig. V-3). This illustrates that dissolution rates do not necessarily reflect the bulk $\mathrm{pH}$ of the solution; instead, they could be related to the solution $\mathrm{pH}$ at the glass-water interface, which is controlled by glass hydrolysis. The formation of a buffer layer near the interface, such as the residual leaded layer can lend the aqueous silica concentration near the reaction interface to values close to the amorphous silica solubility. While the low rates may be attributable to a protective effect of the alteration layer, the physico-chemical nature of such layers still needs to be established. Nevertheless, these results suggest that the hydrothermal alteration by natural processes may progress at a steady rate after a protective layer has formed. The long-term rate corresponds to measurements experimentally carried out during the first stage of alteration in solutions saturated with respect to amorphous silica. Such a rate may also be readily applied to natural events. A further implication of this study 
is that measurement of short-term initial rates in saturated hydrothermal solution may provide data for predicting the long-term corrosion of basalt glass.

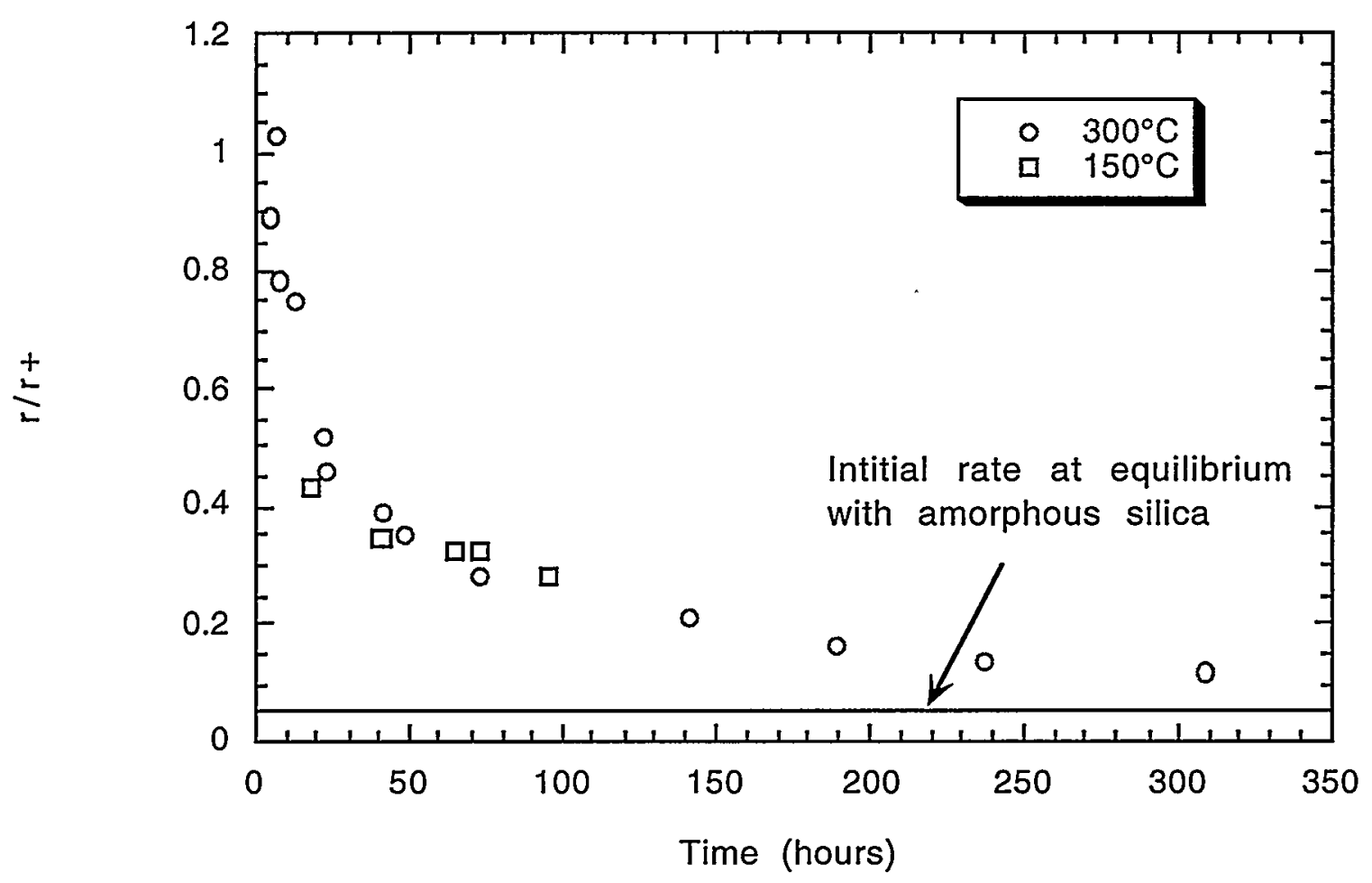

Fig. V-3. Decrease of the Li-spiked glass dissolution rate in neutral feed solutions as a function of time. In these experiments, the silica concentration of the bulk solution never exceeded $10 \%$ of the amorphous silica solubility. The decrease in dissolution rate with time reflects the protective effect of the alteration skin [BERGER-1994].

The rate of palagonitization has been estimated by many investigators through measuring the thickness of the reaction layer as a function of time. Furnes and others [FURNES-1975] determined the rate of palagonitization of three basalt glasses in fresh water at temperatures ranging from 20 to $90^{\circ} \mathrm{C}$. The growth of palagonite showed a complex pattern and was not a simple function of time (Fig. V-4). The palagonite grew rapidly at the initial stages of reaction and then the growth slowed down as the solution became saturated. The rate of palagonitization increased again after about one year, especially in tests at 70 and $90^{\circ} \mathrm{C}$ (see Fig. V-4), perhaps due to the formation of secondary phases that remove $\mathrm{Si}$ and $\mathrm{Al}$ from the solution and desaturate the solution such as analcine. The precipitation-induced rate acceleration has been observed for waste glasses under other test conditions [LEMMENS-1992; EBERT-1993]. However, solution data were generally not provided with the measured palagonite thicknesses. (In some cases, for example, in vapor hydration, the solution data and supply were not available.) In fact, the correlation between the rate of palagonitization and the rate of dissolution has never been demonstrated. 


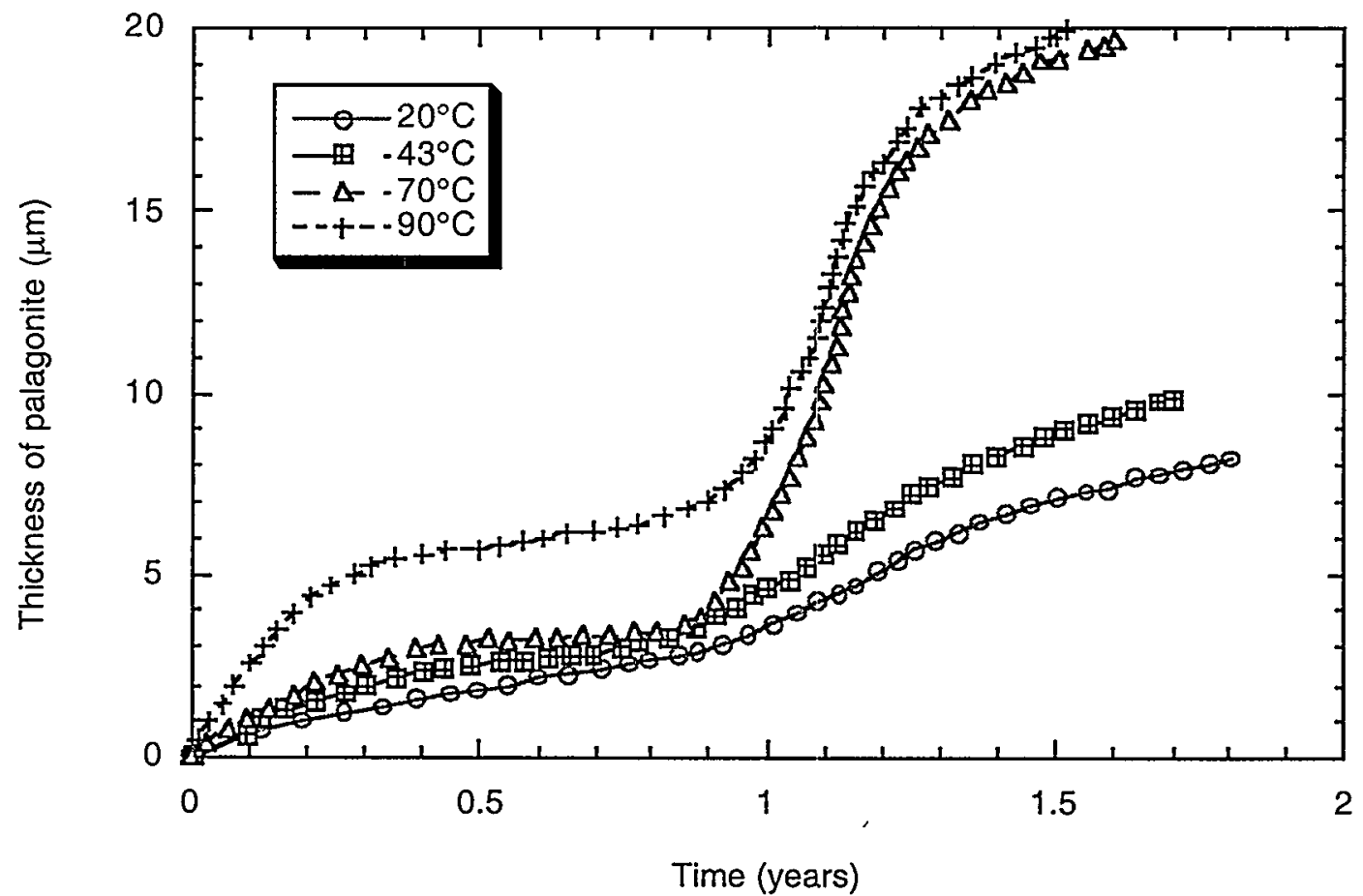

Fig. V-4. Growth rate of palagonite observed from alkali basaltic glass reacted at 20,43, 70 , and $90^{\circ} \mathrm{C}$ in deionized water [FURNES-1975].

Even if the palagonitization rate can be correctly determined in laboratory experiments, it may not necessarily be equal to the dissolution rate. This is because the formation of the palagonite is the final result of dissolution of the glass followed by the precipitation of secondary phases. Changes in the solution chemistry due to precipitation of the alternation products will affect the dissolution rate. The relative contribution of each process to the observed extent of palagonitization has not been quantitatively established. The measured rate of palagonitization could be controlled by the dissolution rate of the glass, the re-precipitation rate of alteration phases, or, most likely be intermediate between these two extremes.

How the polagonite layer will reflect the extent of reaction depends on the alteration system. Dissolution of glass in a closed system contains the release components to the vicinity of the sample such that sparingly-soluble components are likely to remain near the sample of the glass and eventually precipitate onto the surface to form the palagonite layer. In an open system, sparingly soluble components may be transported away from the dissolution glass and precipitate elsewhere. For example, Crovisier and others [CROVISIER-1983, -1987] measured a dissolution rate of $0.001 \mathrm{~g} /\left(\mathrm{m}^{2} \cdot \mathrm{d}\right)$ in seawater at $3^{\circ} \mathrm{C}$ for experimentally altered basalt glass, which was translated into a surface recession rate of $130 \mu \mathrm{m} / 1000 \mathrm{y}$. This rate is nearly two orders of magnitude higher than the palagonitization rate measured for basalt altered by open seawater, which is typically $2-3 \mu \mathrm{m} / 1000 \mathrm{y}$. These results demonstrate that the thickness of the alteration layers may not be a good indicator of the extent of reaction under some conditions. In a closed system, on the other hand, the enrichment of insoluble components in the layer may provide a 
reliable measure of the extent of dissolution. The amount of insoluble material left as residue on the layer as the rest of the glass dissolves can be compared to the composition of the original glass to calculate the volume that must have dissolved to generate the measured amount of residue. For example, the extent of corrosion leading to a layer with a uniform thickness can be estimated by multiplying the density of the glass by the thickness of the layer to obtain the normalized mass loss. Note that this approximation usually requires that an assumption to be made regarding the density of the layer to relate the composition of the layer that is analyzed with microprobe to a total volume. Experiments that analyze solution data and measure the thickness of palagonite rinds can be performed to determine whether the dissolution rate can be quantitatively determined based on palagonite thickness.

\section{Natural Alteration of Basaltic Glasses}

Basalt glasses have reacted in natural environments at various temperatures, effective surface area to volume ratios (S/V), solution compositions, and exposure times. Studying naturally altered basalt glasses allows the effects of these exposure conditions over long periods of time to be evaluated.

\section{Seawater Alteration}

Many studies of seawater-induced alteration have been conducted with basalt glasses that were either dredged from the surface of the ocean floor or recovered from the Deep Sea Drilling Project (DSDP) cores [BYERS-1986; ZHOU-1989; AILIN-PYZIK-1981; STAUDIGEL-1983; CROVISIER-1987]. The dredge samples were likely in contact with the open ocean throughout their history, since there was no overlying sediment. The ages of the dredge samples were estimated from the ages of the ocean ridges from which they were collected, which were up to 11 million years old. The DSDP samples that were recovered from the basalt basement were contacted by interstitial pore water of the sea-bed sediments in which they were buried. The ages of these samples could be up to 13 million years, according to fossil and magnetic anomaly dating [AILIN-PYZIK-1981].

\section{a. Glass Hydration}

Alteration of both dredged and DSDP basalt glasses has been extensively studied by several groups [STAUDIGEL-1983; ZHOU-1989; AILIN-PYZIK-1981; CROVISIER-1987]. The palagonite that had formed on dredged and DSDP samples exhibited similar physical characteristics, despite the different exposure environments. Zhou and others [ZHOU-1989] examined 10 DSDP samples from the Mid-Atlantic Ridge and found palagonitization to occur on the surface, along fractures, and around vesicles (see Fig. V-5). Byers and others [BYERS-1986] and Jercinovic and others [JERCINOVIC-1987] examined the alteration layers that had formed on basaltic samples dredged near Reykjavik from Kopavogur, Arnarnesvogur, and the Brimes. In all cases, samples showed evidence of palagonitization, with the thickness of rinds varying from $3 \mu \mathrm{m}$ to more than $1200 \mu \mathrm{m}$. 


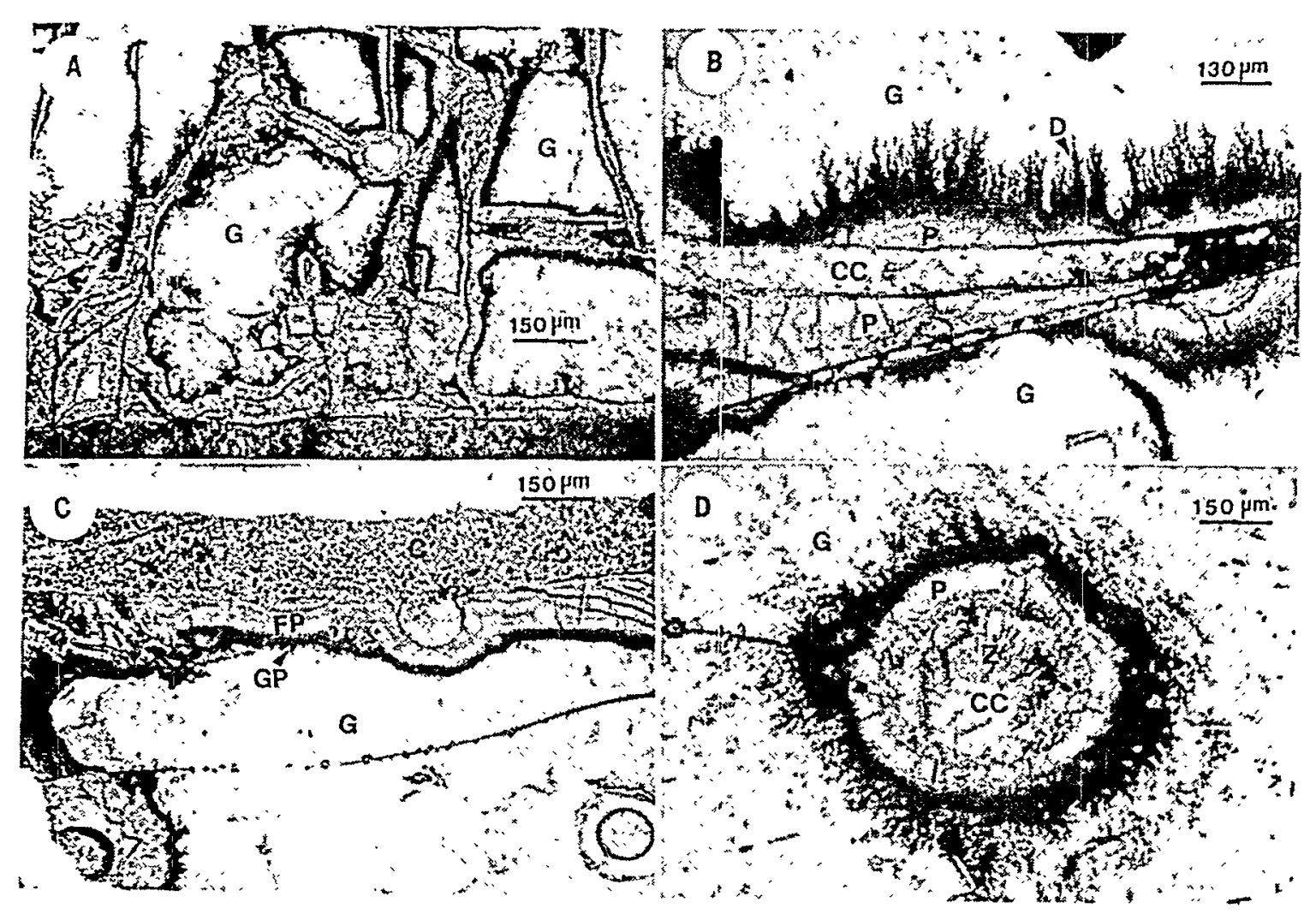

Fig. V-5. Scanning electron micrographs of palagonite formed on a deep sea-altered basaltic glass from the Mid-Atlantic Ridge. Palagonitization occurs along fractures (a), in the form of a dendrite (b), on the glass surface (c), and around vesicles within glass (d). In these figures, $C$, clay vein; $C C$, calcite; $D$, dendrite alteration front; $G$, glass; $G P$, gel palagonite; $F$, fibrous palagonite; $P$, palagonite; $Z$, zeolite [ZHOU-1989].

Palagonite typically has a density in the range of $1.90-2.10 \mathrm{~g} \cdot \mathrm{cm}^{-1}$; the maximum within this range is less than the density of typical basaltic glass, which is about $2.75 \mathrm{~g} \cdot \mathrm{cm}^{-1}$ [STAUDIGEL-1983]. The interface between palagonite and glass is generally sharp and visible under optical examination [AILIN-PYZIK-1981; ZHOU-1989]. The palagonite rinds were found to be optically isotopic or weakly anisotropic. This finding indicates they have an amorphous or poorly crystalline nature [BYERS-1986]. Examination of palagonite with highresolution TEM revealed the presence of fibrous-to-lathy particles similar to smectite clay minerals [ZHOU-1989]. Etch pits were often found to occur at the alteration fronts of both dredged and DSDP samples [JERCINOVIC-1987; STAUDIGEL-1983]. The presence of etch pits and the distinct changes across the sharp boundary between glass and palagonite indicate that corrosion occurred by dissolution of fresh glass, followed by reprecipitation of less soluble components.

Palagonitization is a non-isochemical process in which not all glass components are incorporated into palagonite [STOKES-1971; STAUDIGEL-1983; CROVISIER-1987; ZHOU-1989]. Staudigel and others [STAUDIGEL-1983] analyzed the distribution of major elements between palagonite and glass in DSDP samples with a microprobe technique. The enrichment or depletion of an element was normalized to Ti, which was assumed to have the same concentration in the palagonite and the glass. The gain or loss of an element $\mathrm{i}, \mathrm{X}_{\mathrm{i}}$, was calculated by normalizing analyses to $100 \%$ and using the following equation: 


$$
\mathrm{X}_{\mathrm{i}}=\mathrm{I}_{\text {glass }}-\left\{\left[\mathrm{T}_{\text {palagonite }}-\mathrm{T}_{\text {iglass }}\right] / \mathrm{T}_{\text {iglass }}\right\} \bullet \mathrm{I}_{\text {palagonite }} \bullet 100
$$

where $T_{\text {palagonite }}$ and $I_{\text {palagonite }}$ are the concentrations of Ti and element i measured in palagonite and $T_{i \text { glass }}$ and $I_{\text {glass }}$ are the concentrations of $T i$ and element $i$ measured in insulated glasses. The palagonite was depleted in $\mathrm{Si}, \mathrm{Al}, \mathrm{Mn}, \mathrm{Mg}, \mathrm{Ca}$, and $\mathrm{Na}$, and enriched in $\mathrm{K}$, relative to basalt (Fig. V-6). Byers and others [BYERS-1986] analyzed the palagonite rinds on dredged samples with a microprobe and found less $\mathrm{Si}, \mathrm{Mg}, \mathrm{Ca}$, and $\mathrm{Na}$ in the palagonite than in the glass. In all cases, however, $\mathrm{K}$ was found to be enriched in the palagonite rinds; $\mathrm{K}$ was provided by seawater. On the other hand, the Fe concentration is sometimes slightly increased in palagonite rinds because of its low solubilities in seawater [STAUDIGEL-1983].

Zhou and others [ZHOU-1989] analyzed the concentration profiles of $\mathrm{Fe}$ and $\mathrm{Ti}$ from the unreacted glass to the outer surface of palagonite and found that both the $\mathrm{Fe}$ and Ti contents are highest near the glass/palagonite interface and decrease as the outer surface of palagonite is approached (Fig. V-7). They believe that palagonitization may involve a two-step process. In an early step, basalt glass is dissolved and a gel is formed. Neither Ti nor Fe appear to be mobile during gel formation. However, these elements may become mobilized in the second step and be incorporated into clay minerals, when the gel is converted in situ to fibrous palagonite.

The proportion of elements retained in palagonite and dissolved into solution varies with the local solution chemistry. For example, Byers and others [BYERS-1986] found that $\mathrm{Al}$ was depleted in the palagonites on the samples from Kopavogur and Arnarnesvogur but enriched in the Brimes samples, while Fe was retained in the palagonites on the Kopavogur and Brimes samples, but depleted in palagonite on the Arnarnesvogur samples. These data suggest that the alteration process is sensitive to the local environment to which the glass is exposed, although a systematic correlation has not been established.

Jercinovic and others [JERCINOVIC-1987] analyzed the palagonite rinds that had formed on 14 samples that had essentially identical compositions but were collected in DSDP from different localities. The chemical compositions of the basaltic glass and palagonite rinds were measured with a microprobe, and the results are summarized in Table V-2. It can be seen that, although the concentration of $\mathrm{SiO}_{2}$ in the palagonites formed on most samples is lower than that in the basalt on which it forms, the difference in the depletion of different samples is significant: the concentration of $\mathrm{SiO}_{2}$ decreased $80 \%$ in samples 1 and 2, but increased about $3 \%$ in sample 8. The loss of $\mathrm{SiO}_{2}$ in other samples is intermediate between these extremes. The enrichment or depletion of $\mathrm{Al}_{2} \mathrm{O}_{3}$ also varied among the samples, with a 12\% gain in sample 6 but a $44 \%$ loss in sample 13 . These results strongly suggest that the microenvironment, i.e., the solution chemistry in the immediate vicinity of each sample, may be more influential in the development of palagonite than the macroenvironmental (i.e., the general geochemical region). 


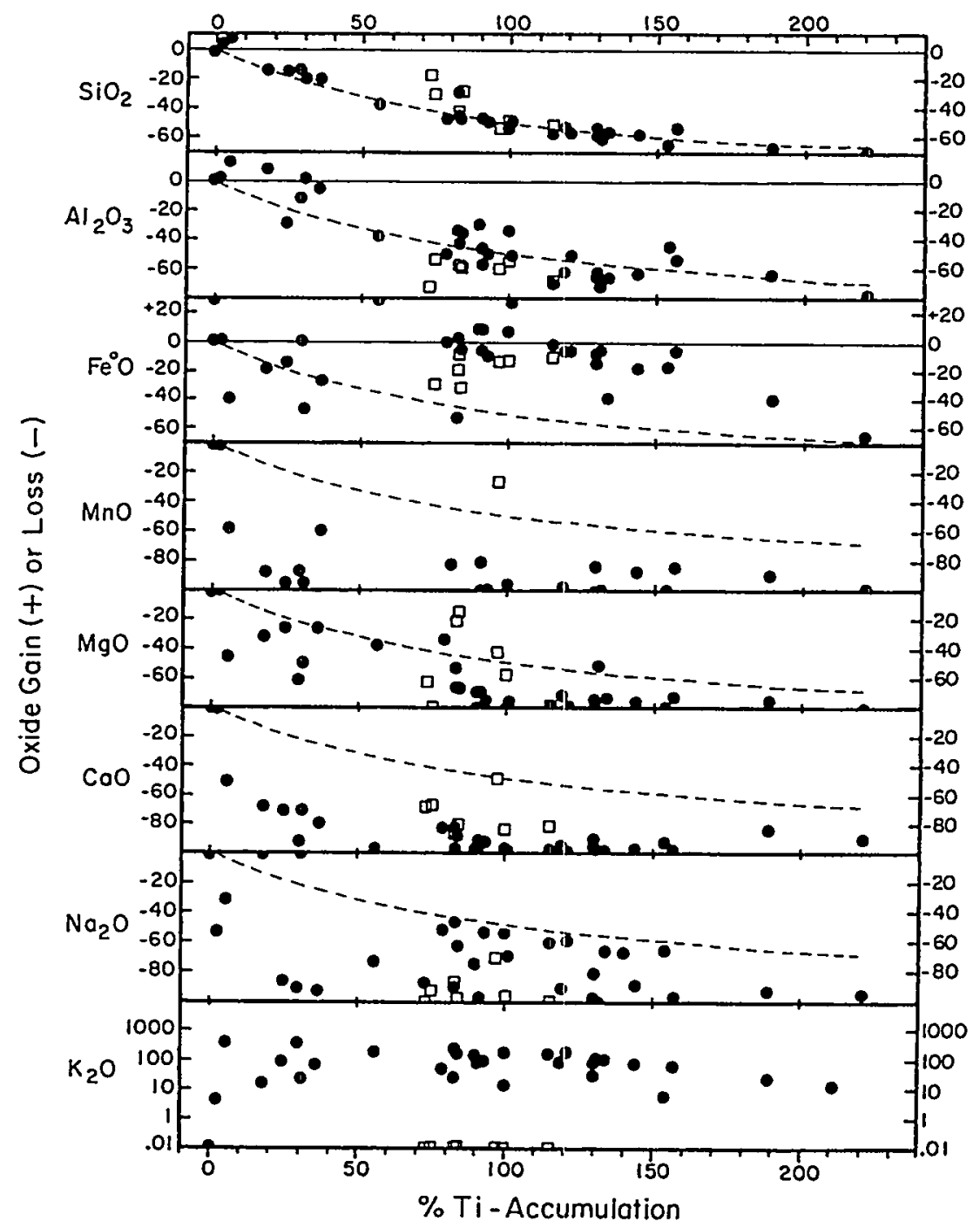

Fig. V-6. Compositional variations between glass and palagonite of basaltic glasses altered under various conditions. Solid dots: glass/palagonite pair from submarine alteration; open squares: glass/palagonite pair from subaerial conditions. 


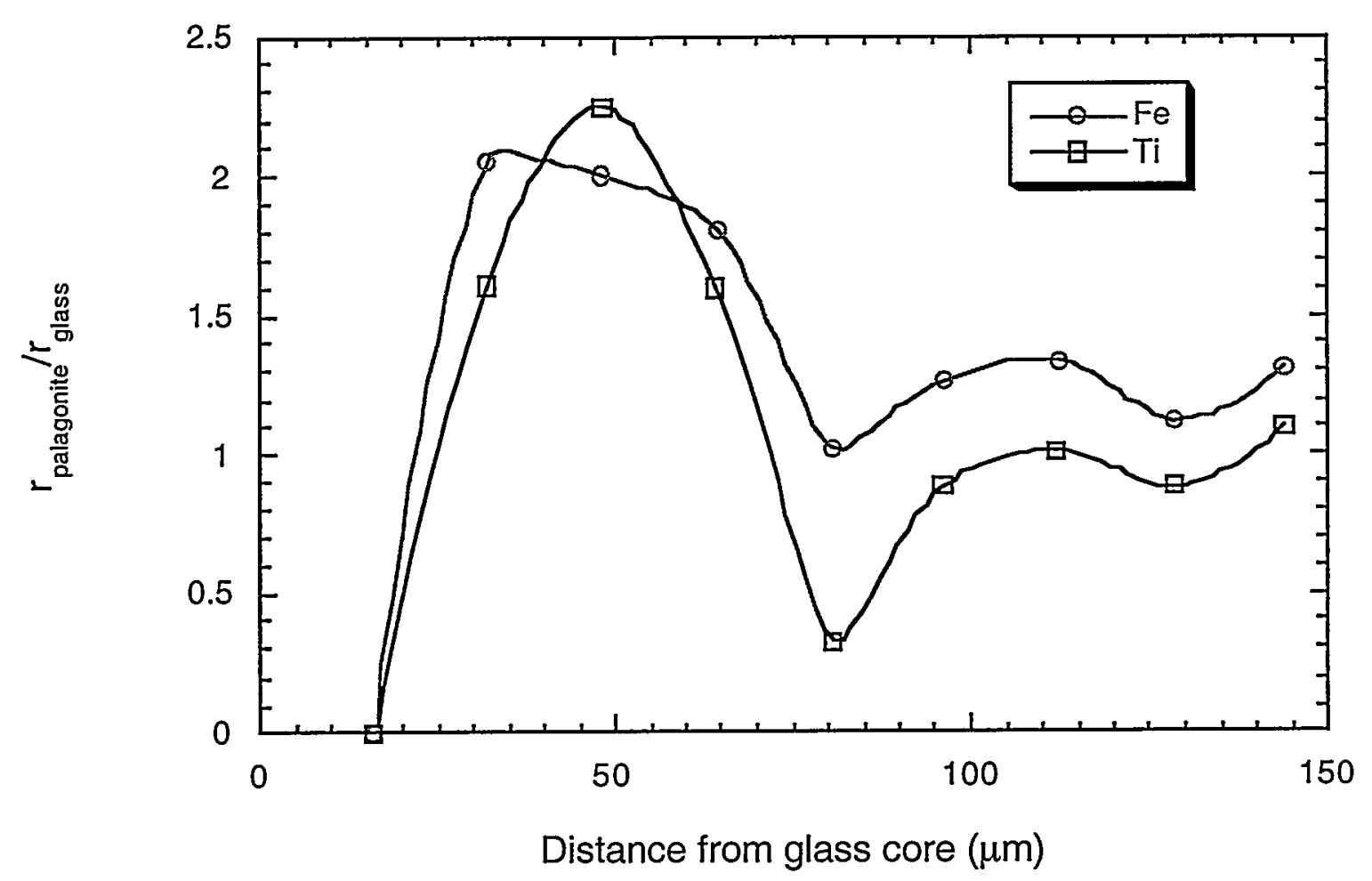

Fig. V-7. Iron and titantium contents versus distance from glass core to palagonite layer. Both $\mathrm{Fe}$ and Ti contents show maxima in gel palagonite and decrease from gel to fibrous palagonite [ZHOU-1989].

\section{b. Secondary Minerals}

Secondary mineral phases have been observed to form at the outer surfaces of the palagonite on naturally corroded samples [STAUDIGEL-1983; ZHOU-1989; AILIN-PYZIK-1981; CROVISIER-1987; JERCINOVIC-1987]. Byers and others [BYERS-1986] examined a number of deep sea dredged samples and found clay minerals (mostly iron-rich saponites) on nearly all the samples. Other minerals, such as zeolites and calcite, were found to outgrow the clay on only a few samples. Zeolites were observed more frequently on DSDP samples than on dredged samples. Among the zeolite minerals, analcime, phillipsite, and chabazite were frequently observed (see Fig. V-8) [JERCINOVIC-1987]. Calcite and analcime formed after precipitation of phillipsite and chabazite. Honnorez [HONNOREZ-1978] reported the relative time sequences of formation of mineral phases in DSDP samples as follows:

$$
\begin{aligned}
& \text { saponite } \rightarrow \text { gyrolite } \rightarrow \text { phillipsite } \rightarrow \text { chabazite } \rightarrow \\
& \text { gmelinite } \rightarrow \text { analcime } \rightarrow \text { apophyllite } \rightarrow \text { calcite }+ \text { opal }
\end{aligned}
$$


Table V-2. Average composition of glass and corresponding palagonite rinds in deep sea dredge samples [JERCINOVIC-1987], in oxide mass \%

\begin{tabular}{|c|c|c|c|c|c|c|c|c|}
\hline & \multicolumn{2}{|c|}{ Sample \#1 } & \multicolumn{2}{|c|}{ Sample \#2 } & \multicolumn{2}{|c|}{ Sample \#3 } & \multicolumn{2}{|c|}{ Sample \#4 } \\
\hline & Glass & Palagonite & Glass & Palagonite & Glass & Palagonite & Glass & Palagonite \\
\hline $\mathrm{SiO}_{2}$ & 50.9 & 10.0 & 50.8 & 11.1 & 50.1 & 12.8 & 49.9 & 11.2 \\
\hline $\mathrm{TiO}_{2}$ & 1.60 & 4.00 & 1.60 & 3.93 & 1.11 & 2.44 & 1.27 & 3.43 \\
\hline $\mathrm{Al}_{2} \mathrm{O}_{3}$ & 14.0 & 14.9 & 14.1 & 10.4 & 14.3 & 10.7 & 14.7 & 15.9 \\
\hline $\mathrm{FeO}^{2}$ & 12.3 & 31.5 & 12.5 & 27.8 & 11.8 & 32.7 & 10.7 & 28.9 \\
\hline $\mathrm{MnO}$ & 0.21 & $<0.08^{b}$ & 0.18 & $<0.07^{b}$ & 0.19 & $<0.14^{\mathrm{b}}$ & 0.19 & 0.29 \\
\hline $\mathrm{MgO}$ & 6.9 & 4.42 & 6.8 & 1.91 & 8.0 & 3.78 & 8.2 & 2.69 \\
\hline $\mathrm{CaO}$ & 11.3 & 2.22 & 11.2 & 1.51 & 12.0 & 1.82 & 11.7 & 1.59 \\
\hline $\mathrm{Na}_{2} \mathrm{O}$ & 2.09 & 2.67 & 2.11 & 2.56 & 2.12 & 1.65 & 2.30 & 1.40 \\
\hline $\mathrm{K}_{2} \mathrm{O}$ & 0.18 & 0.25 & 0.08 & 0.35 & 0.03 & 0.26 & 0.06 & 0.23 \\
\hline $\mathrm{P}_{2} \mathrm{O}_{5}$ & 0.10 & 3.40 & 0.14 & 1.61 & 0.12 & 1.35 & 0.13 & 2.77 \\
\hline \multirow[t]{3}{*}{ Total } & 99.7 & 73.4 & 99.5 & 61.2 & 99.8 & 67.6 & 99.2 & 68.4 \\
\hline & \multicolumn{2}{|c|}{ Sample \#5 } & \multicolumn{2}{|c|}{ Sample \#6 } & \multicolumn{2}{|c|}{ Sample \#7 } & \multicolumn{2}{|c|}{ Sample \#8 } \\
\hline & Glass & Palagonite & Glass & Palagonite & Glass & Palagonite & Glass & Palagonite \\
\hline $\mathrm{SiO}_{2}$ & 51.2 & 27.9 & 50.4 & 41.6 & 51.0 & 23.4 & 52.2 & 55.3 \\
\hline $\mathrm{TiO}_{2}$ & 1.41 & 2.55 & 1.86 & 1.83 & 1.80 & 3.41 & 1.85 & 1.79 \\
\hline $\mathrm{Al}_{2} \mathrm{O}_{3}$ & 15.8 & 14.1 & 15.3 & 18.2 & 15.2 & 18.2 & 15.3 & 14.3 \\
\hline $\mathrm{FeO}^{2}$ & 8.3 & 15.6 & 10.0 & 13.0 & 10.2 & 19.0 & 9.6 & 9.5 \\
\hline $\mathrm{MnO}$ & 0.13 & $<0.01^{b}$ & 0.19 & $<0.02^{b}$ & 0.16 & $<0.05^{b}$ & 0.18 & $<0.06^{\mathrm{b}}$ \\
\hline $\mathrm{MgO}$ & 7.2 & 3.21 & 7.7 & 2.78 & 7.5 & 1.59 & 6.3 & 9.2 \\
\hline $\mathrm{CaO}$ & 10.8 & 0.37 & 10.8 & 1.57 & 10.9 & 1.41 & 10.5 & 0.52 \\
\hline $\mathrm{Na}_{2} \mathrm{O}$ & 2.79 & 1.36 & 3.02 & 1.91 & 2.99 & 1.60 & 2.84 & 2.15 \\
\hline $\mathrm{K}_{2} \mathrm{O}$ & 0.58 & 2.99 & 0.14 & 2.29 & 0.12 & 0.52 & 0.77 & 1.90 \\
\hline $\mathrm{P}_{2} \mathrm{O}_{5}$ & 0.21 & 0.54 & 0.19 & 0.26 & 0.18 & 1.19 & 0.34 & $<0.03^{b}$ \\
\hline \multirow[t]{27}{*}{ Total } & 98.4 & 68.6 & 99.6 & 83.5 & 100.0 & 70.4 & 99.9 & 94.8 \\
\hline & & \multicolumn{2}{|c|}{ Sample \#9 } & \multicolumn{2}{|c|}{ Sample \#10 } & \multicolumn{2}{|c|}{ Sample \#11 } & \\
\hline & & Glass & Palagonite & Glass & Palagonite & Glass & Palagonite & \\
\hline & $\mathrm{SiO}_{2}$ & 47.5 & 22.5 & 51.1 & 43.1 & 50.4 & 41.3 & \\
\hline & $\mathrm{TiO}_{2}$ & 3.07 & 3.58 & 2.80 & 3.06 & 2.81 & 3.29 & \\
\hline & $\mathrm{Al}_{2} \mathrm{O}_{3}$ & 11.5 & 3.04 & 12.8 & 7.4 & 12.9 & 7.2 & \\
\hline & $\mathrm{FeO}^{2}$ & 16.9 & 27.5 & 14.1 & 20.1 & 14.2 & 20.5 & \\
\hline & $\mathrm{MnO}$ & 0.24 & 0.16 & 0.23 & $<0.09^{b}$ & 0.19 & $<0.05^{\mathrm{b}}$ & \\
\hline & $\mathrm{MgO}$ & 4.89 & 2.05 & 5.8 & 2.14 & 5.8 & 2.15 & \\
\hline & $\mathrm{CaO}$ & 9.3 & 1.82 & 9.8 & 1.10 & 9.5 & 0.75 & \\
\hline & $\mathrm{Na}_{2} \mathrm{O}$ & 2.38 & 2.63 & 2.82 & 2.29 & 2.89 & 1.91 & \\
\hline & $\mathrm{K}_{2} \mathrm{O}$ & 0.18 & 0.91 & 0.17 & 2.42 & 0.03 & 2.70 & \\
\hline & $\mathrm{P}_{2} \mathrm{O}_{5}$ & 0.39 & 1.47 & 0.27 & 0.32 & 0.24 & 0.18 & \\
\hline & \multirow[t]{3}{*}{ Total } & 96.4 & 65.7 & 99.9 & 82.0 & 99.0 & 80.0 & \\
\hline & & \multicolumn{2}{|c|}{ Sample \#12 } & \multicolumn{2}{|c|}{ Sample \#13 } & \multicolumn{2}{|c|}{ Sample \#14 } & \\
\hline & & Glass & Palagonite & Glass & Palagonite & Glass & Palagonite & \\
\hline & $\mathrm{SiO}_{2}$ & 51.6 & 38.6 & 49.0 & 44.6 & 50.2 & 45.4 & \\
\hline & $\mathrm{TiO}_{2}$ & 1.09 & 0.94 & 0.96 & 0.60 & 2.32 & 0.47 & \\
\hline & $\mathrm{Al}_{2} \mathrm{O}_{3}$ & 15.5 & 5.2 & 17.2 & 7.6 & 13.1 & 7.3 & \\
\hline & $\mathrm{FeO}^{\mathrm{a}}$ & 8.8 & 23.0 & 8.1 & 20.1 & 12.9 & 25.7 & \\
\hline & $\mathrm{MnO}$ & 0.15 & 0.81 & 0.14 & $<0.29^{b}$ & 0.23 & $<0.00^{\mathrm{b}}$ & \\
\hline & $\mathrm{MgO}$ & 8.3 & 2.41 & 9.6 & 2.93 & 6.5 & 4.79 & \\
\hline & $\mathrm{CaO}$ & 12.6 & 0.86 & 12.3 & 0.37 & 11.0 & 0.42 & \\
\hline & $\mathrm{Na}_{2} \mathrm{O}$ & 1.86 & 2.44 & 2.50 & 1.70 & 2.67 & 1.41 & \\
\hline & $\mathrm{K}_{2} \mathrm{O}$ & 0.04 & 1.59 & 0.04 & 3.62 & 0.17 & 2.55 & \\
\hline & $\mathrm{P}_{2} \mathrm{O}_{5}$ & 0.10 & 0.37 & 0.11 & 0.12 & 0.21 & $<0.01^{\mathrm{b}}$ & \\
\hline & Total & 100.0 & 76.2 & 99.9 & 82.0 & 99.3 & 88.1 & \\
\hline
\end{tabular}



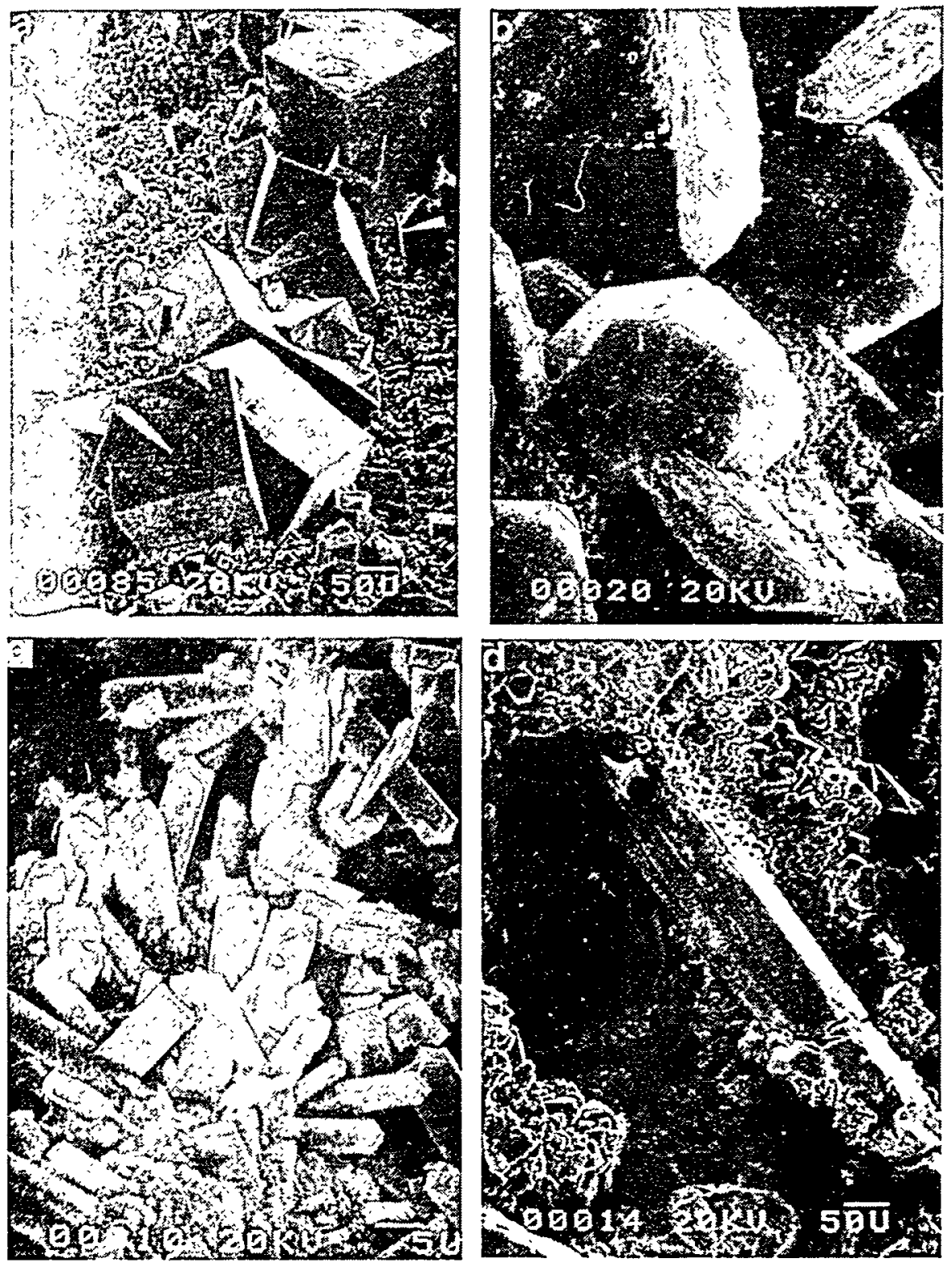

Fig. V-8. Commonly observed secondary phases formed on the surface of seawater-altered basaltic glasses: (a) chabazite, (b) analcime, (c) phillipsite, and (d) calcite outgrowing zeolites [JERCINOVIC-1987].

\section{Subglacial Alteration}

Most studies of subglacial alteration have been carried out on samples recovered from Iceland and British Columbia, Canada [CROVISIER-1992; GISLASON-1987A, -1987B; THORSETH-1991; JERCINOVIC-1987; BYERS-1986]. In most cases, these basaltic glasses have been altered by cold $\left(\sim 0^{\circ} \mathrm{C}\right)$ and dilute glacial melt and rain waters, although some samples may have been subjected to alternately submarine and subglacial environments due to the fluctuations of the sea level [BYERS-1986; THORSETH-1991]. The ages of these samples ranged from two thousand to more than two million years, as estimated from lavas dated by $\mathrm{K} / \mathrm{Ar}$ and radiogenic methods [CROVISIER-1992]. Gislason and others [GISLASON-1987B] analyzed the compositions of waters from the rift zone of N.E. Iceland and showed that their chemistries are 
consistent with a mixture of fresh water and seawater in the ratio of about 1 to 10,000 . These waters typically have $\mathrm{pH}$ values between 5.1 and 6.7 , and contain $0.5-1.2 \mathrm{mg} / \mathrm{L} \mathrm{SiO}_{2}, 0.66-$ $2.55 \mathrm{mg} / \mathrm{L} \mathrm{Na}, 0.2-0.8 \mathrm{mg} / \mathrm{L} \mathrm{Ca}, 0.2-1.1 \mathrm{mg} / \mathrm{L} \mathrm{K}, 0.08-0.3 \mathrm{mg} / \mathrm{L} \mathrm{Mg}, 1.0-3.4 \mathrm{SO}_{4}$, and 0.9$3.2 \mathrm{mg} / \mathrm{L} \mathrm{Cl}$ [GISLASON-1987B]. These data are important because they allow one to define the processes of solute acquisition and the saturation states of the waters with respect to alteration minerals, on a macroscopic scale, as well as the reaction paths and mass transfer during alteration.

\section{a. Glass Hydration}

Daux and others [DAUX-1994] examined eleven samples ranging in age from 2000 years to 2.4 million years that were recovered from Húsafell, Hengill, and Thingvellir, Iceland. All the samples were found to have a palagonite layer. The color of the palagonite formed under transmitted polarizing light varied from a bright golden yellow to a very pale yellow. Crovisier and others [CROVISIER-1992] analyzed samples from the same areas of Iceland with x-ray diffraction and observed peaks characteristic of smectite clay. Examinations of these samples with TEM revealed sharp boundaries between the unaltered glass and a mostly fibrous palagonite layer. Thin, irregular, and partly folded smectite lamellae were also observed in the palagonite layer. Jercinovic and others [JERCINOVIC-1990] studied the palagonite on basalt glasses obtained from Pleistocene subglacial volcanoes in north-central British Columbia, Canada. They observed 2- to $140-\mu \mathrm{m}$-thick palagonite layers on exposed surfaces, glass shard peripheries, vesicle walls, and fractures. Like basaltic glass alterecl in seawater, the glass immediately beneath the palagonite rinds was usually pitted.

The sharp boundaries of palagonite/glass interface and the presence of etched pits supports a palagonitization mechanism of progressive glass dissolution with contemporaneous reprecipitation of material at the glass surface. However, it is unclear based on these examinations whether the glass dissolution is congruent. Crovisier and others [CROVISIER-1992] suggested that the dissolution is congruent based on the observation of the very different textures and structures of palagonite and glass. However, Thorseth and others [THORSETH-1991] examined the glass/palagonite boundary with SEM/EDS and observed a 2- to 4- $\mu \mathrm{m}$-thick zone at the glass surface in which all the major elements were depleted except Si and Al. Their results suggest that the glass may be leached prior to dissolution.

The concentrations of most major elements in palagonite rinds are less than those in the glass, except for $\mathrm{Fe}$ and $\mathrm{Ti}$, which usually have similar concentrations in the palagonite and glass [JERCINOVIC-1990; THORSETH-1991; CROVISIER-1992; GISLASON-1987B]. The alkali and alkaline earth elements, such as $\mathrm{Na}, \mathrm{K}$, and $\mathrm{Mg}$, are generally depleted in the palagonite relative to the glass as a result of their high solubilities. An exception is seawater-induced alteration, in which $\mathrm{K}$ is incorporated into palagonite from the seawater, while $\mathrm{Na}$ and $\mathrm{Mg}$ from the seawater are generally not incorporated.

\section{b. Secondary Minerals}

Authigenic mineralization generally occurs in subglacially altered basalt glasses during the late stages of palagonitization. Jercinovic and others [JERCINOVIC-1990] observed that zeolites formed a significant proportion of the weathering products on samples from three Pleistocene subglacial volcanoes in north-central British Columbia, Canada. Most zeolites were found to be calcic varieties. Phillipsite was present as radiating aggregates of elongated prisms. Chabazite typically formed euhedral or subhedral rhombs that overgrew phillipsite. Analcime occurred as trapezohedra on some samples, and calcite was found to form as the youngest (last) phase in the paragenetic sequence. Chabazite and erionite have also 
been reported to have formed on 0.5-2.4 million years old samples from Iceland [CROVISIER-1992].

Because a phase will precipitate only after the solubility became saturated, the authigenic phase compositions can be used to deduce solution compositions in which natural samples are altered. For example, if $\mathrm{Al}$ is dissolved into solution during palagonitization, and the solution flow rates do not exceed elemental release rates from the glass, then solubility limits of authigenic aluminosilicates may be reached. Indeed, palagonites on samples that also contain zeolites are generally found to have significant losses of Al [JERCINOVIC-1990; CROVISIER-1992]. Also, in samples where Ca is largely retained in palagonite, the smectite clay tends to form within the palagonite. The growth of clay results in the release of $\mathrm{Ca}$ to solution and removal of $\mathrm{Mg}$ from the solution and also increase the $\mathrm{Ca} / \mathrm{Mg}$ ratio in the local aqueous environment to a level that is conducive to zeolite formation. When the $\mathrm{Ca} / \mathrm{Mg}$ ratio is high in solution, zeolites may form when the Al concentration becomes high enough. Analcime and calcite precipitate at high $\mathrm{pH}$ and in the presence of $\mathrm{Na}, \mathrm{Al}, \mathrm{Si}$, and $\mathrm{Ca}$ in the solution [CROVISIER1992].

\section{Subaerial Alteration}

In subaerial environments, basalt glasses are either exposed to the air or shallowly buried beneath the ground surface. They are exposed to unsaturated conditions and are corroded by rain water and humid air. The ages of the samples that have been examined range from several hundred years to about 1 million years. Corrosion takes place at temperatures that vary daily and seasonally. Nesbitt and others [NESBITT-1992] reported that the temperatures to which typical continental basalts found in the Baynton site near Melboume, Australia, were exposed were warm: daytime summer temperatures of about 30 to $38^{\circ} \mathrm{C}$ and daytime winter temperatures of about 10 to $17^{\circ} \mathrm{C}$.

Spring water and groundwater may also contact subaerial basalt glasses. Arai [ARAI-1989] analyzed the composition of the groundwater near Mount Fuji Volcano area, Japan, and concluded that the composition of the groundwater was intermediate between that of rain water and spring water. Samples contained $62-218 \mathrm{mg} / \mathrm{L} \mathrm{SiO}_{2}, 6.2-8.4 \mathrm{mg} / \mathrm{L} \mathrm{Na}, 4-4.6 \mathrm{mg} / \mathrm{L}$ $\mathrm{Ca}, 2.6-3.3 \mathrm{mg} / \mathrm{L} \mathrm{K}, 1-1.3 \mathrm{mg} / \mathrm{L} \mathrm{Mg}, 0.7-5 \mathrm{Fe} \mathrm{mg} / \mathrm{L}, 2.9-6.4 \mathrm{mg} / \mathrm{L} \mathrm{SO}_{4}, 33-35 \mathrm{mg} / \mathrm{L} \mathrm{HCO}$, and $1.5-4.3 \mathrm{mg} / \mathrm{L} \mathrm{Cl}$. However, the water chemistry, the humidity, and temperature usually vary with location and over time. In most cases, the variations that occurred in the environmental conditions over the course of alteration in the past cannot be known.

\section{a. Glass Hydration}

Basaltic glasses alter to form palagonite under unsaturated conditions. Arai and others [ARAI-1989] reported the formation of $\sim 0.5-\mu \mathrm{m}$-thick palagonite rinds in relatively young (280 years) Fuji basaltic glasses. Cowan and others [COWAN-1989] studied the alteration of 12,000- to 28,000-year-old Hawaiian basaltic glasses and observed palagonite rinds on most samples. In many cases, however, the palagonites on subaerially altered glasses are not observed as continuous rinds around the glass shards, owing to the spallation of layers during wet/dry cycles. For example, Cowan and others [COWAN-1989] found that the thicknesses of palagonite rims ranged from 0 to over $2 \mathrm{~mm}$ on Hawaiian basalts of ages from 12,000 to 28,000 years. Luo and others [LUO-1997] examined 10 younger basalt glass samples (550 to 750 years) from two archaeological sites in Oahu, Hawaii. They also observed spallation of palagonite layers from these samples (Fig. V-9). Spallation may affect the accurate 
determination of the reaction rates, because the kinetics are generally calculated based on the measurement of the thickness of palagonite layers formed on the glass surface.

The palagonites formed in unsaturated conditions exhibit physical and chemical characteristics similar to those formed in subglacial conditions. The palagonites formed on subaerially altered basalt are generally reddish or yellow-brown and are optically isotopic and x-ray amorphous [FURNES-1984; AIIN-PYZIK-1981; LUO-1997]. The glass surface underneath the palagonite layer (which can be seen in the areas from which the layer has spalled) generally has a high density of etching pits. Furnes and others [FURNES-1984] analyzed the chemical changes during the progressive subaerial palagonitization of Quaternary basalt from Mosfell with SEM and microprobe analyses. They found that the concentrations of $\mathrm{Si}, \mathrm{Na}, \mathrm{K}, \mathrm{Ca}$, and $\mathrm{Mg}$ were lower in palagonite layer than in glass, whereas $\mathrm{Fe}$ and $\mathrm{Ti}$ were slightly enriched in the altered layer. This chemical pattern seems to be common among the subaerially altered glasses [HAY-1968, -1972; FURNES-1984; ARAI-1989; COWAN-1989; MORGENSTEIN-1976].

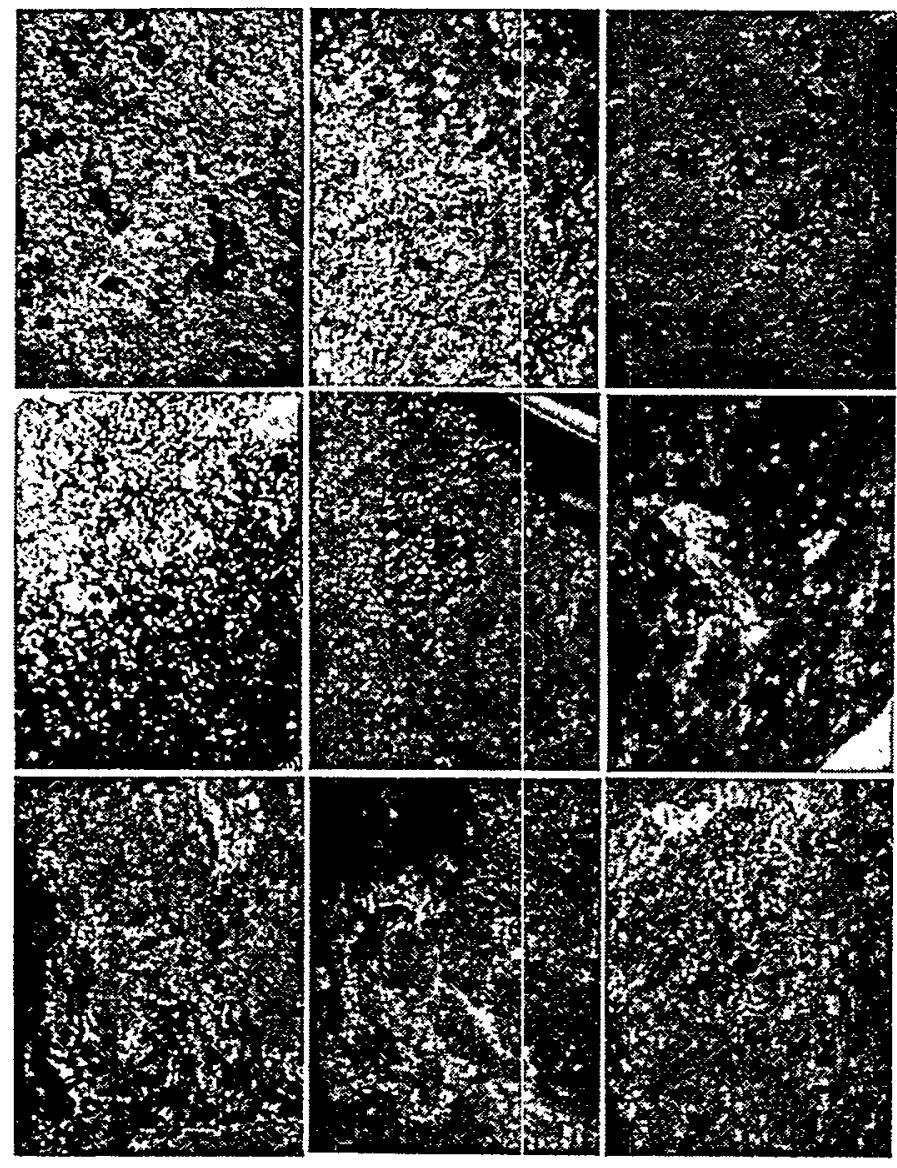

Fig. V-9. Optical images of the surfaces of naturally altered Hawaiian basaltic glasses showing spallation taking place in many samples due to dry/precipitation cycling. 


\section{b. Secondary Minerals}

Secondary mineralization generally occurs in older samples that exhibit more extensive palagonitization. The mineral phases that are observed most often include smectite clays, phillipsite, chabazite, analcime, and calcite [HAY-1968, -1972; FURNES-1984; ARAI-1989; COWAN-1989]. The formation and order of the appearance of mineral phases depend on both the glass compositions and the localities (i.e., microenvironments). Hay and others [HAY-1968] found that the principal authigenic minerals from Hawaiian basalt glasses were deposited in the following sequence:

$$
\begin{gathered}
\text { phillipsite } \rightarrow \text { chabazite } \rightarrow \text { thomsonite } \rightarrow \text { gonnardite } \rightarrow \\
\text { natrolite } \rightarrow \text { analcime } \rightarrow \text { montmorillonite, opal, calcite }
\end{gathered}
$$

However, Cowan and others [COWAN-1989] reported that the paragenetic sequence of zeolites is analcime $\rightarrow$ phillipsite $\rightarrow$ chabazite in Hawaiian glasses with $\mathrm{Na}_{2} \mathrm{O}$ contents $>4$ wt\%. Keith and others [KEITH-1985] studied the zeolites and associated minerals in a tholeiitic basaltic pillow lava that makes up part of the Eocene Siletz River Volcanics in the central Coast Range of Oregon. They identified, in general order of paragenetic sequence, smectite, pyrite, calcite, thomsonite, natrolite, analcime, scolecite, mesolite, stilbite, heulandite, apophyllite, chabazite, mordenite, laumontite, and amesthstine quartz. The actual paragentic sequence and mineral assemblages varied from sample to sample. The most common mineral assemblages were natrolite-analcimestilbite, stilbite-heulandite-chabazite, stilbite-apophyllite-chabazite, and natrolite-mesolitelaumontite. The different minerals formed on glasses that had similar compositions, suggesting that the formation of zeolite minerals was sensitive to slight variations in environmental and chemical conditions.

\section{Hydrothermal Alteration}

In a 1962-m-deep geothermal well that penetrates a sequence of East Rift Zone, Kilauea, Hawaii (Hawaii Geothermal Project Well-A [HGP-A]), basalt samples were recovered from drill cores and cutting chips generated during the drilling of a geothermal well. These glasses were located in active geothermal fields and exposed to hydrothermal fluids at temperatures from ambient up to $300^{\circ} \mathrm{C}$. By examining samples recovered from different depths, one can analyze the alteration of the glass at different temperatures. Smith and others [SMITH-1991] reported that the hydrothermal fluids are low salinity $(5-25 \mathrm{mg} / \mathrm{mL})$ meteoric waters, which are recharged by the percolation surface water into the fractured dike rocks. The groundwater chemistries indicated several different sources, including cold meteoric waters, seawaters, hydrothermal fluids of meteoric origins, and hydrothermally modified seawater. Both the temperature and the solution composition of the water varied with drill depth; as a consequence, glasses at different depths may have been attacked by waters of different chemistries and temperatures. The results of sample analyses are given in the following section.

\section{a. Glass Hydration}

Smith and others [SMITH-1991] systematically examined the mineralogy, texture, and compositions of basalt core taken from the HGP-A geothermal well. Samples from ten different depths in the core were examined. Alteration was found to have occurred on basalts in all the samples and was most extensive in fractures and vesicles of basalt grains. Layers of palagonite and secondary minerals formed at the reacted glass surfaces. Microprobe analyses revealed that the concentrations of most elemients were lower in palagonite 
than in the glass except for $\mathrm{Fe}$ and $\mathrm{Ti}$, which had similar concentrations in the palagonite and glass. The concentration of $\mathrm{K}$ was higher in palagonite than in the basalt, because seawater introduced $\mathrm{K}$ into palagonites.

Jakobsson and Moore [JAKOBSSON-1986] studied the alteration of basalt glass associated with the 1963-1967 eruptions of the volcanic island Surtsey, Iceland. Samples were collected by drilling a bore hole that intersected a hydrothermal system in which the maximum temperature at the bottom of the core was about $150^{\circ} \mathrm{C}$. As might be expected, the extent of palagonitization on samples taken from the core was strongly affected by temperature: the palagonite thickness doubled for about every $12^{\circ} \mathrm{C}$ increase. This corresponds for an effective activation energy of $19.1 \mathrm{~kJ} / \mathrm{mol}$.

\section{b. Secondary Minerals}

Secondary mineralization has been found to depend on the exposure temperature and the phase stability of particular secondary minerals at that temperature. Stakes and O'Neil [STAKES-1982] correlated the formation of secondary phases with temperature in altered glassy basalt from the East Pacific Rise, California. Their results are summarized in Fig. V-10. Nontronite and celadonite form at about $350^{\circ} \mathrm{C}$, saponite-rich pillow breccia form between 130 and $170^{\circ} \mathrm{C}$, and calcite-rich greenstone brecias and epidote-rich greenstone between 200 and $350^{\circ} \mathrm{C}$. The mineral assemblages generally varied from one hydrothermal system to another, although some common phases were found to form on samples from different areas. Smith and others [SMITH-1991] observed the alteration sequence in the HGP-A geothermal well as follows: intermittent palagonite at depths between 0 and $675 \mathrm{~m}$, smectite between 675 and $1350 \mathrm{~m}$, chlorite between 1350 and $1890 \mathrm{~m}$, and actinolite-epidote-anhydrite between 1840 and $1962 \mathrm{~m}$. The corresponding temperatures at different depths were not given, although the temperature is known to increase from about $20^{\circ} \mathrm{C}$ at ground surface to about $300^{\circ} \mathrm{C}$ at a depth of $1962 \mathrm{~m}$. The most commonly identified phases in hydrothermally altered basalt glasses are saponite, chlorite, and epidote [SMTTH-1991; STONE-1978; STAKES-1982].

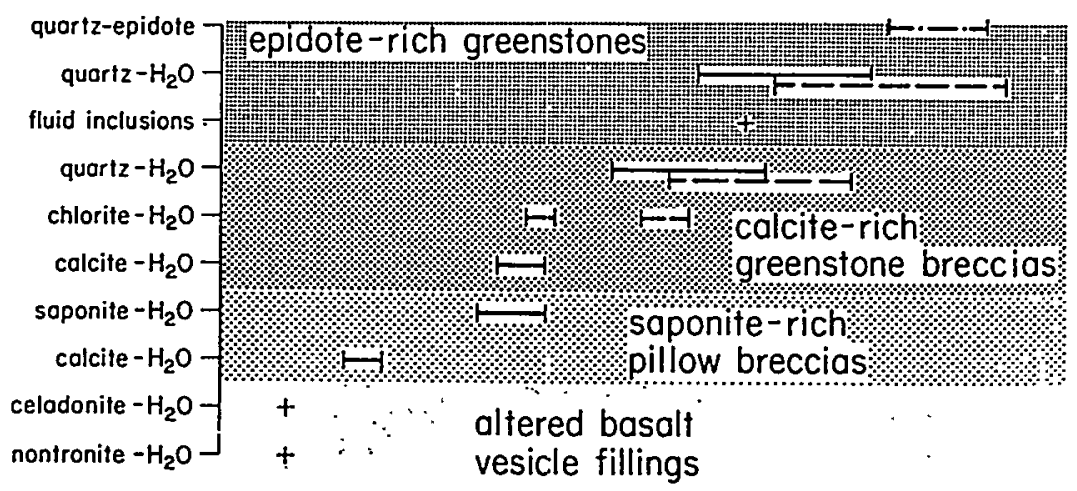

CRYSTALLINE ROCKS

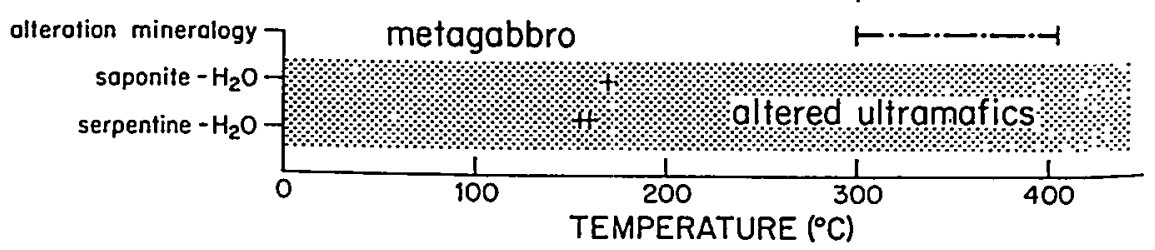

Fig. V-10. Formation of alteration phases as a function of temperature for glassy and crystalline basalts from the East Pacific Rise, California [STAKES-1982]. 
Studies of hydrothermal alteration have also demonstrated that the alteration minerals that formed at low temperatures will not necessarily form when glasses are exposed to higher temperature fluids. Kristmannsdottir and others

[KRISTMANNSDOTTIR-1978] reported that low-temperature alteration phases, such as mordenite, heulandite, stilbite, epistilbite, chabazite, thomsonite, and mesolite-scapolite, had been replaced by laumontite on samples tested at 100 to $120^{\circ} \mathrm{C}$ from geothermal areas in Iceland. Saponite can form over a temperature range from 20 to over $200^{\circ} \mathrm{C}$ [STAKES-1982], while the occurrence of chlorite seems restricted to glasses that have been altered by seawater at high temperatures [STONE-1978; SCHEIDEGGER-1977, SMITH-1991]. The observation of Calc-silicates has been restricted to hydrothermally altered rocks. They have been found in samples tested at temperatures below $200^{\circ} \mathrm{C}$, whereas epidote appeared only with samples altered at temperatures above $200^{\circ} \mathrm{C}$ [KRISTMANNSDOTTRR-1978]. Whether or not a mineral forms under particular conditions will depend on its thermodynamic stability and its solubility in solution, both of which depend on the reaction temperature. Information regarding the temperature dependence of mineral formation will be useful when extrapolating the results of laboratory tests performed at high temperatures to low temperatures.

\section{5. $\quad$ Reaction Rates}

Many researchers have tried to measure the kinetics of basalt glass corrosion in natural environments by using palagonite thickness. The rate calculated by dividing the thickness by the age of glass is actually the rate of palagonitization, which is a function of temperature and the exposure time (i.e., the period during which the glass is in contact with water). However, the rate of palagonitization may not be representative of the rate of glass dissolution. The palagonitization rate inferred based on the rind thickness and sample age should be considered to provide a minimum rate bound to the dissolution rate of glass, because the exposure time will always be less than or equal to the age of the glass.

Table V-3 provides a summary of data from the literature on the palagonitization rates of basaltic glasses in various natural environments [MOORE-1966; GRAMBOW-1985; JERCINOVIC-1987; MORGENSTEIN-1976]. These palagonitization rates vary by about four orders of magnitude and range from 0.004 to $>20 \mu \mathrm{m} / 1000 \mathrm{y}$. These results imply that there is not a typical corrosion rate for basalt glass in natural environments. Several differences in the basalt compositions and environmental conditions appear to create a significant effect on the corrosion rate. A single, linear alteration rate can not be used to explain the persistence of some basalt over geologic time periods [ROBINSON-1983; SCHMINKE-1978; GRAMBOW-1985]. Schminke [SCHMINKE-1978] postulated that a sealing process may have preserved years-old glasses in the deep sea sediments. Grambow [GRAMBOW-1985] proposed a two-stage process for the alteration of basalt glass in natural environments.

The first process occurs when basalt glass is exposed to seawater on the open sea floor, where the glass alters into amorphous palagonite. The authigenic minerals do not form because of the low silica concentration in open seawater $\left(0.4\right.$ to $\left.4 \mathrm{mg} / \mathrm{L} \mathrm{SiO}_{2}\right)$. The alteration rate of this process is called the forward rate. As given in Table V-3, the rates measured for basalt in the open ocean range from 3 to $20 \mu \mathrm{m} / 1000 \mathrm{y}$. 
Table V-3. Summary of reaction rates of basalt glass in aqueous environments at approximately $3^{\circ} \mathrm{C}$, as calculated from age and palagonite rind thickness [GRAMBOW-1985, MORGENSTEIN-1976]

\begin{tabular}{lcc}
\hline Rate $(\mu \mathrm{m} / 1000 \mathrm{y})$ & Environment & $\begin{array}{c}\text { Age (million } \\
\text { years) }\end{array}$ \\
\hline 3 & Seawater/Open Ocean & $<0.1$ \\
20 & Seawater/Open Ocean & $0.01-0.001$ \\
0.10 & Seawater/Sediment Cover, DSDP 409 & 2.4 \\
0.004 & Seawater/Sediment Cover, DSDP 410 & 9.5 \\
$>0.2$ & Seawater/Sediment Cover, DSDP 413 & 3.4 \\
$>0.007$ & Seawater/Sediment Cover, DSDP 417D & 119 \\
& & \\
No Glass left & Seawater/Sediment Cover, DSDP 417A & 119 \\
0.003 & Seawater/Sediment Cover, DSDP 417D & 119 \\
0.15 & Seawater/Sediment Cover, DSDP 332 & 1 \\
0.15 & Seawater/Sediment Cover, DSDP 395 & 2 \\
$0.04-0.2$ & Seawater/Shallow Marine & $0.2-0.5$ \\
$0.01-0.06$ & Seawater(?) Mixed, Subaerial & $0.7-3.1$ \\
$0.1-0.2$ & Fresh Water/Cemented & $0.01-0.02$ \\
$\sim 10$ & Subaerial/Hawaii & $<0.1$ \\
$2-14$ & Fresh Water/Highly Cemented & $0.01-0.02$ \\
\hline
\end{tabular}

The second process takes place after the glass has been buried by sediments. In this situation, the interstitial pore water of sea-bed sediments can become supersaturated with respect to various secondary minerals, which can precipitate on the glass surface and eventually envelop the glass. Further corrosion of the basalt glass is slowed since the layer of minerals reduces the contact between glass and water. Growth of the patagonite layer under these conditions occurs at the so-called final rate. From Table V-3, this rate could be less than $0.1 \mu \mathrm{m} / 1000 \mathrm{y}$.

Grambow and others [GRAMBOW-1985] plotted the measured palagonite thickness against the age of glass and found that the data can be categorized by either the forward rate or final rate, depending on whether the samples have been sealed in sediments or not [Fig. V-11]. The rate of $3-20 \mu \mathrm{m} / 1000$ y that was observed for open sea samples was interpreted as the forward rate of reaction. Palagonite growth under sediments generally led to a much lower final rate of reaction, in the range of 0.02 to $0.2 \mu \mathrm{m} / 1000 \mathrm{y}$. This two-stage process obviously precludes extrapolating short-term laboratory results to long-term performance, since the rate of glass corrosion is not constant but varies with the solution chemistry.

One should also be careful to relate the rate of palagonitization to the dissolution rate, because in many cases the palagonitization rate may not be directly related to the rate of glass dissolution or any reaction processes involved during the glass alteration. Crovisier and others [CROVISIER-1992] suggested that no general law could correlate palagonite crust thickness with a time factor. Palagonite layers were found to have frequently spalled from subaerially altered glasses due to wet/dry cycling and could not be used to accurately measure the quantity of altered glass. Also, basalt glasses have been found to form no palagonite at high solution flow rates, whereas aluminous secondary minerals such as gibbsite, holloysite, and kaolinite, precipitated under such conditions [CROVISIER-1989A, -1989B; SINGER-1974]. 


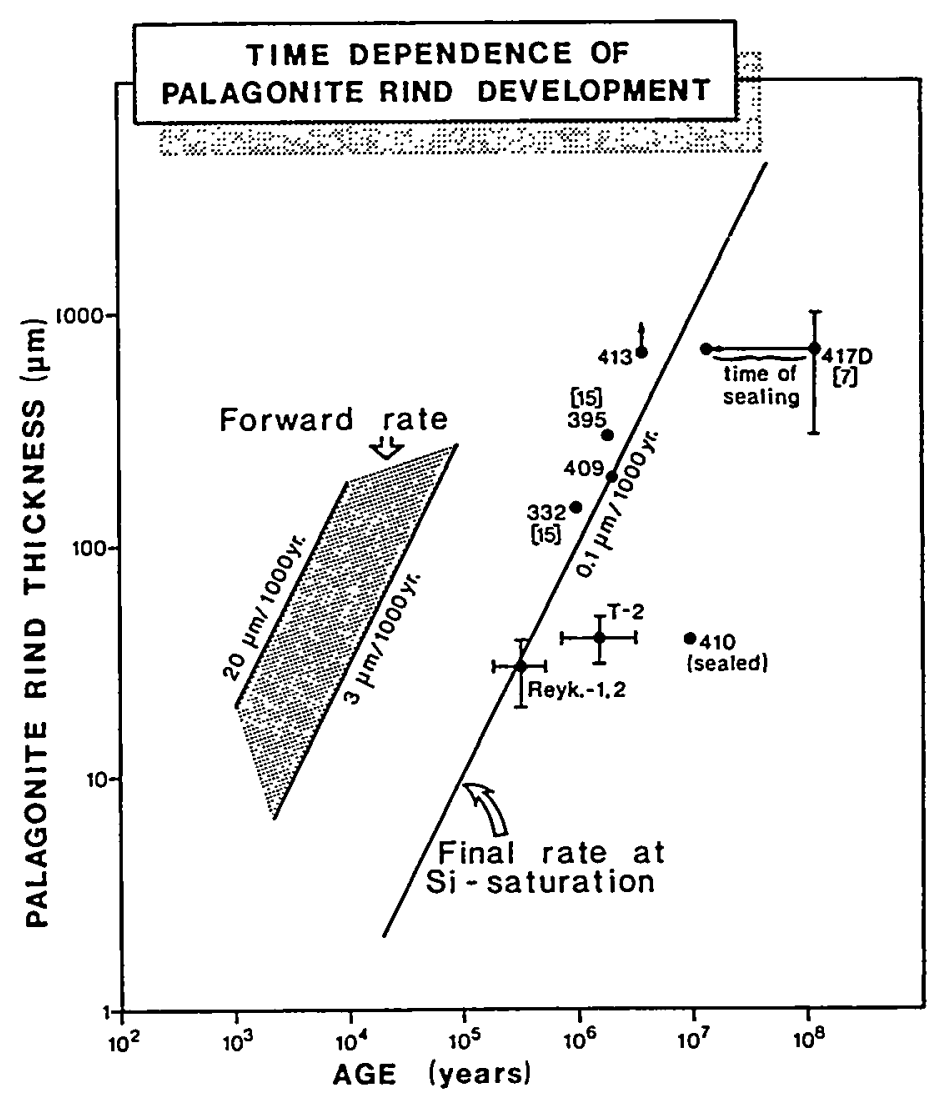

Fig. V-11. The relationship between the rates of palagonite rind formation and the forward and final rates of reaction [GRAMBOW-1985].

To better relate field observations to glass dissolution process, Crovisier and others [CROVISIER-1992] used the term "reaction progress" to describe the advance in corrosion of natural samples. The reaction progress was defined as the total mass of glass dissolved per kilogram of solution. As glass dissolves, the solution becomes increasingly more concentrated, which slows down the corrosion and leads to the precipitation of secondary minerals. By using thermodynamic computer code DISSOL, Crovisier simulated the evolution of the closed-system basaltic glass plus solution and suggested that (1) the first mineral phases reading saturation are iron hydroxide and kaolinite, (2) with further reaction progress, these minerals become unstable and dissolve as the clay forms, and (3) the composition of clay continuously equilibrating with the solution evolves as the dissolution proceeds. In particular, its $\left(\mathrm{SiO}_{2} / \mathrm{MgO}\right)$ ratio increases with increasing reaction progress. Zeolite will precipitate at higher reaction progress. Referring to the dependence of the $\left(\mathrm{SiO}_{2} \mathrm{MgO}\right)$ ratio in the clays on the reaction progress, Crovisier [CROVISIER-1992] showed that the ratio

$$
\mathrm{R}=\left(\mathrm{SiO}_{2} / \mathrm{MgO} \text { in the glass }\right) /\left(\mathrm{SiO}_{2} / \mathrm{MgO} \text { in the palagonite }\right)
$$

increased with increasing reaction progress and was close to unity for samples containing zeolites. Therefore, this ratio could be a good indicator of the reaction progress up to the point where zeolites precipitate. Crovisier [CROVISIER-1992] called the ratio TRZ (Taux de réaction jusqu'à la formation de zéolites), which means "reaction progress up to the formation of zeolites." 
Table V-4 lists the TRZ values calculated for altered basalt glass samples recovered from various localities. As can be seen, the TRZ values were highest for samples containing zeolites, which had a high TRZ value $\sim 0.9^{\circ}$, corresponding to the expected high degree of saturation in the internal zone, whereas for samples with no zeolites, the TRZ values were generally less than 0.56 . These results are consistent with the expectation that the TRZ increases with the degree of saturation in a solution and, therefore, may reflect the reaction progress in a glass. However, the quantity of glass dissolved cannot be inferred directly from TRZ; consequently, the reaction rate can be calculated based on the TRZ values. Another limitation of the TRZ equation is that it cannot be applied to glasses altered in seawater, since $\mathrm{Mg}$ can be incorporated from seawater into palagonite.

Daux and others [DAUX-1994] applied the notion of reaction progress with $\mathrm{Sr}$ instead of $\mathrm{Mg}$ to trace the extent of corrosion. By assuming that the strontium isotopic composition of clay minerals is continuously equilibrating with the solution, the ${ }^{87} \mathrm{Sr} /{ }^{86} \mathrm{Sr}$ ratio of the solution is then intermediate between the one of the glass and the one of the initial water. If the ${ }^{87} \mathrm{Sr} /{ }^{86} \mathrm{Sr}$ ratio and the $\mathrm{Sr}$ content of the initial water are constant through time, the ${ }^{87} \mathrm{Sr} /{ }^{86} \mathrm{Sr}$ ratio of the secondary products is a function of the strontium isotopic ratio. Thus, the strontium concentration of glass and initial water and of the reaction progress (i.e., the mass of glass dissolved per $\mathrm{kg}$ of solution, $\Sigma$ ) can be calculated according to [DAUX-1994] as follows:

$$
\Sigma=\left\{\mathrm{Sr}_{\mathrm{w}}\left(\mathrm{I}_{\mathrm{w}}-\mathrm{I}_{\mathrm{sp}}\right)\left(\mathrm{I}_{\mathrm{g}}+9.375\right) /\left[\mathrm{Sr}_{\mathrm{g}}\left(\mathrm{I}_{\mathrm{sp}}-\mathrm{I}_{\mathrm{g}}\right)\left(\mathrm{I}_{\mathrm{w}}+9.375\right)\right]\right\}
$$

where $I_{w}, I_{g}$, and $I_{s p}$ are the isotopic strontium ratios of initial water, pristine glass, and alteration products, respectively; and $\mathrm{Sr}_{\mathrm{w}}$ and $\mathrm{Sr}_{\mathrm{g}}$ are the strontium concentrations of unreacted water and glass [DAUX-1994]. According to the above formula, Daux and others [1994] calculated the total amount of glass that had been dissolved to be on the order of 0.01 to $0.1 \mathrm{~g} / \mathrm{L}$, based on the isotope ration of $\mathrm{Sr}$ in the palagonite for samples from Iceland that were 90,000 to 100,000 years old. If the amounts of dissolved glass can be calculated for a series of samples of different ages but recovered from similar environments, then the reaction rate of glass in that particular environment may be quantitatively established. However, the calculation of reaction progress by this method is limited by the fact that strontium is present only in trace amount in natural glasses [STAUDIGEL-1983]. Also, the reaction progress can only be quantitatively calculated for glass that has reacted in a nearly closed system, such as along fractures, where the flow of solution is slow. If the flow rate of the solution is high and the residence time of the solution is short, most of the material released from glass will be transported away from the glass, and the reaction progress calculated based on the remaining concentrations of the solution will be too low. 
Table V-4. TRZ ${ }^{\text {a }}$ calculated for subglacial hyaloclastites and other samples from Iceland [FURNES-1978, -1984; JERCINOVIC-1987; CROVISIER-1992]

\begin{tabular}{|c|c|c|c|c|}
\hline Sample No. & Locality & Rock Type & TRZ & $\begin{array}{l}\text { Zeolites } \\
\text { Present }\end{array}$ \\
\hline \multicolumn{5}{|c|}{ Furnes (1978) } \\
\hline 6 Samples & Mosfell & Hyaloclastites & 0.93 & Yes \\
\hline \multicolumn{5}{|c|}{ Furnes (1984) } \\
\hline G2, G4, G7 & Mosfell & Hyaloclastites (external zone) & 0.12 & No \\
\hline \multicolumn{5}{|c|}{ Jercinovic and Ewing (1987) } \\
\hline $\begin{array}{l}\text { M-1 } \\
\text { M-7 } \\
\text { Tr-1 } \\
\text { Mid-1 and } 3 \\
\text { Mid-2 } \\
\text { R-1 } \\
\text { R-2 (IPH) } \\
\text { R-2 } \\
\text { B1-1 } \\
\text { B1-4 } \\
\text { V-1 }\end{array}$ & $\begin{array}{l}\text { Mosfell } \\
\text { Mosfell } \\
\text { Trolladyngia } \\
\text { Middalsfjall } \\
\text { Middalsfjall } \\
\text { Raudafell } \\
\text { Raudafell } \\
\text { Raudafell } \\
\text { Blafell } \\
\text { Blafell } \\
\text { Valafell }\end{array}$ & $\begin{array}{c}\text { Pillow Lava } \\
\text { Hyaloclastite } \\
\text { Hyaloclastite } \\
\text { Hyaloclastite } \\
\text { Conglomerate } \\
\text { Volcanic Ash } \\
\text { Interpillow Hyaloclastite } \\
\text { Pillow Lava } \\
\text { Hyaloclastite } \\
\text { Pillow Lava } \\
\text { Hyaloclastite }\end{array}$ & $\begin{array}{l}0.33 \\
0.25 \\
0.10 \\
0.30 \\
0.20 \\
0.56 \\
0.11 \\
0.10 \\
0.11 \\
0.17 \\
0.48 \\
\end{array}$ & $\begin{array}{l}\text { No } \\
\text { No } \\
\text { No } \\
\text { No } \\
\text { No } \\
\text { No } \\
\text { No } \\
\text { No } \\
\text { No } \\
\text { No } \\
\text { No }\end{array}$ \\
\hline
\end{tabular}

a $\mathrm{TRZ}=\frac{\mathrm{SiO}_{2} / \mathrm{MgO} \text { (glass) }}{\mathrm{SiO}_{2} / \mathrm{MgO} \text { (alteration products) }}$. 


\section{IMPLICATIONS TO NUCLEAR WASTE GLASSES}

\section{A. Introduction}

In this section, we address two key questions already alluded to in the previous chapters: (1) does tektite, obsidian, or basalt glass corrode in a fashion similar to nuclear waste glass in laboratory tests, and (2) can these similarities be used to relate the long-term corrosion behaviors of nuclear waste glasses and natural glasses. The first question acknowledges the possibility that the compositional differences between natural glasses and nuclear waste glasses may lead to recognizably different corrosion behaviors in short-term tests under controlled laboratory conditions. The second question pertains to the certainty with which reaction processes identified as being important in short-term tests can be used to model the long-term corrosion of both natural and nuclear waste glass, but that can only be confirmed for natural glasses. The review of experimental and field alteration of natural glasses in the preceding chapters was, therefore, geared towards identifying reaction products and mechanism(s) that are important not only for the range of glass compositions covered by natural and nuclear waste glasses, but also for aqueous corrosion over short and long time frames. Before we address the aforementioned questions, we briefly summarize the salient features of tektite, obsidian, and basalt glass corrosion.

\section{B. Lessons from Natural Glass Alteration}

\section{Tektites}

In the foregoing review of natural glass alteration in laboratory and natural systems, we tried to carefully differentiate between reactions occurring in liquid water and those involving water vapor. This distinction is motivated by the fact that reactions under these conditions may often result in different corrosion progresses and sometimes different dominant processes over similar time frames. In the case of tektites, for example, reaction with liquid water results in a predominance of surface dissolution or etching, especially at high dilution (i.e., low $\mathrm{S} / \mathrm{V}$ ratios). The formation of alteration products is inhibited because of the large mass of glass that must dissolve to saturate the solution. Reaction layers might not even form. Reaction in a water vapor environment (in which the effective $S / V$ ratio may be quite high) promotes the formation of alteration phases because very little glass has to dissolve to saturate the small solution volume. Alteration of tektites to clays, as observed in samples from the K/T boundary and in laboratory tests with water vapor, proceeded via transformation of a hydrated layer. A similar layer is not observed in tektites exposed to liquid water because dissolution occurs faster than hydration in those environments. The formation of a hydrated layer on the laboratory-reacted samples could also be due, in part, to the very high water pressures attained in vapor hydration tests. For example, the water vapor pressure at $150^{\circ} \mathrm{C}$ is about $475 \mathrm{kPa}(4.7 \mathrm{~atm})$. Such high water pressures promote the diffusion of water into the glass but have little effect on the dissolution rate.

Based on comparison of the reaction products observed on naturally altered tektite with those formed in laboratory tests, corrosion of tektites under aggressive conditions (e.g., high temperature or water vapor pressure) in the laboratory tests seems to reproduce corrosion that occurs in natural environments over long times quite well. Furthermore, reaction rates that are measured in the laboratory are quite similar to those estimated based on the alteration of natural samples.

One issue pertinent to analyzing the comparative behaviors of tektite and nuclear waste glasses is the fact that silica contents of most tektites are significantly higher than those of the latter. Unfortunately, systematic studies of the so called bottle-green tektites, which have silica contents similar to those of nuclear waste glasses, have not been conducted to date. Limited observations on bottle-green tektites altered in deep sea environments, however, suggest 
that surface dissolution also occurs fast enough with this tektite that no residual reaction layers form on the corroded surfaces.

\section{2. $\quad$ Rhyolitic Glasses}

Obsidian hydrates to form perlite, which is a hydrous form of glass, in natural subaerial environments. Hydration proceeds at a rate that is nearly proportional to the square root of time, which suggests that hydration is a diffusion-controlled process. The hydration rates measured for various obsidians range from 1 to $70 \mu \mathrm{m}^{2} / 1000 \mathrm{y}$, depending on the locality and the chemical compositions. In particular, the intrinsic water content of obsidian has been shown to strongly affect the hydration rate. When submerged in liquid water, however, obsidian may also dissolve and form alteration minerals in addition to a hydrated layer.

Laboratory reaction of obsidian in water vapor results in hydration and the formation of birefringent layers that have the same characteristics as the perlite phase formed by natural alteration. The hydration rate is linear with the square root of time and exhibits Arrhenius behavior with activation energies ranging from 68 to $91 \mathrm{~kJ} / \mathrm{mol}$ for obsidians with different compositions. Careful studies of experimental parameters also revealed that the hydration rates are affected by the relative humidity. On the other hand, reaction of obsidian in laboratory hydrothermal solutions may simultaneously involve several processes, including hydration, dissolution, and precipitation of alteration phases. However, the individual rates for each of these processes are difficult to determine.

By comparing the alteration observed for natural samples with that of samples reacted in the laboratory, it is clear that the hydration process that occurs in natural environments can be reproduced relatively well with laboratory experiments. A general diffusion equation has been established to quantitatively describe the hydration rate for both the laboratory reaction and the field alteration of obsidian. The influence of various parameters, such as relative humidity, temperature, and glass compositions on the reaction rates measured, in both the laboratory and terrestrial environments, must be taken into account before experimentally determined reaction rates can be projected backward, when dating obsidian artifacts, or forward, when projecting long-term durabilities of waste glasses.

Like tektites, the analogy between obsidian and nuclear waste glass is limited by the fact that the $\mathrm{SiO}_{2}$ contents in obsidians are substantially higher than in most nuclear waste glass formulations. How this difference limits the analogy will be discussed later in this chapter.

\section{Basaltic Glasses}

Basaltic glasses have $\mathrm{SiO}_{2}$ contents that are more similar to those of nuclear waste glasses than are obsidians and tektites. Similarities in the $\mathrm{SiO}_{2}$ contents of natural glasses and waste glasses are more important than similarities of other components because $\mathrm{SiO}_{2}$ groups form the framework of the glass structure and are by far the most abundant component. Other components of a glass generally weaken the framework and degrade the durability of glass.

Basaltic glasses react with water to form palagonite. Palagonitization is a non-isochemical alteration process that involves progressive dissolution of glass with contemporaneous reprecipitation of insoluble material at the glass surface. Relative to the glass, palagonite generally contains lower concentration of soluble glass components, such as $\mathrm{Si}, \mathrm{Al}$, $\mathrm{Mg}, \mathrm{Ca}$, and $\mathrm{Na}$, and higher concentrations of less soluble components, such as $\mathrm{Fe}$ and $\mathrm{Ti}$.

Palagonites can become enriched in $\mathrm{K}$ and $\mathrm{Mg}$ when glass alters in sea environments because these 
elements are provided by seawater. As more glass dissolves into solution, other phases may precipitate as their solubility limits are reached. The palagonitization rates that are calculated by measured palagonite thickness range from 3-20 $\mu \mathrm{m} / 1000$ y for basalts altered in environments with low silica concentrations to $0.002-0.2 \mu \mathrm{m} / 1000$ y for basalts altered in a silica-saturated environment. However, the palagonitization rate is generally not directly equivalent to the glass dissolution rate. This is because the formation of the palagonite is affected both by the dissolution rate of the glass and by the precipitation rates of the alteration phases. Which is the controlling rate cannot be determined by studying naturally altered samples.

Reaction of basalt glass in laboratory tests results in the formation of palagonite and alteration phases that are similar to those formed during natural alteration. The alteration products formed on basalt glass samples also have characteristics similar to those formed on waste glass samples. In laboratory tests conducted with seawater having a low silica content, the rate of basalt dissolution was measured to be $0.10 \mathrm{~g} /\left(\mathrm{m}^{2} \cdot \mathrm{d}\right)$ at $60^{\circ} \mathrm{C}$ and $0.001 \mathrm{~g} /\left(\mathrm{m}^{2} \cdot \mathrm{d}\right)$ at $3^{\circ} \mathrm{C}$ with an activation energy of $77 \mathrm{~kJ} / \mathrm{mol}$. (The latter rate is equivalent to $130 \mu \mathrm{m} / 1000 \mathrm{y}$.) The dissolution rate decreased by a factor of about 20 when the glass was reacted in a solution that was saturated with respect to amorphous silica. On the other hand, the rate of palagonite formation measured in laboratory tests exhibits a rather complicated time dependence. The growth of palagonite occurs rapidly at first, slows down as the solution becomes saturated, and accelerates again at a later stage. Unfortunately the rate of palagonitization and the rate of dissolution have not been systematically correlated. Experiments that involve both analysis of solution data and measurement of the thickness of palagonite layers must be performed to determine the relationship between the dissolution rate and the palagonitization rate.

\section{Natural Glasses as Nuclear Waste Glass Analogues}

\section{Are Natural Glasses Good Analogues of Nuclear Waste Glasses?}

It is very important to recognize that a full understanding of aqueous corrosion processes in laboratory or geological systems has not yet been achieved, even for glasses of very simple composition. Therefore, a detailed atomistic level of understanding for multicomponent glass compositions cannot be reasonably expected at present, especially with respect to the range of conditions for which a description of aqueous corrosion is desired. However, aqueous corrosion of both natural and nuclear waste glasses has been extensively studied in the past, and even more so in recent years. From these studies, a "consensus" view of nuclear waste glass corrosion has emerged [BATES-1994], and we use this framework to evaluate the extent to which natural glass compositions provide a suitable analogy to nuclear waste glasses. Since nuclear waste glasses have been examined only within laboratory time frames, it is in these systems where the question of analogy must first be answered. This is the crux of the first question raised at the beginning of this section.

Tektites exhibit excellent durability in resisting water corrosion. This can be attributed to the high silica content and high degree of interconnectivity in the silica network. The low alkali and water contents are also thought to lessen the importance of ion-exchange reactions in these glasses. The corrosion mechanism for tektites in laboratory and natural systems appears to be simple compared to that for the corrosion of waste glasses. Dissolution rates determined for tektites in laboratory tests in liquid water are similar to rates estimated for field samples. However, a key difference is that tektites undergo congruent dissolution in laboratory tests conducted with liquid water, while nuclear waste glasses do not. 
Exposure of tektites to water vapor in laboratory experiments results in the formation of a birefringent hydration layer through the process of water diffusion. Formation of this layer in laboratory tests requires high temperatures and water vapor pressures. A similar layer is not observed on nuclear waste glasses reacted under similar conditions. The difference in the corrosion behaviors of tektite and nuclear waste glasses in vapor hydration can be explained by the occurrence of competing reactions during corrosion of waste glasses. The formation of alteration phases during corrosion of several waste glasses has been observed to cause an increase in the hydrolysis rate. This is presumed to occur as precipitating phases remove silica from the solution and increase the reaction affinity. If the hydrolysis rate is greater than the hydration rate during corrosion of waste glasses, the hydrated layer will not become thick enough to be observed. Instead, a crust of alteration phases will form on the surface of the glass. Rate-affecting alteration phases do not form during corrosion of tektites, so the layer thickness is controlled by hydration. Clays have been observed to form on tektites weathered by nature for long times. It has been suggested that the presence of clay minerals on tektites recovered from the field is due to the transformation of a hydrated surface layer over long times [MAZER-1992A]. A similar transformation of a hydrated gel to clays has been seen in tests with waste glass conducted in liquid water [EBERT-1991A]. The formation of clays during waste glass corrosion does not lead to an increase in the glass dissolution rate.

The observation that the vapor hydration tests do not accelerate the corrosion of tektite enough to reproduce the extent of alteration observed on very old field samples, namely the transformation to clay, provides a valuable upper limit for the degree of acceleration that is provided by that test.

Laboratory corrosion of obsidian in liquid water appears to simultaneously involve several processes, including hydration, dissolution, and precipitation of secondary phases. Unfortunately, few studies of the corrosion of obsidian in liquid water have been conducted because the impetus for experiments has been the need to determine the age of obsidian artifacts. These artifacts are thought to have been exposed to water vapor on the earth's surface or in unsaturated soil layers, not submerged in liquid water. The alteration that occurs in natural environments can be reproduced relatively well in laboratory experiments conducted with water vapor instead of liquid water. The influence of relative humidity and temperature must be taken into account before experimentally determined reaction rates can be projected backward to age-date obsidian artifacts or forward to project long-term glass durabilities.

Some workers have suggested that experimentally determined hydration rates in obsidian can be used to evaluate the potential long-term effects of molecular water diffusion processes on nuclear waste glasses [MAZER-1992A]. However, the water diffusion rate in nuclear waste glass is expected to be significantly lower than in obsidian because of the greater silica content and the more highly cross-linked structure of obsidian. Other processes that are important in waste glass corrosion may become rate-limiting and obscure the effects of water diffusion as corrosion progresses. It has been suggested that water diffusion may control the longterm dissolution rate of nuclear waste glass if the solution contacting the glass becomes saturated in silica [e.g., GRAMBOW-1990].

Basaltic glasses have been studied as a nuclear waste glass analogue more extensively than tektites or obsidians because of the similar silica contents of basalt and waste glasses. Basalts react with water to form palagonite through a non-isochemical alteration process that involves progressive dissolution of glass with contemporaneous reprecipitation of alteration phases (palagonite) at the glass surface. Palagonites generally contain less $\mathrm{Si}, \mathrm{Al}, \mathrm{Mg}, \mathrm{Ca}$, and $\mathrm{Na}$ than the original glass, but are enriched in $\mathrm{Fe}$ and $\mathrm{Ti}$ because of their low solubilities in solution. 
Laboratory reaction of basalt glass results in the formation of phases that are very similar to those formed by natural alteration. The similarity of the alteration products formed on basalt glass and waste glass samples suggests that basalt and waste glasses react by similar processes and supports a possible analogue relationship between these two glasses.

In summary, tektites and obsidian have higher silica contents than waste glasses and generally react differently than waste glasses in terms of the reaction path and formation of alteration products. As a result, direct use of these glasses as natural analogues for waste glasses is limited. Nevertheless, experiments on these natural glasses appear to provide the benefit of allowing individual processes (e.g., molecular water diffusion) to be isolated from other reactions that occur during waste glass corrosion. Tektites and obsidian glass provide the opportunity to examine the potential long-term consequences of such processes in natural systems. For example, the hydration of obsidian can be used to study water diffusion, which may dominate waste glass corrosion under silica saturation conditions. Likewise, corrosion of tektites can be used to study the effects of environmental conditions on the dissolution process of glass.

However, results from these studies cannot be directly applied to waste glass without assessing the effects of compositional differences between nuclear waste glasses and natural glasses.

Basalt and waste glasses have been found to form similar alteration products when reacted under similar conditions. Such similarity is the impetus for the more detailed examination of basalt corrosion that follows. It is important to point out that the current state of understanding of the aqueous corrosion mechanism(s) of basalt evolved quite independently of the development of mechanistic models for nuclear waste glasses. Palagonite studies (including experimental palagonitization) predated interest in nuclear waste glass corrosion by at least several decades.

\section{Mechanism and Rate Expression for Palagonitization}

It is evident from the present review that a considerable effort has gone into experimental simulation and modeling of natural basalt corrosion. These studies can be compared directly with similar experimental work on nuclear waste glass formulations [BATES-1994] to evaluate the value and limitations of using basalts as vaste glass analogues.

The reaction of basalt with water results in chemical and structural modification of the glass surface. The end result of the overall interaction is the formation of hydrated glass and amorphous and crystalline alteration products at the glass/solution interface. However, since these final products need not have all resulted from a single fundamental reaction, the kinetic description of the overall palagonitization process must also reflect the different processes that have occurred. This section identifies some of these fundamental reactions and examines how they compare with the reactions described in Section II for nuclear waste glasses.

As with nuclear waste glasses, a useful starting point for a mechanistic analysis of palagonitization is a brief description of the initial molecular structure of the unreacted glass [e.g., ELLISON-1994]. It is generally accepted that the fundamental structural unit in silicate glasses is the $\mathrm{SiO}_{4 / 2}$ tetrahedron. This representation denotes a silicon atom in a tetrahedron with four shared apical oxygen. In pure silica glasses, each $\mathrm{SiO}_{4 / 2}$ tetrahedron is linked to four similar tetrahedra by sharing the apical oxygen atoms. The oxygen are then called bridging oxygen (BO). The three-dimensional array of silicon-oxygen bonds is referred to as the silica network or glass network. The inclusion of other elements in the glass disrupts the network to varying degrees. Instead of another $\mathrm{SiO}_{4 / 2}$ tetrahedron, an alkali metal or alkaline earth element can bond to an apical oxygen. An oxygen that bridges an $\mathrm{Si}$ atom and an alkali metal or alkaline earth ion is 
called a nonbridging oxygen (NBO). One alkaline earth can bridge two NBOs. Both alkali metals and alkaline earths break the glass network and are sometimes referred to as network modifiers. The formation of NBOs is detrimental to glass durability. Trivalent ion such as $\mathrm{Al}^{3+}, \mathrm{B}^{3+}$, or $\mathrm{Fe}^{3+}$ can substitute for $\mathrm{Si}$ in a tetrahedral site, which leads to the formation of a tetrahedron with a net negative charge. That charge is neutralized by the nearby presence of alkali metal or alkaline earth. Alkali metal and alkaline earth components associated with $\mathrm{Al}, \mathrm{B}$, or $\mathrm{Fe}$ are less likely to participate in ion-exchange reactions than those bonded to NBOs. The addition of trivalent ions is not as detrimental to the network structure as the addition of network modifiers, since the network is propogated. Also, trivalents effectively trap network modifiers to reduce the number of NBOs in the glass. Both the structure and reactivity of a glass are known to depend on its composition, although the exact nature of this dependence is complex and has not yet been fully quantified [cf. ELLISON-1994].

Exchange of mobile ions from the glass surface (e.g., alkalis in NBO sites) for a proton or hydronium ion takes place instantaneously upon contact with water. This is followed by the release of the freed mobile glass component to solution [CROVISIER-1983]. In simple alkali silicate glasses, the exchange of alkalis at sites near the surface for a proton or hydronium ion is followed by bulk diffusion of hydronium into the glass and alkalis toward the surface from deeper portions of the glass [e.g., DOREMUS-1973]. The surface layer that is formed by diffusion becomes chemically distinct from the bulk glass because of this exchange between hydrogen species and mobile glass components. However, because the composition can vary gradually from the bulk glass to the outermost surface, the dealkalized zone may not be physically distinguishable from the bulk glass. There is strong evidence from laboratory tests with basalts that this type of bulk exchange process also occurs during reaction of multicomponent glasses, specifically basalt, with water [FURNES-1975, -1978; CROVISIER-1983; BYERS-1984; ABRAJANO-1987]. This process alone should lead to formation of a surface layer that grows parabolically with time. The growth of this layer is governed by an interdiffusion coefficient, $\mathrm{D}$, the value of which approaches that of the self-diffusion coefficient of the slowest diffusing species as the difference between the self-diffusion coefficients between diffusing species becomes large [DOREMUS-1973].

Hydrolysis of bridging bonds is another process known to occur during the interaction of glass and water (reactions $\Pi-1 \mathrm{a}$ and $\Pi \mathrm{I}-1 \mathrm{~b}$, Section II). As with nuclear waste glasses, nucleophilic attack by hydroxide (reaction II-1b) is thought to dominate the hydrolysis of basalt glass, and high $\mathrm{pH}$ levels are attained when basalt glass is reacted with water in static systems [CROVISIER-1986, 1987]. Between one and four Si-O bonds must be hydrolyzed to release silicic acid into solution. Cleavage of the last bond is taken to be the rate-limiting step for glass dissolution. The interaction between water and the residual silica network in the dealkalized layer results in varying degrees of hydrolysis of tetrahedral silicate units. The combination of dealkalization and hydrolysis leads to glass dissolution and the formation of palagonite. Some phases may form within the palagonite layer, while other precipitate from solution.

Simultaneously with the conversion of glass into palagonite, the outer surface of the palagonite dissolves at the interface with water. Dissolution of palagonite is known to follow zero-order kinetics at the initial stages of dissolution when the solution concentrations of dissolved glass components are low [ABRAJANO-1987, CROVISIER-1987]. The net kinetics of the initial rate of growth of the layer is determined by the parabolic kinetics of diffusion and the linear kinetics of dissolution [e.g., BORSAY-1968; SULLIVAN-1984; ABRAJANO-1987]. The essential result is that growth of the palagonite layer is initially parabolic when hydration dominates, but the layer thickness becomes constant after longer reaction times as corrosion becomes controlled by the dissolution rate. 
In summary, the basic processes that appear to control basalt glass dissolution are consistent with those used to describe nuclear waste glass dissolution (Section II). The primary process is network hydrolysis reactions that eventually lead to the release of components from the glass network, although the diffusion of water and ion-exchange processes are important, too, because they "open up" the glass and expose network bonds to hydrolysis. Dissolution reactions are best described as a nucleophilic attack by $\mathrm{OH}^{-}$or $\mathrm{H}_{2} \mathrm{O}$ on the framework structure. The form of the rate expression for this reaction for basalt is the same as that used for waste glasses, give as reaction [AAGAARD-1982; GRAMBOW-1985; CROVISIER-1987; GRAMBOW-1990; BOURCIER-1990], although the values for the rate parameters will likely be different. For the purposes of the analogue approach, it is important that the governing mechanisms be the same. The present review clearly demonstrates that such is the case between basalt and nuclear waste glasses.

\section{Long-Term Kinetics}

The final question posed at the beginning of this chapter addresses whether or not similarities observed in the short-term corrosion behaviors of nuclear waste glasses and natural glasses can be applied to understand long-term similarities in the corrosion behavior. This question is best answered by considering the application of individual steps of the mechanisms determined by the short-term laboratory experiments over longer reaction times. The question then becomes: Is it likely that processes that are of minor importance to corrosion in short-term experiments, either due to the corrosion mechanism or conditions of the test method, assume a greater role in the long-term? This question lies at the foundation of the analogue approach and emphasizes the importance of having made a connection between the corrosion mechanisms of natural and nuclear waste glasses in short-term experiments. For it is only with natural glasses that the relationship between the mechanism derived from short-term laboratory tests and long-term alteration can be studied. Such studies of long-term palagonitization were presented in Section V.C, and we here recap the essential components of that review with respect to mechanisms and rate expressions for long-term corrosion.

Table V-3 summarized the literature data on natural palagonitization rates, assuming zero-order kinetics. As noted earlier, a wide range of palagonitization rates $(0.004$ to $>20 \mathrm{~mm} / 100 \mathrm{y}$ ) has been calculated for naturally altered samples. That the rates span more than three orders of magnitude reflects both the wide range of compositions of basalts studied and the variations in conditions in which the glasses reacted. Estimation of the growth rate of the palagonite layer requires independent knowledge of the duration of exposure of the basalt glass surface to aqueous solution. Uncertainties in the exposure ages of young basaltic glasses necessarily propagate into uncertainties in palagonite layer growth rates.

To illustrate the problem of determining exposure ages of basalts, we note that a number of the studies we reviewed earlier [e.g., MOORE-1966; HEKINIAN-1975; BRYAN-1977] used exposure ages determined from the thickness of manganese-bearing layers on basaltic glasses. Palagonite growth rates on dredged basalt samples from the Mid-Atlantic Ridge have been studied by Hekinian and Hoffert and by Bryan and Moore. Using Hekinian and Hoffert's [HEKINIAN-1975] data alone, the palagonitization rate may be estimated to range from 2.6 to $4.3 \mu \mathrm{m} / 1000 \mathrm{y}$ at temperatures of 0 to $5^{\circ} \mathrm{C}$ by assuming that manganese accumulates at a constant rate of $3 \mu \mathrm{m} / 1000 \mathrm{y}$. As Bryan and Moore [BRYAN-1977] pointed out, because manganese accumulation rates can vary regionally up to $20 \mu \mathrm{m} / 1000$ y near the ridge axis, palagonitization rates could be up to three times faster than manganese accumulation rates [cf. 
HEKINIAN-1975]. If an average manganese accumulation rate of $3 \mu \mathrm{m} / 1000 \mathrm{y}$ is applied to Bryan and Moore's data, a palagonitization rate of $5 \mu \mathrm{m} / 1000$ y is estimated.

Better estimates of natural palagonitization rates may be obtained from basalts from eruptions within historical times. Moore and others [MOORE-1985] summarized data for samples collected from several locations (see Table V-3). For samples exposed to water at temperatures of 23 to $25^{\circ} \mathrm{C}$, the rates range from 15 (Etna) to $100 \mu \mathrm{m} / 1000 \mathrm{y}$ (Mauna Loa). Rates of 4.7 to $9.4 \mu \mathrm{m} / 1000 \mathrm{y}$ were estimated for samples of 1877 Mauna Loa lavas that had hydrated at a temperature between 4 to $6^{\circ} \mathrm{C}$, whereas samples from Fuji lavas that had corroded in a freshwater lake at 5 to $15^{\circ} \mathrm{C}$ showed a range of 6.4 to $8.2 \mu \mathrm{m} / 1000 \mathrm{y}$. Jakobsson and Moore

[JAKOBSSON-1986] performed a similar study of palagonite layers formed on basaltic glasses from Surtsey. They estimated rates of 11 to $28 \mu \mathrm{m} / 1000$ y for a submarine-erupted sample altered at temperatures from 7 to $10^{\circ} \mathrm{C}$. Finally, Morgenstein and Rosendahl [MORGENSTEIN$1975,-1976]$ measured the palagonite layer thickness on samples of a variety of Hawaiian basaltic glasses of known eruption ages. They concluded that a linear rate of about $12 \mu \mathrm{m} / 1000 \mathrm{y}$ at $25^{\circ} \mathrm{C}$ best describes palagonite layer growth with time. This rate, which is for samples from a subaerial environment, is lower than the hydration rates in subaqueous environments at the same temperature [e.g., MOORE-1985]. Interestingly, all the above estimates are at the high end of the range of "linear rates" observed in natural palagonites (Table V-3).

As noted in Chapter $\mathrm{V}$, the suggestion has been made that palagonitization rates in excess of $3 \mu \mathrm{m} / 1000$ y represents the "forward" rate of palagonitization (i.e., palagonitization in "dilute" solutions [GRAMBOW-1985]). Grambow [GRAMBOW-1985] suggested that when the concentrations of dissolved components are allowed to increase in the aqueous phase, a lower "final rate" of $<0.1 \mu \mathrm{m} / 1000 \mathrm{y}$ will be achieved. By implication, the prehistoric basalts (in contrast to those formed during more recent eruptions) exhibit the "true" long-term palagonitization rate. We repeat the caution here that the exposure ages of prehistoric basalts may not be completely reliable; hence, the best that can be said at present is that the closedsystem rate of palagonitization for time scales longer than a thousand years is likely lower than $1 \mu \mathrm{m} / 1000 \mathrm{y}$.

Regardless of the actual magnitude of long-term palagonitization rates, however, comparison of these field-measured palagonitization rates with those measured in laboratory tests suggests that long-term rates in the field are generally lower than the short-term rates measured in the laboratory. This is not surprising from the kinetic description deduced for laboratory systems, which show first-order kinetics dictated by the degree of saturation of the solution. Systems governed by first-order kinetics will have rates that decrease with time, yielding the general result that the estimated overall rate will decrease as the exposure time increases.

It is apparent that palagonitization rates for basalts exposed in nature for long periods of time are consistent with rates measured in the laboratory. It appears that natural behavior can be reproduced with laboratory experiments and that kinetic expressions developed from experiments can be reliably applied to natural systems over long times. This implies that it is likely that the mechanisms that control palagonitization in laboratory experiments are also operative over the long term in nature. While it is unlikely that mechanisms that result in enhanced degradation rates over long periods occur in natural systems, uncertainties in assumed exposure ages and variations in the composition of the aqueous phase and the temperature of palagonitization preclude detailed quantification of the kinetics expressions for natural palagonites. Mechanisms that may slow mass transport during palagonitization cannot be discounted from the long-term observations. Diffusive barriers due to restructuring of palagonites or deposition of secondary precipitates may reduce palagonitization rates over time. It is possible that the extremely low 
palagonitization rates inferred from the examination of very old basalt glasses show the combined effects of saturation and mass transport.

In summary, palagonites formed over long periods in natural systems are similar to those formed on experimentally reacted basalts. Palagonitization rates estimated for samples reacted in nature over long times appear to be reasonably consistent with the predictions of kinetic expressions that were developed from short-term laboratory experiments. It can therefore be surmised that mechanistic inferences made in short-term experiments can be applied to longterm natural palagonitization. Since alteration of basalt and nuclear waste glasses within laboratory time frames can be described by the same first-order kinetic expression, and since the same kinetic expression can also be applied to basalts reacted in water over long periods of time, it can be suggested with confidence that the same kinetic expressions can also be applied to the long-term corrosion of nuclear waste glasses. 


\section{CONCLUSIONS}

In this report, we reviewed a wide range of natural and experimental corrosion studies involving three major groups of natural glasses: tektite, obsidian, and basalt. Information available on natural glass was then compared to corresponding information on the corrosion of nuclear waste glasses, specifically to resolve two key questions: (1) whether one or more natural glasses behave similarly to nuclear waste glasses in laboratory tests, and (2) how these similarities can be used to support projections of the long-term corrosion of nuclear waste glasses.

The corrosion behavior of basaltic glasses was most similar to that of nuclear waste glasses, and the reactions and processes that control basalt glass dissolution are similar to those that are important to nuclear waste glass dissolution. The key reaction of the overall corrosion mechanism is network hydrolysis, which eventually breaks down the glass network structure that remains after the initial ion-exchange and diffusion processes.

Finally, we consider whether the same mechanistic model can be used to describe the longterm corrosion behavior of both nuclear waste glasses and natural glasses. This was addressed by extending the mechanism revealed by the short-term laboratory experiments to longer reaction times to determine if the mechanism was consistent with alteration observed on naturally altered materials of great age. This was done to determine if there are processes that are not observed in laboratory systems but that become important in the long term. A detailed examination of the alteration products on samples weathered naturally over very long periods revealed that long-term rates can be adequately predicted from kinetic expressions developed from experimental systems. Admittedly, it is difficult to completely reconstruct the geochemical conditions under which palagonitization reactions occurred in natural systems. Hence, our understanding of long-term palagonitization rates is necessarily limited. However, examination of basaltic glass corrosion under a range of geochemical conditions and glass compositions has so far supported the prediction of glass corrosion rates based on experimental systems. Furthermore, even attempts to derive empirical rate expressions from natural observations have produced kinetic expressions not unlike mechanistic models developed from laboratory tests. At the very least, it could be said with a high degree of confidence that there are no processes observed in natural palagonitization reactions that have not also been observed in experimental systems or accounted for in kinetic models derived from experiment. The possibility that hydration layers can reorganize to such an extent that they could form transport barriers for water and glass components over long time frames has been considered in some kinetic models derived from experimental systems. Such an effect, if it becomes important at all, will simply serve to further retard corrosion in the same sense that saturation effects would. Transport barriers provided by overlying sediments in natural palagonites create small pockets of solution immediately adjacent to the corroding glass that quickly become saturated with dissolved components and decrease the dissolution rate.

Likewise, reorganization or crystallization of the surface layer, if it forms a transport barrier, has the same impact on reactions at the interface of the surface layer and unreacted glass. The presence of very thin palagonite layers on basalt glasses erupted millions of years ago can thus be attributed to saturation effects that are fully accounted for in Eqs. II-2 and II-3.

In balance, the present review also highlighted some unresolved issues related to the application of an analogue we approach to predicting long-term behavior of nuclear waste glass corrosion. It is notable that we have not made an attempt to fully quantify the kinetic parameters in Eqs. II-2 and II-3. That is because the rate law and absolute rates for given conditions (e.g., those appropriate for a disposal system or natural conditions) are not yet firmly established at present. Existing estimates based on field studies such those reviewed here remain to be calibrated by using an absolute dating technique which, unfortunately, does not currently exist. This makes absolute determination of the exposure ages of natural basalt inaccurate at present. Relative exposure ages could be useful but only in a qualitative sense. Furthermore, discrepancies still exists between experimental and field-based estimates of kinetic parameters for basaltic glasses 
(e.g., activation energies). Such discrepancies are not unexpected given our inability to fully recreate natural alteration conditions. On the other hand, a reasonable convergence must be achieved to make full utility of the analogue approach to support predictions of the performance of nuclear waste glasses. The development of accelerated testing procedures for basalt and nuclear waste glasses is one of the most meaningful ways of addressing these remaining uncertainties. 


\section{ACKNOWLEDGMENTS}

This work was supported by the U.S. Department of Energy, Office of Environmental Management, under Contract W-31-109-Eng-38. The authors thank Drs. J. K. Bates, R. Finch, and D. Strachan for their critical reading of the manuscript and V. Strezo, D. Tipton, and J. Andrew for their editorial assistance. 


\section{REFERENCES}

AAGAARD-1982

Aagaard, P., and H. C. Helgeson (1982). "Thermodynamic and kinetic constraints on reaction rates among minerals and aqueous solutions I. Theoretical considerations," American Journal of Science 282: 237-285.

ABRAJANO-1986

Abrajano, T. A., J. K. Bates, et al. (1986). "Aqueous corrosion of natural and nuclear waste glasses I. Comparative rates of hydration in liquid and vapor environments at elevated temperatures." Journal of Non-Crystalline Solids 84: 251-257.

ABRAJANO-1987

Abrajano, T. A., J. K. Bates, et al. (1987). The reaction of glass during gamma irradiation in a saturated tuff environment. Part III. Long-term experiments at $10^{4} \mathrm{rad} /$ hour. Argonne National Laboratory Report ANL-88-14.

ABRAJANO-1989

Abrajano, T. A., J. K. Bates, et al. (1989). "Aqueous corrosion of natural and nuclear waste glasses II. Mechanisms of vapor hydration of nuclear waste glasses." Journal of Non-Crystalline Solids 108: 269-288.

ABRAJANO-1990

Abrajano, T. A., J. K. Bates, et al. (1990). "Secondary phase formation during nuclear wasteglass dissolution." Clays and Clay Minerals 38(5): 537-548.

ADAMS-1984

Adams, P. B. (1984). "Glass corrosion. A record of the past? A predictor of the future?" Journal of Non-Crystalline Solids 67: 193-206.

ADVOCAT-1991

Advocat, J. L., Crovisier, et al. (1991). "Hydrolysis of R7T7 nuclear waste glass in dilute media: Mechanism and rate as a function of $\mathrm{pH}$." Materials Research Society Symposium Proceedings 212: 57-64.

AILIN-PYZIK-1981

Ailin-Pyzik, I. B., and S. E. Sommer (1981). "Microscale chemical effects of low-temperature alteration of DSDP basaltic glasses." Journal of Geophysical Research 86(B10): 9503-9510.

ALLEN-1981

Allen, C. C., J. L. Gooding, et al. (1981). "Altered basaltic glass: A terrestrial analogue to the soil of Mars." Icarus 45: 347-369.

ALLNATT-1983

Allnatt, A. R., G. M. Bancroft, et al. (1983). "Leaching behavior and electrical conductivity of natural rhyolite and modified synthetic rhyolites." Chemical Geology 38: 329-357.

ALVAREZ-1980

Alvarez, L. W., W. Alvarez, et al. (1980). "Extraterrestrial cause for the Cretaceous-Tertiary extinction." Science 208: 1095-1108.

ALVAREZ-1995

Alvarez, W., P. Claeys, et al. (1995). "Emplacement of Cretaceous-Tertiary boundary shocked quartz from Chicxulub crater." Science 269: $930-935$. 
AMBROSE-1976

Ambrose, W. (1976). "Intrinsic hydration rate dating of obsidian." In Advances in Obsidian Glass

Studies. Ed. R. E. Taylor. Noyes Press, Park Ridge, NJ, pp. 81-105.

ARAI-1989

Arai, T., Y. Yusa, et al. (1989). "Natural analogue study of volcanic glass: A case study of basaltic glasses in pyroclastic fall deposits of Fuji Volcano, Japan." Materials Research Society Symposium Proceedings 127: 73-80.

ASTM-1991

Standard Practice for "Prediction of the Long-term Behavior of Waste Package Materials Including Waste Forms Used in the Geologic Disposal of High-Level Nuclear Waste," C1174-91, prepared by ASTM Subcommittee C26.13, ASTM, 1916 Race St. Philadelphia, PA 19103 (1991).

BARKATT-1984

Barkatt, A., M. S. Boulos, et al. (1984). "The chemical durability of tektites: A laboratory study and correlation with long-term corrosion behavior." Geochimica et Cosmochimica Acta 48: 361-371.

BARKATT-1986

Barkatt, A., E. E. Saad, et al. (1986). Leaching of microtektite glass compositions in sea-water. Advances in Ceramics. Eds. D. E. Clark, W. B. White, and A. J. Machiels, The American Ceramic Society, Westerville, OH, pp. 681-687.

BARNES-1990

Barnes, V. E. (1990). “Tektite research 1939-1990,” Meteorites 25: 149-159.

BATES-1994

Bates, J. K., and E. C. Buck (1994). "Waste glass weathering." Materials Research Society Symposium Proceedings 333: 41-54.

BATES-1982A

Bates, J. K., L. J. Jardine, et al. (1982). "Hydration aging of nuclear waste glass." $\underline{\text { Science }}$ 218(October): 51-53.

BATES-1982B

Bates, J. K., L. J. Jardine, et al. (1982). The Hydration Process of Nuclear Waste Glass: An Interim Report. Argonne National Laboratory Report ANL-82-11.

BERGER-1988

Berger, G., J. Schott, et al. (1988). "Behavior of $\mathrm{Li}, \mathrm{Rb}$ and $\mathrm{Cs}$ during basalt glass and olivine dissolution and chlorites, smectites and zeolites precipitation from seawater: Experimental investigation and modelization between $50^{\circ} \mathrm{C}$ and $300^{\circ} \mathrm{C}$." Chemical Geology 71: 297-312.

BERGER-1994

Berger, G., C. Claparols, et al. (1994). "Dissolution rate of a basalt glass in silica-rich solutions: Implications for long-term alteration," Geochimica et Cosmochimica Acta 58: 4875-4886.

BOKSAY-1968

Boksay, Z., G. Bouquet, et al. (1968). "The kinetics of the formation of leached layers on glass surfaces." Physics and Chemistry of Glasses 9: 69-71. 
BOURCIER-1990

Bourcier, W. L., D. W. Peiffer, et al. (1990). "A kinetic model for borosilicate glass dissolution based on the dissolution affinity of a surface alteration layer." Materials Research Society

Symposium Proceedings 176: 209-216.

BOURCIER-1991

Bourcier, W. L. (1991). "Overview of chemical modeling of nuclear waste glass dissolution." Materials Research Society Symposium Proceedings 212: 3-18.

BOURCIER-1994A

Bourcier, W. L. (1994). Critical Review of Glass Performance Modeling. Argonne National Laboratory Report ANL-94/17.

BOURCIER-1994B

Bourcier, W. L. (1994). "Waste glass corrosion modeling: Comparison with experimental results." Materials Research Society Symposium Proceedings 333: 69-82.

BRYAN-1977

Bryan, W. B., and J. G. Moore (1977) "Compositional Variation of Young Basalts in the MidAtlantic Ridge Rift Valley near lat 36 Degrees 49'N." Geological Society of American Bulletin 88: 556-570.

BYERS-1986

Byers, C. D., R. C. Ewing, et al. (1986). "Experimental alteration of basalt glass applied to the alteration of nuclear waste glass." Advances in Ceramics 20: 733-744.

BYERS-1987

Byers, C. D., M. J. Jercinovic, et al. (1987). A Study of Natural Glass Analogues as Applied to Alteration of Nuclear Waste Glass. Argonne National Laboratory Report ANL-86-46.

CHALMERS-1979

Chalmers, R. O., E. P. Henderson, et al. (1979). "Australasian microtektites and the stratigraphic age of the australites: Discussion and reply." Geological Society of American Bulletin 90: 508512.

CHAPMAN-1984

Chapman, N. A., I. G. McKinley, et al. (1984). The Potential of Natural Analogues in Assessing Systems for Deep Disposal of High-Level Radioactive Waste. SKB Technical Report TR 84-16.

CÔME-1986

Côme, B., and N. A. Chapman (1986). CEC Nuclear Science and Technology Report. EUR 10671. Commission of the European Communities, Luxembourg.

COWAN-1989

Cowan, R., and R. C. Ewing (1989). "Freshwater alteration of basaltic glass, Hanauma Bay, Oahu, Hawaii: A natural analogue for the alteration of borosilicate glass in fresh water." Materials Research Society Symposium Proceedings 127: 49-56.

CROVISIER-1983

Crovisier, J. L., J. H. Thomassin, et al. (1983). "Experimental seawater-basaltic glass interaction at $50^{\circ} \mathrm{C}$ : Study of early developed phases by electron microscopy and X-ray photoelectron spectrometry." Geochimica et Cosmochimica Acta 47: 377-387. 
CROVISIER-1986

Crovisier, J. L., B. Fritz, et al. (1986). “ Dissolution of basaltic glass in seawater: Experiments and thermodynamic modelling," Materials Research Society Symposium Proceedings 50: 273280.

CROVISIER-1987

Crovisier, J. L., J. Honnorez, et al. (1987). "Dissolution of basaltic glass in seawater: Mechanism and rate." Geochimica et Cosmochimica Acta 51: 2977-2990.

CROVISIER-1989A

Crovisier, J. L., T. Advocat, et al. (1989). "Alteration of basaltic glass in Iceland as a natural analogue for nuclear waste glasses: Geochemical modeling with DISSOL." Materials Research Society Symposium Proceedings 127: 57-64.

CROVISIER-1989B

Crovisier, J. L., H. Atassi, et al. (1989). "A new insight into the nature of the leached layers formed on basaltic glasses in relation to the choice of constraints for long term modeling." Materials Research Society Symposium Proceedings 127: 41-48.

CROVISIER-1992

Crovisier, J. L., J. Honnorez, et al. (1992). "Dissolution of subglacial volcanic glasses from Iceland: laboratory study and modeling." Applied Geochemistry Suppl. Issue No. 1: 55-81.

CUNNANE-1995

Cunnane, J. C., J. K. Bates, et al. (1995) High-Level Waste Borosilicate Glass: A Compendium of Corrosion Characteristics. Report DOE-EM-0177.

DAUX-1994

Daux, V., J. L. Crovisier, et al. (1994). "Geochemical evolution of basaltic rocks subjected to weathering: Fate of the major elements, rare earth elements, and thorium." Geochimica et Cosmochimica Acta 58(22): 4941-4954.

\section{DICKIN-1981}

Dickin, A. P. (1981). "Hydrothermal leaching of thyolite glass in the environment has implications for nuclear waste disposal." Nature 294: 342-347.

DOREMUS-1973

Doremus, R. H. (1973), Glass Science, John Wiley \& Sons, Inc., New York.

EBERT-1991A

Ebert, W. L., and J. K. Bates (1991). "The importance of secondary phases in glass corrosion." Materials Research Society Symposium Proceedings 212: 89-97.

EBERT-1991B

Ebert, W. L., R. F. Hoburg, et al. (1991). "The sorption of water on obsidian and a nuclear waste glass." Physics and Chemistry of Glasses 32: 133-137.

EBERT-1993

Ebert, W. L., J. K. Bates, et al. (1993). "Accelerated glass reaction under PCT conditions." Materials Research Society Symposium Proceedings 294: 569-576. 
EBERT-1996

Ebert, W.L., and S.-W. Tam (1996). "Dissolution rates of DWPF glasses from long-term PCT." Materials Research Society Symposium Proceedings 465: 149-156.

ELLISON-1994

Ellison, A. J. G., J. J. Mazer, et al. (1994). Effect of glass composition on waste form durability: a critical review. Argonne National Laboratory Report ANL-94-27.

ERICSON-1976

Ericson, J. E., J. D. Mackenzie, et al. (1976). "Physics and chemistry of the hydration process in obsidians I: Theoretical implications." In Advances in Obsidian Glass Studies. Ed. R. E. Taylor. Noyes Press, Park Ridge, NJ, pp. 25-45.

ERICSON-1980

Ericson, J. E. (1980). "Durability of rhyolitic obsidian glass inferred from hydration dating research," in Scientific Basis for Nuclear Waste Management 3, Ed. J. G. Moore, Plenum Press, New York, pp 283-290.

ERICSON-1988

Ericson, J. E. (1988). "Obsidian hydration rate development," Materials Research Society Symposium Proceedings 125: 345-354.

EWING-1979

Ewing, R. C. (1979). "Natural glasses: Analogues for radioactive waste forms." Scientific Basis for Nuclear Waste Management. Ed. G. J. McCarthy. Plenum Press, New York, pp. 35-68.

EWING-1987

Ewing, R. C., and M. J. Jercinovic (1987). "Natural analogues: Their applications to the prediction of the long-term behavior of nuclear waste forms." Materials Research Society Symposium Proceedings 84: 67-83.

EWING-1992

Ewing, R. C. (1992). "The role of natural analogues in performance assessment: Applications and limitations." The 3rd Annual International Meeting on High-Level Radioactive Waste Management, Las Vegas, American Nuclear Society.

FRIEDMAN-1966

Friedman, I., R. L. Smith, et al. (1966). "Hydration of natural glass and formation of perlite." Geological Society of American Bulletin 77: 323-326.

FRIEDMAN-1976

Friedman, I., and W. Long (1976). "Hydration rate of obsidian." Science 191: 347-352.

FRIEDMAN-1978

Friedman, I., and F. W. Trembour (1978). "Obsidian: The dating stone." American Scientist 66: 44-51.

\section{FRIEDMAN-1984}

Friedman, I., and W. Long (1984). "Volcanic glasses, their origins and alteration processes." Journal of Non-Crystalline Solids 67: 127-133.

FRIEDMAN-1994

Friedman, I., F. W. Trembour, et al. (1994). "Is obsidian hydration dating affected by relative humidity?" Quaternary Research 41: 185-190. 


\section{FURNES-1975}

Furnes, H. (1975). "Experimental Palagonitization of Basalt Glasses of Varied Composition," Mineralogy and Petrology 50: 105-113.

FURNES-1978

Furnes, H. (1978). "Elemental mobility during palagonitization of a subglacial hyaloclastite in Iceland." Chemical Geology 22: 249-264.

FURNES-1984

Furnes, $\mathrm{H}$. (1984). "Chemical changes during progressive subaerial palagonitization of a subglacial olivine tholeiite hyaloclastite: A microprobe study." Chemical Geology 43: 271-285.

GHIIARA-1993

Ghiara, M. R., E. Franco, et al. (1993). "Hydrothermal interaction between basaltic glass, deionized water and seawater." Chemical Geology 104: 125-138.

GISLASON-1987A

Gislason, S. R., and H. P. Eugster (1987). "Meteoric water-basalt interactions. I: A laboratory study." Geochimica et Cosmochimica Acta 51: 2827-2840.

GISLASON -1987B

Gislason, S. R., and H. P. Eugster (1987). "Meteoric water-basalt interactions. II: A field study in N.E. Iceland." Geochimica et Cosmochimica Acta 51: 2841-2855.

GISLASON-1993

Gislason, S. R., D. R. Veblen, et al. (1993). "Experimental meteoric water-basalt interactions:

Characterization and interpretation of alteration products." Geochimica et Cosmochimica Acta 57: 1459-1471.

GLASS-1972

Glass, B. P. (1972). "Bottle-green microtektites.” Journal of Geophysical Research 77: 70577064.

\section{GLASS-1997}

Glass, B. P., D. W. Muenow, et al. (1997). "Fragmentation and hydration of tektites and microtektites." Meteoritic \& Planetary Science 32: 333-341.

GLASS-1981

Glass, B. P., and J. Crosbie (1981). Final Technical Report for NASA Contract NAS 5-26273. Report DE-AI09-80ET-47927.

GLASS-1984A

Glass, B. P. (1984). "Solution of naturally-occurring glasses in the geological environment." Journal of Non-Crystalline Solids 67: 265.

GLASS-1984B

Glass, B. P. (1984). “Tektites.” Journal of Non-Crystalline Solids 67: 333-344.

GRAMBOW-1985

Grambow, B., M. J. Jercinovic, et al. (1985). "Weathered basalt glass: A natural analogue for the effects of reaction progress on nuclear waste glass alteration." Materials Research Society Symposium Proceedings 50: 263-272. 
GRAMBOW-1990

Grambow, B. and R. Muller (1990) "Chemistry of glass corrosion in high saline brines."

Materials Research Society Symposium Proceedings 176: 229-240.

HAY-1968

Hay, R. L. and A. Ijima (1968). "Petrology of palagonite tuffs of the koko craters, Oahu, Hawaii." Contributions to Mineralogy and Petrology 17: 141-154.

HAY-1972

Hay, R. L. and B. F. Jones (1972). "Weathering of basaltic tephra on the Island of Hawaii." Geological Society of American Bulletin 83: 317-332.

HEKINIAN-1975

Hekinian,, R. and M. Hoffert (1975) "Rate of Palagonitization and Manganese Coating on Basaltic Rocks from the Rift Valley in the Atlantic Ocean near 36 Degrees 50'N." Marine Geology 18: 91 109.

HONNOREZ-1978

Honnorez, J. (1978) "Generation of Philipsites by Palagonitization of Basaltic Glass in Sea Water and the Origin of K-rich Deep-Sea sediments," in Natural Zeolites: Occurrence, Properties and Use. Eds. L. B. Sand and F. A. Mumpton, Pergamon Press, Oxford, pp. 245-258.

IAEA-1989

International Atomic Energy Agency (IAEA) (1989). Natural Analogues in Performance

Assessments for the Disposal of Radioactive Wastes. IAEA Technical Report 304.

IZETT-1991

Izett, G. A., G. B. Dalrymple, et al. (1991). ${ }^{، 40} \mathrm{Ar} /{ }^{39} \mathrm{Ar}$ age of Cretaceous-Tertiary boundary tektites from Haiti." Science 252: 1539-1542.

JAKOBSSON-1986

Jakobsson, S. P. and J. G. Moore (1986). "Hydrothermal minerals and alteration rates at Survey

Volcano, Iceland, Geological Society of America Bulletin 97: 648-659.

JERCINOVIC-1987

Jercinovic, M. J., and R. C. Ewing (1987). Basaltic Glasses from Iceland and the Deep Sea:

Natural Analogues to Borosilicate Nuclear Waste-Form Glass. JSS Project Technical Report. JSS88-01.

JERCINOVIC-1992

Jercinovic, M. J., and R. C. Ewing (1992). Corrosion of geological and archaeological glasses. Corrosion of Glass, Ceramics and Ceramic Superconductors. Eds. D. E. Clark and B. K. Zoitos. Noyes Publications, pp. 330-371.

JERCINOVIC-1990

Jercinovic, M. J., K. Keil, et al. (1990). "Alteration of basaltic glasses from north-central British Columbia, Canada." Geochimica et Cosmochimica Acta 54: 2679-2696.

KARKHANIS-1980

Karkhanis, S. N., G. M. Bancroft, et al. (1980). "Leaching behavior of rhyolitic glass." Nature 284: $435-437$. 
KEITH-1985

Keith, T. E. C., and L. W. Staples (1985). "Zeolites in ocean basaltic pillow lavas of the Siletz River volcanics, Central Coast Range, Oregon." Clays and Clay Minerals 33: 135-144.

KNAUSS-1990

Knauss, K. W. L. Bourcier, et al. (1990). "Dissolution kinetics of a simple analogue waste glass as a function of $\mathrm{pH}$, time and temperature." Materials Research Society Symposium Proceedings 176: $371-381$.

KOEBERL-1988

Koeberl, C. and B. P. Glass (1988). "Chemical composition of North American microtektites and tektite fragments from Barbados and DSDP Site 612 on the continental slope off New Jersey," Earth and Planetary Science Letters 87: 286-292.

KOEBERL-1992

Koeberl, C. and H. Sigurdsson (1992). "Geochemistry of impact glasses from the K/T boundary in Haiti: Relation to semectites and a new type of glass," Geochimica et Cosmochimica Acta 56:

2113-2129.

\section{KRING-1991}

Kring, D. A., and W. V. Boynton (1991). "Altered spherules of impact melt and associated relic glass from the K/T boundary sediments in Haiti." Geochimica et Cosmochimica Acta 55: 17371742 .

KRISTMANNSDOTTIR-1978

Kristmannsdottir, H. (1978). "Alteration of basaltic rocks by hydrothermal activity at $100-300^{\circ} \mathrm{C}$," in International Clay Conference, Developments in Sedimentalogy 27. Eds. M. M. Mortland and V.C. Farmer, Elsevier, New York, pp. 359-367.

LaMARCHE-1984

LaMarche, P. H., F. Rauch, et al. (1984). "Reaction between water and tektite glass." Journal of Non-Crystalline Solids 67: 361-369.

LANFORD -1977

Lanford, W. A. (1977). “Glass hydration: A method of dating glass objects.” Science 196: 975976.

\section{LAURSEN-1978}

Laursen, T., and W. A. Lanford (1978). "Hydration of obsidian." Nature 276: 153-156.

\section{LEMMENS-1992}

Lemmens, K. and P. Van Iseghem (1992). "The long-term dissolution behavior of the Pamela Borosilicate glass SM527-Application of SA/V as accelerating parameter," Materials Research Society Symposium Proceedings 257: 49-56.

LEE-1974

Lee, R. R., D. A. Leich, et al. (1974). "Obsidian hydration profile measurements using a nuclear reaction technique." Nature 250: 44-47.

LUO-1997

Luo, J. S., W. L. Ebert., et al. (1997). "Simulation of natural corrosion by vapor hydration test: Seven-year results," Materials Research Society Symposium Proceedings 465: 157-163. 


\section{LUTZE-1985}

Lutze, W., G. Malow, et al. (1985). "Alteration of basalt glasses: Implications for modeling the long-term stability of nuclear waste glasses." Nature 314(21): 252-255.

MAGONTHIER-1992

Magonthier, M.-C., and J.-C. Petit (1992). "Rhyolitic glasses as natural analogues of nuclear waste glasses: Behavior of an Icelandic glass upon natural aqueous corrosion." Applied Geochemistry Suppl. Issue No. 1: 83-93.

\section{MALOW-1984}

Malow, G., W. Lutze, et al. (1984). "Alteration effects and leach rates of basaltic glasses: Implications for the long-term stability of nuclear waste form borosilicate glasses." Journal of Non-Crystalline Solids 67: 305-321.

\section{MARGOLIS-1991}

Margolis, S. V., P. Claeys, et al. (1991). "Microtektites, microkrystites, and spinels from a late Pliocene asteroid impact in the Southern Ocean." Science 251: 1594-1597.

MAZER-1991A

Mazer, J. J., J. K. Bates, et al. (1991). "Alteration of tektite to form weathering products." Nature 357: $573-576$.

\section{MAZER-1991B}

Mazer, J. M., C. M. Stevenson, et al. (1991). "The experimental hydration of obsidian as a function of relative humidity and temperature." American Antiquity 56: 504-513.

MAZER-1992A

Mazer, J. J., J. K. Bates, et al. (1992). "Water diffusion in tektites: An example of the use of natural analogues in evaluating the long-term reaction of glass with water." Journal of Nuclear Materials 190: 277-284.

MAZER-1992B

Mazer, J. J., J. K. Bates, et al. (1992). "Obsidians and tektites: Natural analogues for water diffusion in nuclear waste glasses." Materials Research Society Symposium Proceedings 257: 513-520.

\section{MAZER-1994}

Mazer, J. J. (1994). "The role of natural glasses as analogues in projecting the long-term alteration of high-level nuclear waste glasses: part 1". Materials Research Society Symposium Proceedings 333: $159-163$.

McGRAIL-1988

McGrail, B. P., L. R. Pederson, et al. (1988). "Obsidian hydration dating-field, laboratory and modeling results." Materials Research Society Symposium Proceedings 125: 393-399.

McGRAIL-1995

McGrail, B. P. and D. K. Peeler. (1995). Evaluation of the Single-Pass Flow-Through Test to Support s Low-Activity Waste Specification. Pacific Northwest Laboratory Report PNL-10746.

McGRAIL-1997

McGrail, B. P., W.L. Ebert et al. (1997). "Measurement of kinetic rate law parameters on a NaCa-Al borosilicate glass for low-activity waste." Joumal of Nuclear Materials 249: 175-189. 
McKENZIE-1990

McKenzie, W.F. (1990). Natural glass analogues to alteration of nuclear waste glass: A review and recommendations for further study. Lawrence Livermore National Laboratory Report UCID21871.

MELOSH-1991

Melosh, H. J., and A. M. Vickery (1990). "Melt droplet formation in energetic impact events." Nature 350: 494-496.

MICHELS-1983

Michels, J. W., I. S. T. Tsong, et al. (1983). "Obsidian dating and East African archeology." Science 219: 361-366.

MILLER-1994

Miller, W., R. Alexander, et al. (1994). Natural Analogue Studies in the Geological Disposal of Radioactive Wastes. Elsevier, Amsterdam.

MILLER-1995

Miller, B., and N. Chapman (1995). "Postcards from the past: Archaeological and industrial analogues for deep repository materials." Radwaste Magazine 2: 32-41.

MOORE-1966

Moore, J. G. (1966). "Rate of palagonitization of submarine basalt adjacent to Hawaii." U.S. Geological Survey Professional Papers 550D: 163-171.

MOORE-1985

Moore, J. G., D. J. Forni, et al. (1985). "Basalts from the 1877 submarine eruption of Mauna Loa, Hawaii: New data on the variation of palagonitization rate with temperature," U. S.

Geological Survey Bulletin 1663: 11-18.

MORGENSTEIN-1975

Morgenstein, M., and T. J. Riley (1975). "Hydration-rind dating of basaltic glass: A new method for archeological chronologies." Asian Perspectives 17: 145-159.

MORGENSTEIN-1976

Morgenstein, M., and P. Rosendahl (1976). "Basaltic glass hydration dating in Hawaiian archaeology." In Advances in Obsidian Glass Studies. Ed. R. E. Taylor. Noyes Press, Park Ridge, NJ pp. 141-164.

MURAKAMI-1988

Murakami, T., R. C. Ewing, et al. (1988). "Analytical electron microscopy of leached layers on synthetic basalt glass," Materials Research Society Symposium Proceedings 112: 737-748.

NESBITT-1992

Nesbitt, H. W., and R. E. Wilson (1992). "Recent chemical weathering of basalts." American Journal of Science 292: 740-777.

O'KEEFE-1984

O'Keefe, J. A. (1984). “Natural glass.” Journal of Non-Crystalline Solids 67: 1-17.

O'KEEFE-1986

O'Keefe, J. A. (1986). "The corrosion of tektite glass." Advances in Ceramics 20: 689-692. 
O'KEEFE-1994

O’Keefe, J. A. (1994). “Origin of tektites.” Meteorites 29: 73-78.

PETTT-1992A

Petit, J. C. (1992). "Natural analogues for the design and performance assessment of radioactive waste forms: A review." Journal of Geochemical Exploration 46: 1-34.

PETIT-1992B

Petit, J. C. (1992). "Reasoning by analogy: Rational foundation of natural analogue studies." Applied Geochemistry Suppl. Issue No. 1: 9-11.

POLLASTRO-1987

Pollastro, R. M., and C. L. Pillmore (1987). "Mineralogy and petrology of the Cretaceous-

Tertiary boundary clay bed and adjacent clay-rich rocks, Raton Basin, New Mexico and

Colorado." Journal of Sedimentary Petrology 57: 456-466.

PRASAD-1990

Prasad, M. S., and P. S. Rao (1990) "Tektites far and wide," Nature 347: 340.

RAUCH-1992

Rauch, F., J. E. Ericson, et al. (1992). "Hydration of tektite glass." Journal of Non-Crystalline Solids 144: 224-230.

ROBINSON-1983

Robinson, P. T., W. G. Melson, et al. (1983). "Vocalnic glass composition of the troodos ophiolite, cyprus." Geology 11: 400-404.

RYAN-1993

Ryan, J., D. McPhail, et al. (1993). "Glass deterioration in the museum environment." Chemistry and Industry 5: 498-501.

SCHEIDEGGER-1977

Scheidegger, K. F., and D. S. Stakes (1977). "Mineralogy, chemistry and crystallization sequence of clay minerals in altered Tholeiitic basalts from the Peru Trench." Earth and Planetary Science

Letters 36: 413-422.

SCHMTNCKE-1978

Schmincke, H.-U., P. T. Robinson, et al. (1878). "Basaltic Hyaloclastites from Hole 396B, DSDP Leg 46," in Initial Reports of the Deep Sea Drilling Project 46, Eds. L. Dmitriev et al. U. S. Government Printing Office, Washington, D. C., pp. 341-355.

SEYFRIED-1979

Seyfried, W. E., and J. L. Bischoff (1979). "Low temperature basalt alteration by seawater: An experimental study at 70 and $150^{\circ} \mathrm{C}$." Geochimica et Cosmochimica Acta 43: 1937-1947.

SIGURDSSON-1991

Sigurdsson, H., S. D'Hondt, et al. (1991). "Glass from the Cretaceous/Tertiary boundary in Haiti." Nature 349: 482-487.

SINGER-1974

Singer, A. (1974). "Mineralogy of palagonitic material from the Golan Heights, Israel," Clays and Clays Minerals 22: 231-241. 
SMITH-1991

Smith, D. K. (1991). "Mineralogical, textural and compositional data on the alteration of basaltic glass from Kilauea, Hawaii to $300^{\circ} \mathrm{C}$ : Insights to the corrosion of a borosilicate glass waste-form." Materials Research Society Symposium Proceedings 212: 115-121.

STAKES-1982

Stakes, D. S., and J. R. O'Neil (1982). "Mineralogy and stable isotope geochemistry of hydrothermally altered oceanic rocks." Earth Planetary Science Letters 57: 285-304.

STAUDIGEL-1983

Staudigel, H., and S. R. Hart (1983). "Alteration of basaltic glass: Mechanisms and significance for the oceanic crust-seawater budget." Geochimica et Cosmochimica Acta 47: 337-350.

STEVENSON-1993

Stevenson, C. M., E. Knaus, et al. (1993). "Homogeneity of water content in obsidian from the Coso volcanic field: Implications for obsidian hydration dating." Geoarchaeology 8: 371-384.

STOKES-1971

Stokes, K. R. (1971). "Further investigations into the nature of the materials chlorophaeite and palagonite." Mineralogical Magazine 38: 205-214.

STONE-1978

Stone, C., and P.-F. Fan (1978). "Hydrothermal alteration of basalts from Hawaii geothermal project Well-A, Kilauea, Hawaii." Geology 6: 401-404.

STRACHAN-1994

Strachan, D.M., W.L. Bourcier, et al. (1994) "Towards a Consistent Model for Glass Dissolution," Radioactive Waste Management and Environmental Restoration 19: 129-145.

SULLIVAN-1984

Sullivan, T. M., and A. J. Machiels (1984). "Growth of hydrated gel layers in nuclear waste glasses." Advances in Ceramics 8: 519-527.

\section{SUZUKI-1973}

Suzuki, M. (1973). "Potential of obsidian hydration dating," Journal of the Faculty of Science 4: 241-318, University of Tokyo.

THORSETH-1991

Thorseth, I. H., H. Furnes, et al. (1991). "A textural and chemical study of Icelandic palagonite of varied composition and its bearing on the mechanism of the glass-palagonite transformation." Geochimica et Cosmochimica Acta 55: 731-749.

TOMOZAWA-1984

Tomozawa, M., S. Ito, et al. (1984). "Hygroscopicity of glasses with high water content." Journal of Non-Crystalline Solids 64: 269-278.

TREMAINE-1988

Tremaine, K. J., and D. A. Fredrickson (1988). "Induced obsidian hydration experiments: An investigation in relative dating." Materials Research Society Symposium Proceedings 125: 401-408.

TSONG-1978

Tsong, I. S. T., C. A. Houser, et al. (1978). "Obsidian hydration profiles measured by sputterinduced optical emission." Science 201: 339-341. 
WALLACE-1983

Wallace, R. M., and G. G. Wicks (1983). "Leaching chemistry of defense borosilicate glass." Materials Research Society Symposium Proceedings 15: 23-28.

WHITE-1983

White, A. F. (1983). "Surface chemistry and dissolution kinetics of glassy rocks at $25^{\circ} \mathrm{C}$."

Geochimica et Cosmochimica Acta 47: 805-815.

YANG-1990

Yang, W.-H. A., and R. J. Kirkpatrick (1990). "Hydrothermal reaction of a rhyolitic-composition glass: A solid-state NMR study." American Mineralogist 75: 1009-1019.

YAPER-1931

Yaper, W. A., and S. O. Morgan (1931). Journal of Physical Chemistry 35: 2026.

ZHOU-1989

Zhou, Z., and W. S. Fyfe (1989). "Palagonitization of basaltic glass from DSDP Site 355, Leg 37:

Textures, chemical composition, and mechanism of formation." American Mineralogist 74: 1045-

1053. 


\section{APPENDIX: \\ Laboratory Testing and Characterization of Natural Analogue and Waste Glasses}




\section{APPENDIX \\ TABLE OF CONTENTS}

Page

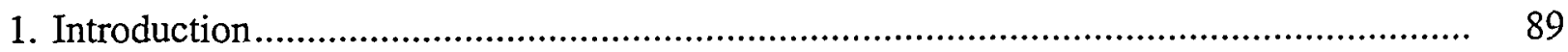

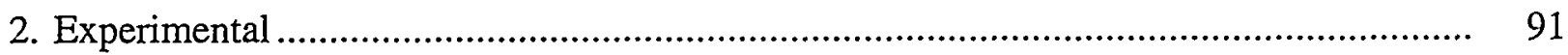

2.1. Sample Selection ............................................................................................. 91

2.1.1. Obsidian ....................................................................................... 92

2.1.2. Basaltic Glasses ......................................................................................... 93

2.1.3. High-Level Waste Glasses ...................................................................... 94

2.2. Experimental Reaction Conditions ..................................................................... 94

2.3. Sample Analysis and Characterization................................................................. 95

2.3.1. Obsidian .............................................................................................. 95

2.3.2. Basaltic and High-Level Waste Glasses ....................................................... 95

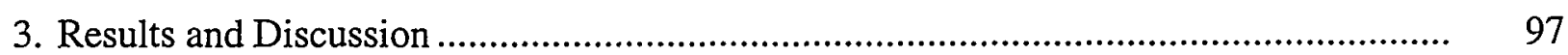

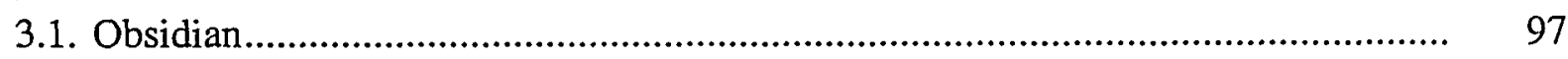

3.1.1. Saturated Vapor Hydration ....................................................................... 97

3.1.2. Unsaturated Vapor Hydration .................................................................... 99

3.1.3. Summary of Obsidian Studies................................................................. 100

3.2. Naturally Reacted Hawaiian Basaltic Glass ......................................................... 100

3.2.1. Optical and Scanning Electron Microscopy Analyses................................ 100

3.2.2. Analytical Electron Microscopy Analyses................................................ 104

3.2.3. Summary of Hawaiian Basalt Studies ..................................................... 110

3.3. Laboratory-Reacted Basaltic and Waste Glasses.................................................... 111

3.3.1. Laboratory-Reacted Basaltic Glass ........................................................... 111

3.3.2. Laboratory-Reacted Waste Glass SRL165 …........................................ 123

3.3.3. Laboratory-Reacted Waste Glass SRL131 .............................................. 133

3.3.4. Laboratory-Reacted Waste Glass PNL-76-68 ............................................. 149

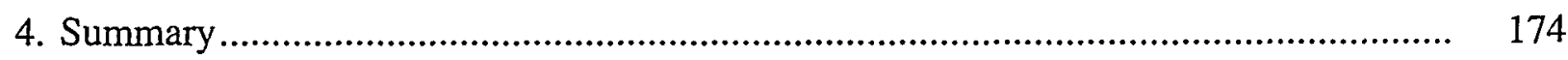

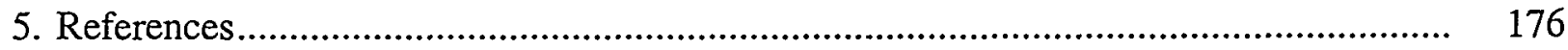




\section{LIST OF TABLES}

$\underline{\text { Page }}$

1. Dated volcanic glass samples received from Bishop Museum ................................. 91

2. Test matrices for reactions of natural glasses and high-level waste glasses at $75^{\circ} \mathrm{C}$

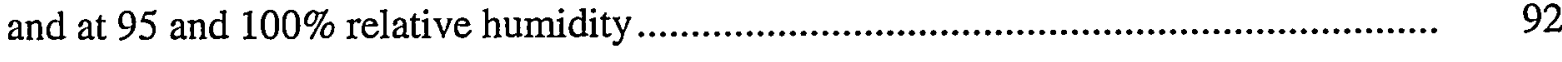

3. Obsidian and basaltic glasses used in hydration experiments ................................... 93

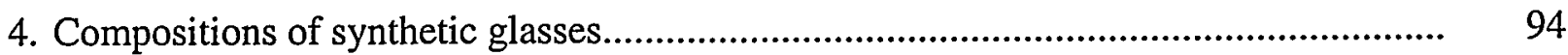

5. Measurements/calibrations to be made in the analysis of reacted glass samples .......... 96

6. The hydration rate derived at various temperatures for Snake River obsidian.............. 98 


\section{LIST OF FIGURES}

Page

1. The growth of birefirengent layers as a function of time and temperature for the Snake River obsidian experimentally hydrated under saturated conditions

2. Arrhenius plot for Snake River obsidian experimentally hydrated at various temperatures under saturated conditions

3. The growth of birefirengent layers as a function of time for a Snake River obsidian experimentally hydrated in an unsaturated vapor atmosphere

4. Hawaiian basaltic glass enclosed by a palagonite shell and with part of the palagonite layer peeled off to show the pitted surface underneath

5. Scanning electron micrograph of surface pits under palagonite layer

6. Typical XRD pattern for the palagonite that formed on the surfaces of the Hawaiian basaltic glass

7. An SEM cross-sectional view of palagonite on surface 103

8. Backscattered electron of palagonite formation along a fracture and X-ray map of the major elements in that area.

9. Typical TEM image of the palagonite layer showing the mixture of multiphases 105

10. TEM image of hemispherical geothite particles. 105

11. Transmission electron micrographs of a large geothite crystal and hemispherical geothite particles

12. Layered scarbroite phase: TEM image and high-resolution TEM image showing the lattice fringes of the scarbroite

13. Kaolinite phase: TEM image and high-resolution TEM image

14. Smectite clay phase: TEM image and electron diffraction pattern and highresolution TEM image of the lattice fringes of the smectite clay phase.

15. High-resolution TEM image and electron diffraction pattern (inset) of phase rich in $\mathrm{Fe}, \mathrm{Ca}, \mathrm{Si}$, and $\mathrm{Mg}$. 


\section{LIST OF FIGURES (Contd.)}

Page

16. Optical microscopy images of the synthetic basalt glass vapor reacted at $75^{\circ} \mathrm{C}$ and $95 \% \mathrm{RH}$ for seven years

17. Scanning electron micrograph of the surface of the synthetic basalt glass vapor reacted at $75^{\circ} \mathrm{C}$ in $95 \% \mathrm{RH}$ for seven years, and EDS spectrum of the particle precipitated on the surface.

18. Cross-sectional SEM image of the synthetic basalt glass vapor reacted at $75^{\circ} \mathrm{C}$ in $95 \% \mathrm{RH}$ for seven years, TEM images of the layer/glass interface showing smooth interface and etching pits, and EDS spectra comparing the compositions of the layer and unreacted glass

19. Optical microscopy images of the synthetic basalt glass vapor reacted at $75^{\circ} \mathrm{C}$ and 95\% RH for nine years

20. SEM images of the surface of the synthetic basalt glass vapor reacted at $75^{\circ} \mathrm{C}$ in in $95 \% \mathrm{RH}$ for nine years.

21. An EDS spectrum of the nubby features shown in SEM images of synthetic basalt glass vapor reacted at $75^{\circ} \mathrm{C}$ and $95 \% \mathrm{RH}$ for nine years

22. An SEM image of precipitates on the surface of the synthetic basalt glass that was vapor reacted at $75^{\circ} \mathrm{C}$ and $95 \% \mathrm{RH}$ for nine years and EDS spectrum of the precipitate.

23. Cross-sectional SEM image of the layer formed on the glass surface of the synthetic basalt glass vapor reacted at $75^{\circ} \mathrm{C}$ and $95 \% \mathrm{RH}$ for nine years.

24. Analyses of cross-sectioned block 1579

25. Optical microscopy images of the synthetic basalt glass vapor reacted at $75^{\circ} \mathrm{C}$ and $100 \% \mathrm{RH}$ for seven years.

26. Scanning electron micrographs of the surface of the synthetic basalt glass vapor reacted at $75^{\circ} \mathrm{C}$ in $100 \% \mathrm{RH}$ for seven years.

27. Cross-sectional TEM image of the layer formed on the glass surface of synthetic basalt glass vapor reacted at $75^{\circ} \mathrm{C}$ and $100 \% \mathrm{RH}$ for seven years and the EDS spectra comparing the alteration layer and unreacted glass 


\section{LIST OF FIGURES (Contd.)}

Page

28. Optical microscopy images of the SRL 165 waste glass vapor reacted at $75^{\circ} \mathrm{C}$ and 95\% RH for seven years

29. An SEM image of the layer formed on the surface of the SRL 165 glass vapor reacted at $75^{\circ} \mathrm{C}$ in $95 \% \mathrm{RH}$ for seven years and its EDS spectrum

30. Cross-sectional SEM image of the limited layer formed on the surface of the SRL 165 glass vapor reacted at $75^{\circ} \mathrm{C}$ in $95 \% \mathrm{RH}$ for seven years and a TEM image of the sectional sample

31. Analyses of crystalline precipitates, saponite clay, and the amorphous matrix on SRL 165 glass vapor reacted at $75^{\circ} \mathrm{C}$ and $95 \%$ RH for seven years

32. Optical microscopy images of the SRL 165 waste glass vapor reacted at $75^{\circ} \mathrm{C}$ and $95 \% \mathrm{RH}$ for nine years.

33. Scanning electron micrographs of the surface of the SRL 165 glass vapor reacted at $75^{\circ} \mathrm{C}$ and $95 \% \mathrm{RH}$ for nine years showing the layer formed and the glass underneath the layer having many etched pits....

34. Cross-sectional SEM image of the layer formed on the surface of the SRL 165 glass vapor reacted at $75^{\circ} \mathrm{C}$ and $95 \% \mathrm{RH}$ for nine years, TEM image of the sectioned sample, and EDS spectra comparing the amorphous zone and the clay

35. Optical images of the SRL 165 waste glass vapor reacted at $75^{\circ} \mathrm{C}$ and $100 \% \mathrm{RH}$ for seven years

36. An SEM image of the surface of the SRL 165 waste glass vapor reacted at $75^{\circ} \mathrm{C}$ and $100 \% \mathrm{RH}$ for seven years and a cross-sectional SEM image of the surface sowing no apparent layer formation

37. Transmission electron micrograph of clay layer that formed on the SRL 165 glass vapor reacted at $75^{\circ} \mathrm{C}$ and $100 \% \mathrm{RH}$ for seven years and EDS spectra comparing the layer and the glass.

38. Optical images of the SRL 131 waste glass vapor reacted at $75^{\circ} \mathrm{C}$ and $95 \% \mathrm{RH}$ for seven years

39. Formation of precipitates on surface of SRL 131 


\section{LIST OF FIGURES (Contd.)}

40. Cross-sectional SEM image of the thick layer formed on the surface of the SRL 131 waste glass vapor reacted at $75^{\circ} \mathrm{C}$ and $95 \% \mathrm{RH}$ for seven years and its EDS spectrum.

41. Optical images of the SRL 131 waste glass vapor reacted at $75^{\circ} \mathrm{C}$ in $95 \% \mathrm{RH}$ for nine years taken at (a) $6 \mathrm{X}$ and (b) $50 \mathrm{X}$.

42. An SEM image of the precipitates on the surface of the SRL 131 waste glass vapor reacted at $75^{\circ} \mathrm{C}$ and $95 \% \mathrm{RH}$ for nine years and their EDS spectrum

43. Cross-sectional SEM image of the layer formed on the surface of the SRL 131 glass vapor reacted at $75^{\circ} \mathrm{C}$ and $95 \% \mathrm{RH}$ for nine years.

44. Results of AEM examination of layer formed on SRL 131 waste glass vapor reacted at $75^{\circ} \mathrm{C}$ and $95 \% \mathrm{RH}$ for nine years

45. Results of AEM examination of crystalline particle formed on SRL 131 waste glass vapor reacted at $75^{\circ} \mathrm{C}$ and $95 \% \mathrm{RH}$ for nine years

46. Optical images of the SRL 165 waste glass vapor reacted at $75^{\circ} \mathrm{C}$ and $100 \% \mathrm{RH}$ for seven years.

47. Surface of the SRL 131 glass vapor reacted at $75^{\circ} \mathrm{C}$ and $100 \% \mathrm{RH}$ for seven years ...

48. Analyses of block 1722

49. Analysis of the sectioned particle.

50. Optical images of the PNL $76-68$ waste glass vapor reacted at $75^{\circ} \mathrm{C}$ at $95 \% \mathrm{RH}$ for seven years

51. Scanning electron micrographs of the layer formed on the surface of the PNL 76-68 glass vapor reacted at $75^{\circ} \mathrm{C}$ in $95 \% \mathrm{RH}$ for seven years

52. An EDS spectrum of the alteration layer formed on PNL 76-68 glass vapor reacted at $75^{\circ} \mathrm{C}$ and $95 \% \mathrm{RH}$ for seven years

53. Results of AEM analysis of sample from surface of PNL 76-68 waste glass vapor reacted at $75^{\circ} \mathrm{C}$ and $95 \% \mathrm{RH}$ for seven years 


\section{LIST OF FIGURES (Contd.)}

54. Results of AEM analysis of white particle with black inclusion from surface of PNL $76-68$ waste glass vapor reacted at $75^{\circ} \mathrm{C}$ and $95 \% \mathrm{RH}$ for seven years

55. Results of AEM analysis of red particle from surface of PNL 76-68 waste glass vapor reacted at $75^{\circ} \mathrm{C}$ and $95 \% \mathrm{RH}$ for seven years

56. Optical microscopy images of the PNL 76-68 waste glass vapor reacted at $75^{\circ} \mathrm{C}$ in $95 \%$ $\mathrm{RH}$ for nine years

57. Layer formed on the surface of the PNL 76-68 glass vapor reacted at $75^{\circ} \mathrm{C}$ in $95 \%$ $\mathrm{RH}$ for nine years

58. Cross-sectional and high magnification cross-sectional SEM images of the alteration layer formed on the surface of the PNL 76-68 glass reacted at $75^{\circ} \mathrm{C}$ in $95 \% \mathrm{RH}$ for nine years and the EDS spectrum of the alteration layer.

59. Analysis by AEM

60. Analysis by AEM of white precipitate from surface of PNL 76-68 waste glass vapor reacted at $75^{\circ} \mathrm{C}$ and $95 \% \mathrm{RH}$ for nine years

61. Optical microscopy images of the PNL 76-68 waste glass vapor reacted at $75^{\circ} \mathrm{C}$ in $100 \% \mathrm{RH}$ for seven years

62. An SEM image of the alteration layer formed on the surface of the PNL 76-68 glass vapor reacted at $75^{\circ} \mathrm{C}$ and $100 \% \mathrm{RH}$ for seven years

63. An EDS spectrum of the white precipitate from the surface of the PNL 76-68 waste glass vapor reacted at $75^{\circ} \mathrm{C}$ for seven years

64. Cross-sectional SEM image of the alteration layer formed on the surface of the PNL 76-68 waste glass vapor reacted at $75^{\circ} \mathrm{C}$ and $100 \% \mathrm{RH}$ for seven years and its EDS spectrum.

65. Analysis by AEM of sample from surface of PNL 76-68 waste glass vapor reacted at $75^{\circ} \mathrm{C}$ and $100 \% \mathrm{RH}$ for seven years

66. Analysis by AEM of particle from surface of PNL 76-68 waste glass vapor reacted at $75^{\circ} \mathrm{C}$ and $100 \%$ RH for seven years 


\section{INTRODUCTION}

The purpose of this work was to elucidate the long-term corrosion behavior of natural glasses and to evaluate the effectiveness of laboratory test methods in reproducing the reactions of glass in nature. These goals can be generally achieved through (1) establishing the reaction kinetics both in nature and under the accelerating laboratory conditions for natural glasses (primarily obsidian), (2) establishing the nature of glass alteration and secondary-phase formation that occur in nature over long periods of time and in accelerated environments (primarily basalt glasses), and (3) determining whether accelerating techniques alter the fundamental mechanisms of glass reaction by comparing the results obtained in natural environments and in accelerating laboratory environments. Further comparisons are made between reaction processes of basaltic glasses and synthetic waste glasses based on the reaction kinetics and the composition of the alteration phases. The goal of this study is to determine whether (1) the long-term alteration products formed by natural processes can be reproduced by laboratory experiments and (2) the experimental method developed to simulate naturally occurring alteration can produce similar reactions in waste glass. These investigations allow the reaction kinetic models, whose development is based on short-term experiments, to be applied to the calculation of long-term corrosion of waste glass with more confidence.

The reaction of obsidian glass and water results in the formation of an alteration product called perlite, which contains $2-5 \mathrm{wt} \%$ water and has a composition similar to the parent obsidian. Perlite is formed as a result of atmospheric molecular water diffusing into the silicate framework of the obsidian. The kinetics of perlite growth has been described as constant versus the square root of time at conditions encountered by natural obsidians and has been found to be identical for obsidians reacted in a vapor atmosphere at high temperatures in laboratory experiments. Previously, the effect of relative humidity $(\mathrm{RH})$ on obsidian hydration was assumed to be negligible [FRIEDMAN-1984]. However, recent experiments performed on borosilicate glasses suggest that at elevated temperatures, the effect of relative humidity may be significant [ABRAJANO-1989; YAPER-1931; STANWORTH-1950]. Here we provide supporting evidence that the same hydration processes observed at elevated temperatures occur at lower temperatures. Furthermore, we will clarify the previously observed effect of relative humidity at lower temperatures.

Basalt glass, which has a range of compositions similar to one of the selected waste form borosilicate glasses, reacts with water in nature to form an amorphous, gel-like alteration phase called palagonite and various assemblages of secondary minerals [JERCINOVIC-1987; BYERS-1987]. Similar alteration assemblages have been produced in laboratory tests under a wide variety of experimental conditions at high temperatures [BYERS-1987, ABRAJANO-1989]. The processes by which basalt glass hydrates are disputed, although they certainly include molecular water diffusion, dealkalization, network hydrolysis, and network dissolution [ABRAJANO-1989, CROVISIER-1987]. The reaction kinetics of basalt glass in vapor tests has been reported both as diffusion controlled and as a linear function of time [DIEBOLD-1986; ABRAJANO-1989]. In this study, we examined the natural alteration of a Hawaiian basaltic glass and conducted laboratory vapor hydration tests with a synthetic basalt glass that has a composition similar to its natural counterpart. The alteration products generated during long-term corrosion of natural glasses are compared to those generated in accelerated laboratory tests and to those previously observed in high-temperature experiments. The effects of relative humidity on the assemblage of alteration products are also examined. These results indicate whether the vapor hydration tests accelerate the reaction without altering the fundamental reaction processes. However, the reaction kinetics, equally indicative of corrosion mechanism, was not addressed in this work because of limited data points for both natural and synthetic glasses and because of the unavailability of solution data. 
The compositions of high-level waste (HLW) glasses are similar to those of the basalt glass. Therefore, basalt glasses can be regarded as natural analogues for nuclear waste glasses for the purpose of studying long-term reaction mechanisms. In many cases, alteration processes associated with natural glasses occurring over a wide range of conditions also occur with HLW glasses in the laboratory under accelerated conditions [ABRJANO-1989]. Nevertheless, questions still remain regarding the effects of glass composition and of various environmental parameters, especially temperature and humidity. Here, we present the results of new experiments that characterize the alteration products of four different types of HLW glasses that have been reacted in water vapor at a relatively low temperature $\left(75^{\circ} \mathrm{C}\right)$ for up to nine years. The alteration behavior of $\mathrm{HLW}$ is compared to that of basaltic glasses and to that previously observed in the experiments conducted at high temperatures. These results are then synthesized and can be used to verify whether laboratory vapor hydration test methods can be employed to effectively reproduce and project the long-term reaction of HLW glass under similar conditions. 


\section{EXPERIMENTAL}

\subsection{Sample Selection}

Samples that have been experimentally reacted in our laboratory include natural glasses classified as obsidian, synthetic basalt, and selected high-level waste glasses Savannah River Laboratory (SRL) 131 and 165 and Pacific Northwest Laboratory (PNL) 76-68). For comparison naturally reacted basalt samples received from the Bishop Museum in Hawaii were also examined.

Samples were identified with existing sample numbers that are unique for each sample. Laboratory- reacted samples are uniquely identified as follows:

\section{$\mathrm{XXX}(\mathrm{X})-\mathrm{XX}(\mathrm{X}) \mathrm{RH}$}

The first three or four characters identify the type of glass: SRL 131 and 165 glasses are prefixed as 131- and 165-, PNL 76-68 glass as 7668-, basalt as BAS, and obsidian as OBS-. The characters after the hyphen represent the relative humidity (e.g., $95 \mathrm{RH}$ for 95\% relative humidity). Table 1 lists the naturally reacted basaltic samples received from the Bishop Museum in Hawaii. Table 2 lists all the laboratory-reacted samples and their testing conditions including sample numbers, relative humidity, and test duration.

Table 1. Dated volcanic glass samples received from Bishop Museum

\begin{tabular}{|c|c|c|}
\hline Bishop Sample No. & ANL sample No. & $\mathrm{C}^{14}$ Date \\
\hline 50-OA-G5-101-TP7-1-769 & NBG-1 & Between $720 \pm 80$ and $750 \pm 80 \mathrm{BP}$ \\
\hline 50-OA-G5-101-TP7-1-770 & NBG-2 & Between $720 \pm 80$ and $750 \pm 80 \mathrm{BP}$ \\
\hline 50-OA-G5-101-TP7-1-777 & NBG-3 & Between $720 \pm 80$ and $750 \pm 80 \mathrm{BP}$ \\
\hline 50-OA-G6-17-TP3-57 & NBG-4 & $480 \pm 80 \mathrm{BP}$ \\
\hline 50-OA-G6-17-TP3-58 & NBG-5 & $480 \pm 80 \mathrm{BP}$ \\
\hline 50-OA-G6-17-TP3-125 & NBG-6 & $480 \pm 80 \mathrm{BP}$ \\
\hline 50-OA-G6-17-TP3-126 & NBG-7 & $480 \pm 80 \mathrm{BP}$ \\
\hline 50-OA-G6-17-TP3-137 & NBG-8 & $480 \pm 80 \mathrm{BP}$ \\
\hline 50-OA-G6-17-TP3-138 & NBG-9 & $480 \pm 80 \mathrm{BP}$ \\
\hline 50-OA-G6-17-TP3-139 & NBG-10 & $480 \pm 80 \mathrm{BP}$ \\
\hline
\end{tabular}


Table 2. Test matrices for reactions of natural glasses and high-level waste glasses at $75^{\circ} \mathrm{C}$ and at 95 and $100 \%$ relative humidity

\begin{tabular}{cccccccc}
\hline Glass & Test Type & $\begin{array}{c}\text { Vessel } \\
\text { No. }\end{array}$ & $\begin{array}{c}\text { Sample } \\
\text { ID }\end{array}$ & $\begin{array}{c}\text { Duration, } \\
\text { days }\end{array}$ & \%H & Date In & Date Out \\
\hline Obsidian & OBS-95RH & 193 & V193 & 2672 & 95 & $7 / 27 / 88$ & $12 / 21 / 95$ \\
Obsidian & OBS-95RH & 118 & V118 & 3367 & 95 & $10 / 3 / 86$ & $12 / 21 / 95$ \\
Obsidian & OBS-100RH & 165 & V195 & 2575 & 100 & $9 / 2 / 88$ & $11 / 20 / 95$ \\
& & & & & & & \\
Basalt & BAS-95RH & 183 & V183 & 2672 & 95 & $7 / 27 / 88$ & $12 / 21 / 95$ \\
Basalt & BAS-95RH & 122 & V122 & 3367 & 95 & $10 / 3 / 86$ & $12 / 21 / 95$ \\
Basalt & BAS-100RH & 163 & V163 & 2575 & 100 & $9 / 2 / 88$ & $11 / 20 / 95$ \\
& & & & & & & \\
SRL131 & $131-95 R H$ & 164 & V164 & 2672 & 95 & $7 / 27 / 88$ & $12 / 21 / 95$ \\
SRL131 & 131-95RH & 110 & V110 & 3367 & 95 & $10 / 3 / 86$ & $12 / 21 / 95$ \\
SRL131 & $131-100 R H$ & 159 & V159 & 2575 & 100 & $9 / 2 / 88$ & $11 / 20 / 95$ \\
& & & & & & & \\
SRL165 & 165-95RH & 153 & V153 & 2672 & 95 & $7 / 27 / 88$ & $12 / 21 / 95$ \\
SRL165 & 165-95RH & 106 & V106 & 3367 & 95 & $10 / 3 / 86$ & $12 / 21 / 95$ \\
SRL165 & $165-100 R H$ & 158 & V158 & 2575 & 100 & $9 / 2 / 88$ & $11 / 20 / 95$ \\
& & & & & & & \\
PNNL-7668 & $165-95 R H$ & 173 & V173 & 2672 & 95 & $7 / 27 / 88$ & $12 / 21 / 95$ \\
PNNL-7668 & $165-95 R H$ & 114 & V114 & 3367 & 95 & $10 / 3 / 86$ & $12 / 21 / 95$ \\
PNNL-7668 & $7668-100 R H$ & 161 & V161 & 2575 & 100 & $9 / 2 / 88$ & $11 / 20 / 95$ \\
\hline
\end{tabular}

\subsubsection{Obsidian}

Obsidian samples were collected from the Coso field in California. All samples were collected from the same flow at the field in order to ensure that identical materials were being used in experiments. The composition of Coso obsidian was previously determined with X-ray fluorescence (XRF) and is listed in Table 3.

To prepare glass for use in vapor hydration experiments, pieces of the obsidian were core drilled. Fresh, unhydrated core sections were selected and sliced into discs approximately $1 \mathrm{~mm}$ thick. The disc faces were polished first with 600 -grit Carborundum paper, using water as lubricant, then with 6 - and $1-\mu \mathrm{m}$ diamond pastes using an oil lubricant to achieve the final finish. The experiments were generally started on the same day the glass discs were prepared to minimize the effects of atmospheric interaction. 
Table 3. Obsidian and basaltic glasses used in hydration experiments

\begin{tabular}{lccc}
\hline Component & $\begin{array}{c}\text { Snake River } \\
\text { Obsidian }\end{array}$ & $\begin{array}{c}\text { Hawaiian } \\
\text { Basalt }\end{array}$ & $\begin{array}{c}\text { Synthetic } \\
\text { Basalt }\end{array}$ \\
\hline $\mathrm{SiO}_{2}$ & 74.94 & 48.99 & 52.0 \\
$\mathrm{Al}_{2} \mathrm{O}_{3}$ & 14.20 & 13.72 & 12.7 \\
$\mathrm{Na}_{2} \mathrm{O}$ & 4.67 & 2.68 & 3.8 \\
$\mathrm{~K}_{2} \mathrm{O}$ & 4.59 & 0.48 & 0.60 \\
$\mathrm{CaO}$ & 0.53 & 9.22 & 10.7 \\
$\mathrm{MgO}$ & 0.02 & 6.37 & 6.2 \\
$\mathrm{MnO}$ & 0.03 & 0.15 & \\
$\mathrm{MnO}_{2}$ & -- & --.20 & 0.20 \\
$\mathrm{Fe}_{2} \mathrm{O}_{3}$ & 0.96 & 11.35 & 12.7 \\
$\mathrm{TiO}_{2}$ & 0.04 & 1.95 & 1.7 \\
$\mathrm{Cu}_{\mathrm{Zn}}$ & 153.0 & & \\
$\mathrm{Rb}$ & 47.0 & & \\
$\mathrm{Sr}$ & 198.0 & & \\
$\mathrm{Y}$ & 17.0 & & \\
$\mathrm{Nb}$ & 9.0 & & \\
$\mathrm{~Pb}$ & 23.0 & & \\
$\mathrm{Zr}$ & 35.0 & & \\
$\mathrm{Ba}$ & 57.0 & & \\
$\mathrm{H}_{2} \mathrm{O}$ & - & & \\
& 0.87 & & \\
\hline
\end{tabular}

\subsubsection{Basaltic Glasses}

\subsubsection{Hawaiian Basaltic Glass}

Ten samples of volcanic basaltic glass were collected by the Bishop Museum staff from two archaeological sites in Oahu, Hawaii (see Table 1). These samples came from 5 to $85 \mathrm{~cm}$ below ground level in generally wet and cool environments. Although the exact humidity and temperature values for the Hawaiian samples are not known, the relative humidity has been reported to be close to $100 \%$ in most soil environments [FRIEDMAN-1994]. The samples range in ages from 480 to $720 \pm 80$ years, according to radiocarbon dating of the occupation layer of charcoal. The glasses have been altered in nature by meteoric water and water vapor. The palagonite layer that formed on the surface was typically yellowish. There are areas on the samples where the layer has spalled off and the glass surface beneath the layer can clearly be seen, showing heavily etched pits. Two glass samples whose layers had completely spalled off were analyzed with inductively coupled plasma/atomic emission spectroscopy (ICP/AES) and their compositions are listed in Table 3.

\subsubsection{Synthetic Basaltic Glass}

The composition of the synthetic basalt used in the laboratory tests was modeled after a Hawaiian alkali basalt glass, whose composition is also listed in Table 3 . The glass was made by melting appropriate amounts of reagentgrade oxides and carbonates at $1600^{\circ} \mathrm{C}$, quenching and homogenizing the resulting frit, remelting, and annealing the final product at $550^{\circ} \mathrm{C}$ for about two hours. 


\subsubsection{High-Level Waste Glasses}

Experiments were conducted on two HLW glasses, Savannah SRL 131 and SRL 165 and Pacific Northwest Laboratory (PNL) 76-68 (provided by SRL and PNL, respectively). Their compositions are listed in Table 4. Glasses 131 and 76-68 are early formulations and are relatively silicon poor, while 165 is a more recent formulation in which the amount of silicon has been increased to improve its durability.

Table 4. Compositions of synthetic glasses*

\begin{tabular}{cccc}
\hline & \multicolumn{3}{c}{ Glass Type and Composition, oxide wt\% } \\
\cline { 2 - 4 } Oxide & SRL 131 & SRL 165 & PNL 76-68 \\
\hline & 3.8 & 4.3 & 0.6 \\
$\mathrm{Al}_{2} \mathrm{O}_{3}$ & 10.9 & 6.8 & 9.1 \\
$\mathrm{~B}_{2} \mathrm{O}_{3}$ & 1.4 & 1.6 & 2.2 \\
$\mathrm{CaO}$ & 14.3 & 11.7 & 8.7 \\
$\mathrm{Fe}_{2} \mathrm{O}_{3}$ & -- & 0.2 & 0.7 \\
$\mathrm{~K}_{2} \mathrm{O}$ & 4.2 & 4.8 & -- \\
$\mathrm{Li}_{2} \mathrm{O}$ & 1.6 & 0.6 & 0.2 \\
$\mathrm{MgO}$ & 3.1 & 2.8 & -- \\
$\mathrm{MnO}$ & 13.7 & 10.8 & 10.5 \\
$\mathrm{Na}_{2} \mathrm{O}$ & 1.8 & 0.8 & 0.2 \\
$\mathrm{NiO}$ & 44 & 51.6 & 41.2 \\
$\mathrm{SiO}$ & 0.7 & 0.2 & 2.8 \\
$\mathrm{TiO}$ & 0.4 & 0.7 & 1.5 \\
$\mathrm{ZrO}$ & & & 22.3 \\
& 0.4 & 3.1 & \\
Other & & &
\end{tabular}

*Ref. [ABRAJANO-1989].

\subsection{Experimental Reaction Conditions}

Tests were conducted on the synthetic basaltic glass and the selected nuclear waste glasses. To prepare the test samples, wafers were cut approximately $1 \mathrm{~cm}$ in diameter and $1 \mathrm{~mm}$ thick. The faces were polished with 600-grit Carborundum paper, then by diamond pastes of 6 to $1 \mu \mathrm{m}$ with silicon oil as a lubricant. Test were then conducted under both saturated $(100 \% \mathrm{RH})$ and unsaturated $(95 \% \mathrm{RH})$ vapor conditions.

For saturated tests, each thoroughly cleaned sample was suspended with a Teflon thread from a type 304L stainless steel support bar in the test vessel, to which enough water had been added to ensure saturated humidity conditions. Each vessel was tightly sealed to prevent water loss, weighted, and placed in the appropriate oven. The sample run was terminated by removing the reaction vessel from the oven, allowing it to cool for about 15 minutes at ambient conditions, then cooling it in tap water for 10 minutes. The reaction vessel with its contents was weighted, and then the vessel was opened. After the samples were removed, ad the $\mathrm{pH}$ of the remaining water was taken with $\mathrm{pH}$ Hydrion paper. If the $\mathrm{pH}$ of the water on the bottom of the test vessel was approximately 6 , it was assumed that the samples had not touched the crossbar or sides of the vessel and that water condensed on the surface had not dripped from the sample. 
For unsaturated vapor tests in $95 \% \mathrm{RH}$ at $75^{\circ} \mathrm{C}$, the experiments were performed using a dual oven apparatus in an air-circulating Blue $M$ humidity oven, which consists of two pressure vessels connected by a tube. A supply vessel held the volume of water used to produce vapor at a given pressure within the reaction vessel. Each vessel resided in a separate oven, allowing the temperature and pressure in the reaction vessel to be controlled independently. The samples were placed in a Teflon pan, which was placed inside the reaction vessel. This technique allows us to control the relative humidity to $\pm 2 \%$. The vessels were allowed to heat to the reaction temperatures before stream was introduced into the reaction vessel.

\subsection{Sample Analysis and Characterization}

\subsubsection{Obsidian}

After each experiment, the reacted sample was thin-sectioned and the thickness of the birefringent hydration layer measured. The measurements were done at ASC Group, Inc., by C. M. Steveson. An Aus Jena optical microscope with a 40X objective lens was used to examine $30-\mu \mathrm{m}$-thick sections of each selected sample at a magnification of $1000 \mathrm{X}$. The hydration-layer thickness reported was the average of seven measurements on each sample, with a variation of $\pm 0.2 \mu \mathrm{m}$. All samples were measured by the same operator so that any systematic operator-induced errors would be constant throughout the measurements. The composition of Coso obsidian was previously determined by XRF and is listed in Table 3.

\subsubsection{Basaltic and High-Level Waste Glasses}

The unreacted samples were analyzed by ICP/MS to determine the chemical compositions of the glasses. The reacted solids were analyzed to characterize the alteration of the glass and to identify secondary phases formed during the reaction under different conditions, be means of various techniques, including $\mathrm{x}$-ray diffraction (XRD), optical microscopy, scanning electron microscopy (SEM), and analytical electron microscopy (AEM). Equipment used to analyze and characterize reacted glass samples and their calibration requirements are summarized in Table 5. Equipment is either calibrated periodically or at the time of use, and the calibration status is documented using a Material and Test Equipment sheet (M\&TE), which is a part of the quality assurance (QA) file.

Optical microscopy was used to examine macroscopic appearance of reacted layer formed on the surface and to determine the uniformity of the corrosion reaction. Scanning electron microscopy with backscattered electron detection was utilized for locating various secondary phases formed during glass reaction. The reacted alterationlayer thickness was measured quantitatively using optical microscopy and SEM. The Robinson backscattered electron detector has a resolution of \pm 0.2 atomic number units and permits secondary phases to be differentiated in a relatively short period of time. Energy dispersive $\mathrm{x}$-ray spectroscopy (EDS) and wave-length $\mathrm{x}$-ray dispersive spectroscopy (WDS) combined with SEM can detect elements present in various phases and semiquantitatively analyze chemical compositions of each phase. X-ray diffraction was utilized to determine the crystal habits of alteration phases. 
Table 5. Measurements/calibrations to be made in the analysis of reacted glass samples

\begin{tabular}{ccccc}
\hline Measurement & Procedure & Device & $\begin{array}{c}\text { Expected Precision of } \\
\text { Accuracy }\end{array}$ & $\begin{array}{c}\text { Calibration } \\
\text { Frequency/Method }\end{array}$ \\
\hline $\begin{array}{c}\text { Glass sample } \\
\text { mass }\end{array}$ & M\&TE SN* & Balance & $\pm 0.02 \mathrm{~g}$ & $\begin{array}{c}6 \text { mo./to NIST standard } \\
\text { mass. }\end{array}$ \\
$\begin{array}{c}\text { Microscopic } \\
\text { length } \\
\text { (Magnification) }\end{array}$ & M\&TE SN* & $\begin{array}{c}\text { Scanning Electron } \\
\text { Microscope }\end{array}$ & $\pm 5 \%$ to $10 \mathrm{kX}$ & $\begin{array}{c}\text { Biannually/to NIST } \\
\text { magnification standard }\end{array}$ \\
$\begin{array}{c}\text { Microscopic } \\
\text { length }\end{array}$ & M\&TE SN* & $\begin{array}{c}\text { Transmission Electron } \\
\text { Microscope }\end{array}$ & $\pm 20 \%$ to $100 \mathrm{kX}$ & $\begin{array}{c}\text { Annually/to grating } \\
\text { standard }\end{array}$ \\
$\begin{array}{c}\text { Magnification) } \\
\text { X-ray energy }\end{array}$ & M\&TE SN* & $\begin{array}{c}\text { Energy Dispersive } \\
\text { Spectrometer }\end{array}$ & $\pm 0.05 \mathrm{keV}$ & $\begin{array}{c}\text { Biannually/materials } \\
\text { standards vs. literature }\end{array}$ \\
X-ray energy & M\&TE SN* & $\begin{array}{c}\text { Wavelength Dispersive } \\
\text { Spectrometer }\end{array}$ & $\pm 0.05 \mathrm{~nm}$ at $10 \mathrm{~nm}$ & $\begin{array}{c}\text { Before use/to secondary } \\
\text { standards }\end{array}$ \\
Mass (SIMS) & $\begin{array}{c}\text { To be } \\
\text { determined }\end{array}$ & $\begin{array}{c}\text { Secondary Ion Mass } \\
\text { Spectrometer }\end{array}$ & \pm 1 amu & $\begin{array}{c}\text { Before use/to material } \\
\text { standards vs. literature }\end{array}$ \\
\hline *Scheduled calibrations are recorded on Materials and Test Equipment (M\&TE) sheets maintained in the QA \\
file and described in scientific notebook (SN). Calibrations performed prior to measurement are recorded in \\
SN.
\end{tabular}

Analytical electron microscopy combines TEM, EDS, electron energy loss spectroscopy (EELS), selected area electron diffraction (SAED), and convergent beam electron diffraction (CBED) into an extremely powerful tool for investigating inhomogeneous, multi-phased samples because it can handle small inclusions and crystallites at nanometer scale. Reacted samples were studied using AEM to identify and characterize various secondary phases, the general mineralogy of the reacted sample, and interfaces between the glass core and secondary phases as well as between various secondary phase layers. Electron diffraction permits determination of crystal habits of various phases; in combination with EDS and EELS information, semi-quantitative compositions were deduced. 


\section{RESULTS AND DISCUSSION}

\subsection{Obsidian}

\subsubsection{Saturated Vapor Hydration}

A Snake River obsidian sample was removed from the testing vessel after being reacted at $75^{\circ} \mathrm{C}$ and $100 \% \mathrm{RH}$ for seven years. The obsidian sample exhibited a smooth surface: no alteration layer formed. However, a 3.92- $\mu \mathrm{m}$ birefirengent layer was measured with optical microscopy.

To establish whether the behavior of obsidian in our experiment was similar to that previously observed in short-term experiments conducted at high temperatures or $75^{\circ} \mathrm{C}$, we plotted all of the measured thicknesses (see Fig. 1). In the high-temperature experiments, the growth of the hydration layer clearly shows a square root time dependence, which reflects a diffusional rate-controlling reaction mechanism [MAZER1992]. Because of slow hydration at the low temperature, only three data points were obtained and plotted for the experiment conducted at $75^{\circ} \mathrm{C}$. These data also exhibited a $t^{1 / 2}$ dependence, although a little more scattering than the data obtained from high-temperature experiments.

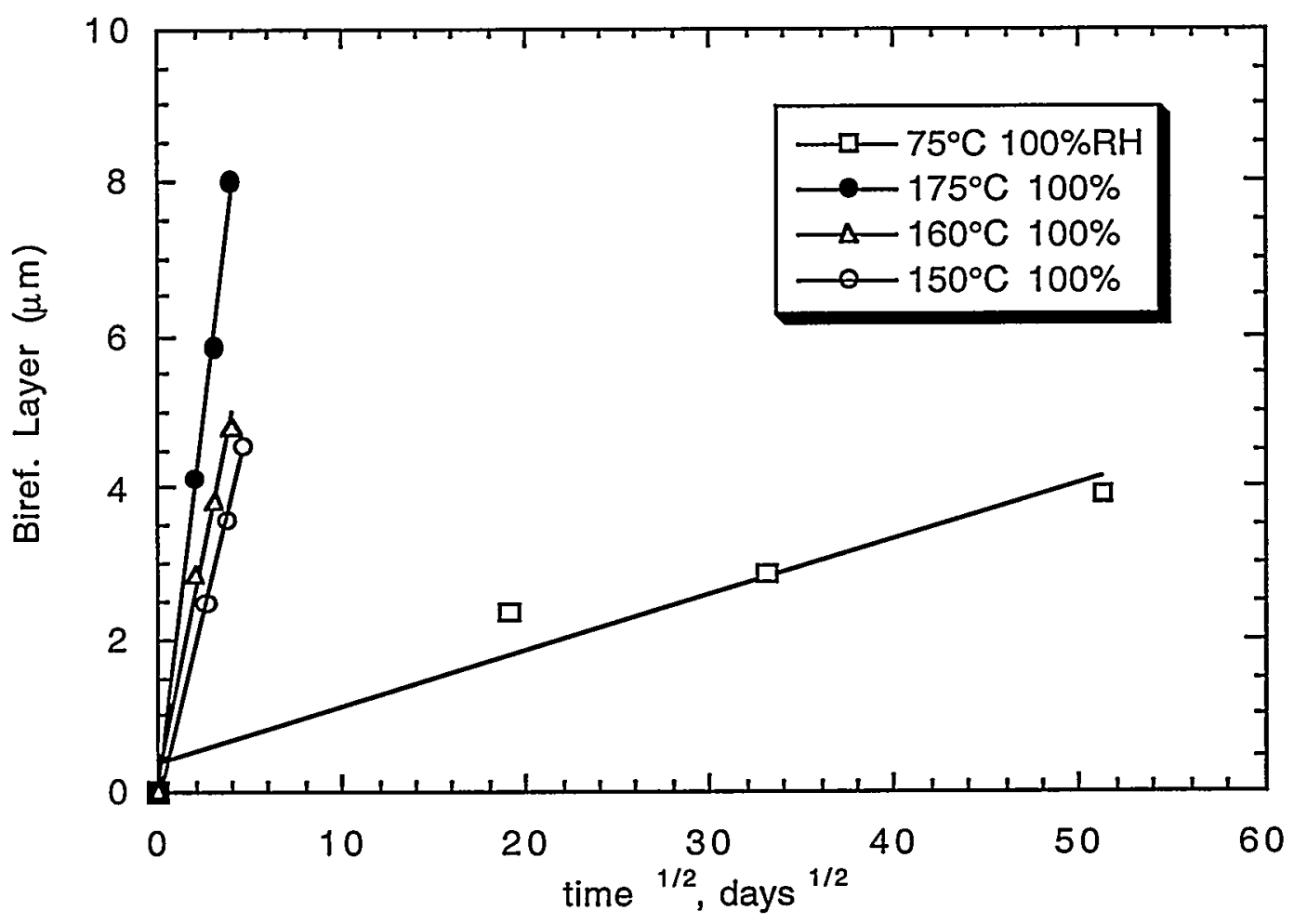

Fig. 1. The growth of birefirengent layers as a function of time and temperature for the Snake River obsidian experimentally hydrated under saturated conditions. 
Linear-regression fits to the hydration-rim measurements were used to derive hydration-rate constants, in units of $\mu \mathrm{m} / \mathrm{d}^{1 / 2}$ (Table 6). The correlation coefficients of each fit were greater than 0.95 . As expected, the hydration rate decreased as the reaction temperature decreased. At $75^{\circ} \mathrm{C}$, the hydration rate was $0.08 \mu \mathrm{m} / \mathrm{d}^{1 / 2}$.

Table 6. The hydration rate derived at various temperatures for Snake River obsidian

\begin{tabular}{cc}
\hline Temperature, ${ }^{\circ} \mathrm{C}$ & Hydration rate constant, $\mu \mathrm{m} / \mathrm{d}^{1 / 2}$ \\
\hline 75 & 0.08 \\
150 & 0.98 \\
160 & 1.20 \\
175 & 1.98 \\
\hline
\end{tabular}

The hydration of obsidian is characterized by an Arrhenius dependence on temperature, based on the hydration experiments conducted at high temperatures [FRIEDMAN-1976; MAZER-1992]. To determine whether the Arrhenius relation is valid at lower temperatures, we plot $\log$ (rate) obtained at each temperature against $1 / T$; the results are shown in Fig. 2. Clearly, the data obtained from the $75^{\circ} \mathrm{C}$ experiment agree well with those extrapolated from high-temperature experiments. These results have immediate implications that we may use accelerated experiments, which are conducted at high temperatures, to produce the results of a hydration that would occur after thousands of years in a natural ambient environment.

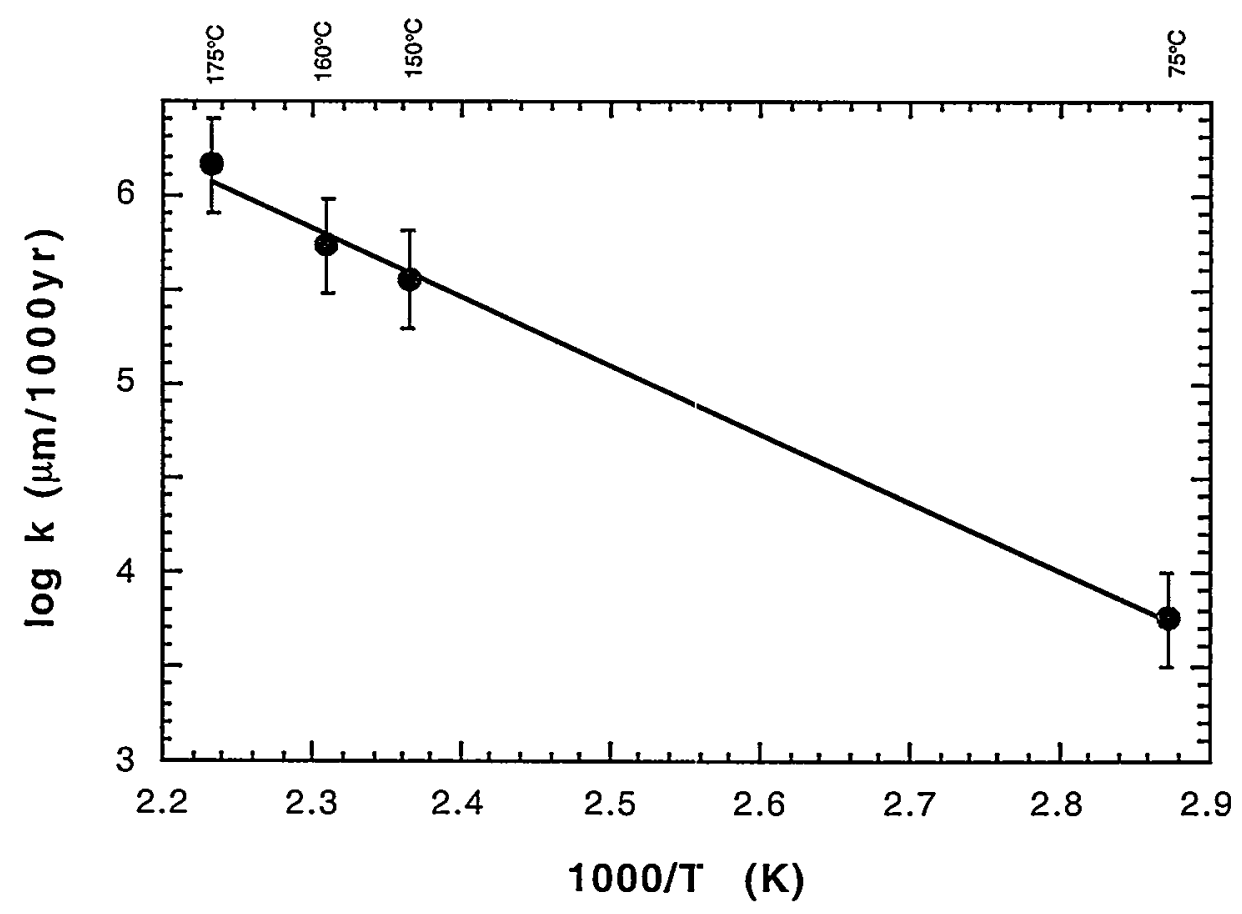

Fig. 2. Arrhenius plot for Snake River obsidian experimentally hydrated at various temperatures under saturated conditions. 


\subsubsection{Unsaturated Vapor Hydration}

Snake River obsidian samples were removed from the test vessel after being reacted in $95 \% \mathrm{RH}$ at $75^{\circ} \mathrm{C}$ for seven and nine years. The samples exhibited smooth surfaces with no formation of an alteration layer. Birefirengent layers of 3.86 and $4.62 \mu \mathrm{m}$ were measured with optical microscopy for samples reacted for seven and nine years, respectively.

Figure 3 plots the relationship between the hydration rim and $t^{1 / 2}$ for Snake River obsidian experimentally hydrated at $75^{\circ} \mathrm{C}$ for seven and nine years, together with the data previously obtained at $75^{\circ} \mathrm{C}$ for shorter periods. The growth of the hydration layer still follows a $t^{1 / 2}$ dependence, which indicates the same diffusional rate-controlling reaction mechanism as that observed in $100 \% \mathrm{RH}$. Interestingly, the hydration-rate derived from linear-regression fits had a value of $0.08 \mu \mathrm{m} / \mathrm{d}^{1 / 2}$, identical to that obtained for $100 \% \mathrm{RH}$, which suggests that the rate is not affected by the $5 \% \mathrm{RH}$ difference. At experiments conducted at high temperatures $\left(150-175^{\circ} \mathrm{C}\right)$, the relative humidity exhibited more pronounced effects on the hydration. The hydration rate (nonlinearly) increased by as much as $25 \%$ between 60 and $100 \% \mathrm{RH}$ with the majority of the rate increase between 90 and $100 \%$ RH [MAZER-1991].

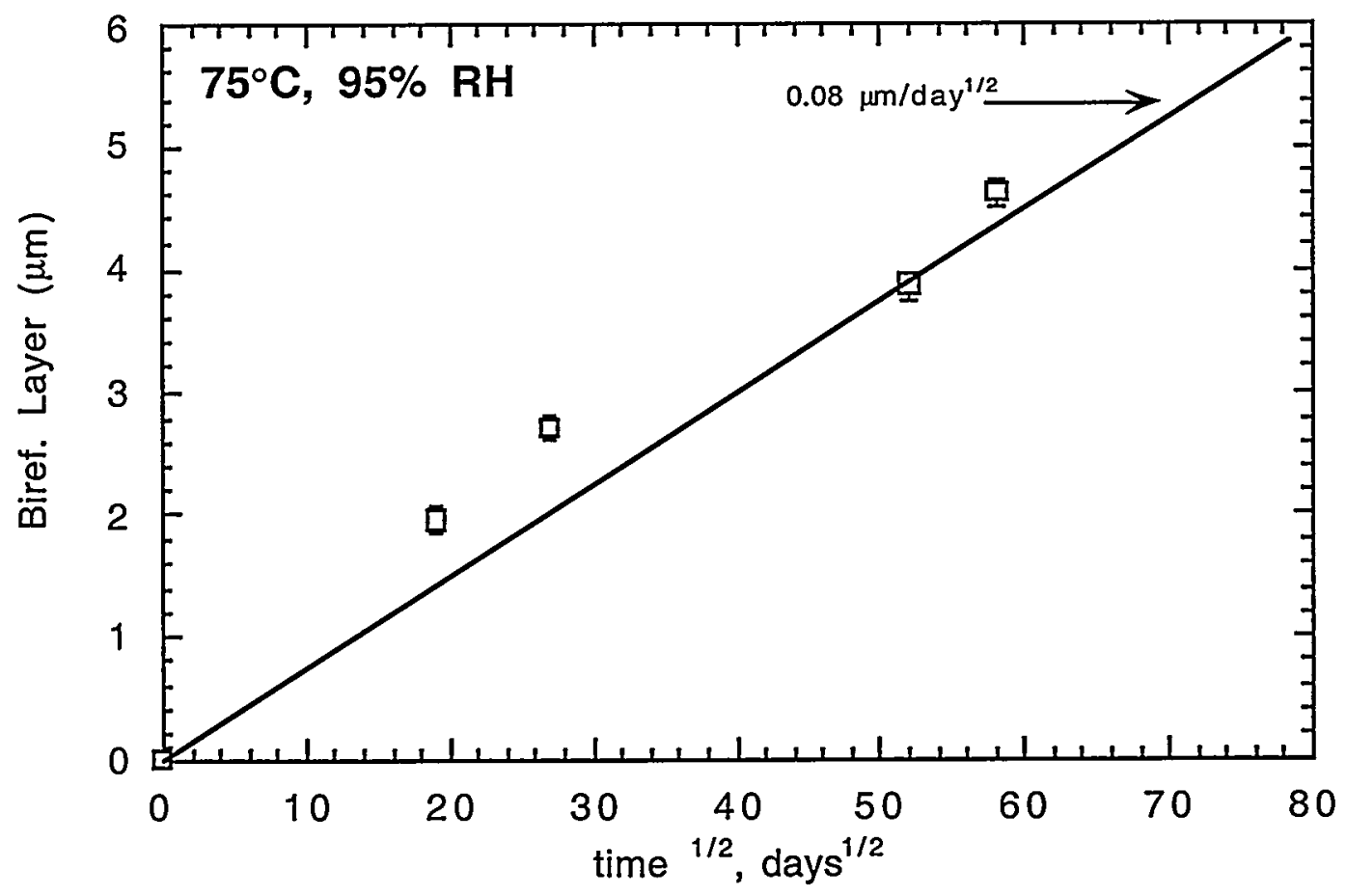

Fig. 3. The growth of birefirengent layers as a function of time for a Snake River obsidian experimentally hydrated in an unsaturated vapor atmosphere. A hydration rate of $0.08 \mu \mathrm{m} / \mathrm{d}^{1 / 2}$ is derived from this plot. 


\subsubsection{Summary of Obsidian Studies}

Snake River obsidian was reacted at $75^{\circ} \mathrm{C}$ at 95 and $100 \% \mathrm{RH}$ and time periods up to seven and nine years. The birefiregent layers were measured, and the results were compared with the previously obtained data for experiments conducted at high temperatures and for short time periods. Under saturated conditions, the hydration rate at $75^{\circ} \mathrm{C}$ follows the same time dependence as those previously observed at higher temperatures and the extrapolations from high-temperature experiments with the Arrhenius relation are in good agreement with the $75^{\circ} \mathrm{C}$ vapor hydration results. Hydration at $95 \%$ $\mathrm{RH}$ exhibits the same reaction kinetics as that at $100 \%$, with a nearly identical rate. These results indicate that hydration at $75^{\circ} \mathrm{C}$ is not very sensitive to the variation in relative humidty, at least in the range of 95 to $100 \%$.

\subsection{Naturally Reacted Hawaiian Basaltic Glass}

\subsubsection{Optical and Scanning Electron Microscopy Analyses}

Ten samples of volcanic glass have been collected from two archaeological sites on windward Oahu, Hawaii. These samples came from 5 to $85 \mathrm{~cm}$ below ground level in generally wet and cool windward environments of the islands. The ages of the samples range from 480 to $720 \pm 80$ years, according the radiocarbon dating for the occupation layer of charcoal (see Table 1). Analysis with EDS indicates that these glasses have the typical composition range of basaltic glasses with $\sim 50 \mathrm{wt} \% \mathrm{SiO}_{2}$, which is consistent with the results of ICP/AES analyses. The glasses are altered by meteoric water and a humid atmosphere.

Optical microscopy reveals similar surface features for all the samples, suggesting that the same reaction processes occur among these samples. These features include the formation of a brown palagonite layer on mat-like surfaces (see Fig. 4). On closer examination of surfaces via SEM, the mat surface was observed to have a high density of etched pits (see Fig. 5), suggesting the dissolution of glass during the reaction with water. X-ray diffraction of the palagonite indicates amorphous nature of the layer, evidenced by the presence of broad peaks (see Fig. 6). It has been noted that the palagonite layer is usually not continuous on surfaces (which allows for the observations of etching pits underneath) and that its coverage of the glass surface differs substantially from sample to sample. It is possible that the palagonite layer of certain samples may have spalled off during repetitive rainfall/dry cycles. This has serious implications in determining the reaction kinetics, because determining the kinetics is generally based on the measurement of the thickness of palagonite layers formed on glass surface. 

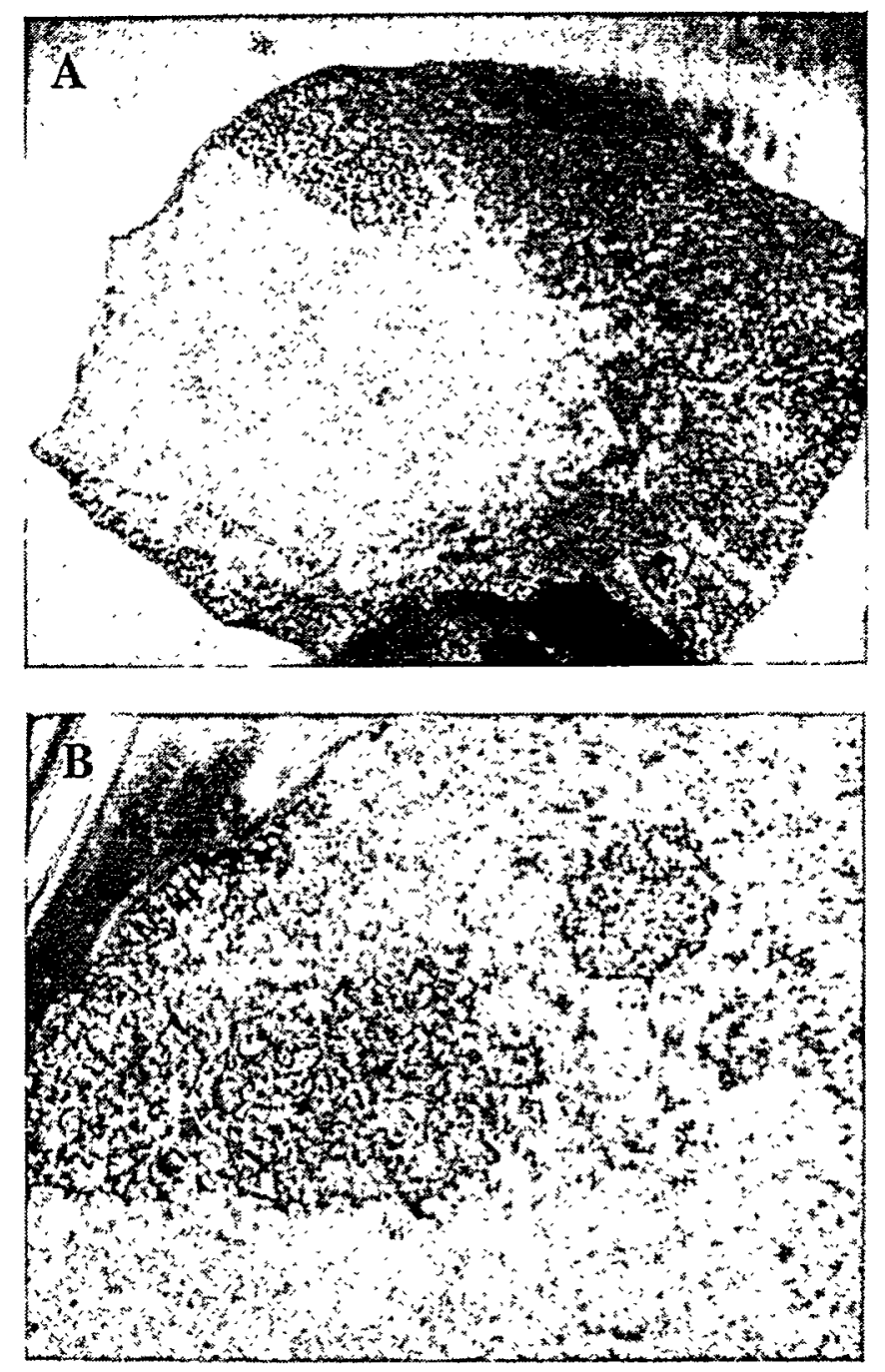

Fig. 4. Hawaiian basaltic glass (a) enclosed by a palagonite shell (b) and with part of the palagonite layer peeled off to show the pitted surface underneath. 


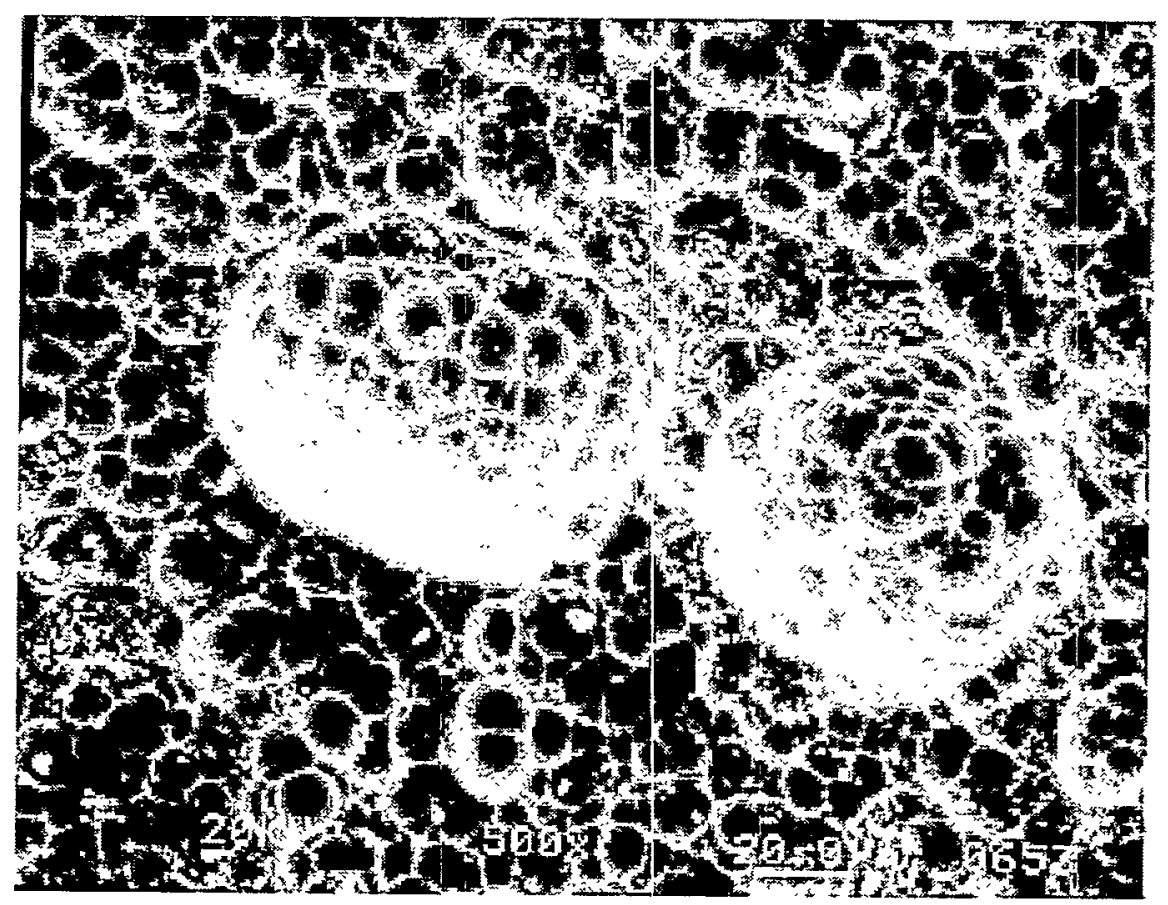

Fig. 5. Scanning electron micrograph of surface pits under palagonite layer.

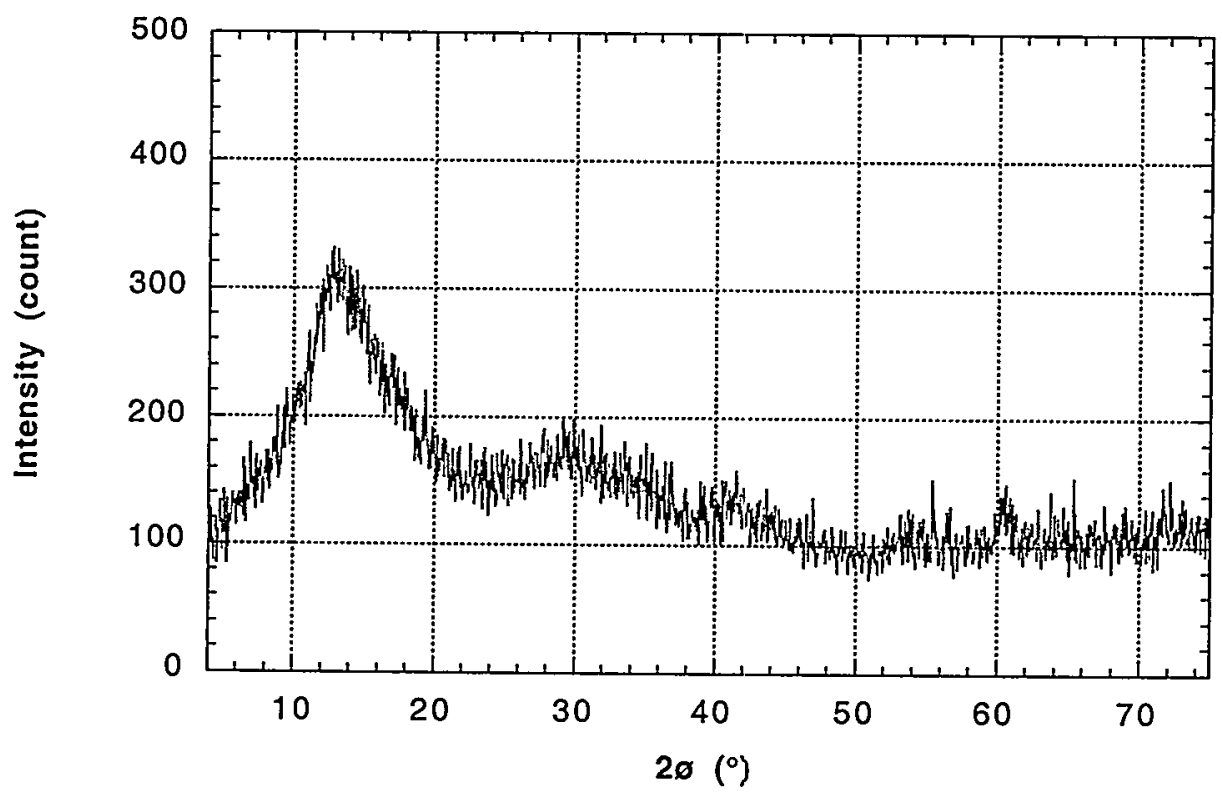

Fig. 6. Typical XRD pattern for the palagonite that formed on the surfaces of the Hawaiian basaltic glass. 
Cross sections of palagonite layers have been examined by SEM.

Palagonite layers formed on glass surfaces are found to consist of an amorphous matrix with various precipitates of (Fe,Ti)-oxides distributed inhomogeneously in the layer (see Fig. 7). The formation of (Fe,Ti)-oxides suggests that a large amount of glass constituents have been dissolved into solution, whereas (Fe,Ti)-oxides precipitate due to limited solubility of $\mathrm{Fe}$ and $\mathrm{Ti}$ in solution. The heterogeneous microstructure shown in Fig. 7 also reflects the variation of environments (flow rate, composition, $\mathrm{pH}$, and temperature of water) during the course of glass alteration. Analyses by EDS of palagonite shows significant depletion on $\mathrm{Na}, \mathrm{Mg}, \mathrm{Ca}$ and enrichment on $\mathrm{Fe}, \mathrm{Ti}$, compared to the unreacted glass core (see Table 6).

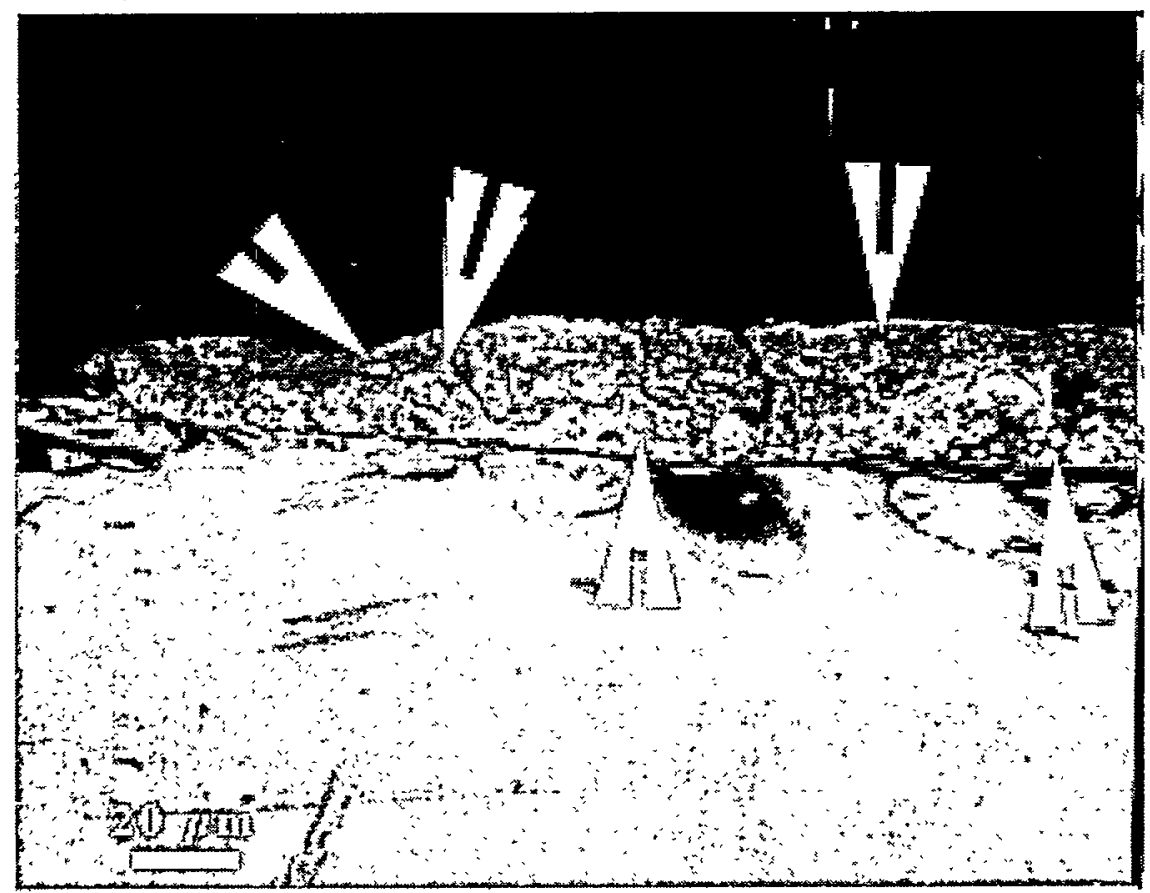

Fig. 7. An SEM cross-sectional view of palagonite on surface. Arrows indicate $(\mathrm{Fe}, \mathrm{Ti})$-oxides.

Interestingly, palagonitization also occurs along fractures of glass. The palagonite formed there shows very different microstructure features under backscattered electron imaging conditions (see Fig. 8a). Typically, palagonite formed along fractures has a sandwich-like microstructure: two outer layers of an amorphous phase plus a central band with well-defined boundaries. The outer layers exhibiting a brighter contrast under backscattered electrons have a higher average atom number than the central band. No precipitation of $(\mathrm{Ti}, \mathrm{Fe}$ )-oxides was observed. X-ray mapping of the major elements for altered areas indicates that $\mathrm{Fe}$ is enriched in outer layers, whereas $\mathrm{Na}$ is depleted in entire altered area (Fig. 8b). The central band apparently consists mainly of $\mathrm{Al}$ and $\mathrm{Si}$, suggesting the formation of zeolites. The formation of zeolites is attributed to the particular environment setting along the fracture where the exchange rate is slow and the solution is rapidly saturated with dissolved species from glass. The apparent reaction rate can be calculated by dividing the thickness of altered layer by the glass age, giving a value of $~ 12$ $\mu \mathrm{m} / \mathrm{y}$, which is in good agreement with the rate observed by Morgenstein 
[MORGENSTEIN-1976]. Unfortunately, fractures were only observed in limited samples during our study and, as a consequence, the statistics on the variation of the apparent reaction rate among samples are unknown.
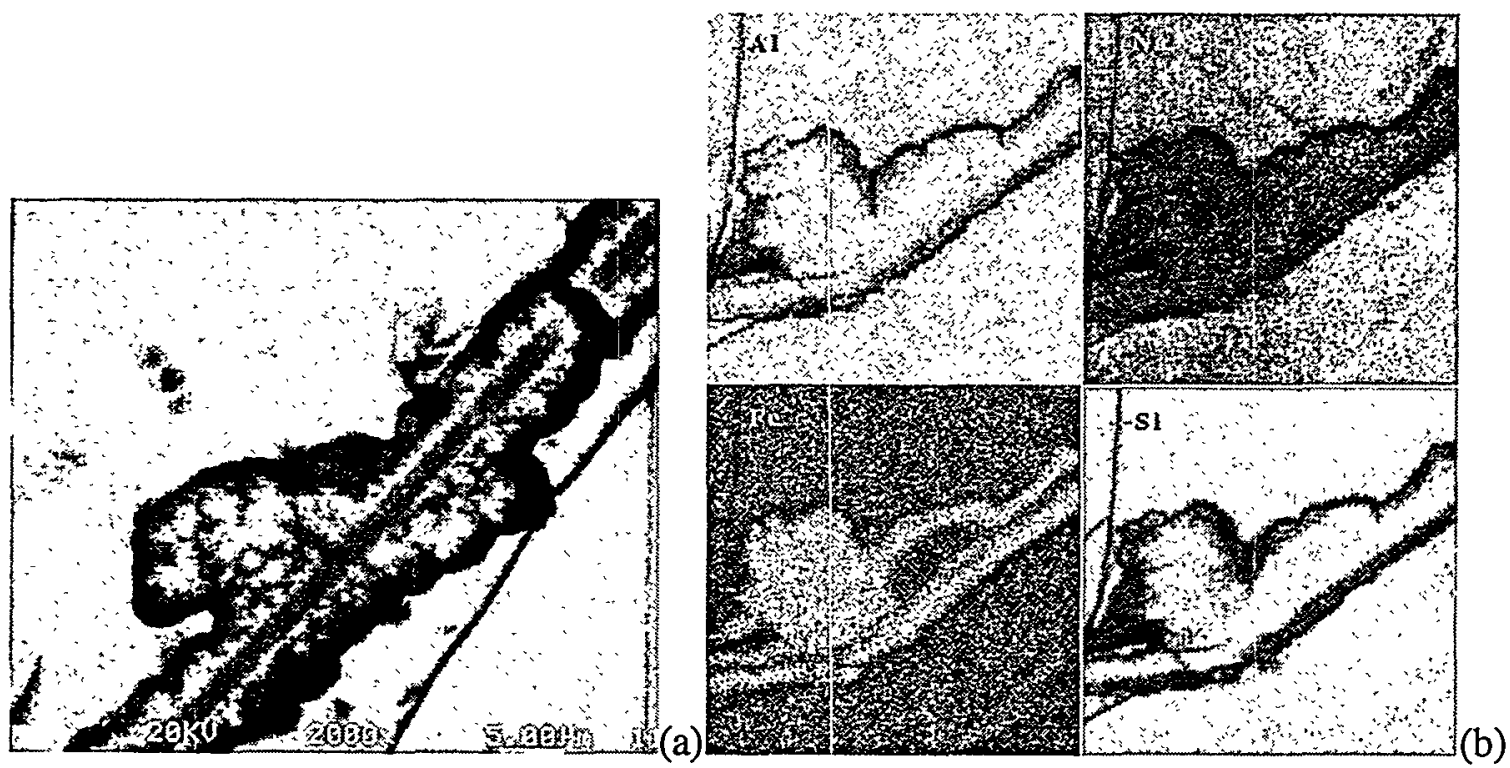

Fig. 8. (a) Backscattered electron of palagonite formation along a fracture and (b) X-ray map of the major elements in that area.

\subsubsection{Analytical Electron Microscopy Analyses}

Representative features of the palagonite were picked up and sectioned with microtomy for AEM analyses. In this study, all the samples was picked up from the palagonite formed on the surface. The layer formed along the cracks was not accessible for AEM analyses. Figure 9 shows a typical section that contain a large $(\sim 5 \times 7.5 \mu \mathrm{m})$ area of palagonite. It clearly shows that the palagonite is a multiphased mixture which is composed of a greylish matrix, various dark precipitates, and several layered or fibrous phases. Figure 10 shows a magnified view of a typical palagonite area. The majority of the palagonite seems to consists of little spongy hair-balls, which are actually a crystalline phase, i.e., electron diffraction is obtained from this phase (see inset of Fig. 10). However, this phase is very beam sensitive and does not exhibit any diffraction pattern after being exposed to the electron beam for several seconds. The other features are more stable under the electron beam, and they are also crystalline. Many of the crystalline precipitates have a layered or fibrous texture, some of which are well developed. Other precipitates having square or round shapes are often isolated from each other.

The alteration products were identified by matching the measured composition and diffraction patterns with the JCPDS-ICDD reference materials. In this section, we summarize the observed phases and show a few representative TEM data from some of these analyses. 


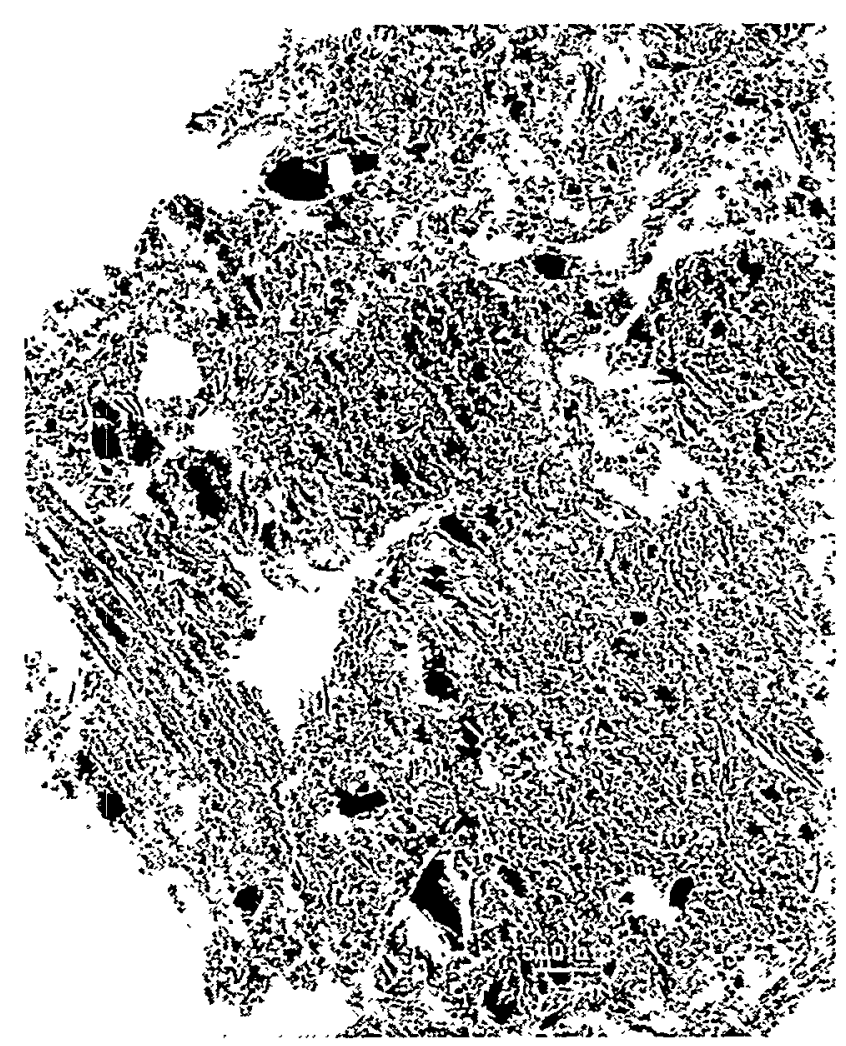

Fig. 9. Typical TEM image of the palagonite layer showing the mixture of multiphases.

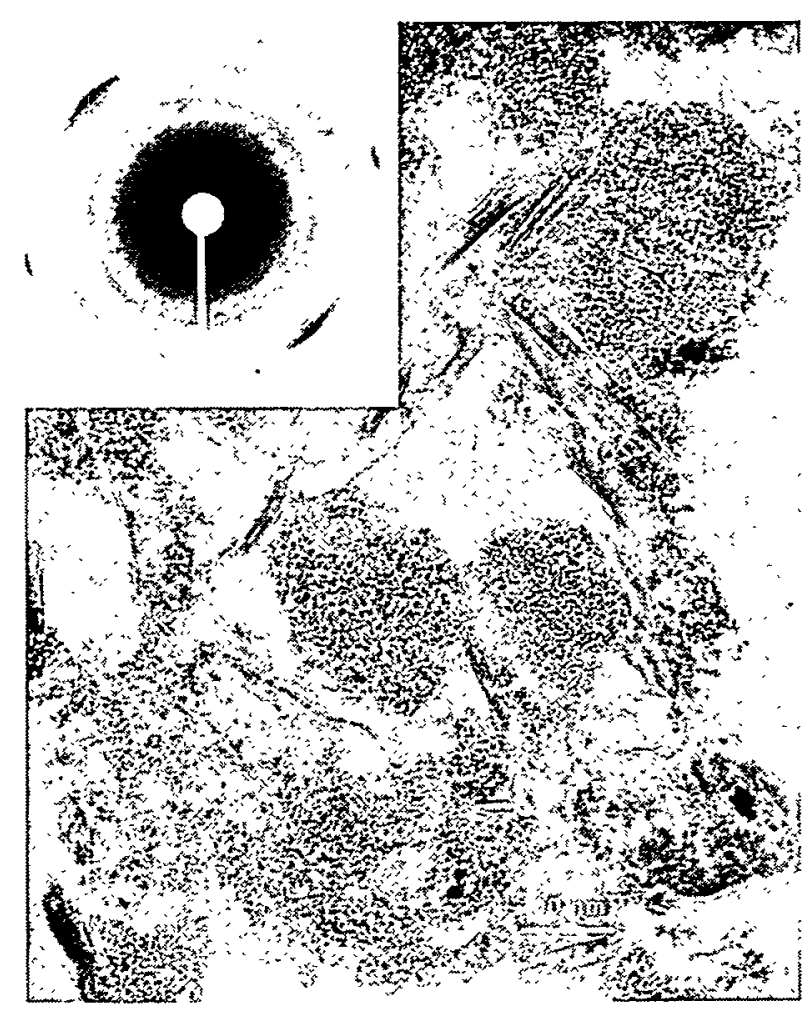

Fig. 10. A TEM image of hemispherical geothite particles. 
Goethite- $\mathrm{FeO}(\mathrm{OH})$

The most abundant phase formed in the palagonite was goethite, a hydroxide of iron oxide. This phase was observed either as large isolated precipitates of up to $5 \mu \mathrm{m}$ (Fig. 11a) or as spongy hair balls (Fig. 11b). It is relatively well crystallized as demonstrated by the rather sharp diffraction spots (see inset in Fig. 11a), although its crystallinity seems poorer when in the form of spongy balls (see inset in Fig. 11b). In any case, this phase is very beam sensitive and becomes completely amorphous after being exposed to the electron beam for a few seconds. Analysis of this phase by EDS shows that it also contains small but variable amounts of $\mathrm{Al}, \mathrm{Si}$, and $\mathrm{Ti}$. The spongy phase has been observed in the alteration layer formed both in the laboratory-acted basalt by meteoric water [GISLASON-1993] and in naturally corroded glass by seawater [ZHOU-1989], both under saturated conditions. In those cases, however, the spongy phase was described as completely amorphous with no diffraction patterns being generated.

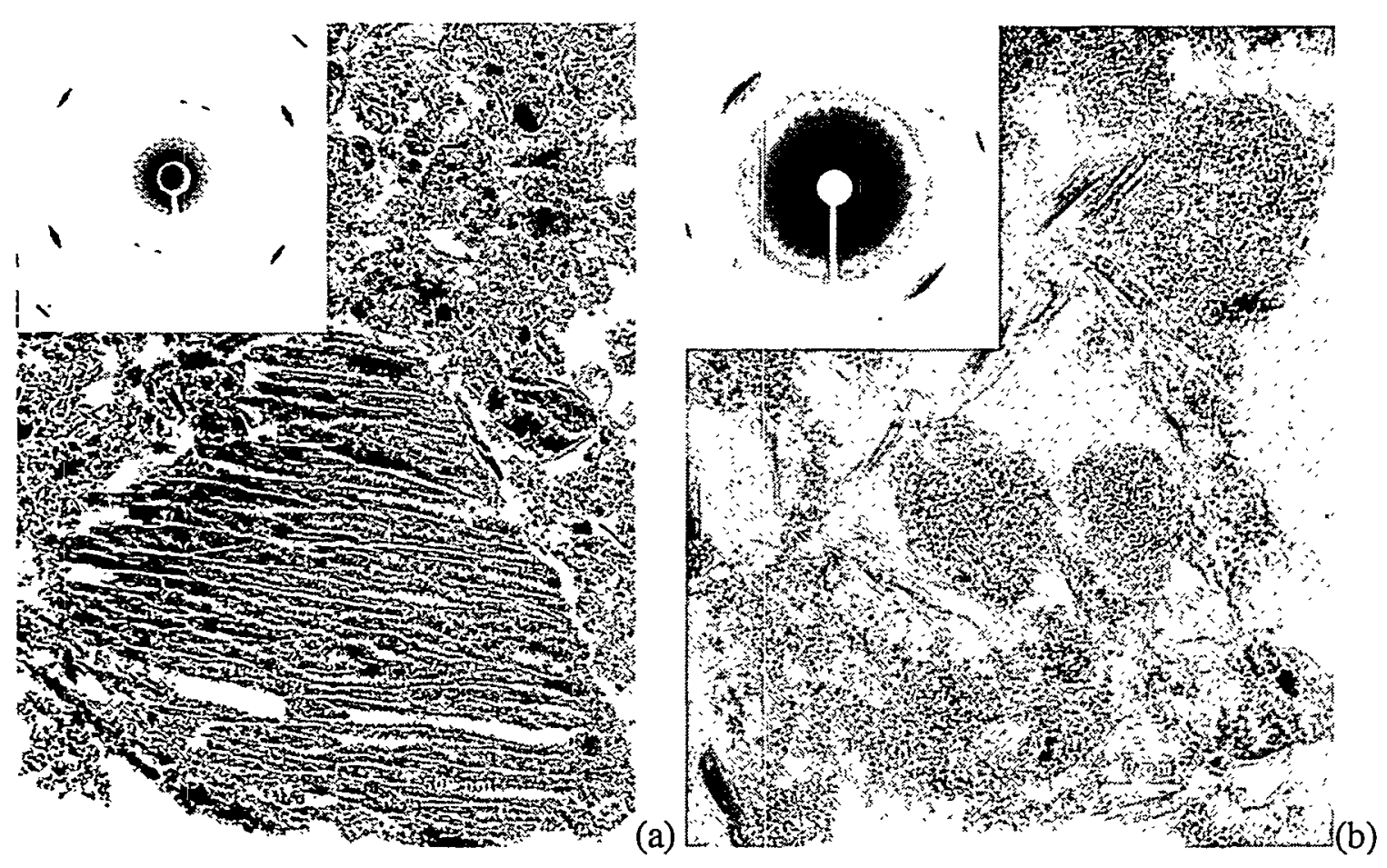

Fig. 11. Transmission electron micrographs of (a) a large geothite crystal and (b) hemispherical geothite particles. Insets are electron diffraction studies.

Scarbroite- $-\mathrm{Al}_{2}(\mathrm{OH})_{6} \mathrm{H}_{2} \mathrm{O}$

This phase has a braided microstructure and is also very beam sensitive (see Fig. 12a and its inset). Analysis by EDS indicates virtually pure $\mathrm{Al}$ and $\mathrm{O}$ ( $\mathrm{H}$ is not detectable by EDS). Two major hydrates of aluminum are reported in the literature, the alteration products gibbsite and scarbroite, which are stable at low temperatures [DEER-1992]. Murakami et al. [MURAKAMT] identified gibbsite with AEM to be a major phase in basalt glass reacted in deionized water and in $\mathrm{NaCl}$ solution. Although gibbsite is often the predominant mineral in many alteration products, scarbroite was found in bauxite deposits near Niksic, Yugoslavia. However, we believe that the phase observed in Hawaiian basalt glass is scarbroite. The most critical evidence was provided by the high-resolution TEM image (Fig. 12b). It shows the presence of lattice fringes that have a d-spacing of $8.5 \AA$, which is close to that of scarbroite $(8.6 \AA)$. Gibbsite has a more compact structure, with 
d-spacings no larger than $4.8 \AA$. Analysis of this phase by EDS confirmed the majority of $\mathrm{Al}$ and $\mathrm{O}$, but also detected a small amount of $\mathrm{Fe}$ in the structure.
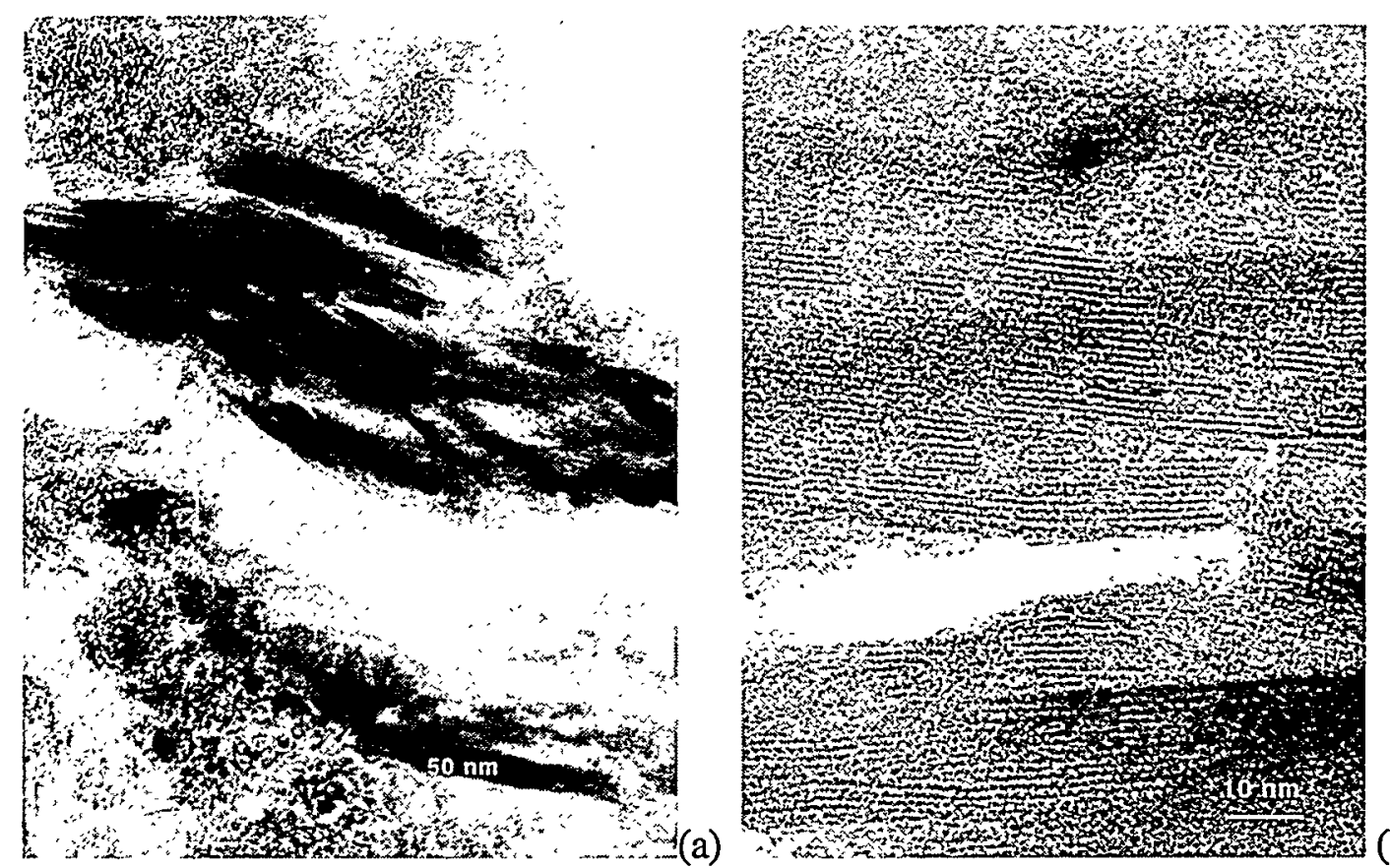

(b)

Fig. 12. Layered scarbroite phase: (a) TEM image and (b) high-resolution TEM image showing the lattice fringes of the scarbroite.

Kaolinite- $\mathrm{Si}_{2} \mathrm{Al}_{2} \mathrm{O}_{5}(\mathrm{OH})_{4}$

This smectite clay exhibits a cylinderic texture (Fig. 13a), that has been reported to be characteristic of kaolinite crystals [SINGH-1995]. This phase is beam sensitive, and no good electron diffraction was obtained. However, the high-resolution TEM lattice image (Fig. 13b) indicates a majority d-spacing of $7.1 \AA$, which perfectly matches that the $\left(\begin{array}{ll}0 & 0\end{array}\right)$ plane of kaolinite. Analysis with EDS confirmed the 1:1 ratio of Al to Si and also revealed the presence of small amounts of Fe (about $1.6 \mathrm{wt} \%$ ). Iron has been reported to be incorporated in soil kaolinites, even though it is generally present only as a trace in geological kaolinites [SINGH-1995]. Gislason et al. observed a possible formation of kaolinite in the alteration layer formed in basalt glass but were unable to identify this phase rigorously because of insufficient AEM data [GISLASON-1993]. 

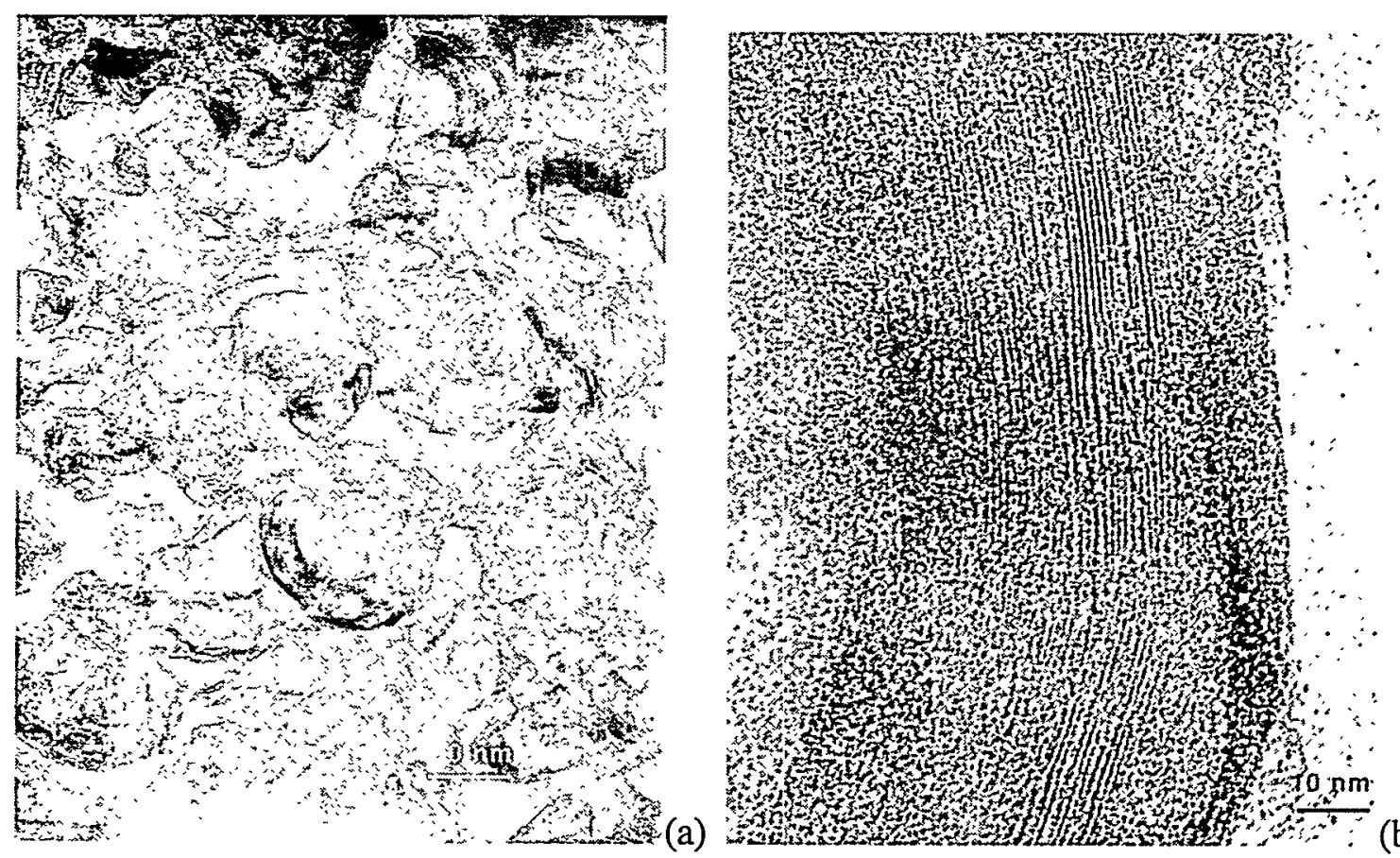

(b)

Fig. 13. Kaolinite phase: (a) TEM image and (b) high-resolution TEM image.

Septechlorite-Montmorillonite-Saponite Mixture

Another fibrous phase frequently observed in palagonite was found to contain a mixture of septechlorite and smectite clays. Electron diffraction of this phase typically revealed diffused bands rather than sharp reflections (see inset in Fig. 14a). High-resolution TEM showed a disordered stacking sequence and an intergrowth of layers with a variety of d-spacings (Fig. 14b). Layers having d-spacings of $9.7,13.5,17.8$, and $22.9 \AA$ were observed. These layers seem to match those of smectite clays, whose basal spacings can vary over a wide range with various interlayer cations and water content. Iron-rich saponites have d-spacings ranging from 14 to $19 \AA$ as the water content increases. Montmorillonite with a high $\mathrm{Mg}$ content has the range of effective basal spacings from 10 to $22 \AA$. Analysis with EDS, which yielded 5.4 at $\% \mathrm{Mg}, 4.5$ at\% Al, 7.3 at\% Fe, and 22 at\% $\mathrm{Si}$, also seemed consistent with the composition of a mixture of montmorillonite-saponite. Montmorillonite has a 0.2 ratio, of $(\mathrm{Al}, \mathrm{Mg})$ to $\mathrm{Si}$, which is slightly lower than the experimental value obtained with quantitative EDS analysis. Iron may be mainly incorporated in saponites or nontronites, with $\mathrm{Fe} / \mathrm{Si}$ ratios of 0.5 and 0.75 , respectively, although nontronite tends to have layers with $\mathrm{d}_{002}$ of about $14-15 \AA$, which were not directly observed in this case. On the other hand, we were able to observed several layers with a d-spacing of around $7 \AA$, which seems to be structurally characteristic of another sheet silicate, septechlorite. Septechlorite is reported to be closely related chemically to the chlorites but can be structurally characterized by serpentine-like layers with $\mathrm{d}_{002}$ of $\sim 7 \AA$ [DEER-1992].

Magnetite- $\mathrm{Fe}_{3} \mathrm{O}_{4}$

Magnetite was identified in the palagonite layer as an isolated precipitate. Analysis with quantitative EDS indicated that this phase often contains a small amount of Ti. This phase has been reported as a primary precipitate or a devitrificated product in basalt glass. 

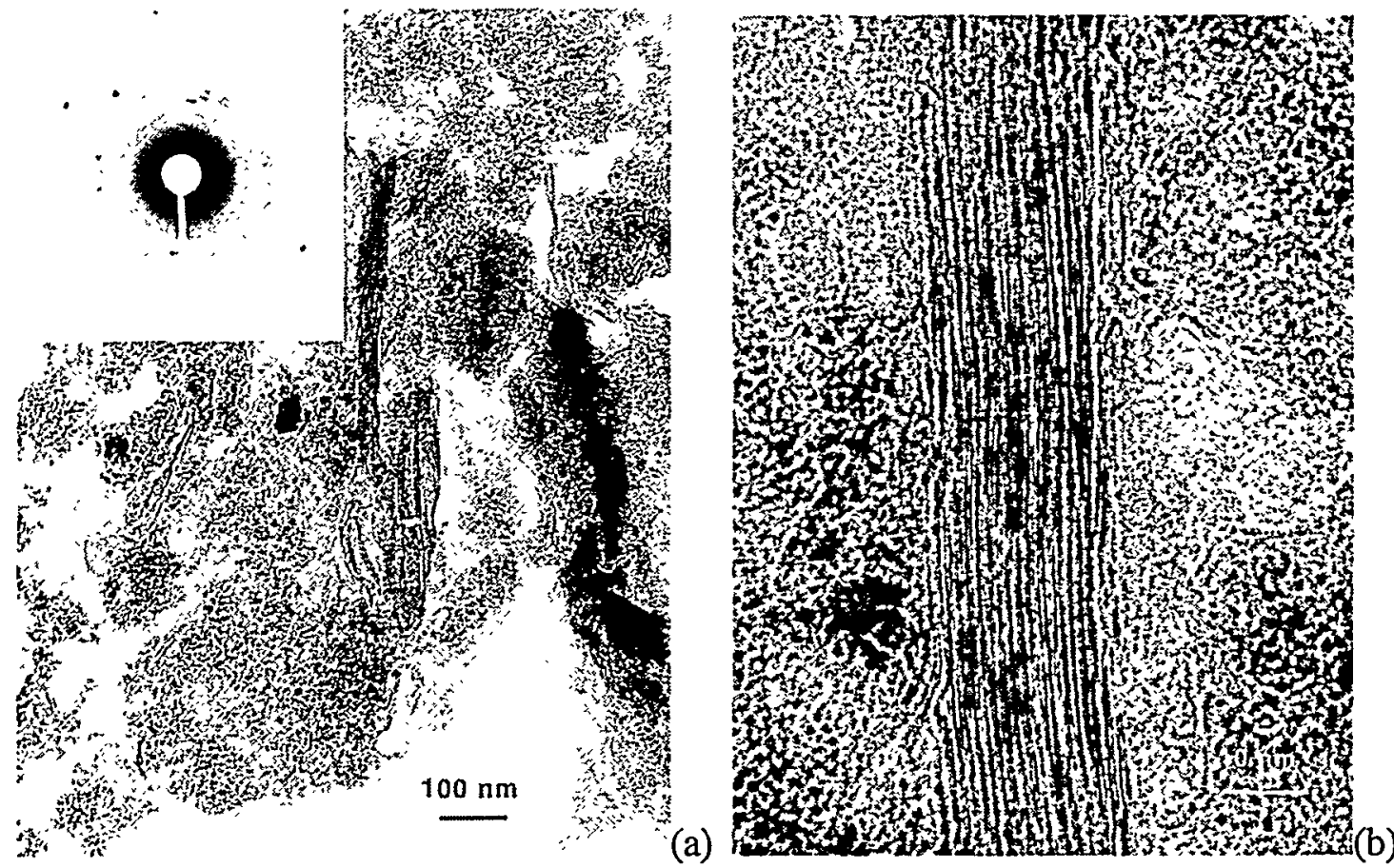

Fig. 14. Smectite clay phase: (a) TEM image and electron diffraction pattern (inset) and (b) high-resolution TEM image of the lattice fringes of the smectite clay phase.

$\alpha-Q u a r t z-\mathrm{SiO}_{2}$

The silica phase that formed in Hawaiian basalt glass was identified as $\alpha$-quartz $\left(\mathrm{SiO}_{2}\right)$ with electron diffraction and EDS analysis. This phase was observed as isolated precipitates in the palagonite layer with a typical size of about 100 to $200 \mathrm{~nm}$. This fine-sized $\alpha$-quartz has also been referred to as chalcedony [GISLASON-1993]. Analysis with EDS reveals nearly pure silica with no other components. This material has also been reported to form in the alteration layer of the basalt glass reacted in meteoric water at 45 to $70^{\circ} \mathrm{C}$ [GISLASON-1993].

\section{Si-Al-Fe-Rich Amorphous Phase}

This amorphous phase was generally enriched with $\mathrm{Fe}, \mathrm{Al}$, and Si and did not exhibit any textures; it may be a different phase from the spongy phase that has been reported [GISLASON-1993 and ZHOU-1989]. We also observed a spongy phase; in our case, however, this phase was identified as crystalline geothite, which became amorphous after short exposure to high-energy electron beams.

In addition to the relatively well-characterized phases described above, we observed a crystalline phase that could not be fully identified because of insufficient electron diffraction data. This phase was observed as square $200-\mathrm{nm}$ precipitates and seemed to have a layered structure (Fig. 15). It was not a major phase and we only observed it once during the analysis of palagonite with AEM. As revealed by quantitative EDS analyses, this phase was Fe-rich and contained substantial amounts of $\mathrm{Ca}, \mathrm{Si}$, and $\mathrm{Mg}$. It was noted that this phase was the only phase of all palagonite constituents that contained substantial amont of $\mathrm{Ca}$. 


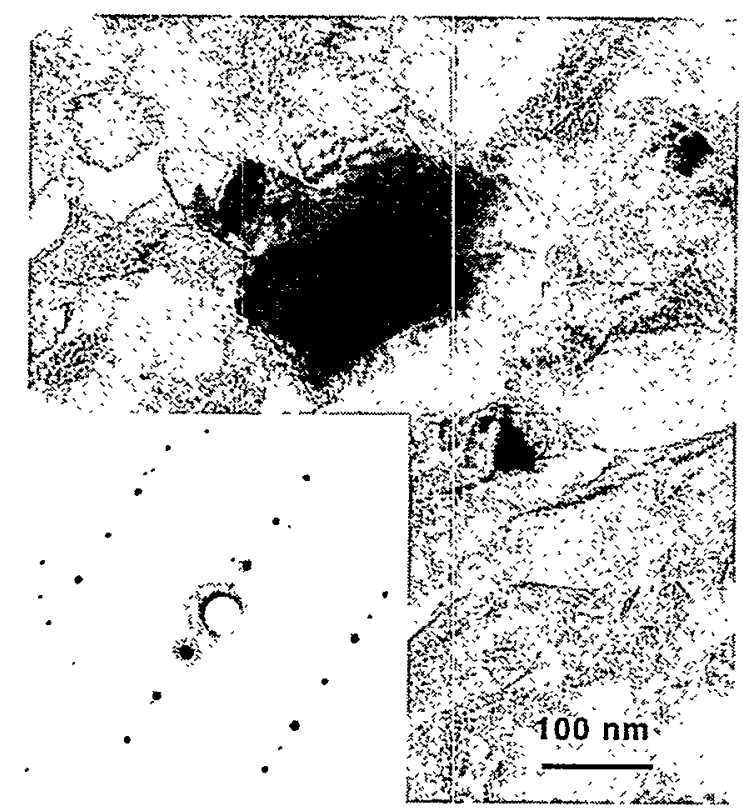

Fig. 15. High-resolution TEM image and electron diffration pattern (inset) of phase rich in $\mathrm{Fe}, \mathrm{Ca}, \mathrm{Si}$, and $\mathrm{Mg}$.

\subsubsection{Summary of Hawaiian Basalt Studies}

The palagonite formed on the surface of Hawaiian basaltic glasses has been characterized by SEM/EDS and AEM/EDS. The palagonite layer was found to consist mainly of geothite, an iron hydroxide, plus several other crystalline precipitates. These precipitates were identified as scarbroite $\left[\mathrm{Al}_{2}(\mathrm{OH})_{6} \mathrm{H}_{2} \mathrm{O}\right]$, kaolinite $\left[\mathrm{Si}_{2} \mathrm{Al}_{2} \mathrm{O}_{5}(\mathrm{OH})_{4}\right]$, a septechlorite-montmorillonite-saponite mixture, magnetite $\left(\mathrm{Fe}_{3} \mathrm{O}_{4}\right), \alpha$-quartz $\left(\mathrm{SiO}_{2}\right)$, an $\mathrm{Fe}$ $\mathrm{Ca}-\mathrm{Si}-\mathrm{Mg}$ containing phase, and an Si-Al-Fe-rich amorphous phase. The formation of these phases are the result of progressive dissolution of glass with contemporaneous reprecipitation at the glass surface of the materials whose solubility limits are reached. The formation of these phases is also consistent with calculations made on the mineralogical sequences in basalt glass using the geochemical computer code DISSOL [CROVISIER-1992].

Our SEM/EDS studies also show that the corrosion of basaltic glass is sensitive to the local environment of the glass surface. The corrosion along cracks of the glass led to the formation of possible zeolite phases, which were not observed on the palagonite formed on the glass surface. The formation of zeolites generally reflects the achievement of a saturated condition along the cracks, where the rate of flow exchange is slow, whereas the phases formed on the surface palagonite correspond to a relatively low reaction rate due to unsaturated conditions. 


\subsection{Laboratory-Reacted Basaltic and Waste Glasses}

\subsubsection{Laboratory-Reacted Basaltic Glass}

A synthetic basaltic glass was reacted in laboratory vapor conditions at $75^{\circ} \mathrm{C}$ for up to nine years. The glass was exposed to two relative humilities, $95 \%$ and $100 \%$. The reacted samples were characterized with optical microscopy, SEM/EDS, and AEM. The examination details are described in detail below.

\subsubsection{Vapor Reaction at $75^{\circ} \mathrm{C}$ and at $95 \% \mathrm{RH}$}

Glass samples were removed from the reaction vessel for examination after being reacted at $75^{\circ} \mathrm{C}$ in $95 \% \mathrm{RH}$ for seven and nine years.

\subsection{Seven-Year Results}

The reacted sample exhibited little reaction on the surface, which was still shiny and a dark green. Optical microscopy showed that a milky stain and some small white precipitates had formed on the parts of surface (Fig. 16). The corrosion of the glass in this test was limited, as the polishing scratches from preparing the test sample were still visible on the surface.

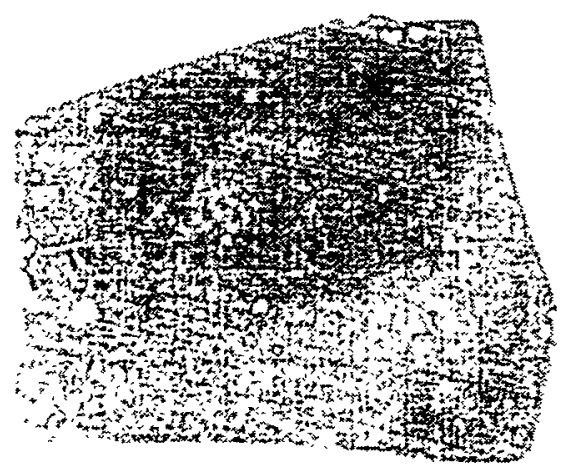

(a)

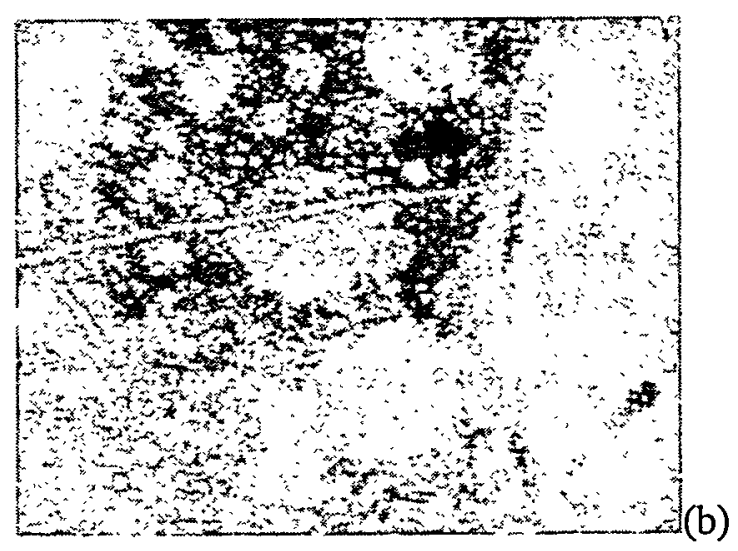

Fig. 16. Optical microscopy images of the synthetic basalt glass vapor reacted at $75^{\circ} \mathrm{C}$ and $95 \% \mathrm{RH}$ for seven years taken at (a) $6 \mathrm{X}$ and (b) $50 \mathrm{X}$.

Figure 17a shows the SEM image of the glass surface. Particles $10 \mu \mathrm{m}$ in size were loosely formed on a relatively smooth surface. Analysis of these particles with EDS revealed a composition generally similar to that of the smooth surface, but containing $S$, which was not detected in the smooth surface (Fig. 17b). This result indicates that gas species from the atmosphere, such as $\mathrm{S}$, may be involved in the corrosion of the basalt glass.

Examination of the cross section of the reacted sample essentially showed a clean surface; no layer had formed that could be observed within the resolution of SEM (Fig. 18a). 
Examination by AEM of a thin chip from the surface of the sample revealed the formation of a uniform amorphous layer $200 \mathrm{~nm}$ thick with no obvious presence of crystalline precipitates in the layer (Fig. 18b). In some areas, etched pits were observed at the layer/glass interface (Fig. 18c). Analysis by EDS of the layer indicated enrichment of $\mathrm{Fe}$ and $\mathrm{Ti}$ and depletion of $\mathrm{Ca}$ and $\mathrm{Mg}$ in the layer compared with the glass core (Fig. 18d). The Si and Al contents are similar in both the layer and in the unreacted glass. This layer is very similar to the "diffusional" layers previously reported to have formed on the surfaces of waste glasses at an early stage of corrosion [BATES-1994, EBERT-1990]. The formation of a diffusional layer is the result of hydration of glass by molecular water and/or ion exchange between more soluble elements, such as $\mathrm{Mg}, \mathrm{Ca}$, and $\mathrm{Na}$, and the water molecules [CUNNANE-1994].

\subsection{Nine-Year Results}

The surface was still dark green but had became relatively rough. Optical microscopy revealed that milky stains had spread over the surface, and a high density of small white precipitates had formed on parts of the surface (Fig. 19).

Examination by SEM using secondary electrons revealed that the surface morphology had became nubby in texture (Fig. 20). Interestingly, imaging the same area with backscattered electrons, which allows the observation of compositional differences, showed that the outgrowing nubs were whiter, indicating that they contained heavier elements than their surrounding areas. In fact, these nubs were found to be highly enriched in transition elements such as $\mathrm{Fe}, \mathrm{Cr}, \mathrm{Ti}$, and $\mathrm{Mn}$, compared to the surrounding areas (Fig. 21), suggesting the precipitation of $(\mathrm{Fe}, \mathrm{Cr}, \mathrm{Ti}, \mathrm{Mn})$-oxides on these areas.

Loose particles ranging from 10 to $100 \mu \mathrm{m}$ were also frequently observed on the reacted surface. Some precipitates were aggregates of smaller precipitates of the same nature (Fig. 22a). Analysis by EDS revealed that these particles generally contained a substantial amount of $\mathrm{S}$ and $\mathrm{Cl}$, neither of which was present in unreacted glasses and most likely came from the atmosphere (Fig. 22b). 

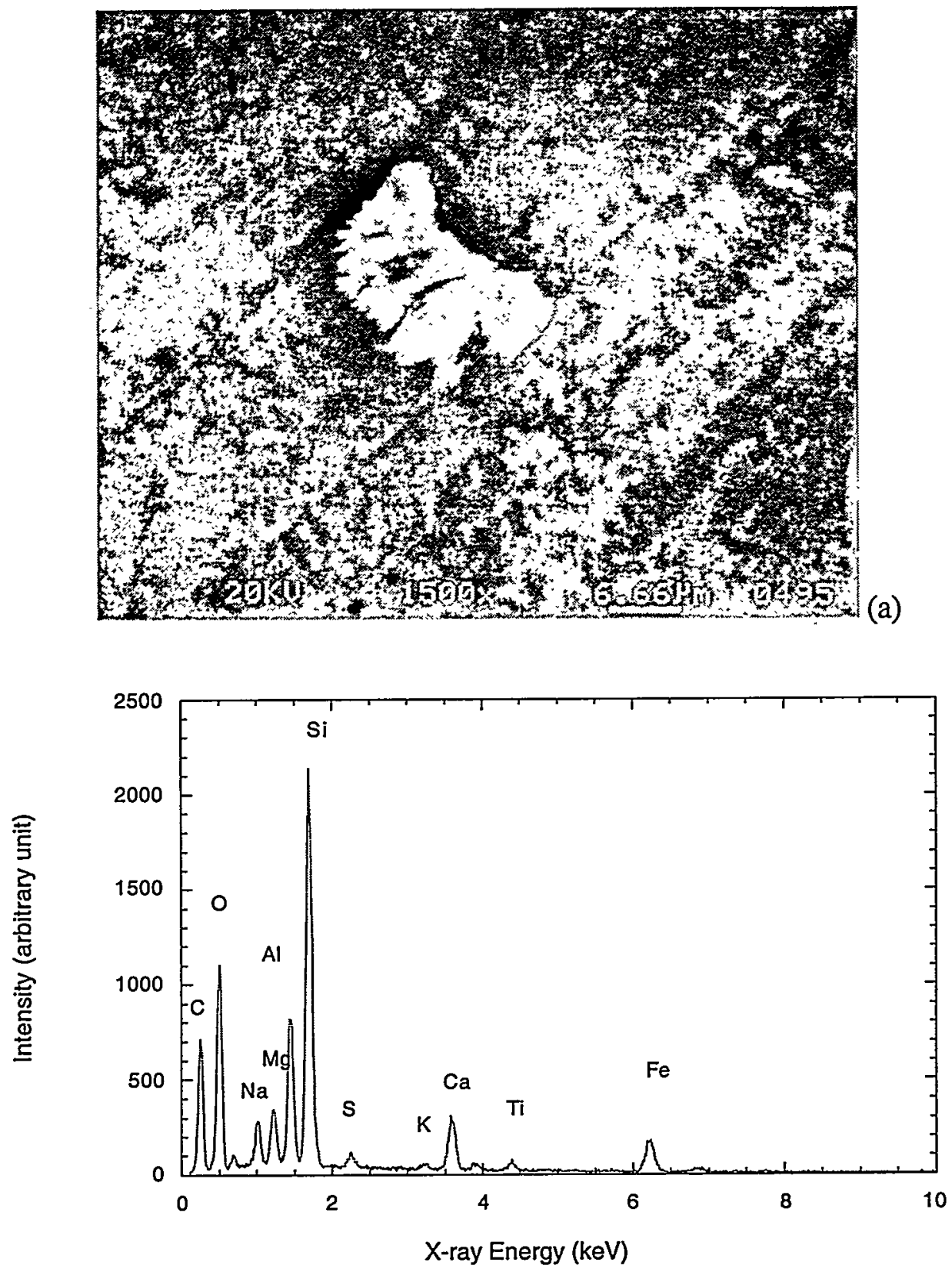

(b)

Fig. 17. (a) Scanning electron micrograph of the surface of the synthetic basalt glass vapor reacted at $75^{\circ} \mathrm{C}$ in $95 \% \mathrm{RH}$ for seven years, and (b) $\mathrm{EDS}$ spectrum of the particle precipitated on the surface. 

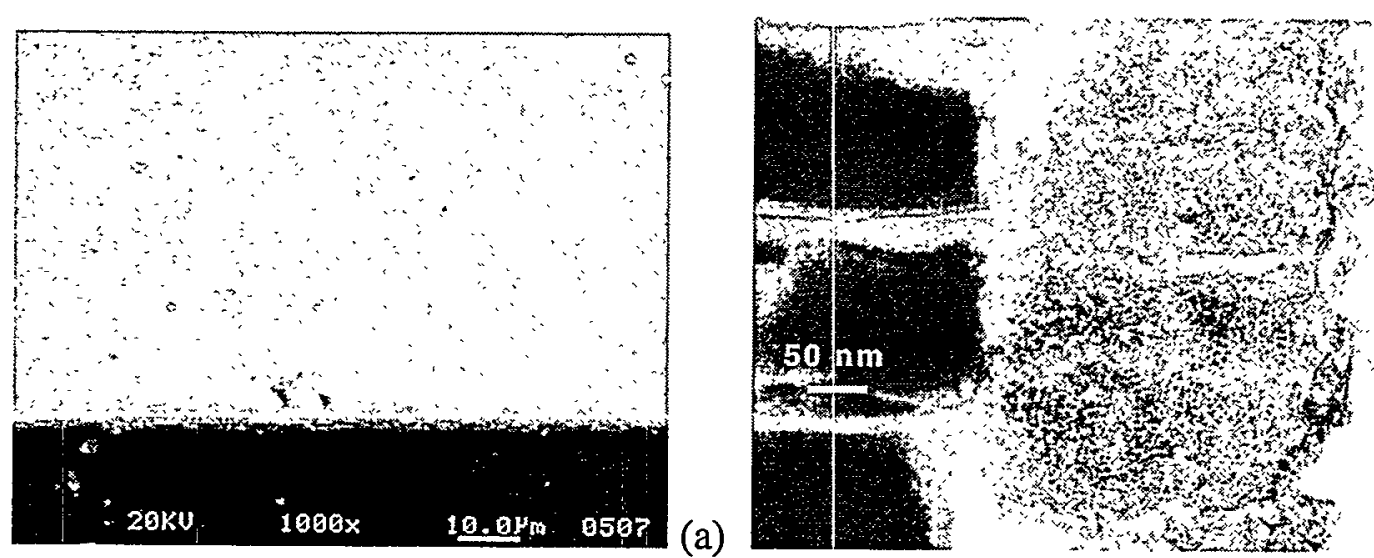

(b)
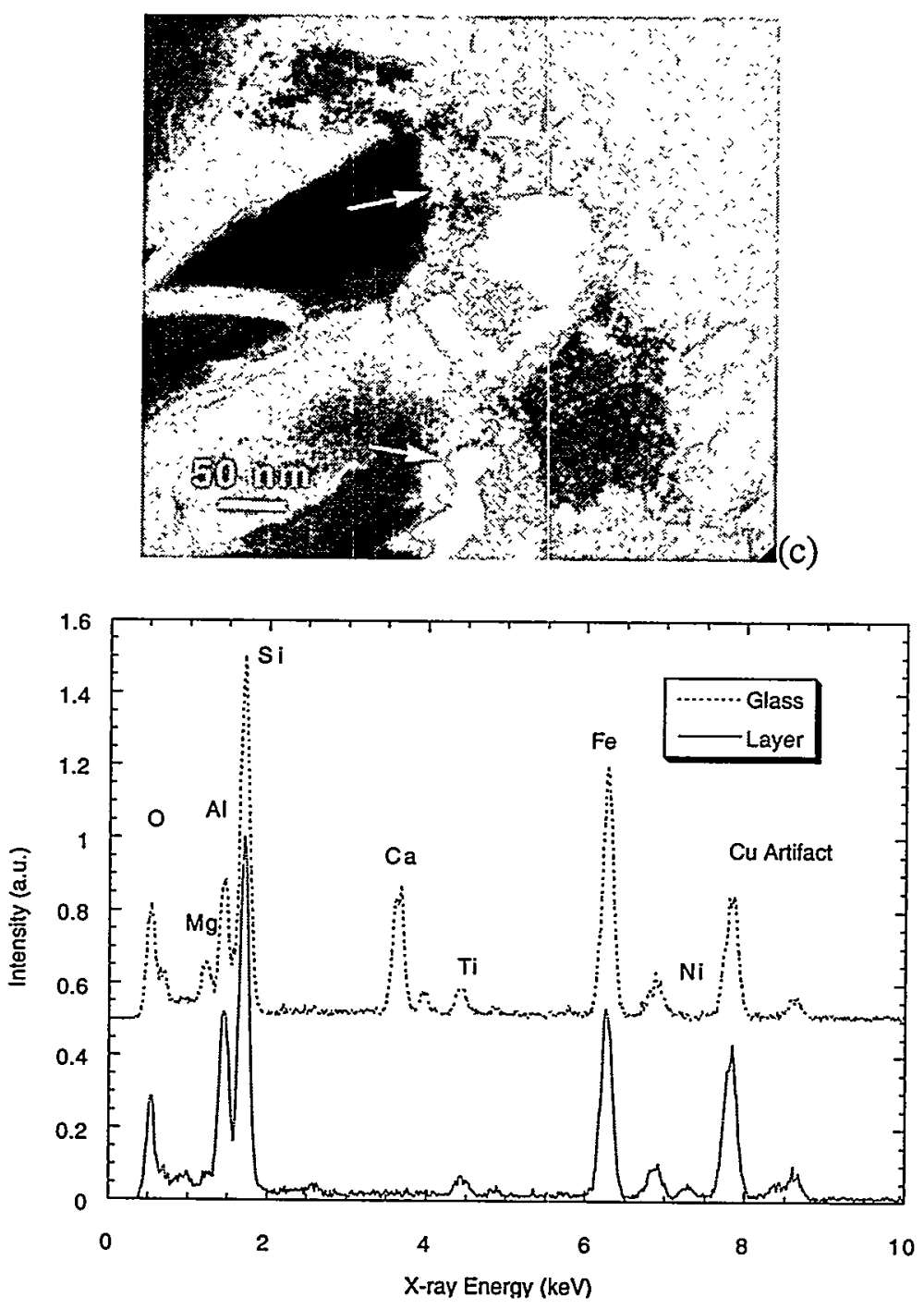

(d)

Fig. 18. (a) Cross-sectional SEM image of the synthetic basalt glass vapor reacted at $75^{\circ} \mathrm{C}$ in $95 \% \mathrm{RH}$ for seven years, TEM images of the layer/glass interface showing (b) smooth interface and (c) etching pits (arrows), and (d) EDS spectra comparing the compositions of the layer and unreacted glass (spectra offset for clarity). 

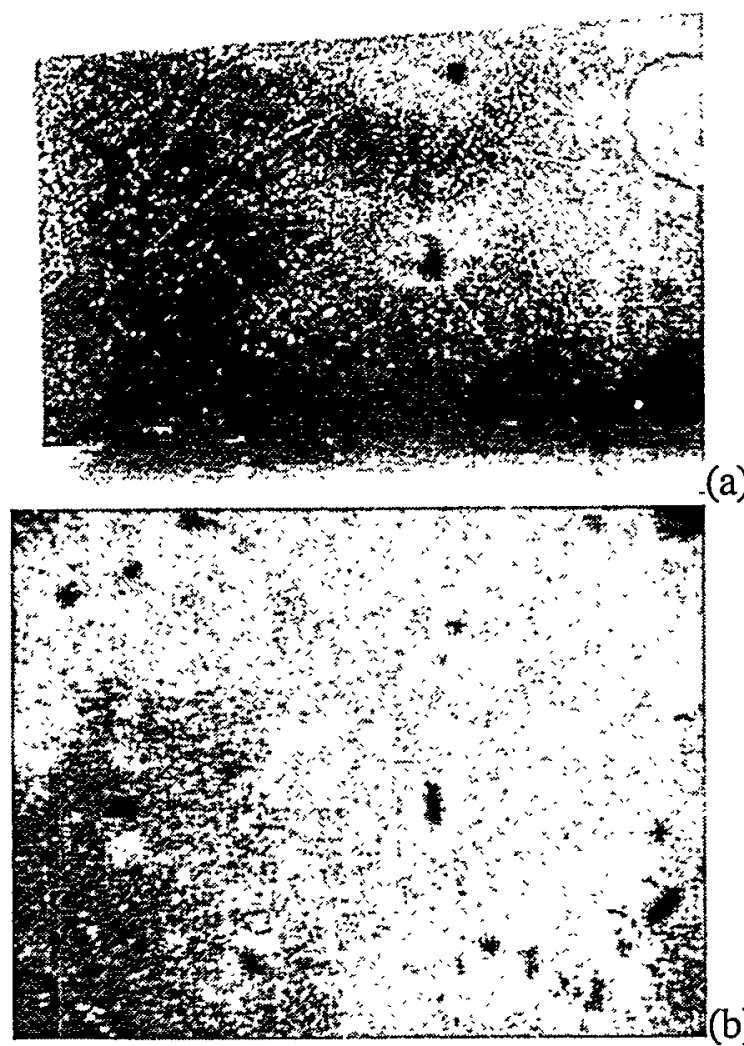

Fig. 19. Optical microscopy images of the synthetic basalt glass vapor reacted at $75^{\circ} \mathrm{C}$ and $95 \% \mathrm{RH}$ for nine years taken at (a) $6 \mathrm{X}$ and (b) $50 \mathrm{X}$.
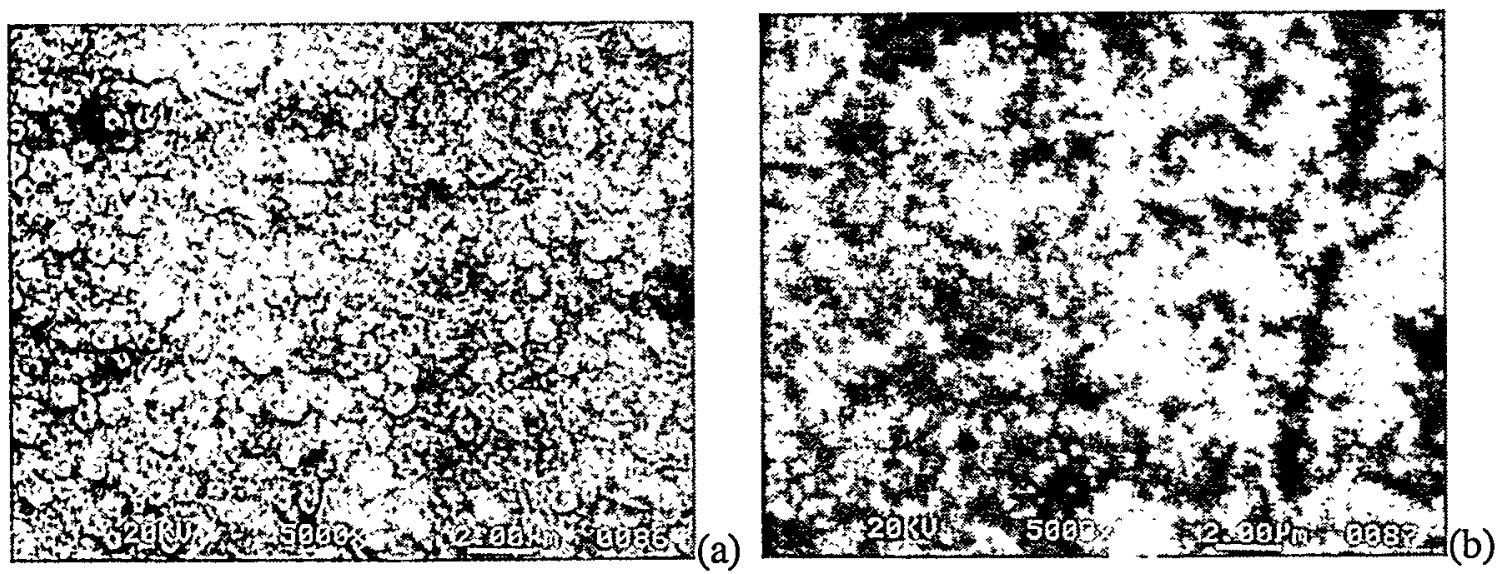

Fig. 20. Scanning electron micrographs of the surface of the synthetic basalt glass vapor reacted at $75^{\circ} \mathrm{C}$ in $95 \% \mathrm{RH}$ for nine years: (a) secondary electron and (b) backscattered electron. 


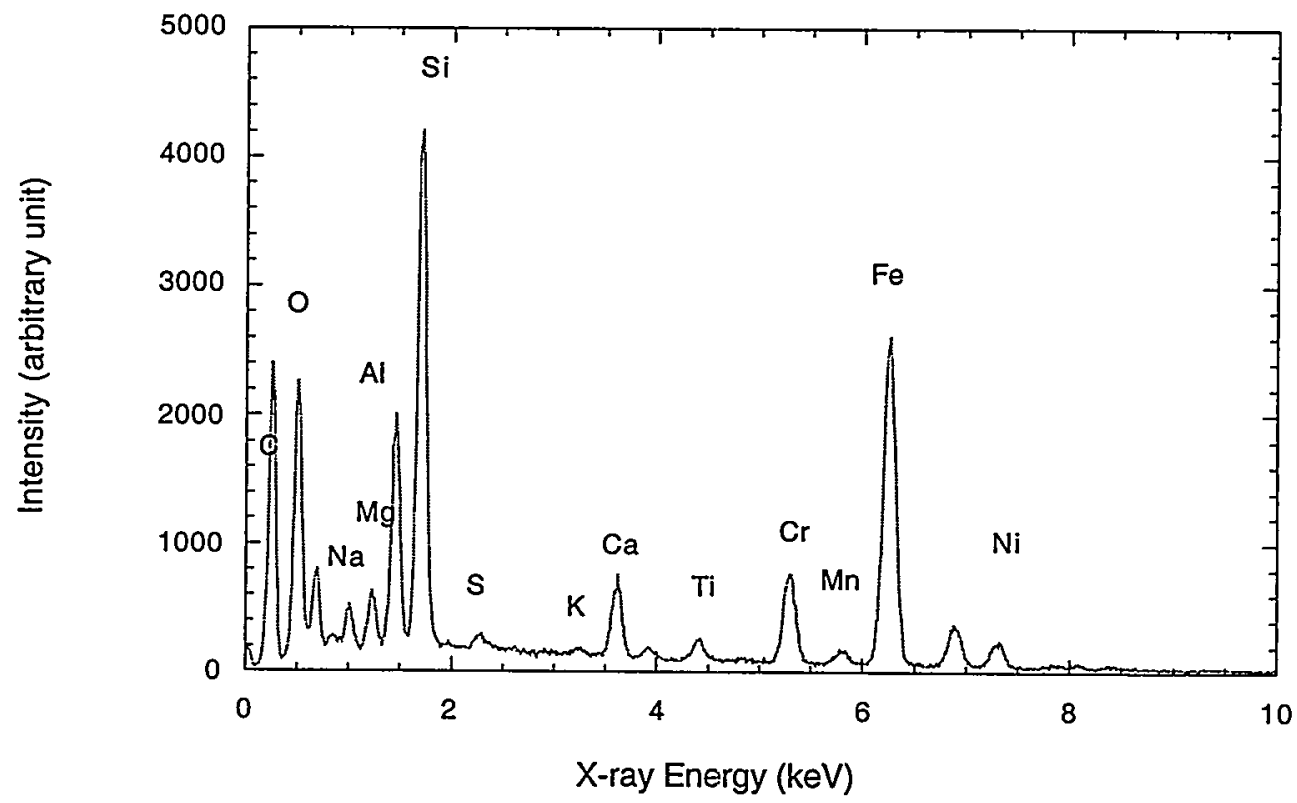

Fig. 21. An EDS spectrum of the nubby features shown in SEM images of synthetic basalt glass vapor reacted at $75^{\circ} \mathrm{C}$ and $95 \% \mathrm{RH}$. for nine years. 

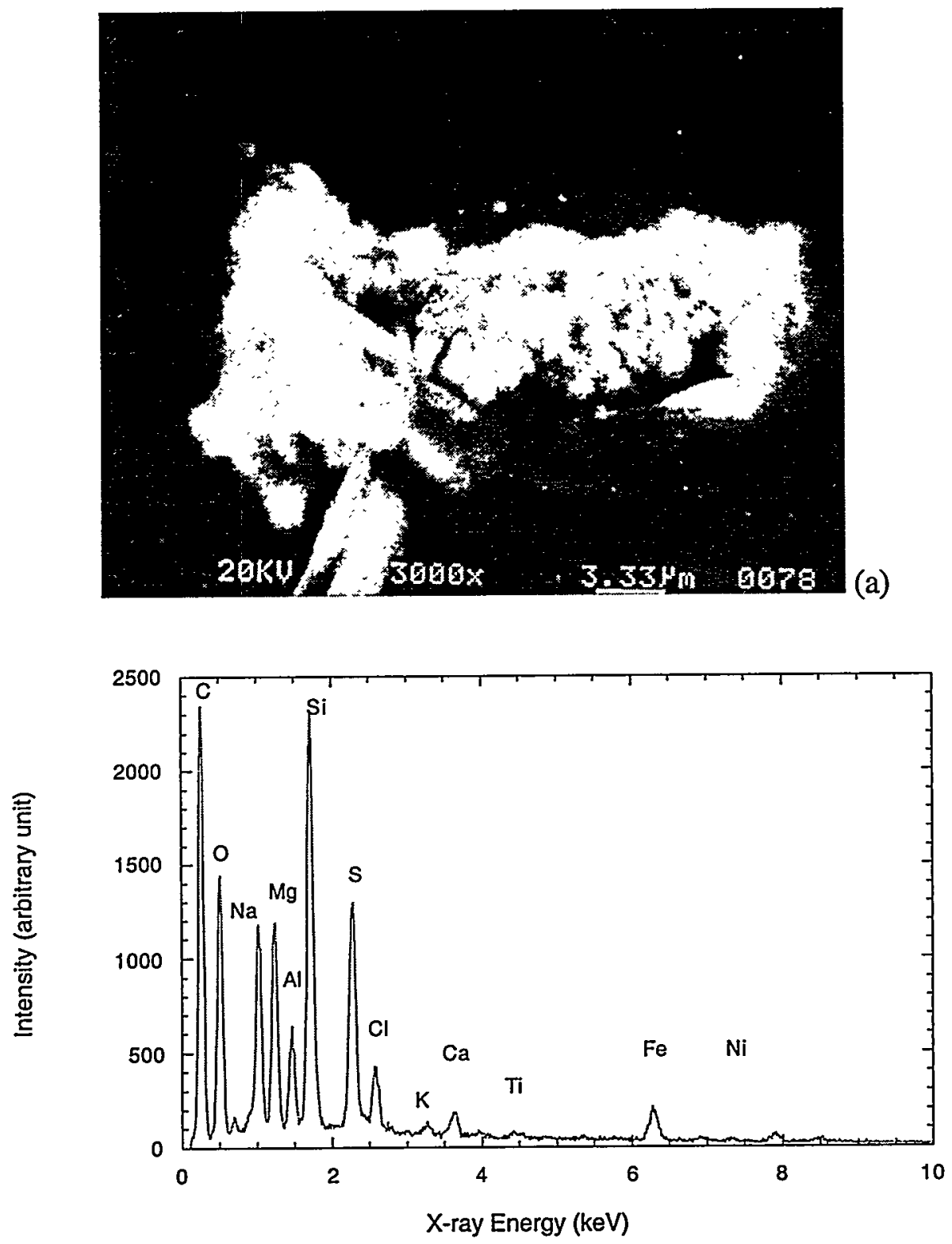

(b)

Fig. 22. (a) An SEM image of precipitates on the surface of the synthetic basalt glass that was vapor reacted at $75^{\circ} \mathrm{C}$ and $95 \% \mathrm{RH}$ for nine years and (b) EDS spectrum of the precipitate.

Cross sections of the reacted sample were also prepared and examined by SEM. A layer about $1 \mu \mathrm{m}$ thick had formed on the surface (Fig. 23). Because it was smaller than the size of the electron beam spot used to perform EDS, no reliable spectrum was obtained from the altered area. 


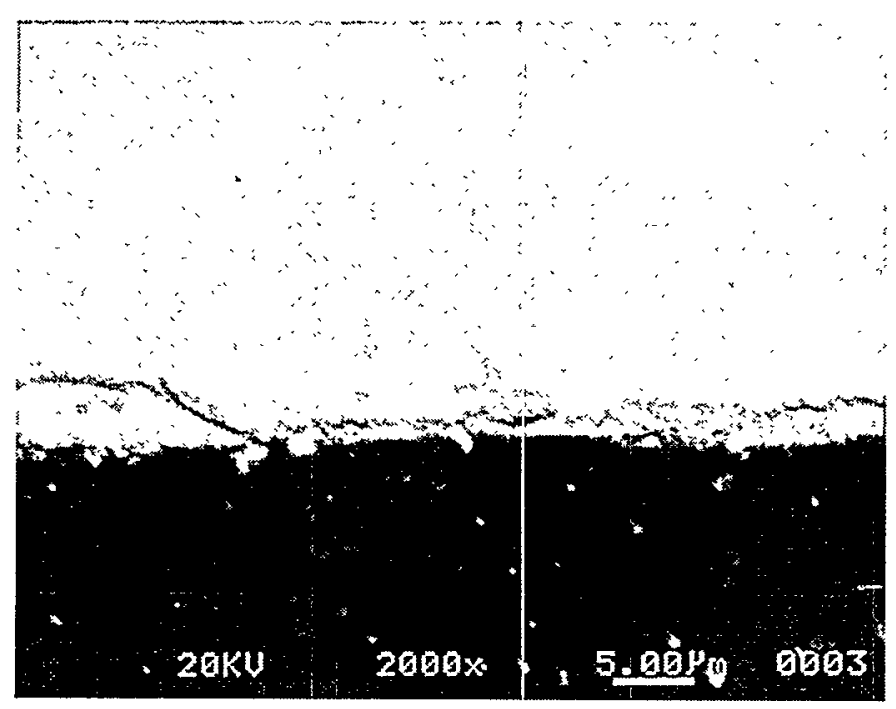

Fig. 23. Cross-sectional SEM image of the layer formed on the glass surface of the synthetic basalt glass vapor reacted at $75^{\circ} \mathrm{C}$ and $95 \% \mathrm{RH}$ for nine years.

A thin chip containing glass and alteration material was sectioned. Examination by AEM revealed the formation of an alteration layer at the surface; the layer had a fibrous microstructure characteristic of clay (Fig. 24). The interface between the pristine glass and the alteration layer was sharp; no diffusional layer was observed in this sample. The fibrous material was identified as saponite with electron diffraction. Analysis by EDS of this layer indicated enrichment of $\mathrm{Fe}$ and $\mathrm{Ti}$ and depletion of Ca compared with the glass core (Fig. 24c). In contrast with the seven-year sample, this one did not retain any amorphous diffusional layer that had formed at an early stage of corrosion. The diffusional layer may have transformed into the more stable crystalline smectite clay. It is possible that as more glass constituents were released into the layer, the solution became increasing saturated, which the suppressed ion exchange and hydration reactions and, consequently, prevented the diffusional layer from forming. 

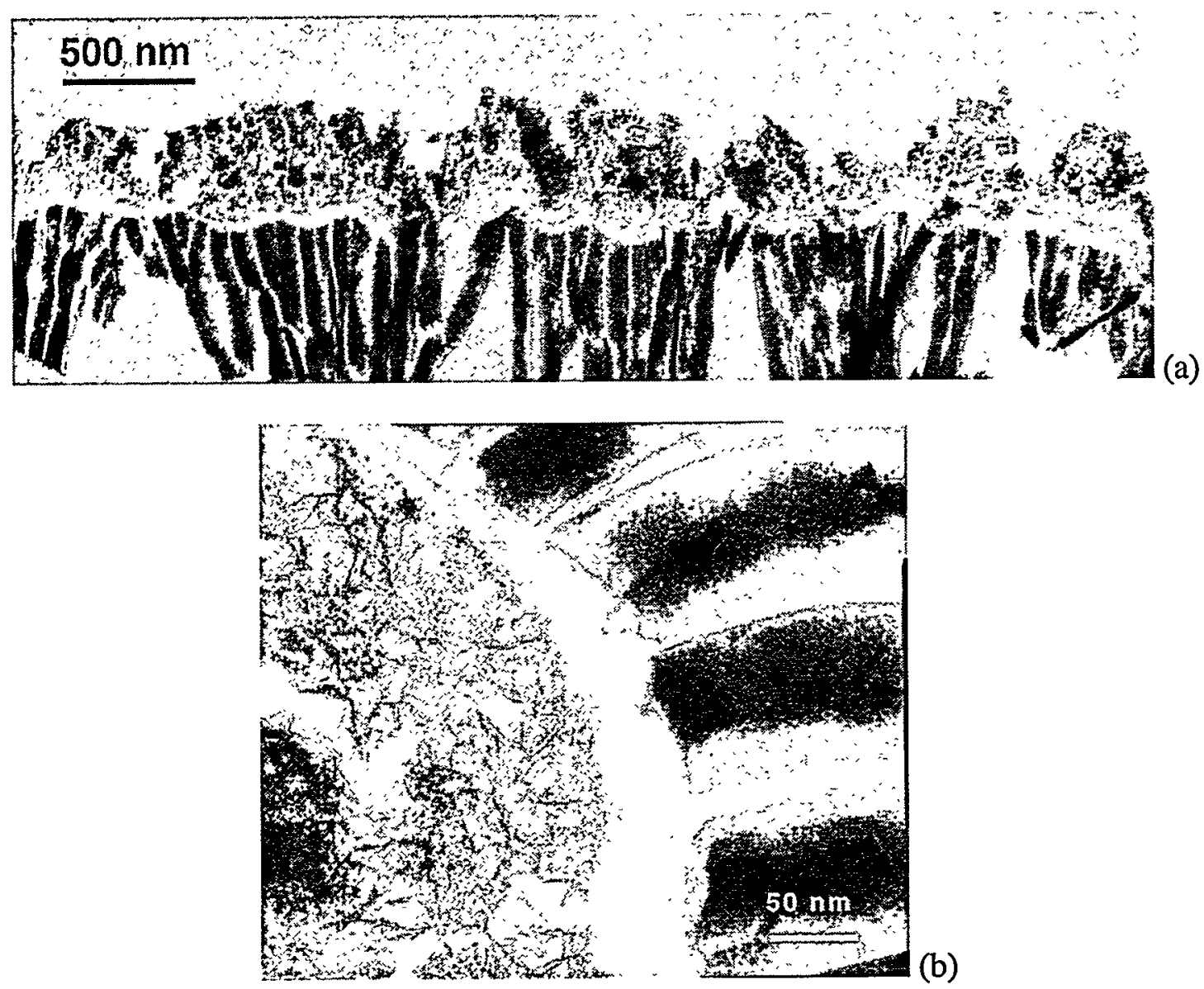

(b)

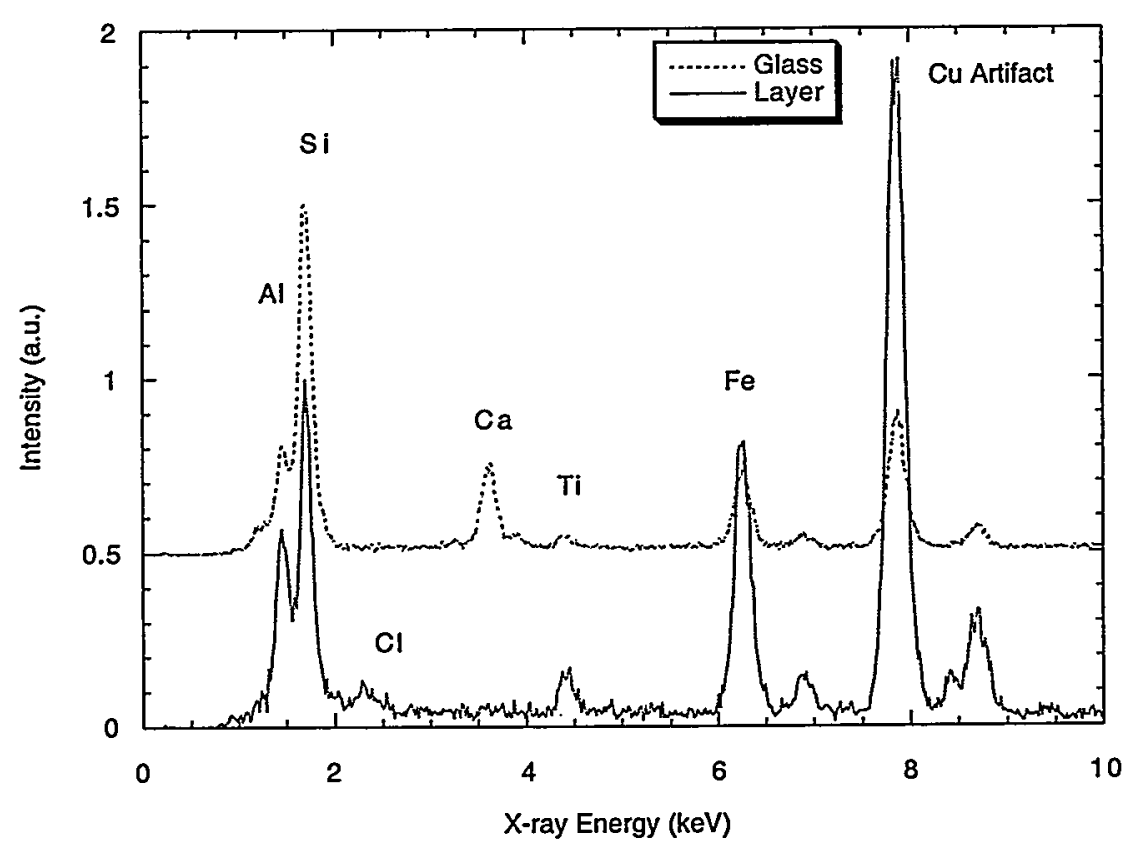

(c)

Fig. 24. Analyses of cross-sectioned block 1579: (a) TEM image of glass and layer,

(b) high magnification of the layer showing the formation of fibrous clay, and (c) EDS spectra comparing glass and layer. 


\subsubsection{Vapor Reaction at $75^{\circ} \mathrm{C}$ and $100 \% \mathrm{RH}$}

The surface of the reacted sample was smooth but covered with a thin milky layer (Fig. 25). It was free of the white specks that were observed in the open-air unsaturated test. Examination with SEM confirmed a smooth surface which seemed to exhibit little reaction (Fig. 26). An occasional loose speck was observed on the surface that was relatively richer in $\mathrm{Ca}$ than the surface (Fig. 26). Examination of the cross section of the reacted sample with SEM essentially showed a clean surface with no layer visible within the resolution of SEM.

Examination by AEM of a cross section of the reacted sample revealed the formation of a layer of fibrous clays (Fig. 27), which were identified to be saponite with electron diffraction. Analysis of the layer with EDS indicated the enrichment of $\mathrm{Fe}$ and depletion of $\mathrm{Ca}$ in comparison with the unreacted glass (Fig. 27).

\subsubsection{Summary}

Alteration layers on synthetic basalt glass formed at both $95 \%$ and $100 \% \mathrm{RH}$. At $95 \% \mathrm{RH}$, an amorphous gel layer first formed, which was then converted, most likely in situ, to saponite fibrous clay. The formation of a gel layer indicates that the reaction may be controlled by water diffusion and ion-exchange processes. At $100 \% \mathrm{RH}$, however, no obvious gel layer was found; instead, there were signs of congruent melting at the surface. The alteration layer consisted mainly of saponite clay, which may have precipitated after it reached its solubility limit as the glass continued to dissolve. 

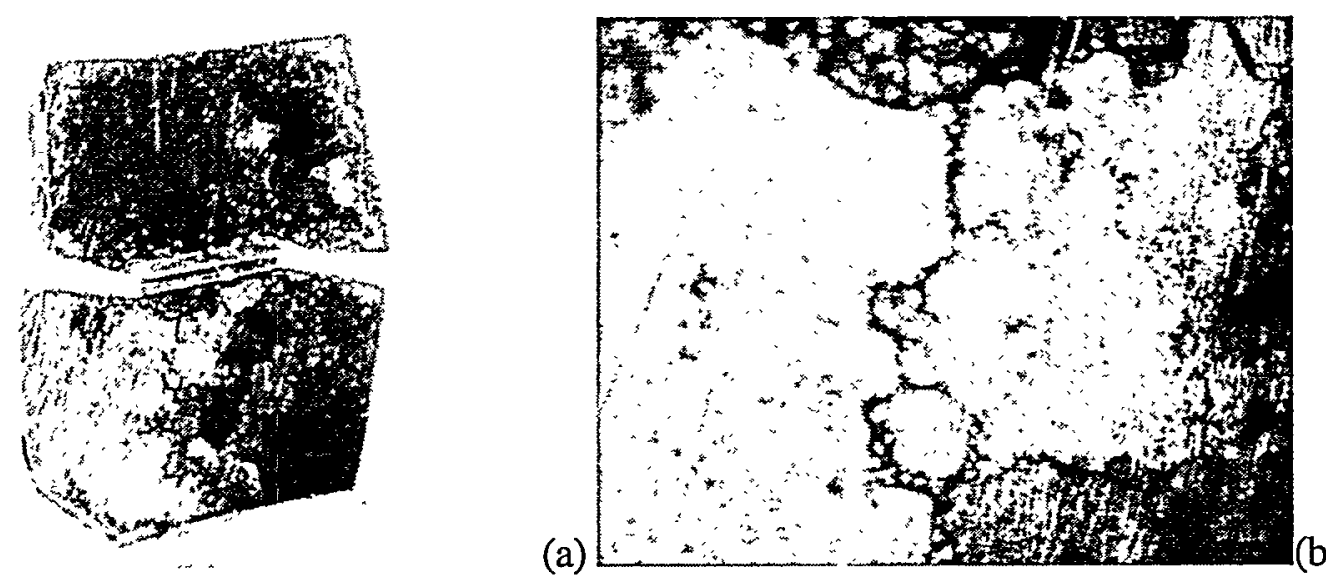

Fig. 25. Optical microscopy images of the synthetic basalt glass vapor reacted at $75^{\circ} \mathrm{C}$ and $100 \% \mathrm{RH}$ for seven years taken at (a) $6 \mathrm{X}$ and (b) $50 \mathrm{X}$.
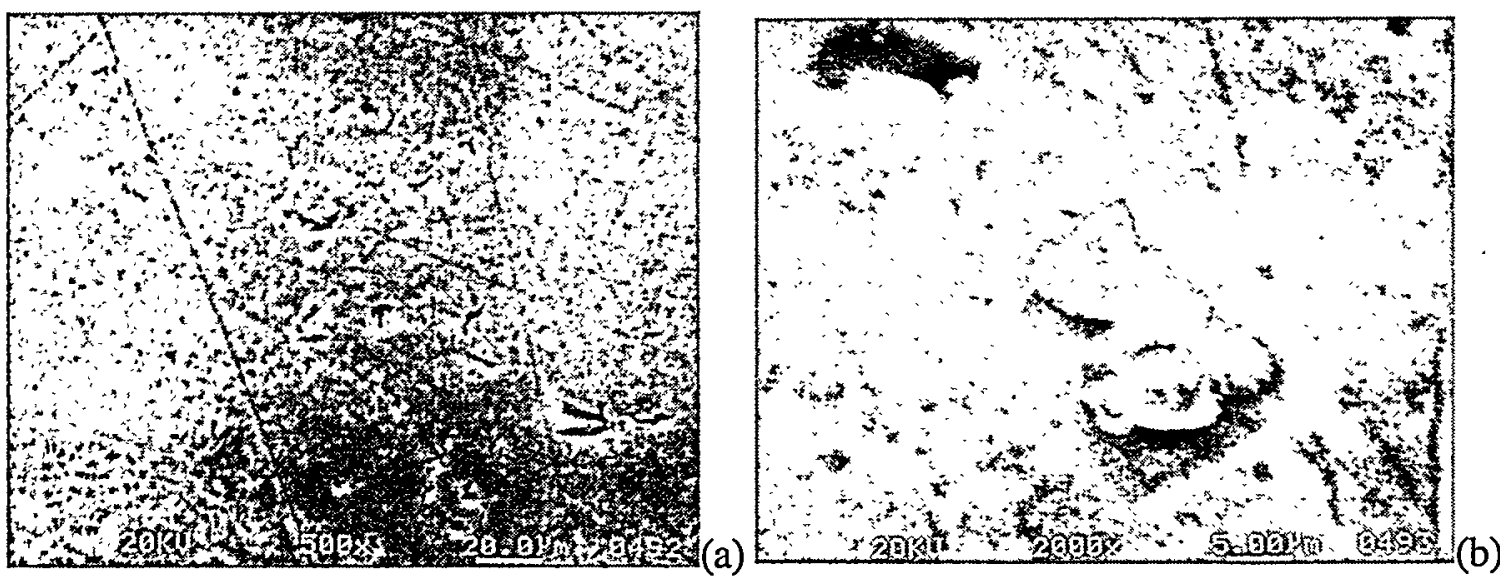

Fig. 26. Scanning electron micrographs of the surface of the synthetic basalt glass vapor reacted at $75^{\circ} \mathrm{C}$ in $100 \% \mathrm{RH}$ for seven years. No layer was observed (a), just precipitated particles (b). 

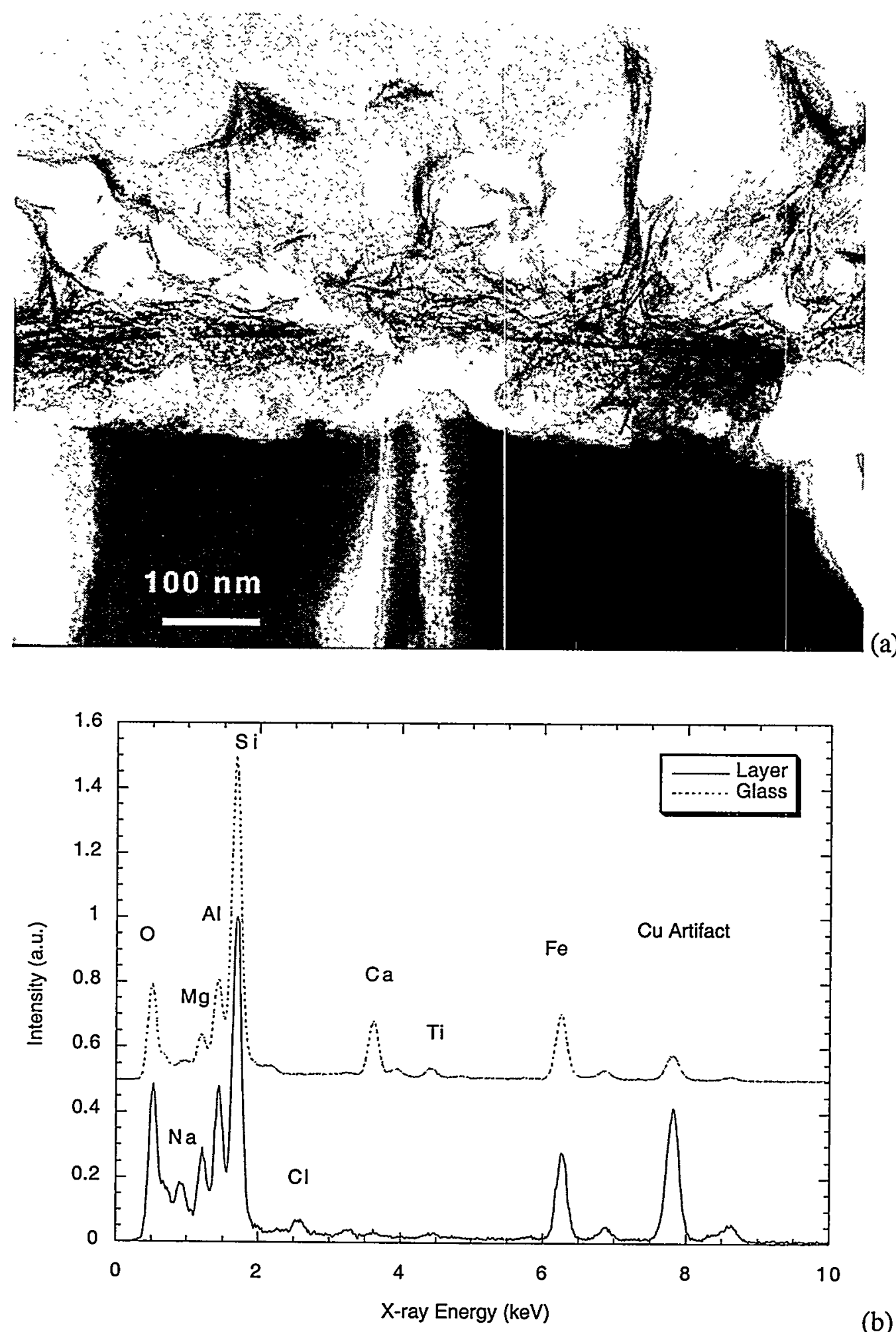

(b)

Fig. 27. (a) Cross-sectional TEM image of the layer formed on the glass surface of synthetic basalt glass vapor reacted at $75^{\circ} \mathrm{C}$ and $100 \% \mathrm{RH}$ for seven years and (b) the EDS spectra comparing the alteration layer and unreacted glass. 


\subsubsection{Laboratory-Reacted Waste Glass SRL165}

\subsubsection{Vapor Reaction at $75^{\circ} \mathrm{C}$ and $95 \% \mathrm{RH}$}

\subsection{Seven-Year Results}

The glass was reacted, and a whitish layer had formed on the glass surface (Fig. 28). Examination by SEM showed the formation of alteration multilayers on the surface, along with large quantities of small balls (about $1 \mu \mathrm{m}$ ) on the outer layer (Fig. 29). Analysis of these layers by EDS revealed a similar composition for all of the layers. Regardless their relative positions and morphologies (Fig. 27): rich in Si, Al, and Fe and often including a small amount of $\mathrm{S}$. The small balls had a composition very similar to that of the layers. Examination of a cross section of the reacted sample revealed a uniform $1-\mu \mathrm{m}$ alteration layer on the surface (Fig. 30a). The alteration layer was richer in $\mathrm{Fe}$ and $\mathrm{Ca}$ and poorer in $\mathrm{Na}$ than the glass.

A thin alteration layer was picked up from the surface and sectioned for AEM examination. Results showed that several crystalline precipitates coexisted in an amorphous matrix (Fig. 30b). The crystals were identified as Fe-rich spinel and saponite clay by electron diffraction (Fig. 31). Analysis of the amorphous matrix by EDS indicated enrichment by $\mathrm{Si}, \mathrm{Al}$, and transition metals, as well as the presence of substantial amounts of $\mathrm{Cl}$ and S (Fig. 31c).

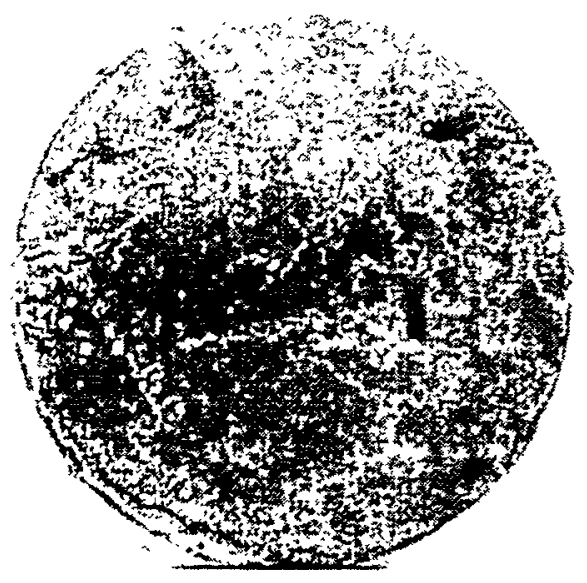

(a)

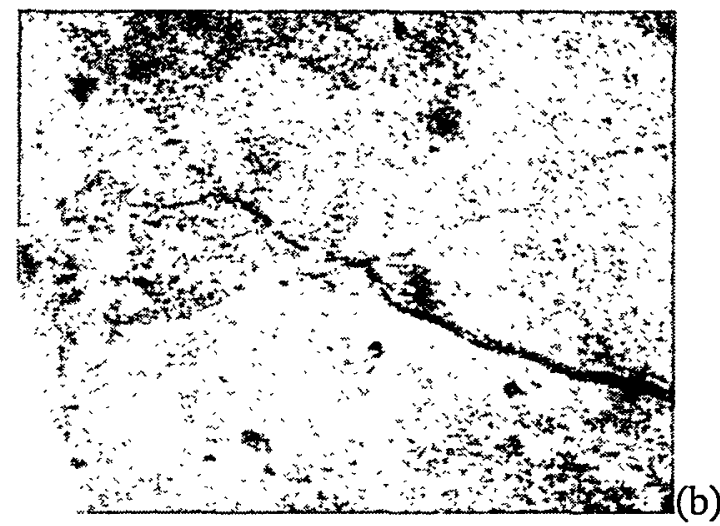

Fig. 28. Optical microscopy images of the SRL 165 waste glass vapor reacted at $75^{\circ} \mathrm{C}$ and 95\% RH for seven years taken at (a) $6 \mathrm{X}$ and (b) $50 \mathrm{X}$. 

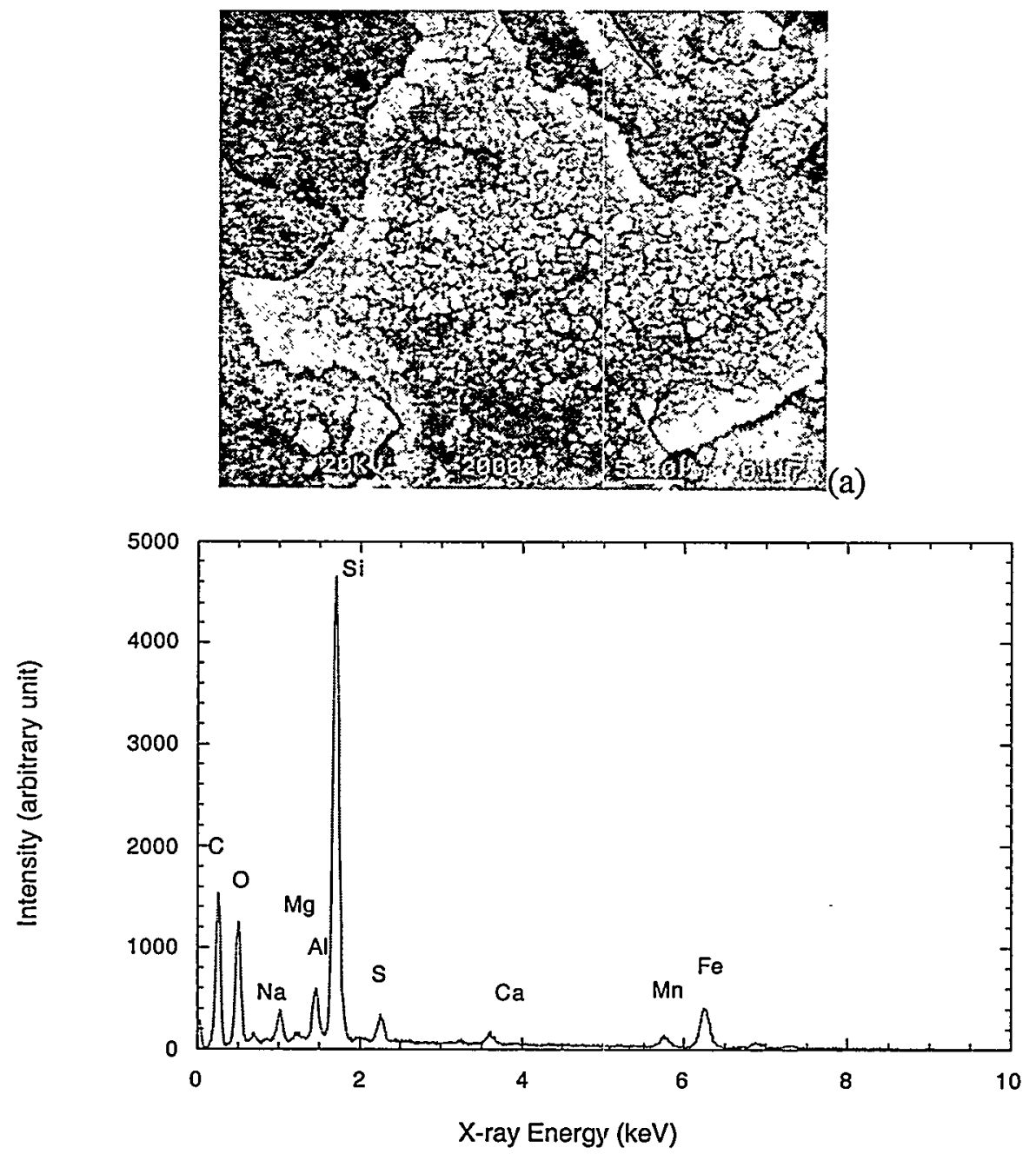

(b)

Fig. 29. (a) An SEM image of the layer formed on the surface of the SRL 165 glass vapor reacted at $75^{\circ} \mathrm{C}$ in $95 \% \mathrm{RH}$ for seven years and (b) its EDS spectrum. 

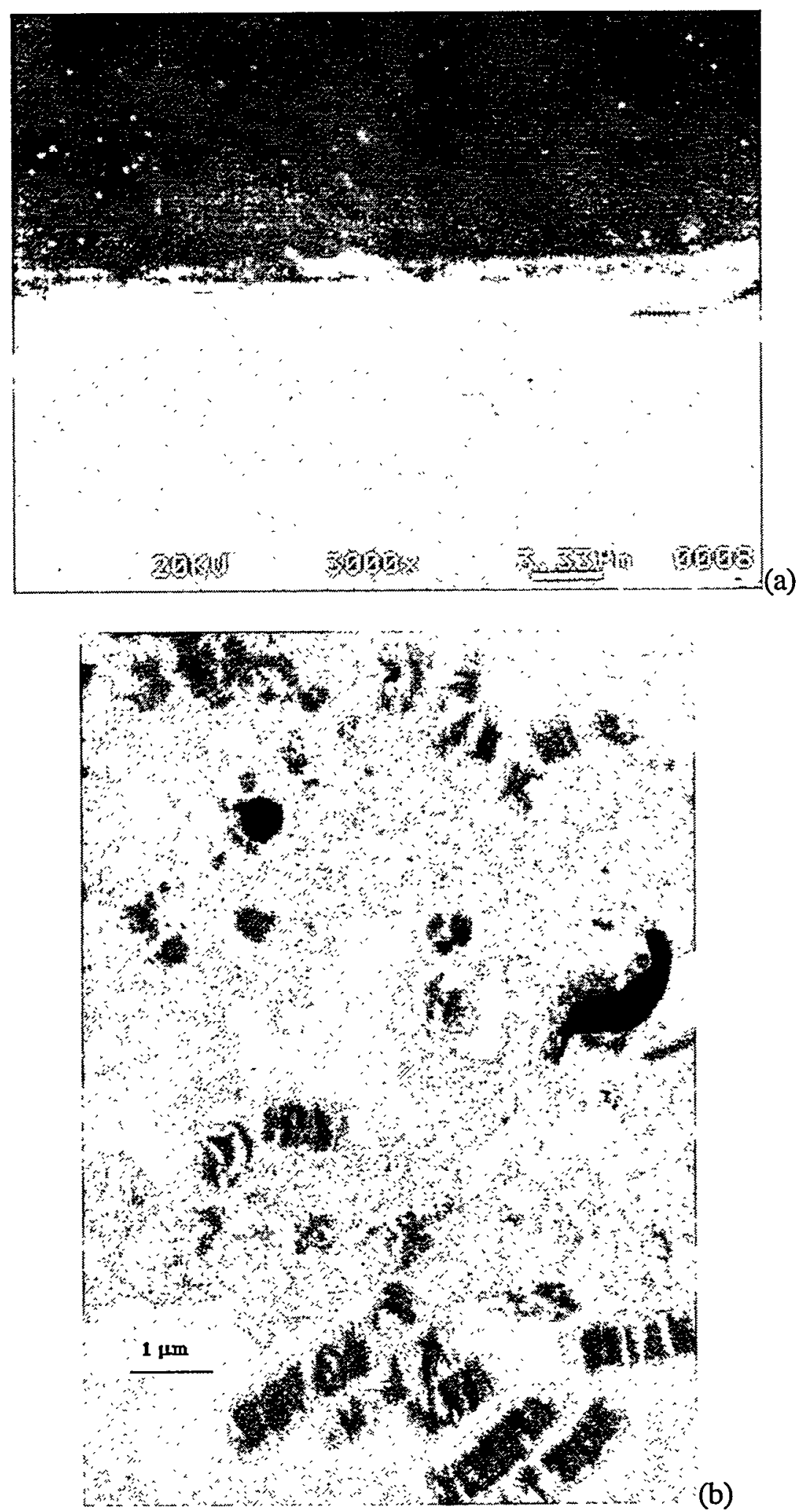

(b)

Fig. 30. (a) Cross-sectional SEM image of the limited layer formed on the surface of the SRL 165 glass vapor reacted at $75^{\circ} \mathrm{C}$ in $95 \% \mathrm{RH}$ for seven years and (b) a TEM image of the sectional sample. 

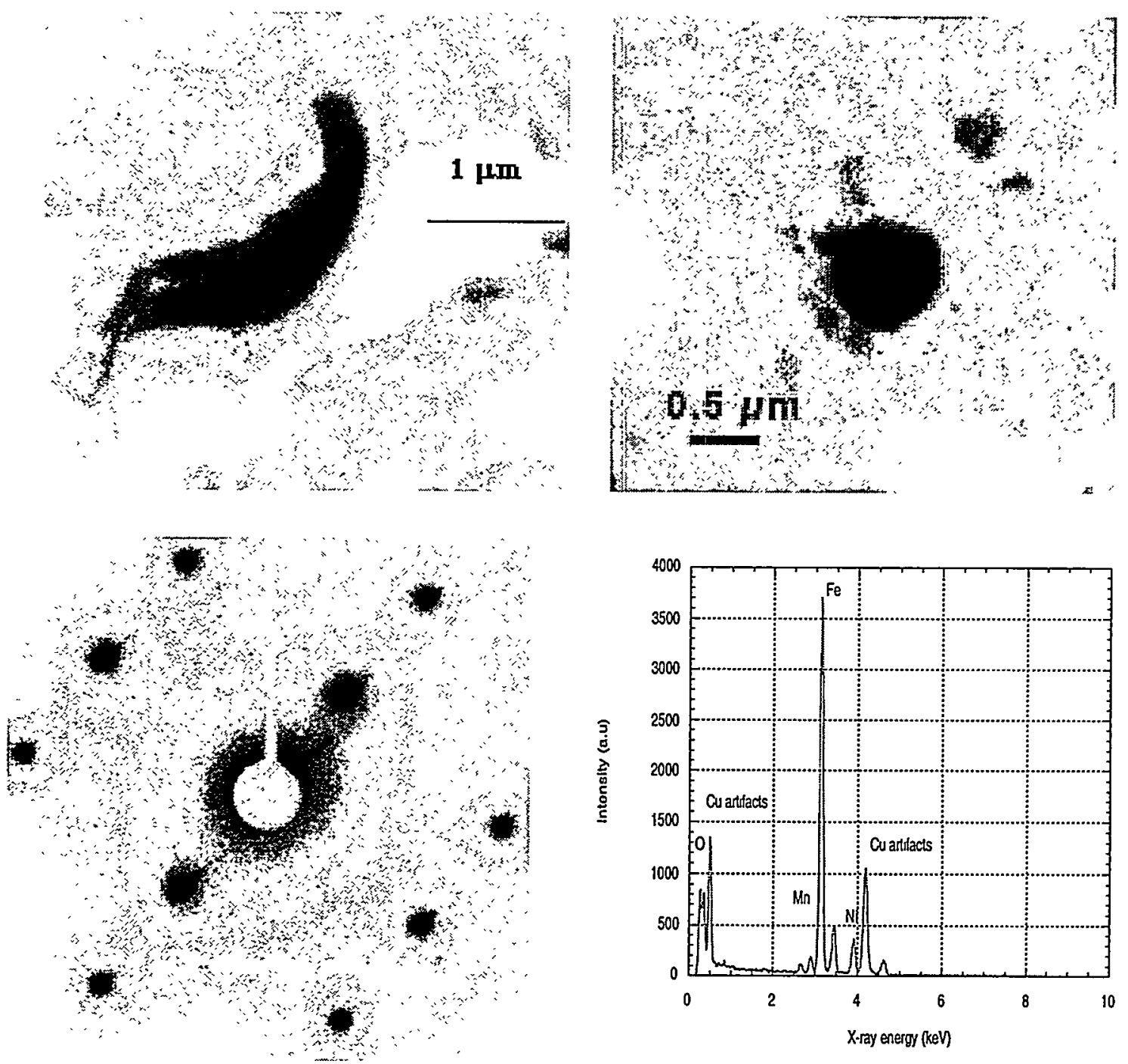

(a)

Fig. 31. Analyses of crystalline precipitates, saponite clay, and the amorphous matrix on SRL 165 glass vapor reacted at $75^{\circ} \mathrm{C}$ and $95 \%$ RH for seven years: (a) TEM image, electron diffraction pattern, and EDS spectrum of the Fe-rich spinel precipitates; (b) TEM image, electron diffraction, and EDS spectrum of the saponite clay; (c) EDS spectrum of amorphous material. 

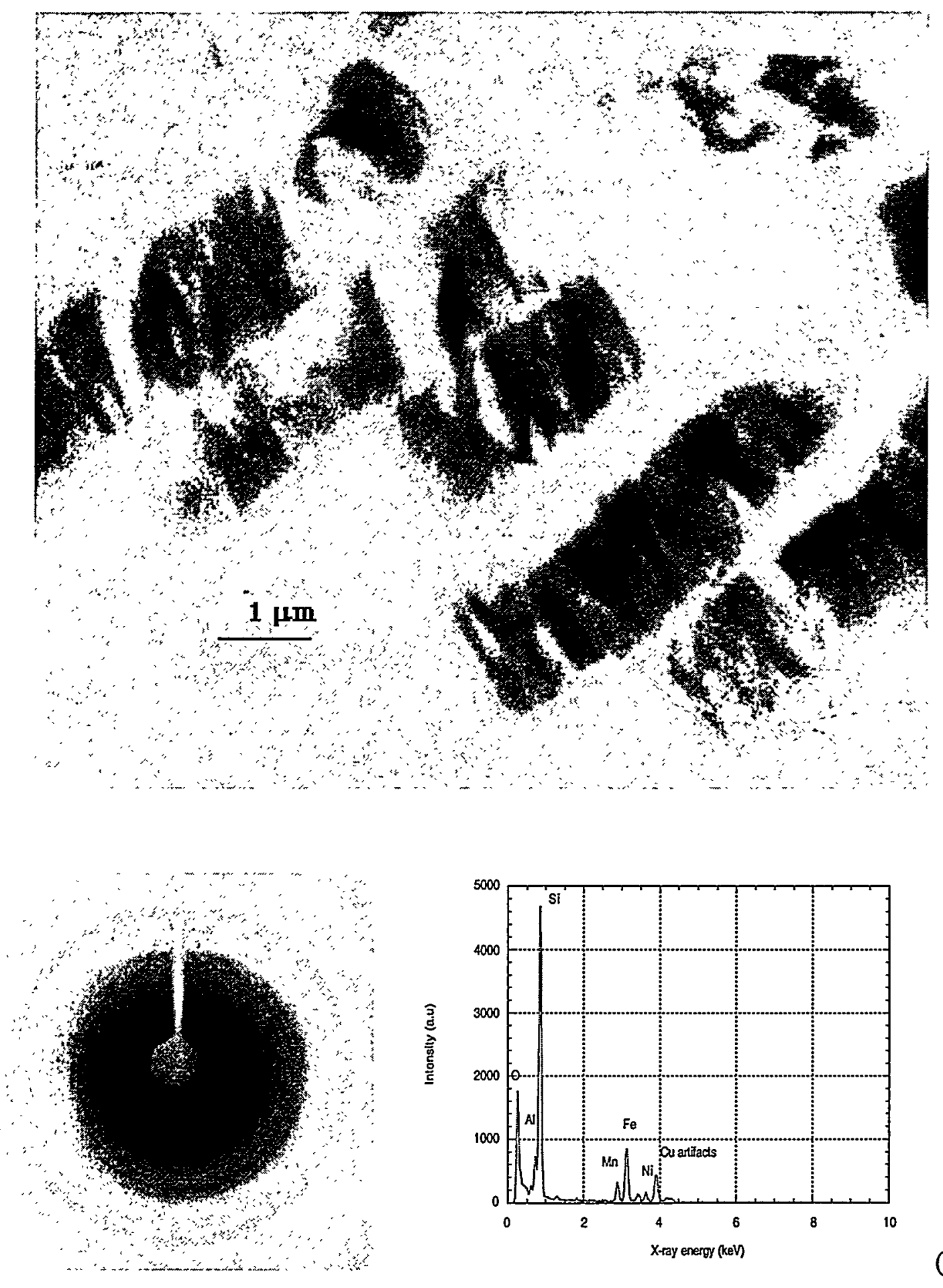

(b)

Fig. 31. Contd. 


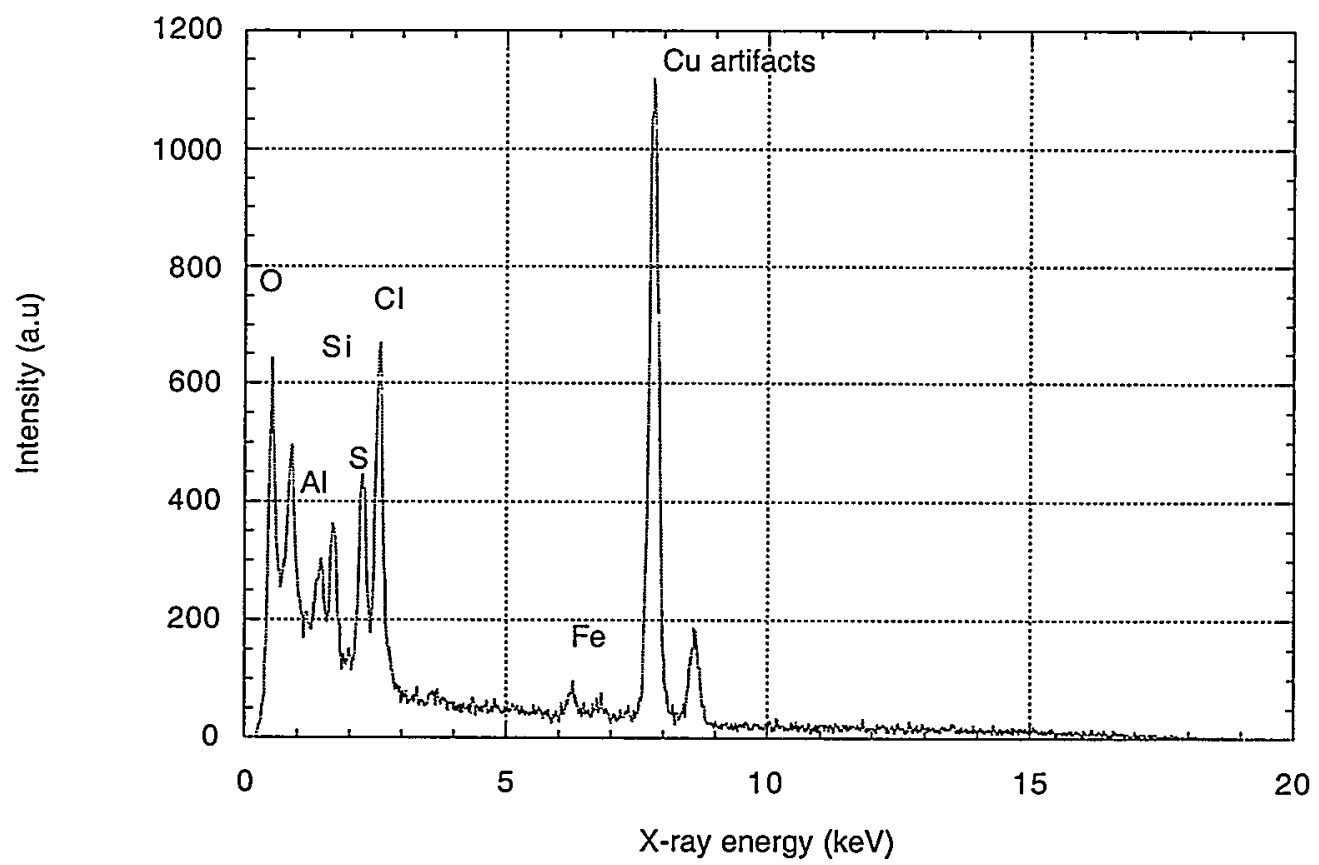

Fig. 31. Contd.

(c)

\subsection{Nine-Year Results}

This glass was heavily reacted, and a yellow layer was formed on the surface (Fig. 32). The reaction did not occur uniformly on the surface, and, in some areas, the layer had started to spall. Examination of the surface by SEM showed that the alteration layer on the outer surface had disintegrated into small round particles of less than $1 \mu \mathrm{m}$ (Fig. 33). In some areas, the layer had spalled off from the surface and the glass underneath the layer could be seen. Interestingly, a heavy density of etched pits was observed to have formed on the surface of the pristine glass (Fig. 33), indicating the dissolution of glass near the glass/layer interface. Analyses with EDS indicated that the layer was generally richer in $\mathrm{Ca}, \mathrm{Fe}$, and $\mathrm{Ti}$ than the glass underneath. In some cases, a strong $\mathrm{S}$ peak was seen associated with a Ti-rich alteration product. 

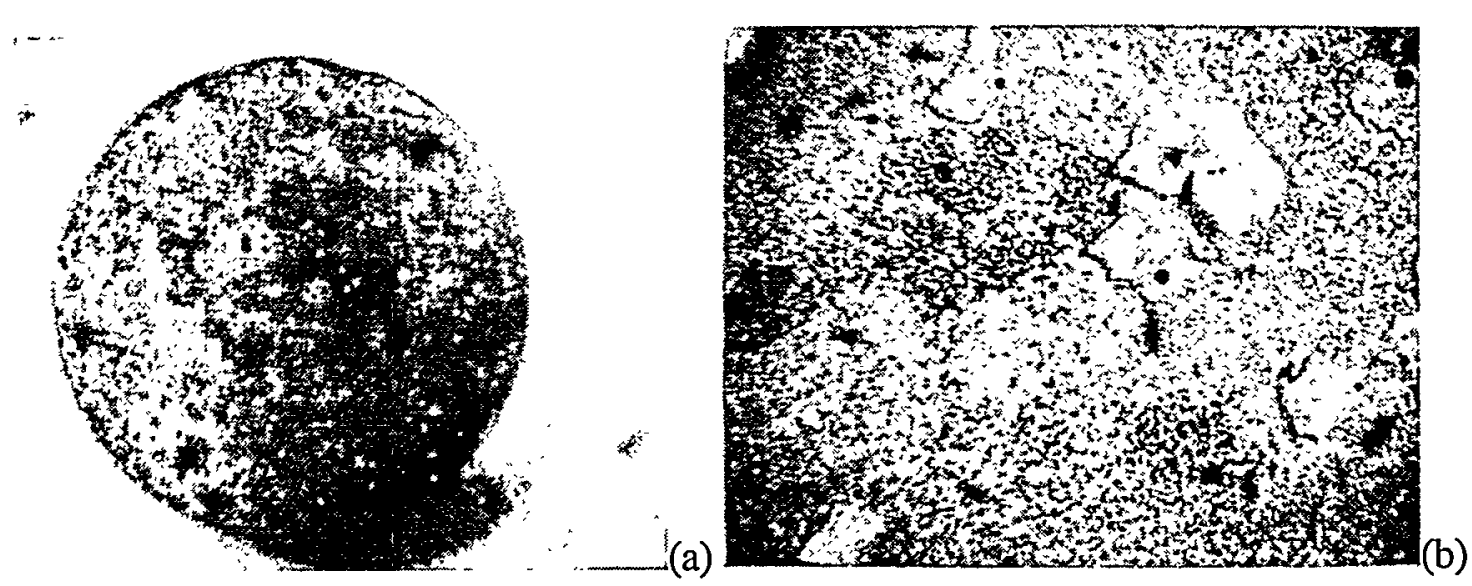

Fig. 32. Optical microscopy images of the SRL 165 waste glass vapor reacted at $75^{\circ} \mathrm{C}$ and $95 \% \mathrm{RH}$ for nine years taken at (a) $6 \mathrm{X}$ and (b) 50X.
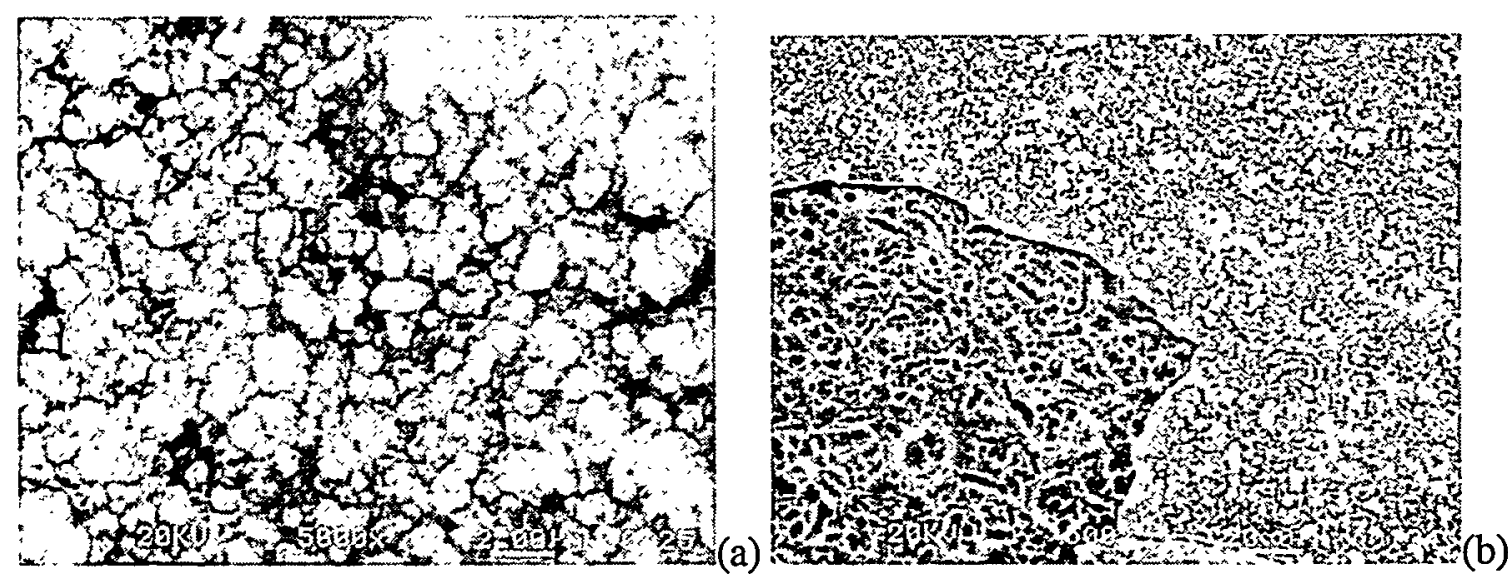

Fig. 33. Scanning electron micrographs of the surface of the SRL 165 glass vapor reacted at $75^{\circ} \mathrm{C}$ and $95 \% \mathrm{RH}$ for nine years showing (a) the layer formed and (b) the glass underneath the layer having many etched pits.

Cross sections of the reacted sample were also prepared and examined under SEM. A layer about $5 \mu \mathrm{m}$ thick was observed to have formed on the surface (Fig. 34) that had a porous microstructure and often was seen to have spalled on the surface. Analyses of both layer and glass with EDS revealed enrichment of $\mathrm{Ca}$ and $\mathrm{Fe}$ in the layer compared with the unreacted glass. 

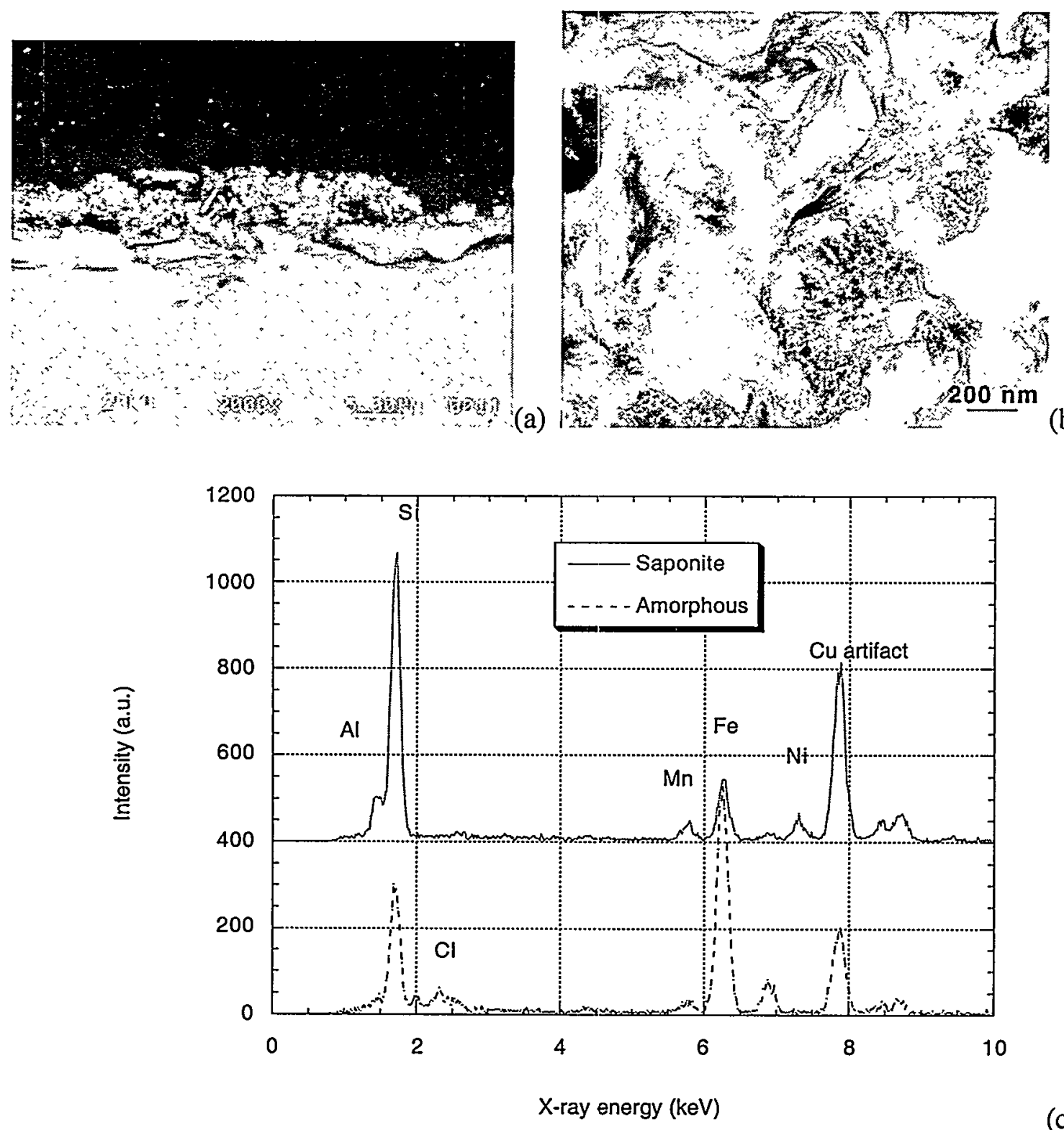

(b) 165 glass vapor reacted at $75^{\circ} \mathrm{C}$ and $95 \% \mathrm{RH}$ for nine years, (b) TEM image of the sectioned sample, and (c) EDS spectra comparing the amorphous zone and the clay.

A thin alteration layer was scratched from the surface and was mounted and sectioned for AEM examination. The sectioned layer was found to mainly consist of smectite-type clay and an amorphous phase (Fig. 34). The clay was identified as saponite with electron diffraction. Analysis by EDS showed Al, Si, Mn, $\mathrm{Fe}$, and $\mathrm{Ni}$ were present in the clay while the amorphous material consisted mainly of $\mathrm{Fe}$ and $\mathrm{Si}$, plus a small amount of $\mathrm{Cl}$ (Fig. 34c). A crystalline material formed on the surface was found to be quartz. Another crystalline precipitate picked up from the middle of the layer was identified as chabazite with electron diffraction and EDS. These precipitates were not abundant and were minor phases on the surface. 


\subsubsection{Vapor Reaction at $75^{\circ} \mathrm{C}$ and in $100 \% \mathrm{RH}$}

Unlike the sample reacted at $95 \% \mathrm{RH}$, the surface of this sample showed little reaction, and the polishing scratches created in preparing the test sample were still visible on the surface (Fig. 35). Examination with SEM confirmed a smooth unreacted surface with a few loose specks (Fig. 36). The cross section of the reacted sample was prepared and examined by SEM. A sharp glass surface was observed with no obvious formation of an alteration layer on the surface (Fig. 36). This result is interesting because it shows that the relative humidity may significantly effect the progress of glass corrosion. In this case, the glass corroded more extensively at $95 \% \mathrm{RH}$ than under saturated conditions, demonstrating that the corrosion could be substantially enhanced under unsaturated condition.

A thin wedge with a layer was selected and sectioned for AEM analysis (see Fig. 37). A thin, fibrous clay layer about $100 \mathrm{~nm}$ thick was found to

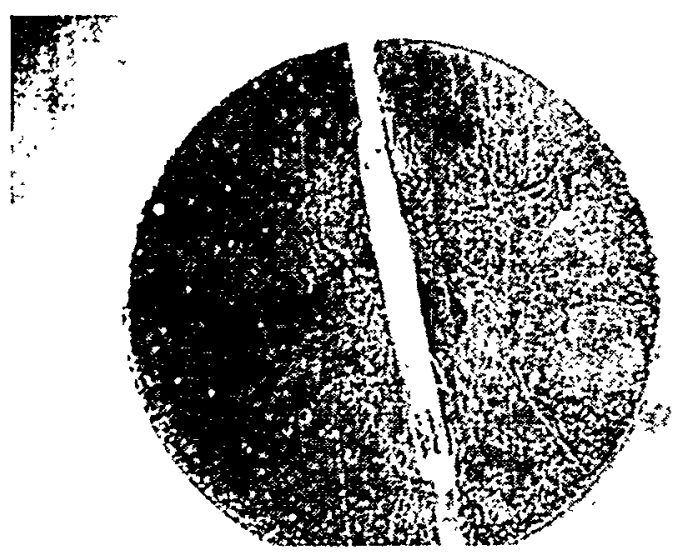

(a)

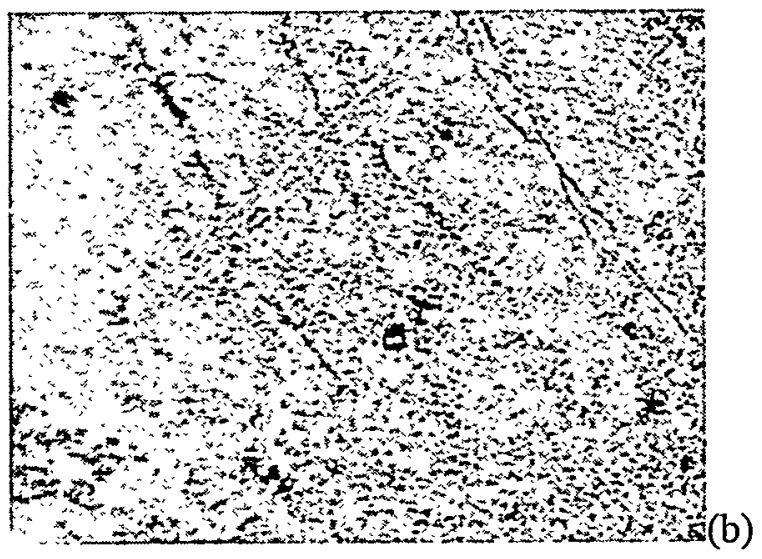

Fig. 35. Optical images of the SRL 165 waste glass vapor reacted at $75^{\circ} \mathrm{C}$ and $100 \% \mathrm{RH}$ for seven years taken at (a) $6 \mathrm{X}$ and (b) $50 \mathrm{X}$.
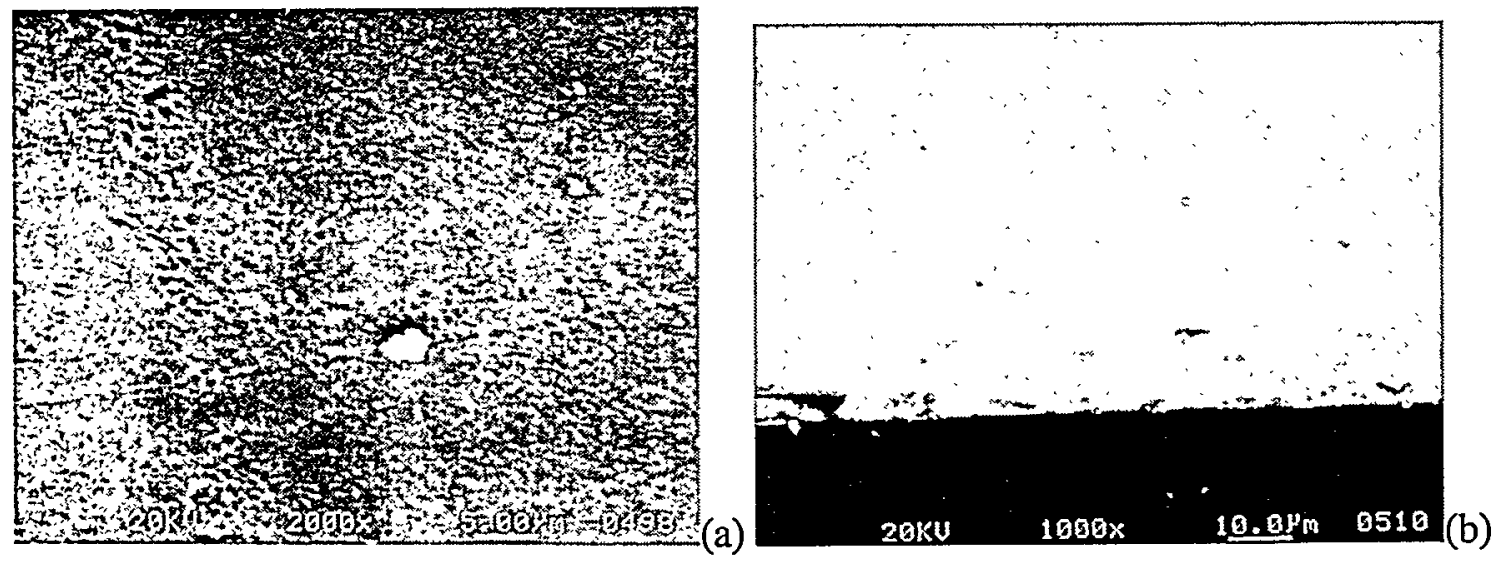

Fig. 36. (a) An SEM image of the surface of the SRL 165 waste glass vapor reacted at $75^{\circ} \mathrm{C}$ and $100 \% \mathrm{RH}$ for seven years and (b) a cross-sectional SEM image of the surface showing no apparent layer formation. 

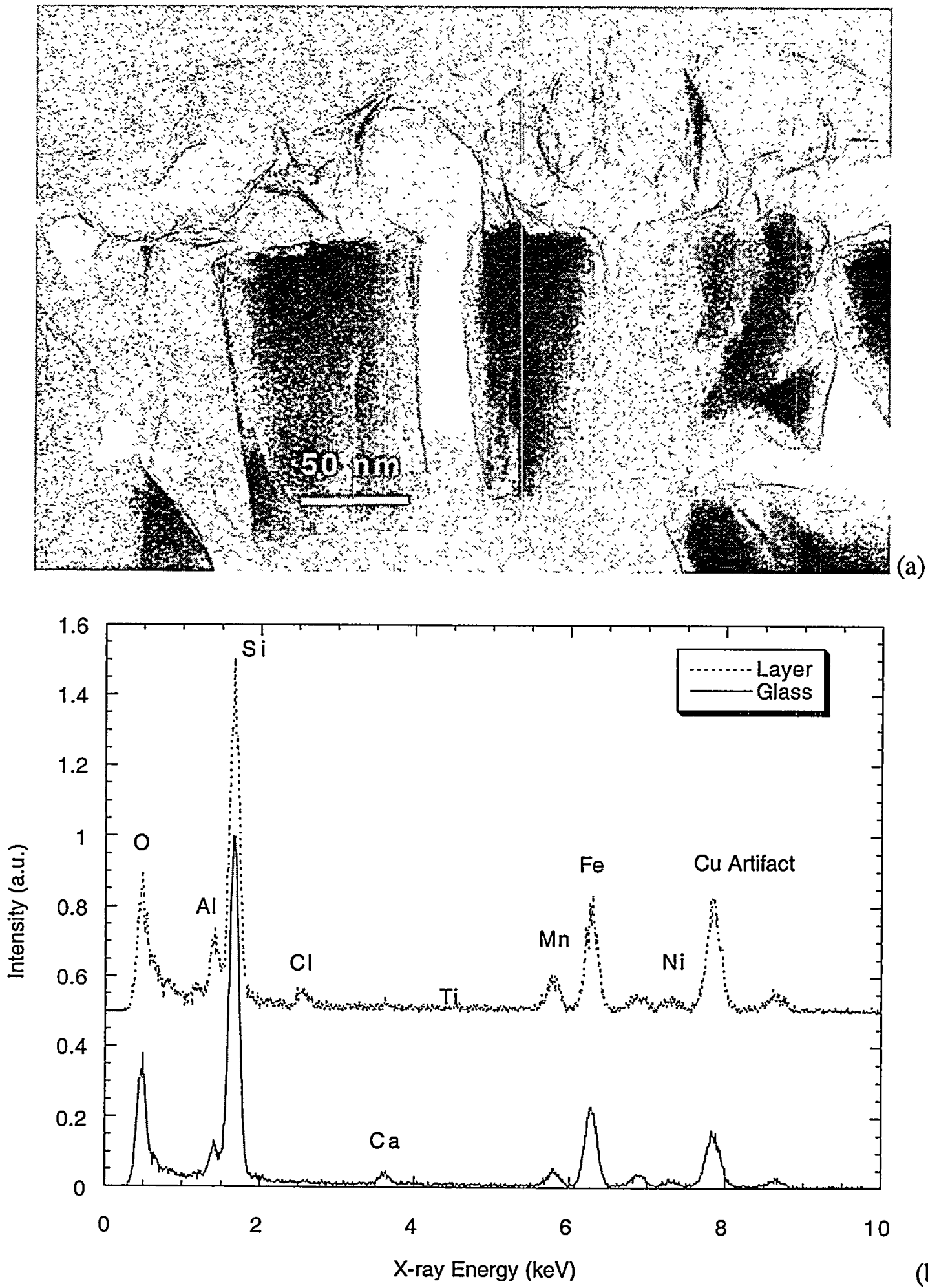

(b)

Fig. 37. (a) Transmission electron micrograph of clay layer that formed on the SRL 165 glass vapor reacted at $75^{\circ} \mathrm{C}$ and $100 \% \mathrm{RH}$ for seven years and (b) EDS spectra comparing the layer and the glass. 
have formed on the surface. Analysis of this layer by EDS indicated enrichment of Mn, $\mathrm{Ni}, \mathrm{Al}$, and $\mathrm{Cl}$ and depletion of $\mathrm{Ca}$ compared with the unreacted glass core (Fig. 36). The clay phase could not be identified with electron diffraction because the layer was too thin to generate a decent diffraction pattern. However, its morphology was very similar to the smectite-like clay that we had observed in other samples.

\subsubsection{Summary}

The alteration of glass was strongly affected by relative humidity. At $95 \% \mathrm{RH}$, alteration layers of $1-5 \mu \mathrm{m}$ were abserved on the surface, whereas no obvious layer was observed for the glass reacted at $100 \% \mathrm{RH}$. The alteration layer consisted mainly of fibrous saponite clay. Secondary-phase precipitates, which were not abundant, were taken from the surface and were identified as chabazite with AEM.

\subsubsection{Laboratory-Reacted Waste Glass SRL131}

\subsubsection{Vapor Reaction at $75^{\circ} \mathrm{C}$ and at $95 \% \mathrm{RH}$}

\subsection{Seven-Year Results}

The glass was reacted, and the surface became covered with a porous yellowish layer (Fig. 38). Examination of the surface with SEM revealed the presence of round particles $(20 \mu \mathrm{m})$, which were loosely attached to the surface (Fig. 39a). The particles themselves were composed of aggregates of smaller particles (1 $\mu \mathrm{m}$ or less; Fig. 39b). Analyses of these particles by EDS indicated that the alteration products were rich in $\mathrm{Si}, \mathrm{Al}$, and $\mathrm{Na}$ and were nearly free of transition metals (Fig. 39c). The composition of the layer underneath the particles was enriched in $\mathrm{Ca}$ and $\mathrm{Fe}$ but depleted in Na, compared with the unreacted glass.

The cross-sectional SEM image of the reacted sample is shown in Fig. 40. Two alteration layers formed on the surface; a dense layer in immediate contact with unreacted glass and a porous outer layer. Some loose precipitates were also observed on the surface (see Fig. 40). Interestingly, different leached elements seemed to have gone to the different alteration products. The alkali elements, such as $\mathrm{K}$ and $\mathrm{Na}$, were largely incorporated in the loose particles (Fig. 40); the layer in direct contact with the unreacted glass was rich in $\mathrm{Si}$ and $\mathrm{Fe}$, and the outer layer was rich in $\mathrm{Ca}$ and $\mathrm{Fe}$ but contained virtually no $\mathrm{Na}$. 

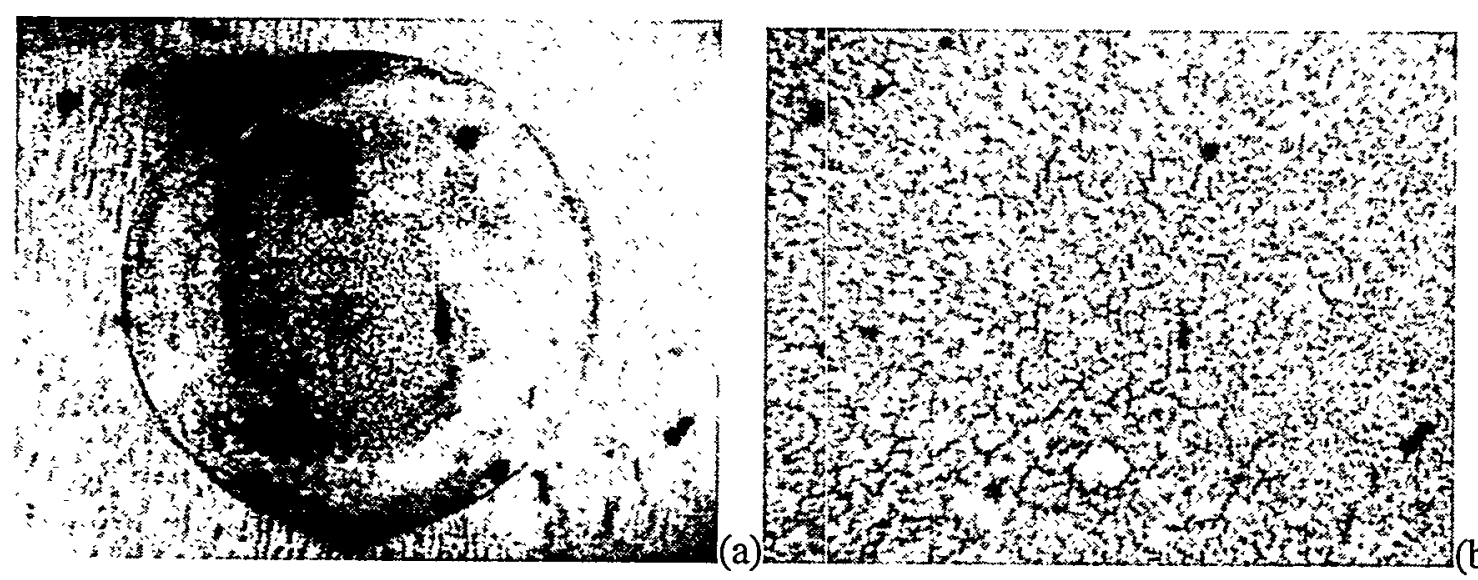

Fig. 38. Optical images of the SRL 131 waste glass vapor reacted at $75^{\circ} \mathrm{C}$ and $95 \% \mathrm{RH}$ for seven years taken at (a) $6 \mathrm{X}$ and (b) 50X. 

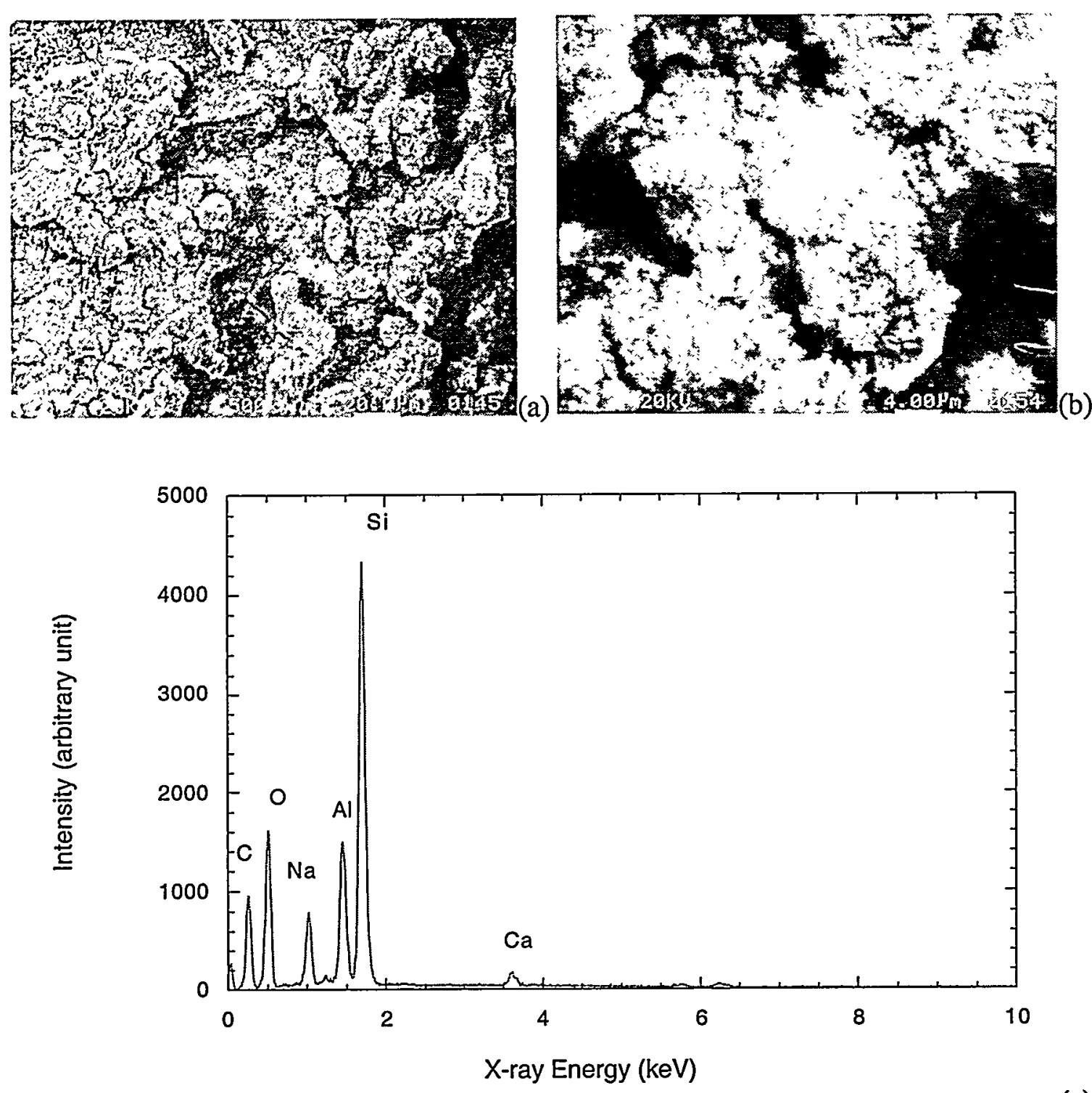

(c)

Fig. 39. Formation of precipitates on surface of SRL 131: (a) SEM image of surface, (b) high-magnification SEM image of the particles, and (c) EDS spectrum of particles. 


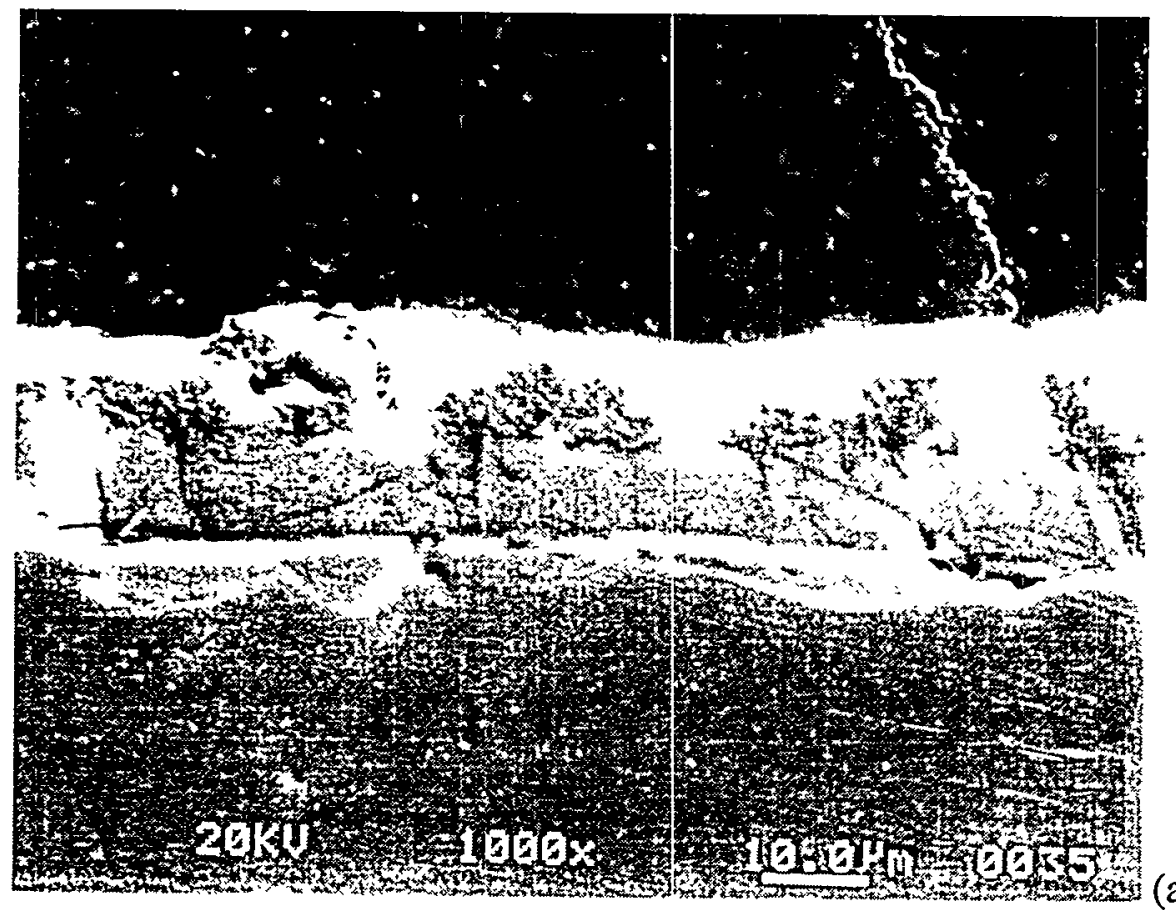

(a)

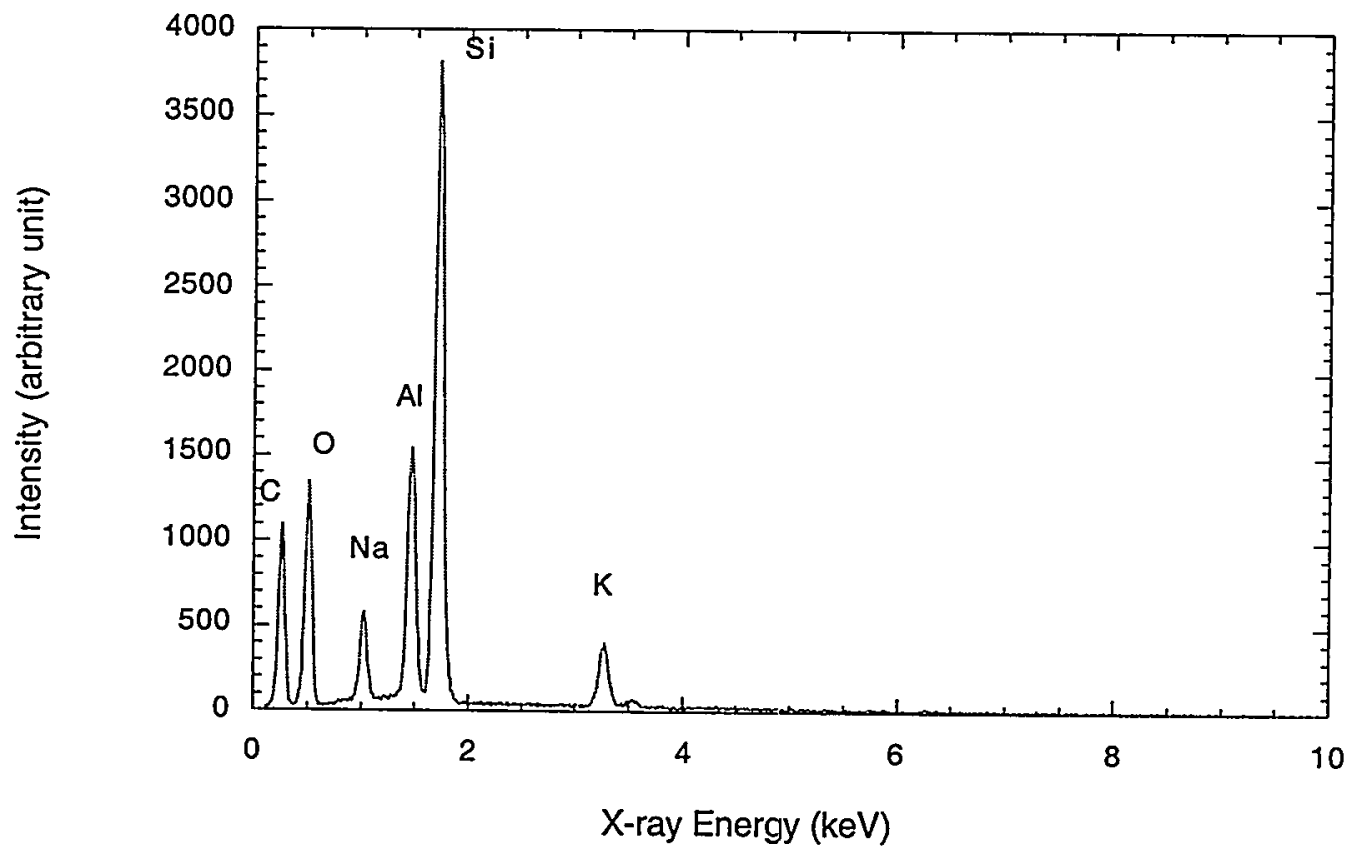

(b)

Fig. 40. (a) Cross-sectional SEM image of the thick layer formed on the surface of the SRL 131 waste glass vapor reacted at $75^{\circ} \mathrm{C}$ and $95 \% \mathrm{RH}$ for seven years and (b) its EDS spectrum. 


\subsection{Nine-Year Results}

A yellowish alteration layer had formed on the surface (Fig. 41). Under the optical microscope, occasional white particles were also seen to have precipitated on the surface (see Fig. 41). Examination of the surface with SEM showed that a dense, heavily cracked alteration layer had formed on the surface, (Fig. 42). Another alteration phase was seen to have precipitated on the top of it, the precipitates typically round and about 7 to $10 \mu \mathrm{m}$ in size. The precipitates contained exclusively Si, Al, and $\mathrm{Na}$ (Fig. 42); the layer underneath was slightly enriched in $\mathrm{Mg}$, $\mathrm{Mn}$, and $\mathrm{Fe}$, but depleted in $\mathrm{Na}$ compared with the unreacted glass.

Cross sections were also prepared and examined under SEM. A uniform alteration layer about $5 \mu \mathrm{m}$ thick was observed to have formed on the surface (Fig. 43), which had a relatively dense microstructure and was compositionally enriched with Fe compared with the pristine glass. 

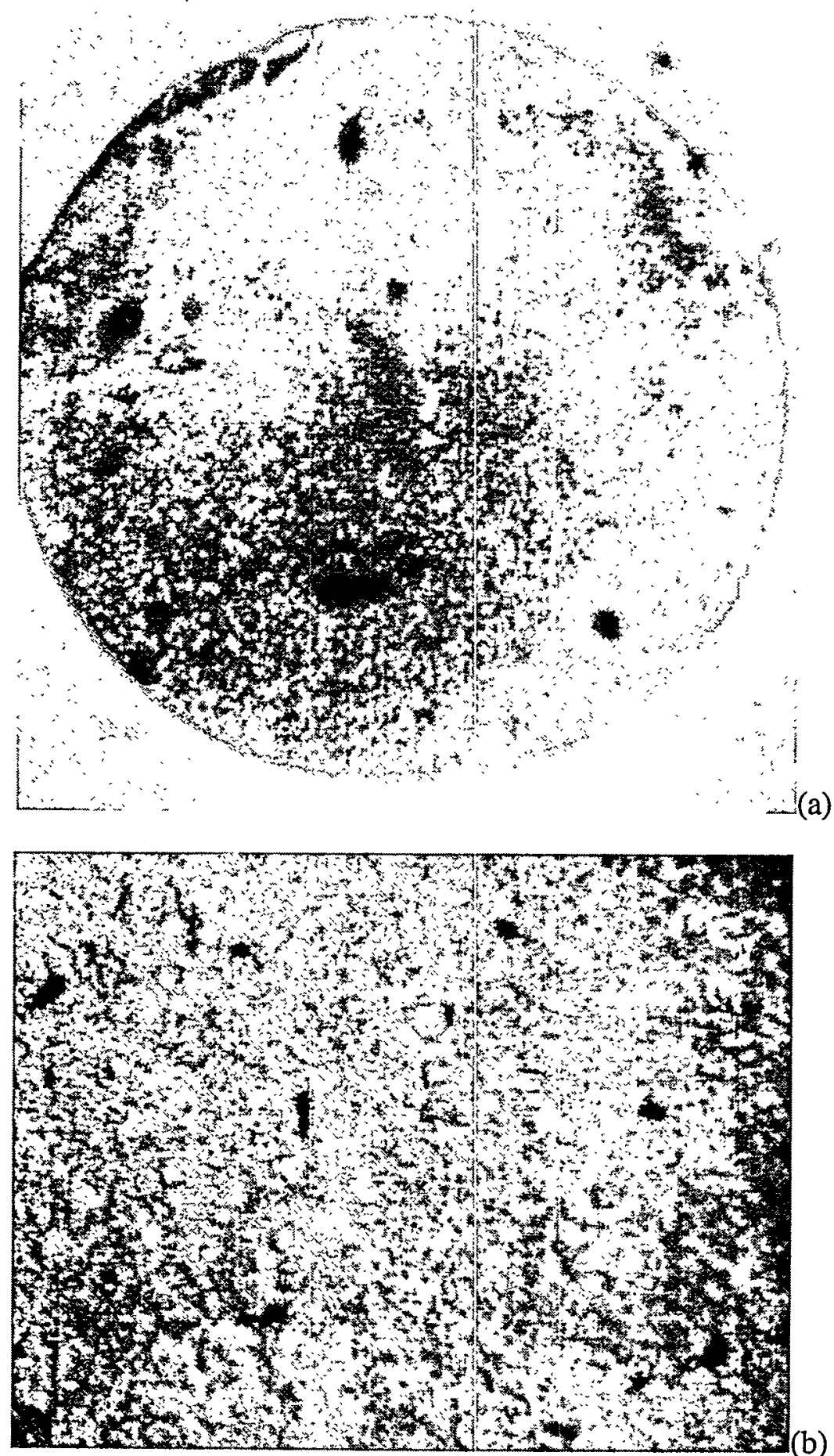

Fig. 41. Optical images of the SRL 131 waste glass vapor reacted at $75^{\circ} \mathrm{C}$ in $95 \% \mathrm{RH}$ for nine years taken at (a) $6 \mathrm{X}$ and (b) $50 \mathrm{X}$. 

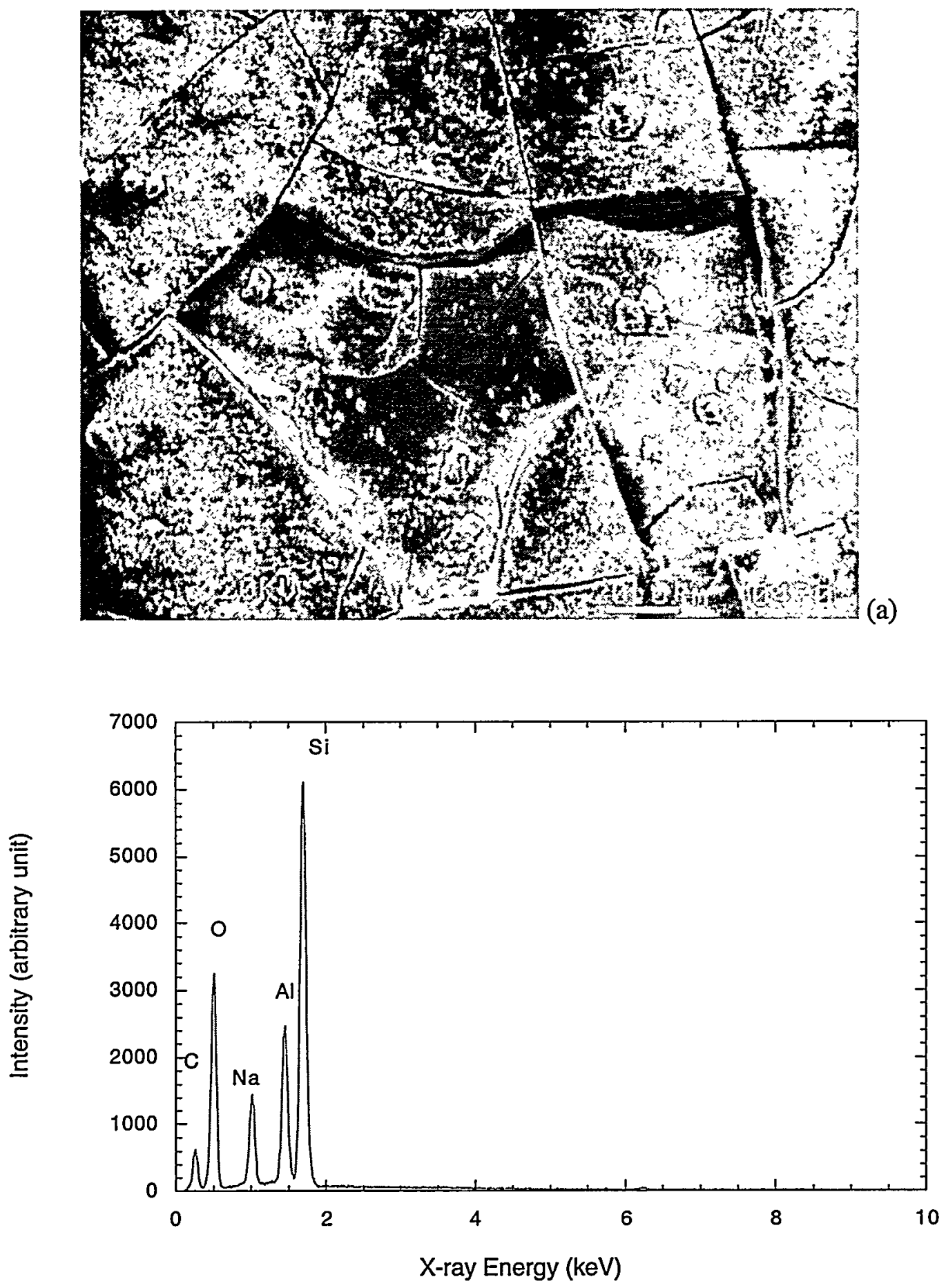

(b)

Fig. 42. (a) An SEM image of the precipitates on the surface of the SRL 131 waste glass vapor reacted at $75^{\circ} \mathrm{C}$ and $95 \% \mathrm{RH}$ for nine years and (b) their EDS spectrum. 


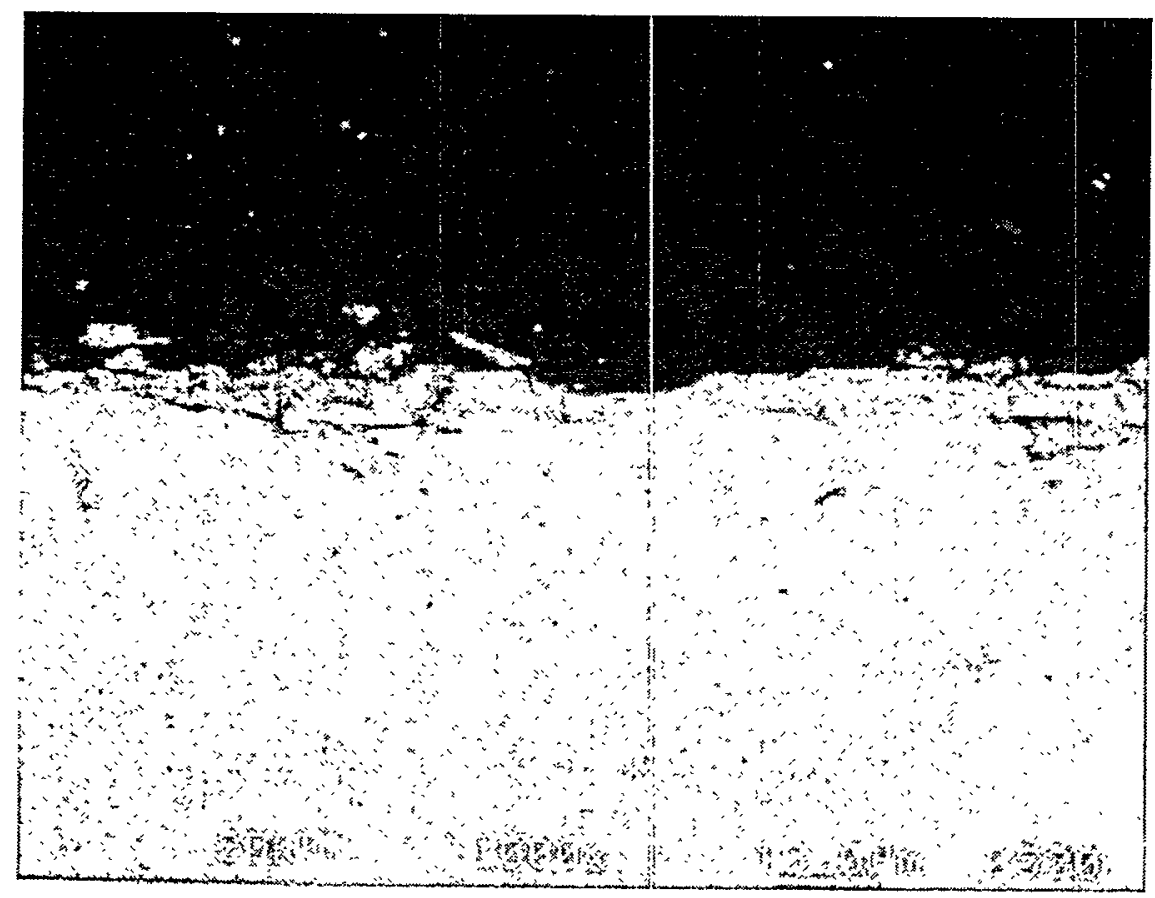

Fig. 43. Cross-sectional SEM image of the layer formed on the surface of the SRL 131 glass vapor reacted at $75^{\circ} \mathrm{C}$ and $95 \% \mathrm{RH}$ for nine years.

A thin alteration layer was removed from the surface, mounted, and sectioned for AEM examination. The sectioned part had been completely reacted, with the formation of randomly oriented clays in the inner layer and textured clays at the outer layer (Fig. 44). The clay was identified as saponite with electron diffraction. Analysis by EDS of the textured layer indicated slight enrichment of Mn and $\mathrm{Mg}$ compared with the randomly oriented layer. Also, a white crystalline particle formed on the surface was sectioned and identified as chabazite by AEM (Fig. 45). 

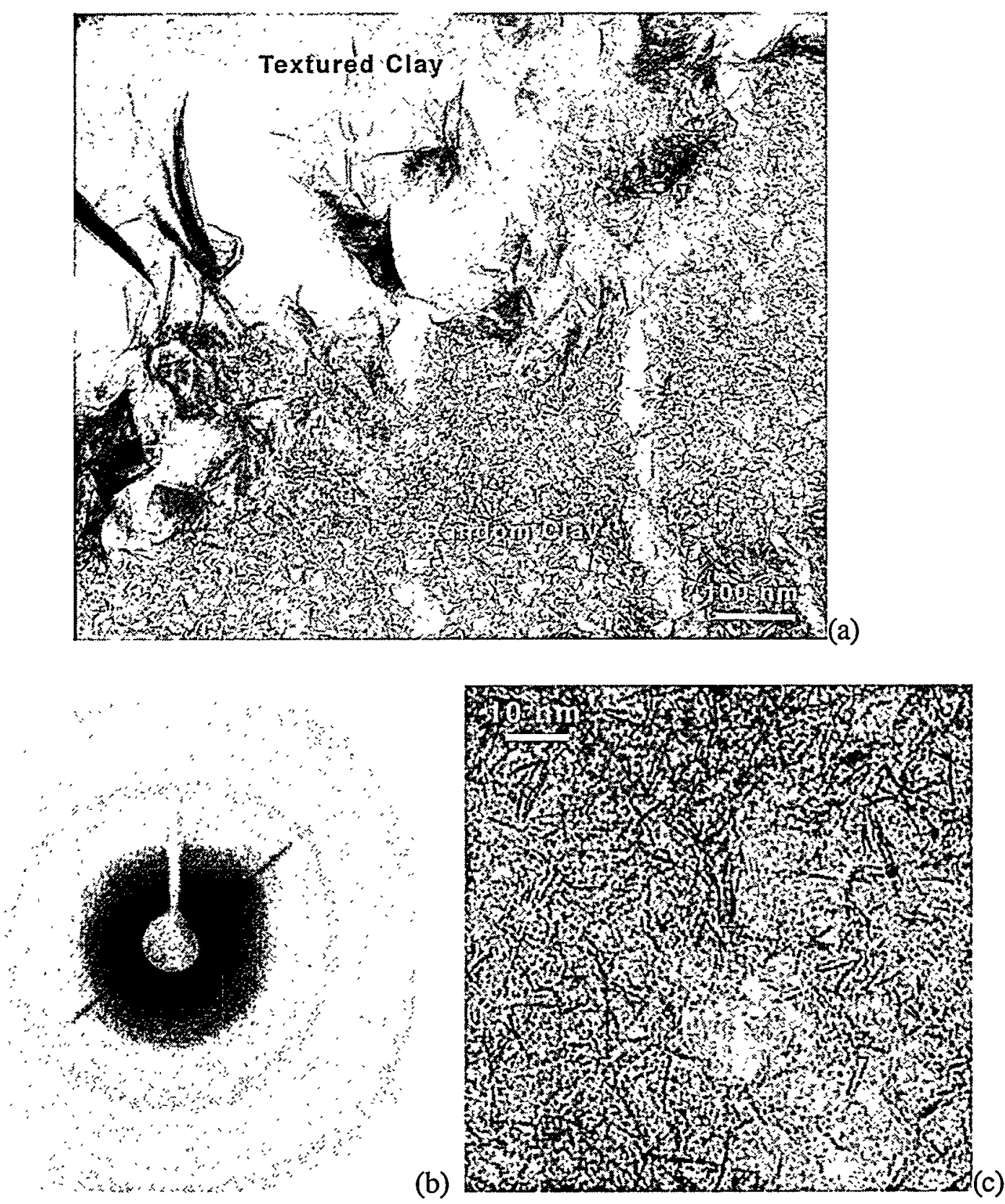

Fig. 44. Results of AEM examinatin of layer formed on SRL 131 waste glass vapor reacted at $75^{\circ} \mathrm{C}$ and $95 \% \mathrm{RH}$ for nine years: (a) TEM image of the sectioned particle, $(b, c)$ electron diffraction pattern and high-magnification image of randomly oriented clays, $(\mathrm{d}, \mathrm{e})$ electron diffraction pattern and high-magnification image of textured clays, and (f) EDS spectra comparing the random and textured clays. 


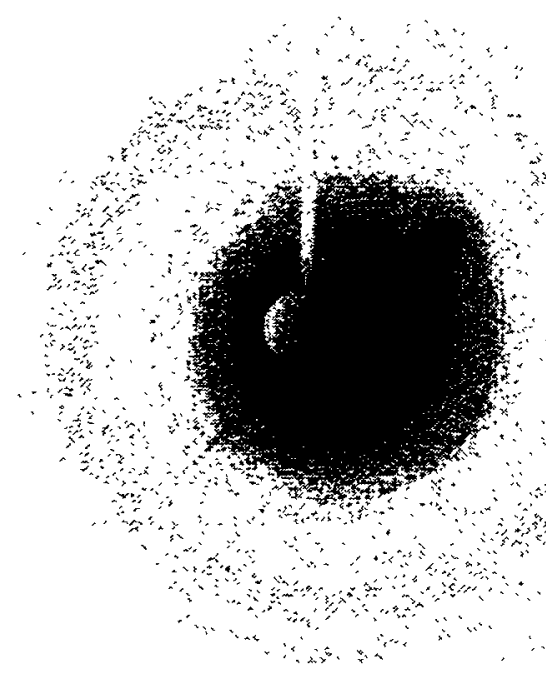

(d)
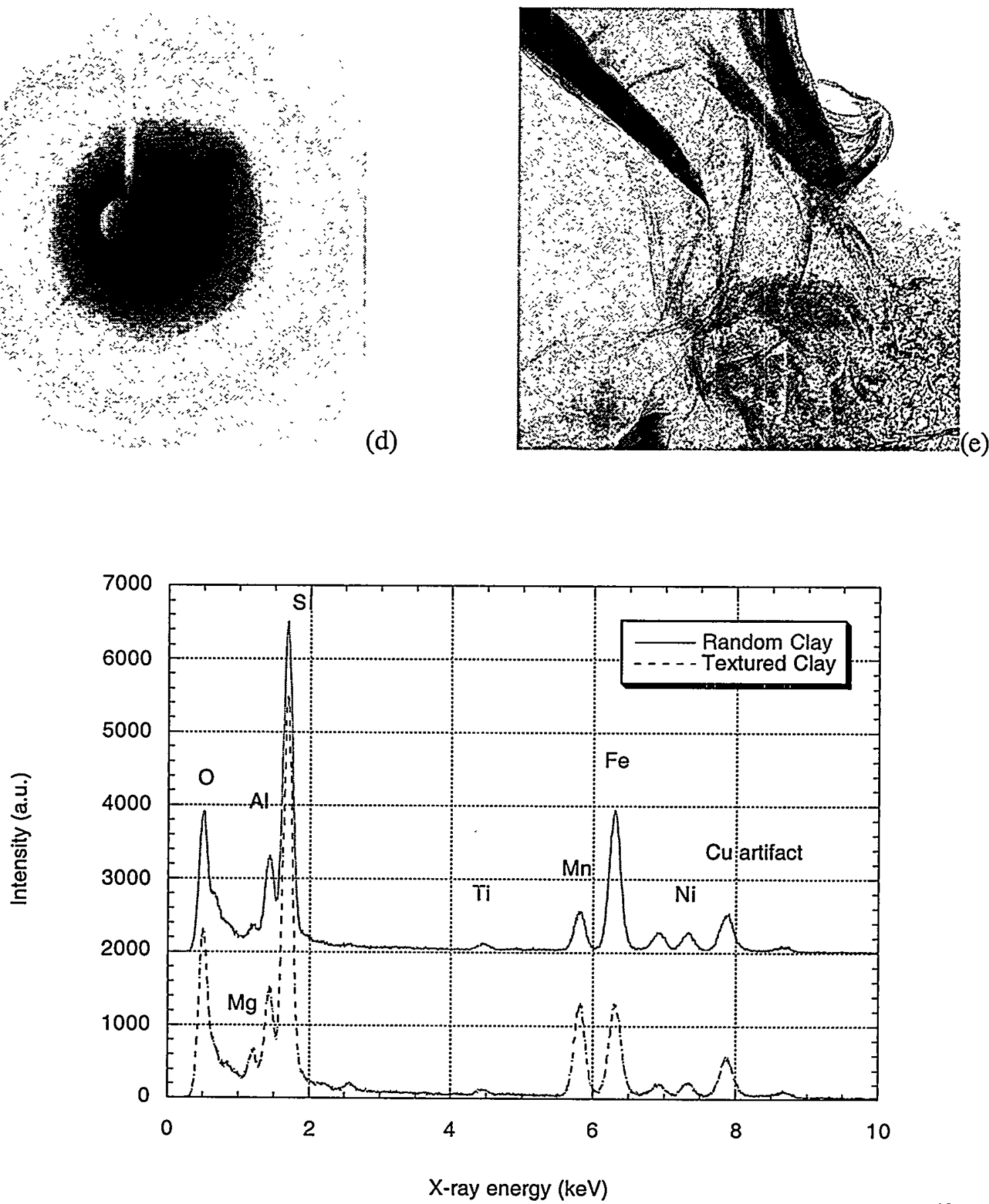

Fig. 44. Contd. 

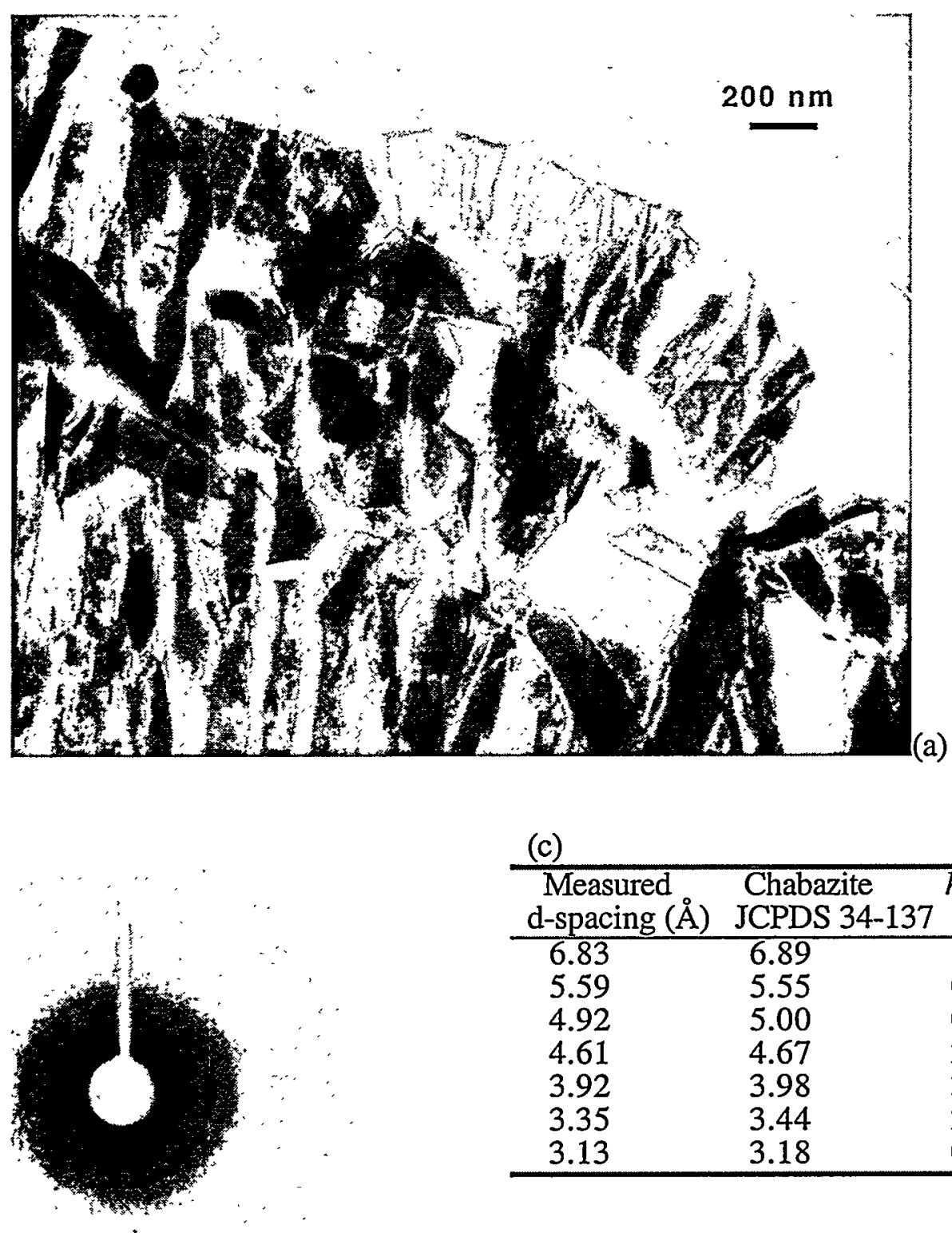

(c)

\begin{tabular}{ccc}
\hline $\begin{array}{c}\text { Measured } \\
\text { d-spacing (̊) }\end{array}$ & $\begin{array}{c}\text { Chabazite } \\
\text { JCPDS }\end{array}$ & $h k-137$ \\
\hline 6.83 & 6.89 & 110 \\
5.59 & 5.55 & 021 \\
4.92 & 5.00 & 003 \\
4.61 & 4.67 & 202 \\
3.92 & 3.98 & 300 \\
3.35 & 3.44 & 220 \\
3.13 & 3.18 & 024 \\
\hline
\end{tabular}

(b)

Fig. 45. Results of AEM examination of crystalline particle formed on SRL 131 waste glass vapor reacted at $75^{\circ} \mathrm{C}$ and $95 \% \mathrm{RH}$ for nine years: (a) TEM image of the sectioned crystalline particle, (b) the electron diffraction pattern taken from the particle, (c) experimentally measured d-spacings matching those of chabazite, and (d) EDS spectrum revealing the presence of $\mathrm{Al}, \mathrm{Si}$, and $\mathrm{Ca}$. 


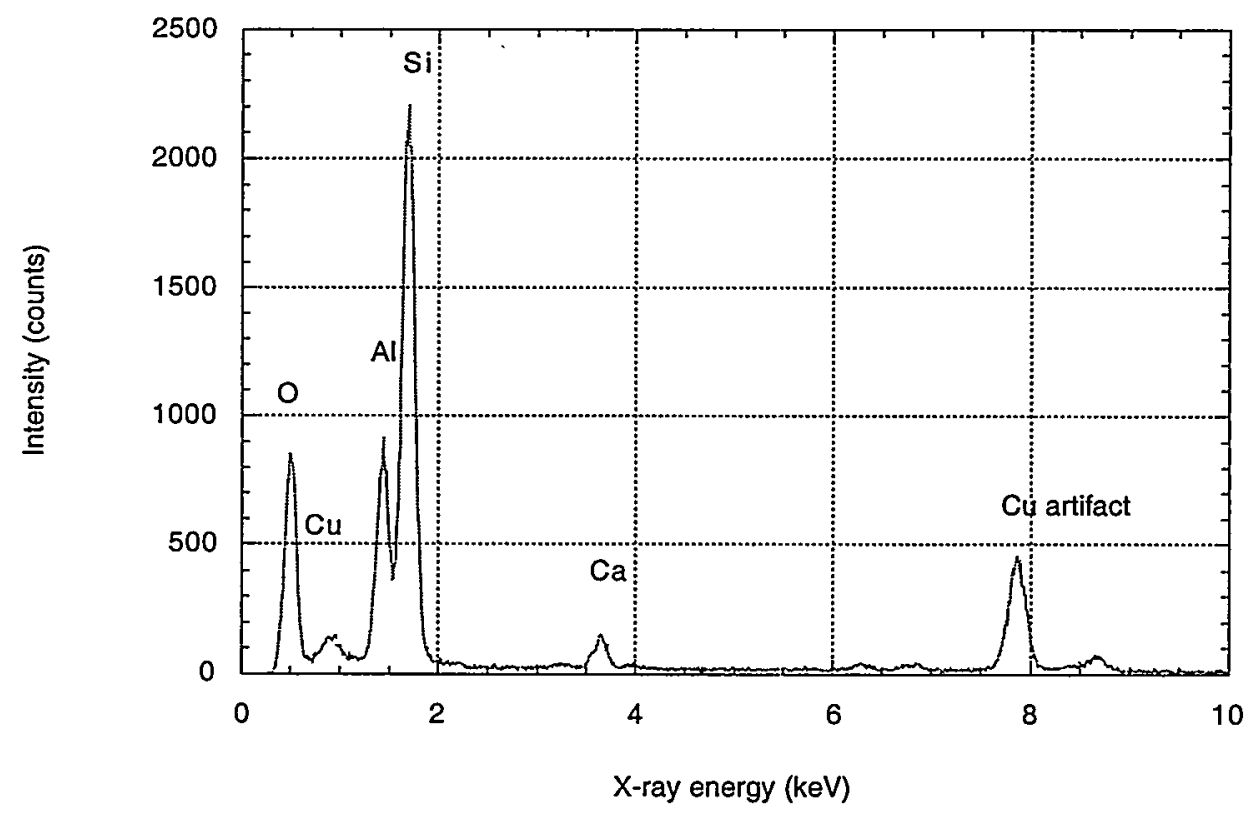

Fig. 45. Contd.

(d)

\subsubsection{Vapor Reaction at $75^{\circ} \mathrm{C}$ and at $100 \% \mathrm{RH}$}

The glass reacted but did not produce a uniform layer on the surface. A yellowish-to-white layer formed that did not fully cover the surface (Fig. 46). Examination of the reacted surface with SEM showed a "webbed" alteration phase over another alteration layer (Fig. 47a). The round precipitate at the center of the web contained mainly $\mathrm{Na}, \mathrm{Al}$, and $\mathrm{Si}$, while the area around it was enriched in $\mathrm{Fe}, \mathrm{Al}$, and $\mathrm{Si}$ and also contained small amounts of $\mathrm{Na}$ and $\mathrm{Mg}$. The cross section of the reacted sample was prepared and examined with SEM. An uniform layer had formed on the surface with a typical thickness of $5 \mu \mathrm{m}$ (Fig. 47b). The layer was enriched in $\mathrm{Ca}$ and $\mathrm{Fe}$, and depleted in $\mathrm{Na}$ and $\mathrm{Mg}$, compared with unreacted glass (Fig. 47c).
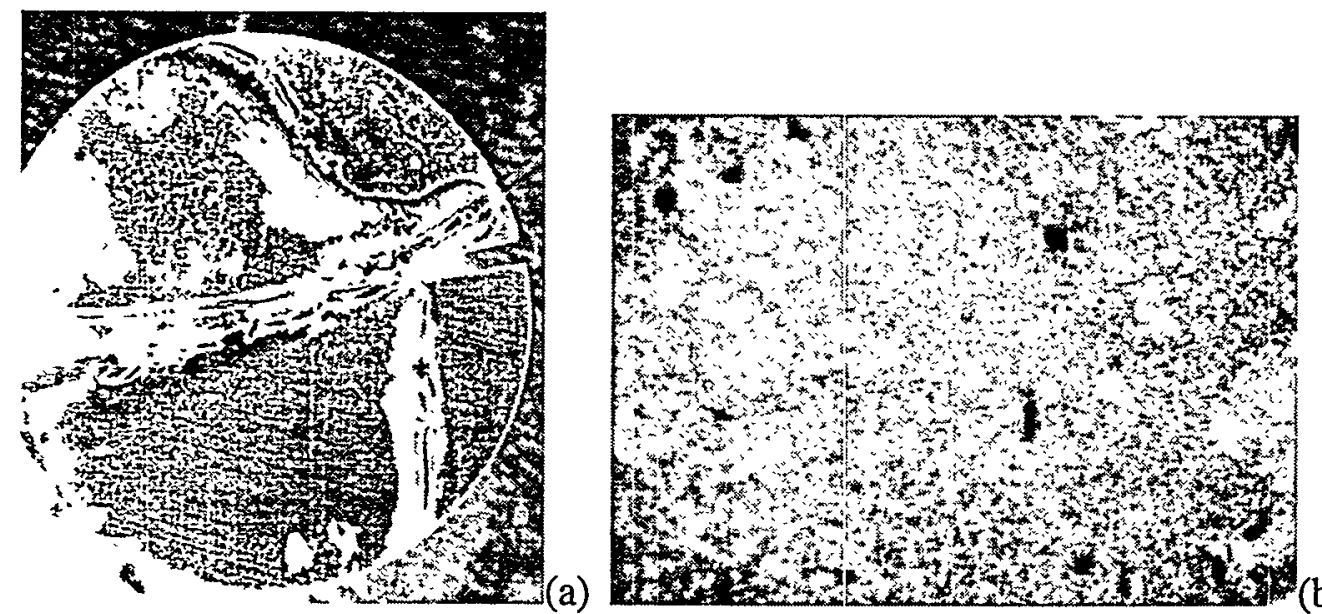

Fig. 46. Optical images of the SRL 165 waste glass vapor reacted at $75^{\circ} \mathrm{C}$ and $100 \% \mathrm{RH}$ for seven years taken at (a) $6 \mathrm{X}$ and (b) $50 \mathrm{X}$. 
A thin chip from the surface was sectioned. Examination by AEM revealed randomly oriented clay particles, which were identified as saponite by electron diffraction (Fig. 48). Analysis by EDS slowed the presence of $\mathrm{Al}, \mathrm{Si}, \mathrm{Ca}, \mathrm{Ti}, \mathrm{Mn}$, $\mathrm{Fe}$, and $\mathrm{Ni}$, which is consistent with the composition of Fe-rich saponite. A small round particle from the web bed alteration layer was also sectioned. This feature was extremely beam sensitive, and good electron diffraction could not be obtained for phase identification. Analysis by EDS showed the presence of mainly $\mathrm{Al}$ and $\mathrm{Si}$ in this phase (Fig. 48d). It is not clear at this point whether this phase is the same round particle observed with SEM that contained so much $\mathrm{Na}$ (See Fig. 49). If this is the same phase, then the Na was almost completely lost during the sample preparation and/or AEM observation due to leaching or beam damages.
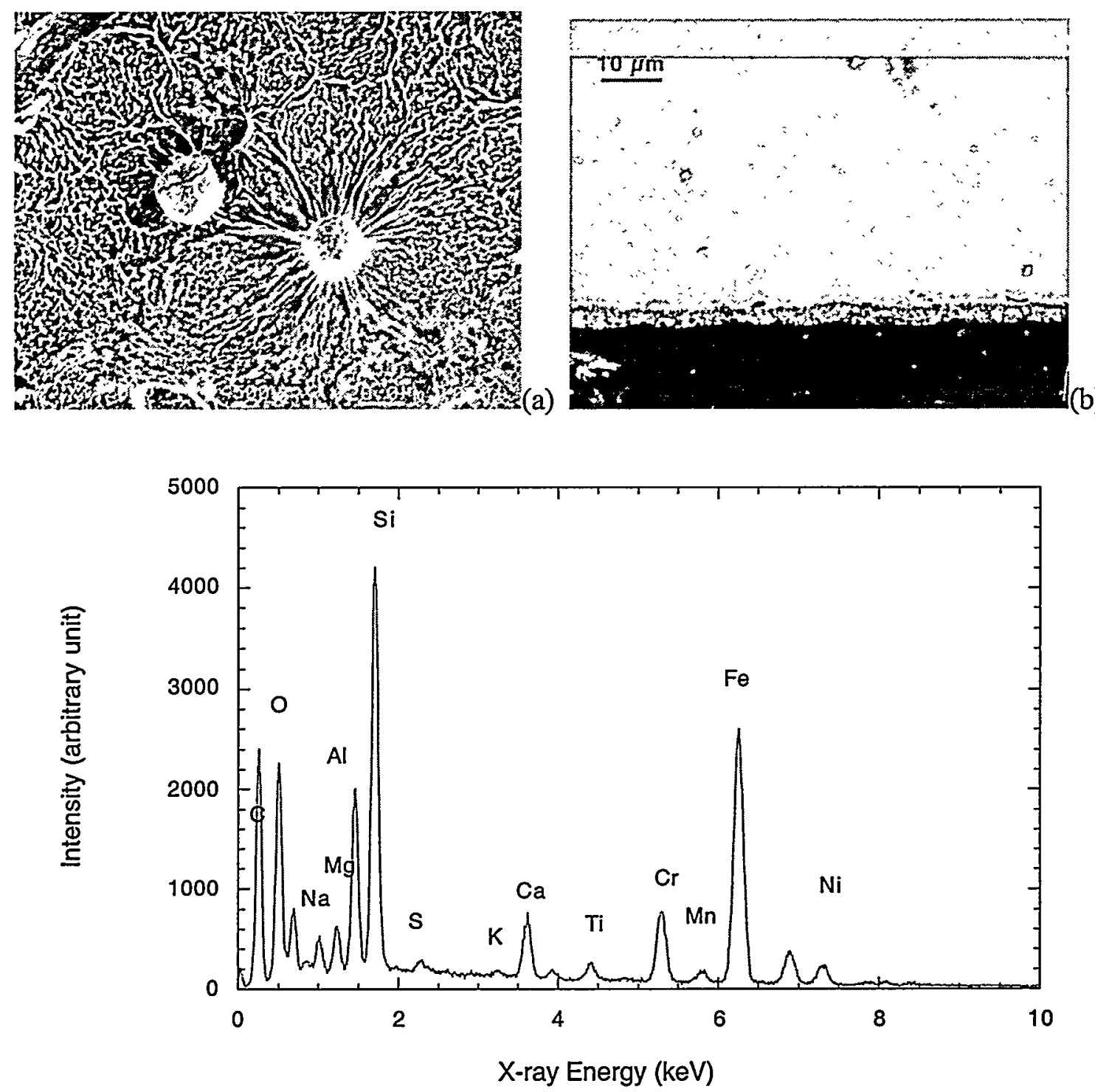

(c)

Fig. 47. Surface of the SRL 131 glass vapor reacted at $75^{\circ} \mathrm{C}$ and $100 \%$ RH for seven years: (a) SEM image of layer formed, (b) cross-sectional SEM image of the layer and the glass, and (c) EDS spectrum of the layer. 


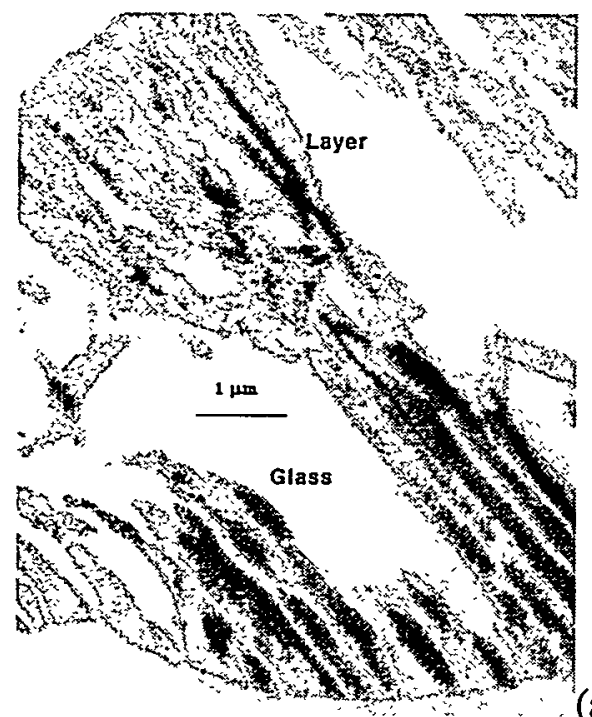

(a)

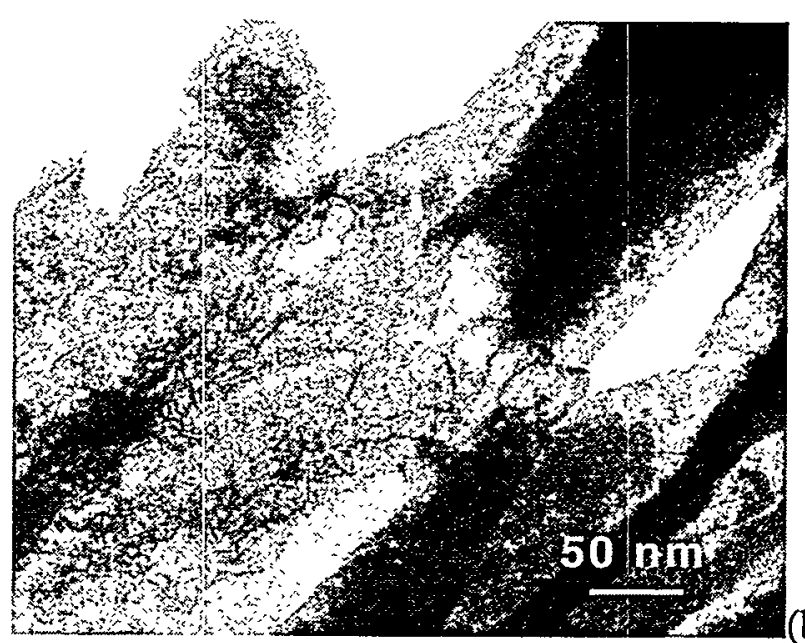

(b)

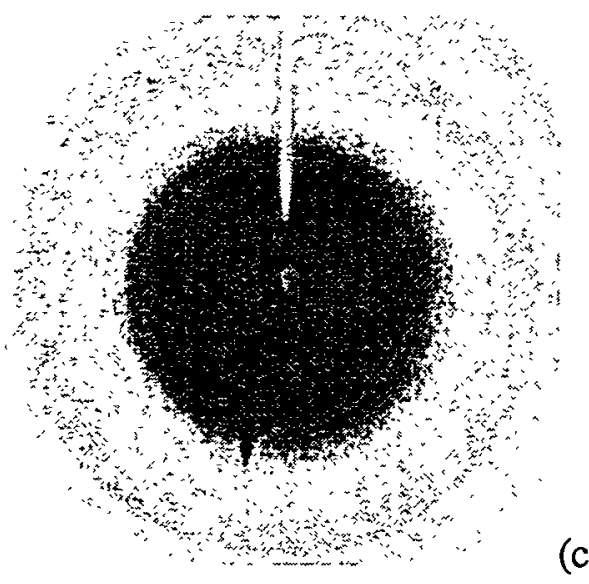

\begin{tabular}{ccc} 
(d) & & \\
\hline $\begin{array}{c}\text { Measured } \\
\text { d-spacing }(\AA)\end{array}$ & Saponite & $h k l$ \\
\hline 4.5317 & 4.5500 & 100 \\
2.5986 & 2.6100 & 111 \\
1.7284 & 1.7400 & 210 \\
1.5292 & 1.5410 & 300 \\
1.3271 & 1.3200 & 220 \\
\hline
\end{tabular}

(c)

Fig. 48. Analyses of block 1722: (a) TEM image of the glass and layer, (b) highmagnification image of the layer/glass interface showing the presence of fibrous clay in the layer, (c) electron diffraction pattern from the layer, (d) the measured d-spacings compared with those of saponite, and (e) EDS spectra comparing the glass and layer. 


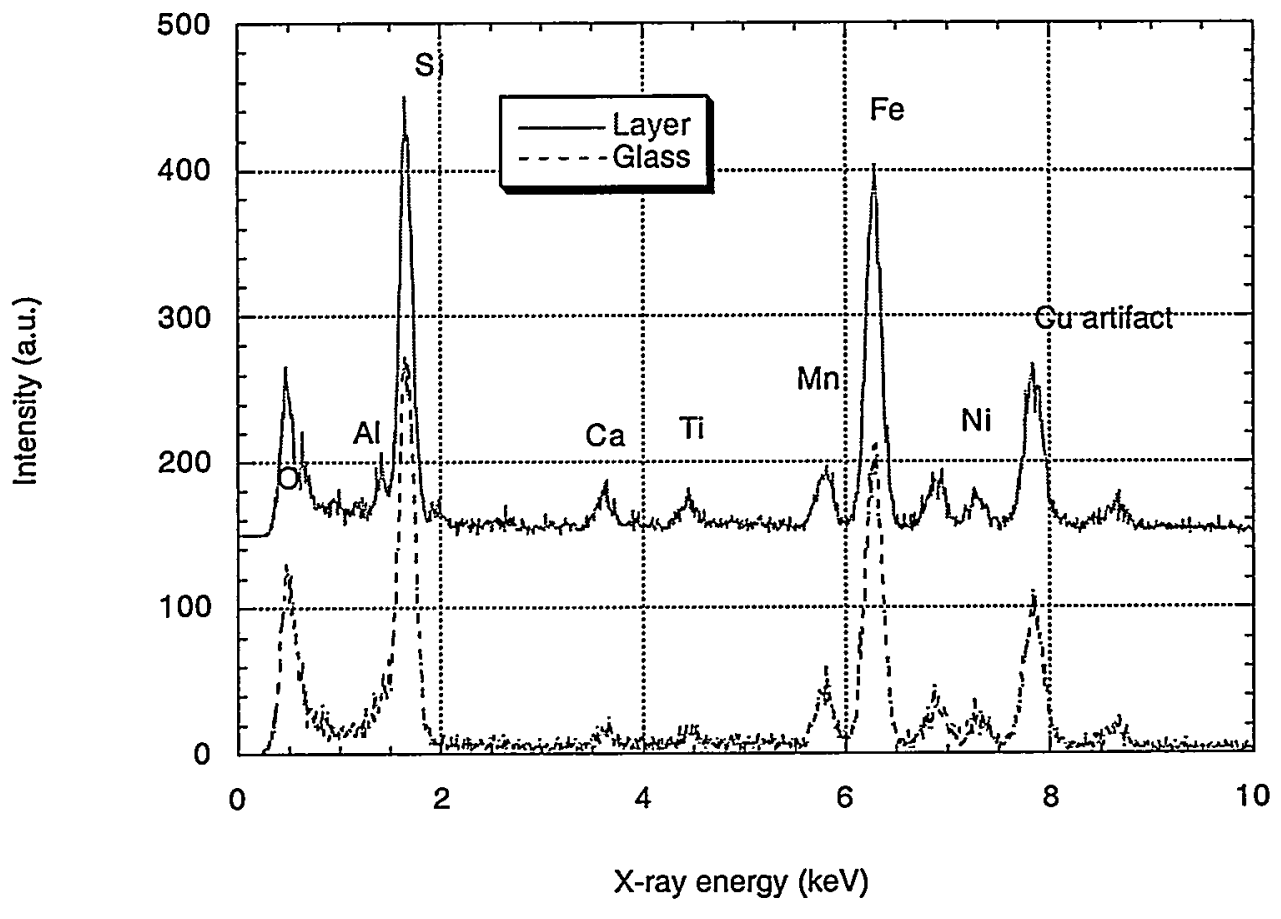

(e)

Fig. 48. Contd. 

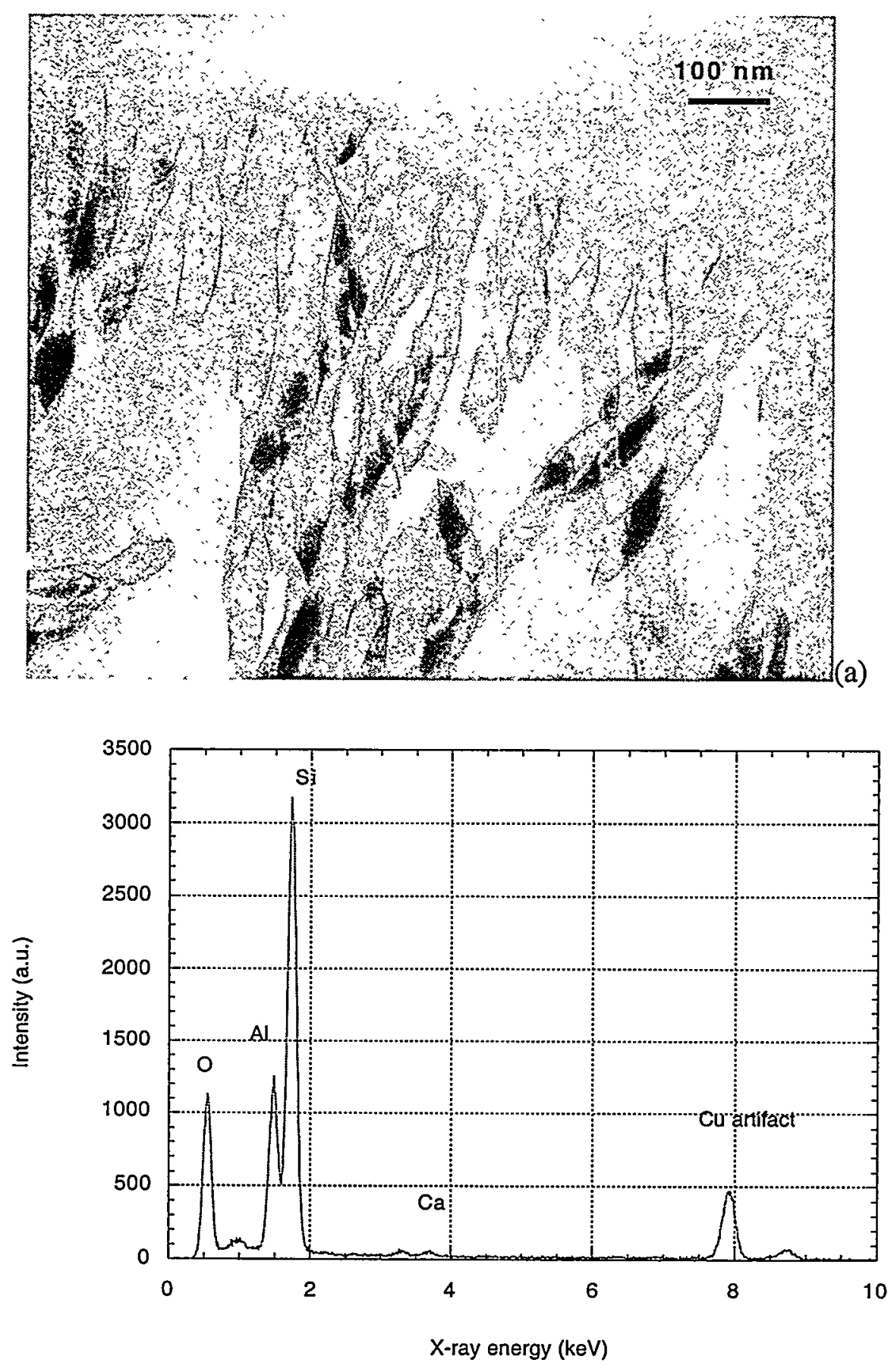

(b)

Fig. 49. Analysis of the sectioned particle: (a) TEM image and (b) EDS spectrum. 


\subsubsection{Summary}

Alteration layers 5 to $10 \mu \mathrm{m}$ thick formed on the surface of SRL 131 glass reacted at both $95 \%$ and $100 \% \mathrm{RH}$. The relative humidity did not appear to strongly affect the thickness. The alteration layer consisted mainly of saponite clay, which was characterized by a fibrous microstructure. In all the samples, secondary phases precipitated on the outer surfaces of the alteration layers; they were identified as chabazite and possibly analcime for glass as reacted at $95 \%$ and $100 \% \mathrm{RH}$.

\subsubsection{Laboratory-Reacted Waste Glass PNL-76-68}

\subsubsection{Vapor Reaction at $75^{\circ} \mathrm{C}$ and $95 \% \mathrm{RH}$}

\subsection{Seven-Year Results}

The surface of the reacted glass was covered with a yellowish smooth layer (Fig. 50). Examination of the surface by SEM revealed the formation of a dense alteration layer on the surface, part of which had spalled off (Fig. 51a). High magnification of the layer showed a honeycombed surface, which is characteristic of semectite clay (Fig. 51b). The surface underneath the layer exhibited a numerous etched pits, indicating dissolution of the glass (Fig. 51c). A cross section of the reacted sample is shown in Fig. 51d. The glass altered to form a uniform alteration layer $5 \mu \mathrm{m}$ thick that was rich in $\mathrm{Fe}$ and Ti but poor in $\mathrm{Na}$ (Fig. 52). A small amount of $\mathrm{S}$ was also observed in the layer but was not present in the unreacted glass.

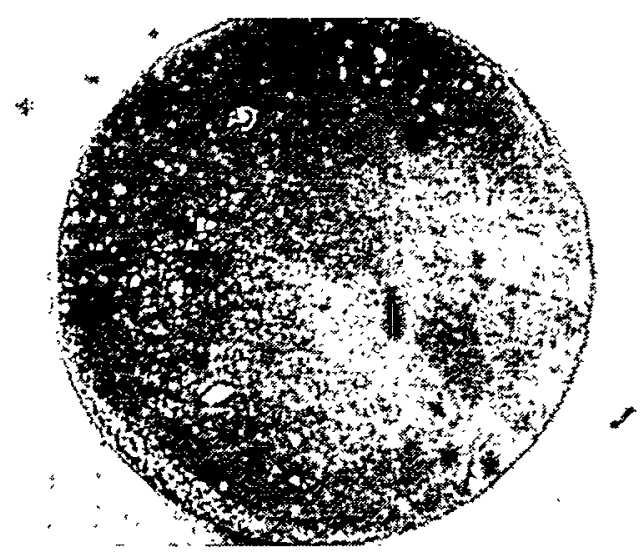

(a)

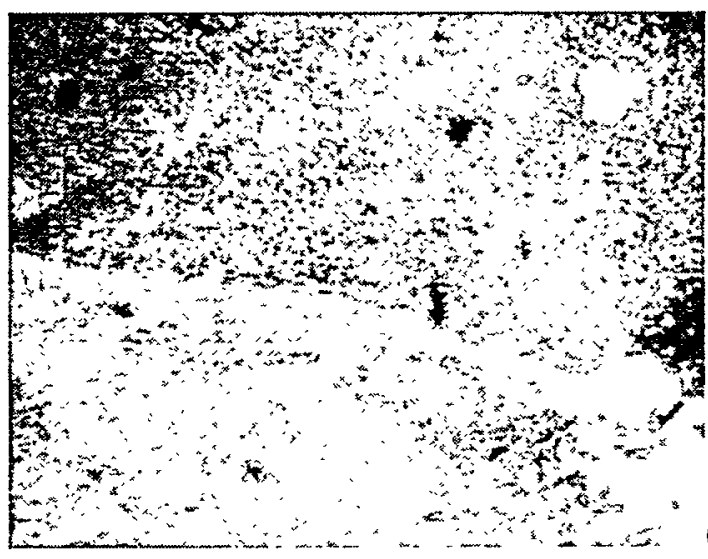

Fig. 50. Optical images of the PNL 76-68 waste glass vapor reacted at $75^{\circ} \mathrm{C}$ at $95 \% \mathrm{RH}$ for seven years taken at (a) $6 \mathrm{X}$ and (b) $50 \mathrm{X}$. 

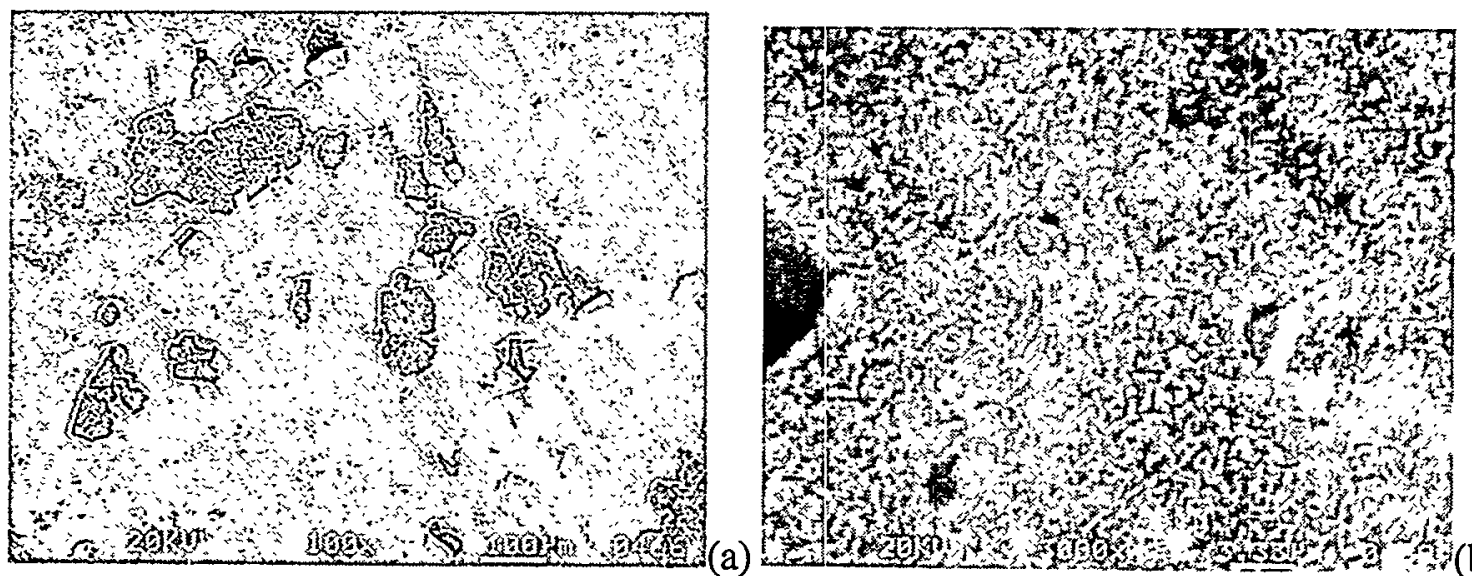

(a)
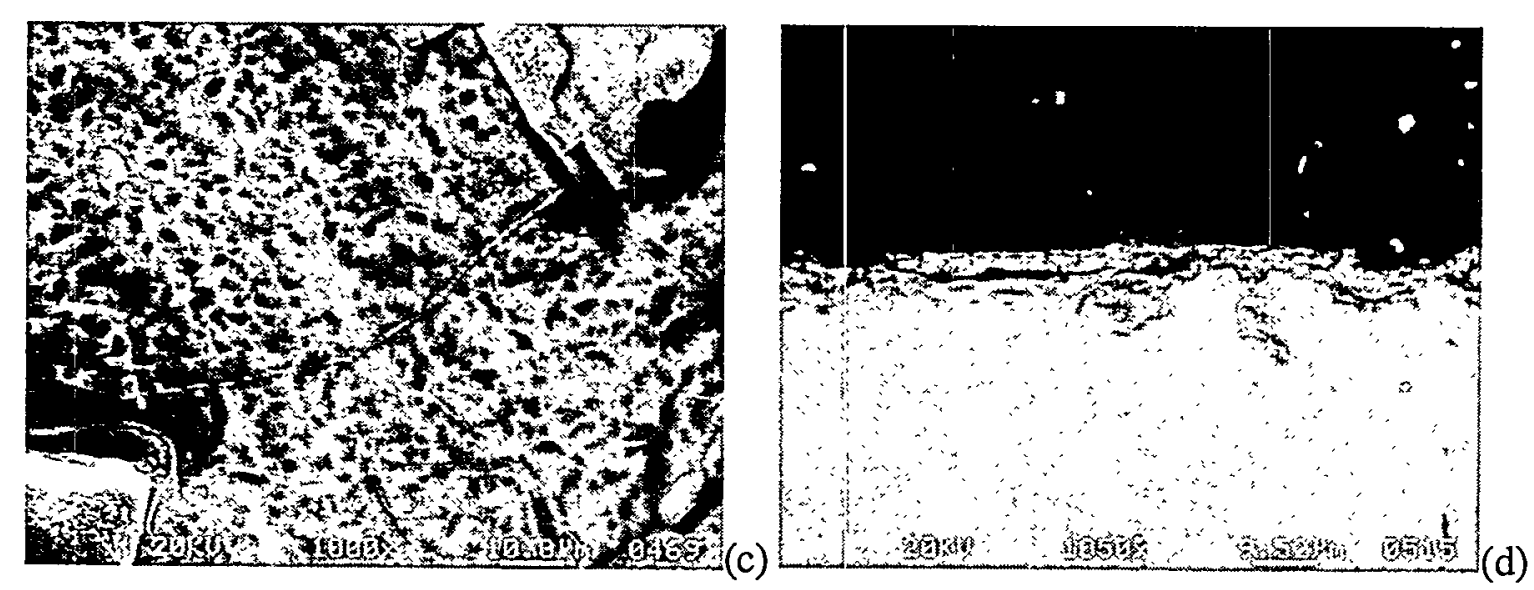

Fig. 51. Scanning electron micrographs of the layer formed on the surface of the PNL 76-68 glass vapor reacted at $75^{\circ} \mathrm{C}$ in $95 \% \mathrm{RH}$ for seven years: (a) SEM image, (b) high-magnification SEM image, (c) high-resolution SEM image, and (d) cross-sectional SEM image. 


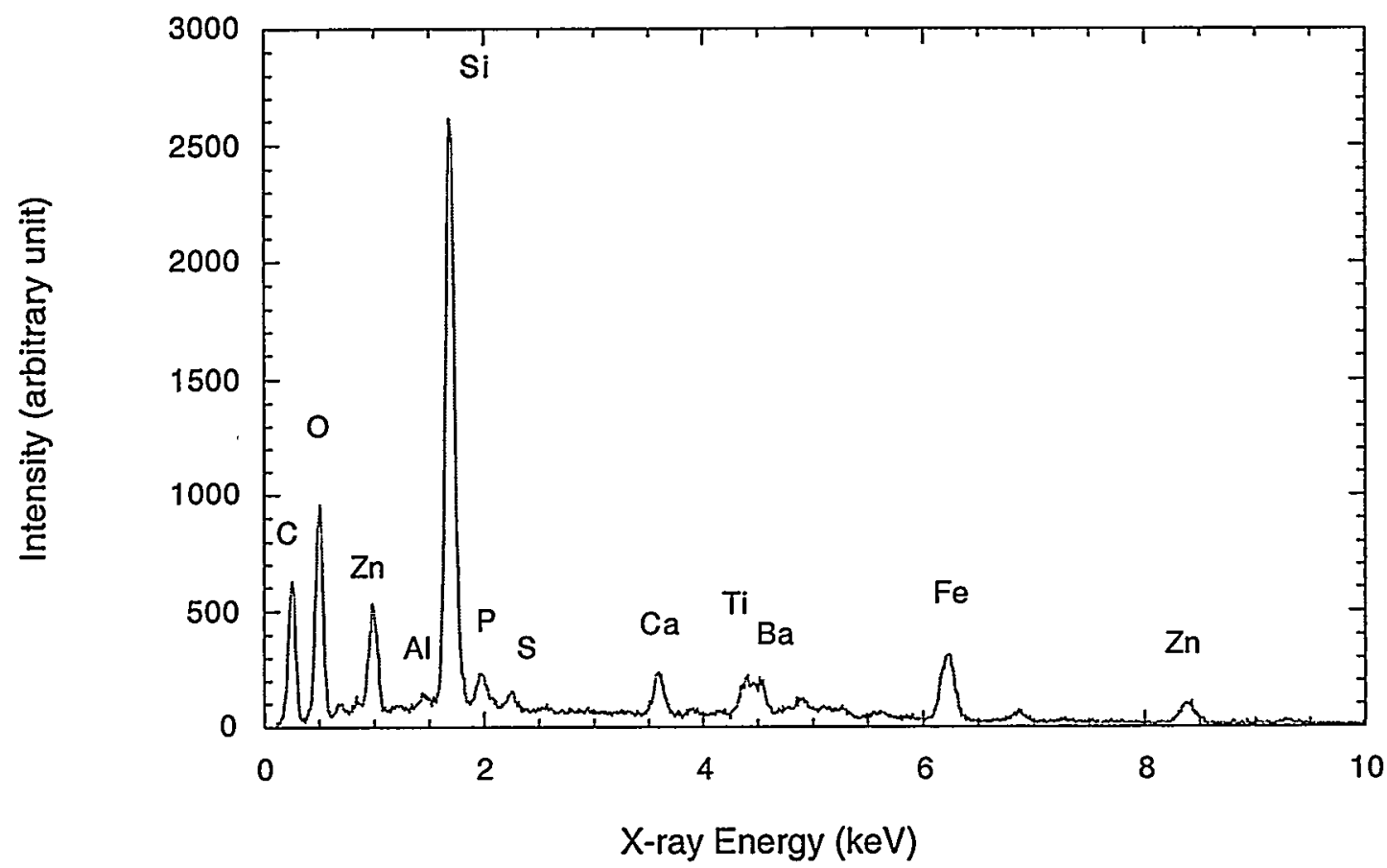

Fig. 52. An EDS spectrum of the alteration layer formed on PNL 76-68 glass vapor reacted at $75^{\circ} \mathrm{C}$ and $95 \% \mathrm{RH}$ for seven years.

Analysis by AEM of a section from the surface revealed the formation of an outer textured layer phase and an inner amorphous one (Fig. 53). Electron diffraction of the outer layer indicates smectite-type clay. Analysis by EDS shows the presence of $\mathrm{Si}, \mathrm{Al}, \mathrm{Ca}, \mathrm{Fe}, \mathrm{Ti}, \mathrm{Ni}$, and $\mathrm{Zn}$, suggesting sauconite, the only clay that contained $\mathrm{Zn}$. Analysis with $\mathrm{EDS}$ also revealed the segregation of $\mathrm{Ca}$ and $\mathrm{Ti}$ in inner areas, which were nearly free of $\mathrm{Zn}$ (see Fig. 53c). In addition to the formation of sauconite on the surface, several individual alteration particles were also found and characterized. A white precipitate with a small black inclusion at surface was sectioned and identified as hydroxyapatite, an calcium hydro-phosphate (Fig. 54). A small red fleck was identified as geothite, an iron hydroxide (Fig. 55). 


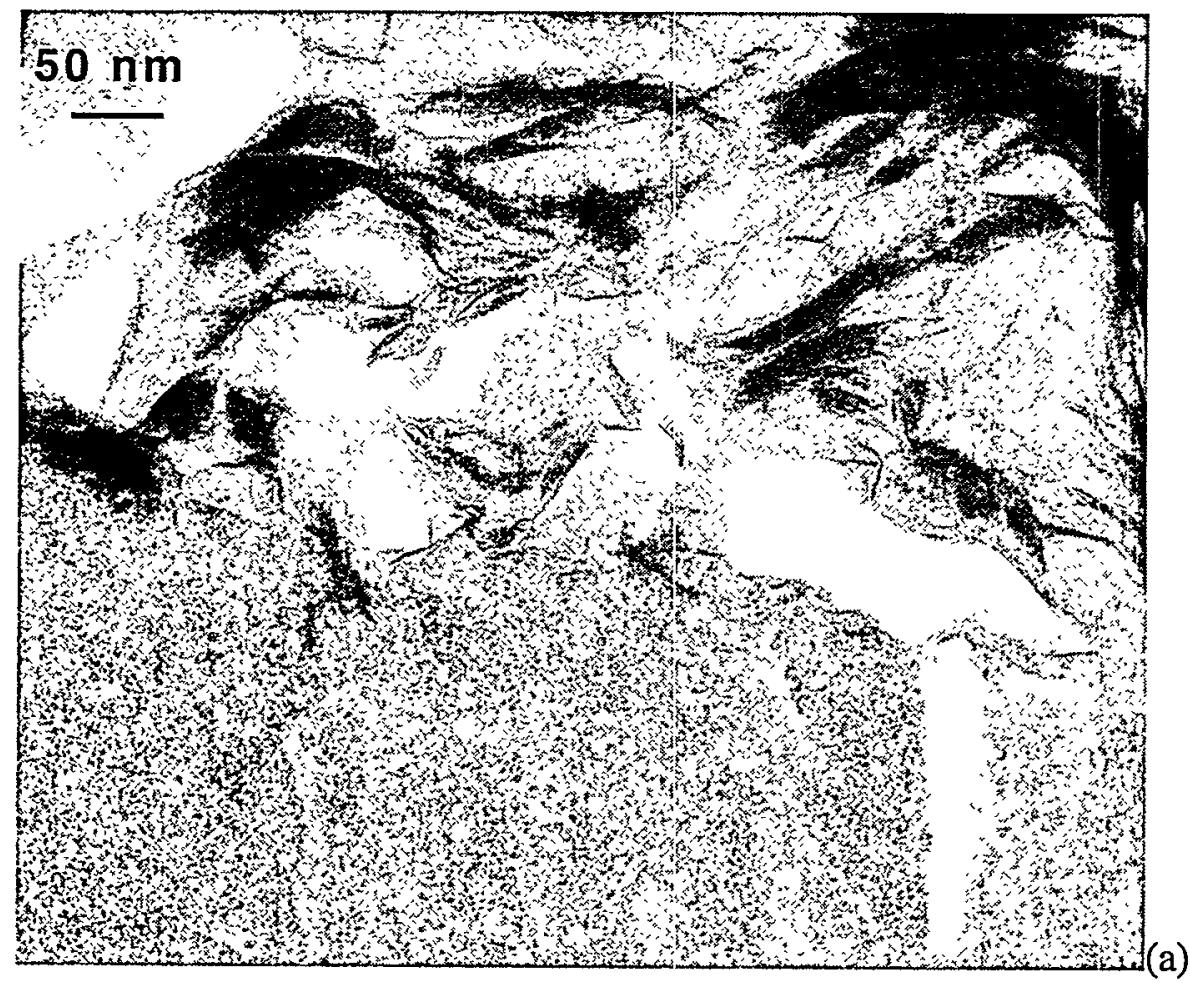

(b)

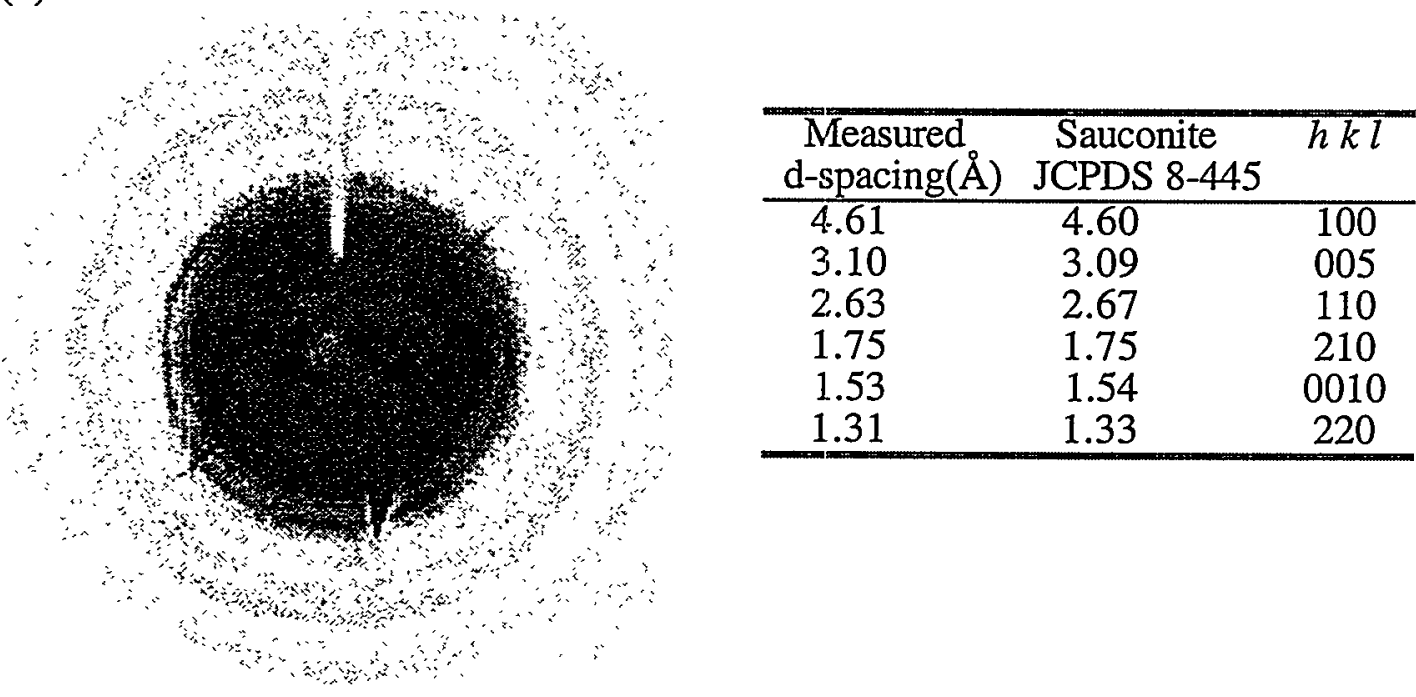

Fig. 53. Results of AEM analysis of sample from surface of PNL 76-68 waste glass vapor reacted at $75^{\circ} \mathrm{C}$ and $95 \% \mathrm{RH}$ for seven years: (a) TEM image of the sectioned feature showing the textured phase at outer surface, (b) electron diffraction pattern of outer layer and comparison of measured d-spacings with those of sauconite (identical diffraction pattern obtained for the inner layer) and (c) EDS spectra comparing both areas. 


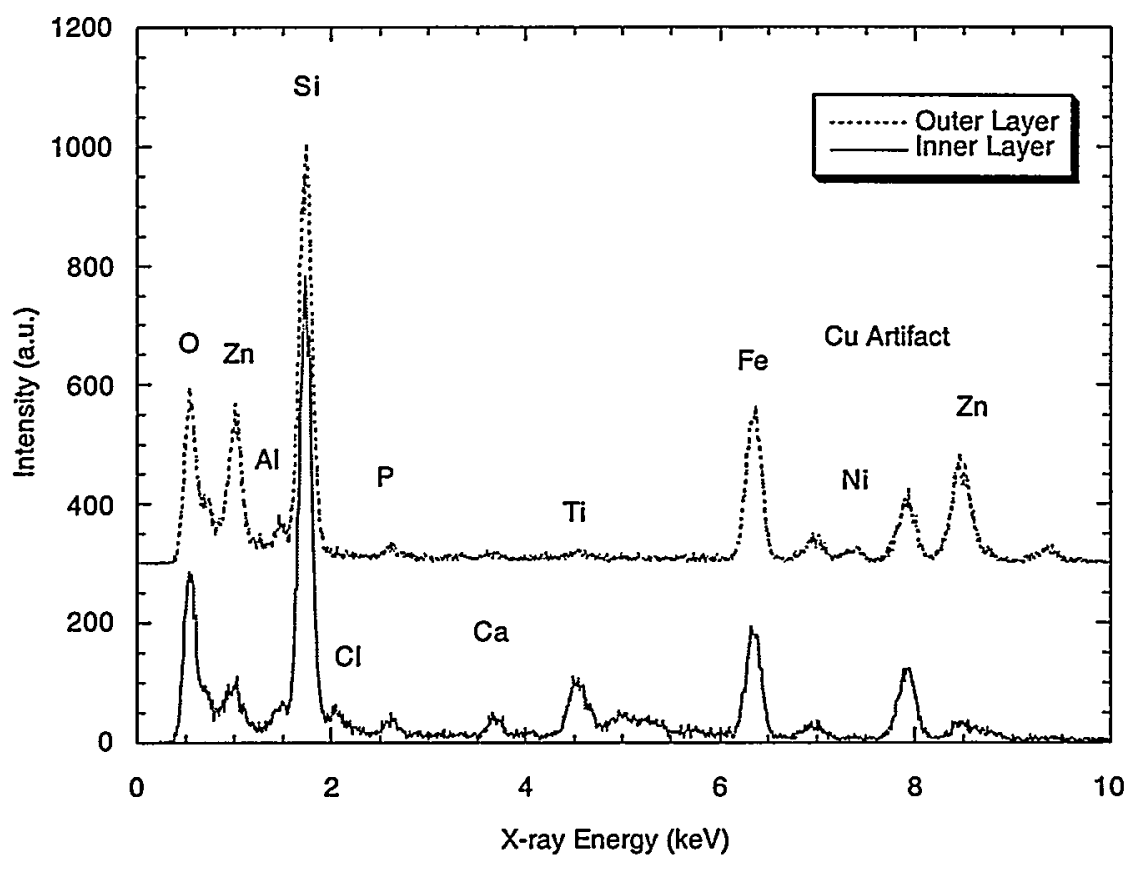

(c)

Fig. 53. Contd. 

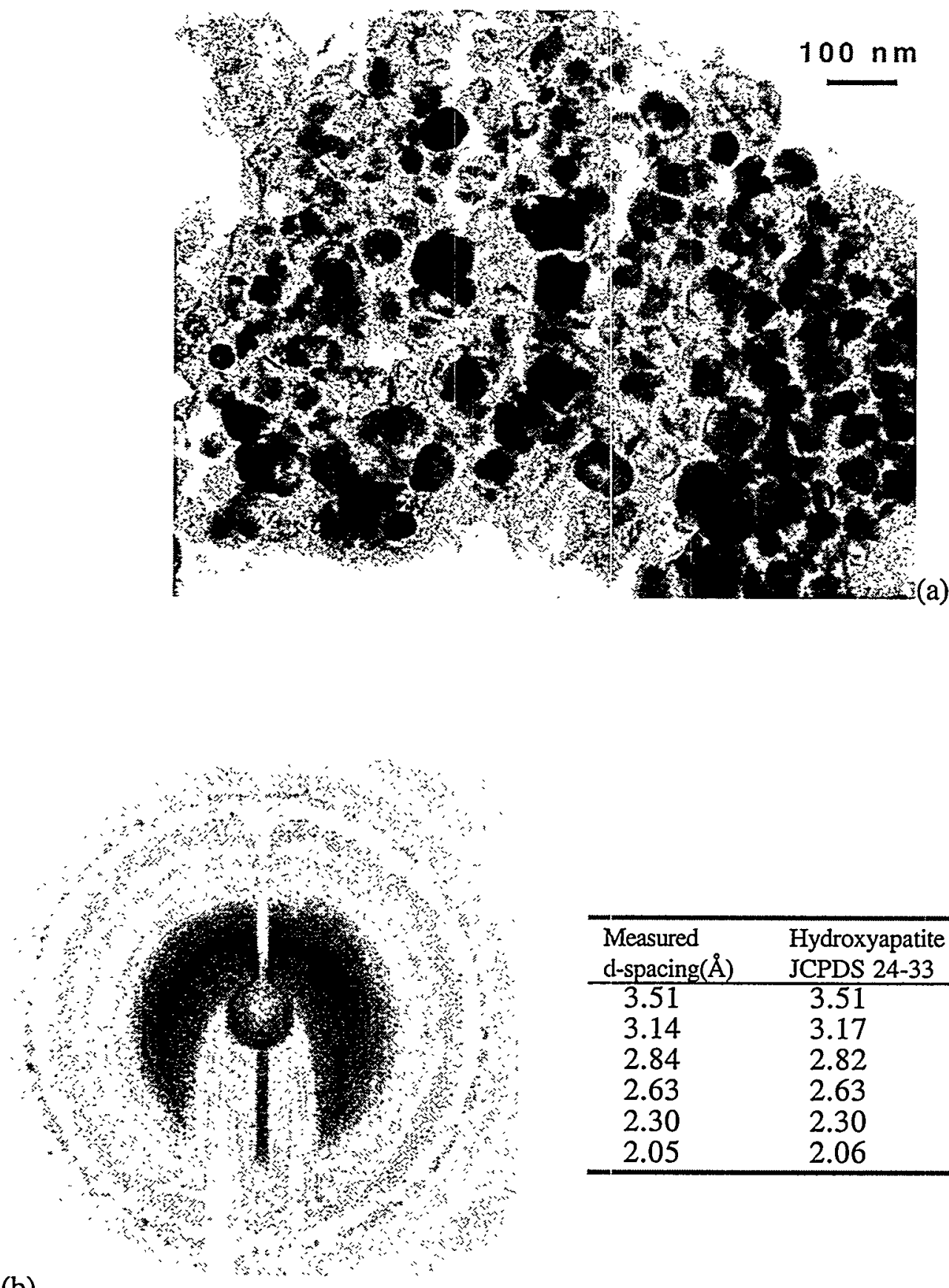

\begin{tabular}{ccc}
\hline $\begin{array}{l}\text { Measured } \\
\text { d-spacing( }(\AA)\end{array}$ & $\begin{array}{c}\text { Hydroxyapatite } \\
\text { JCPDS 24-33 }\end{array}$ & $h k l$ \\
\hline 3.51 & 3.51 & 201 \\
3.14 & 3.17 & 102 \\
2.84 & 2.82 & 211 \\
2.63 & 2.63 & 202 \\
2.30 & 2.30 & 212 \\
2.05 & 2.06 & 113 \\
\hline
\end{tabular}

(b)

Fig. 54. Results of AEM analysis of white particle with black inclusion from surface of PNL 76-68 waste glass vapor reacted at $75^{\circ} \mathrm{C}$ and $95 \% \mathrm{RH}$ for seven years: (a) TEM image of the sectioned feature showing the aggregates of nanometer-sized precipitates, (b) electron diffraction pattern and comparison of measured d-spacings with those of hydroxyapatite, (c) EDS spectrum of sectioned phase. 


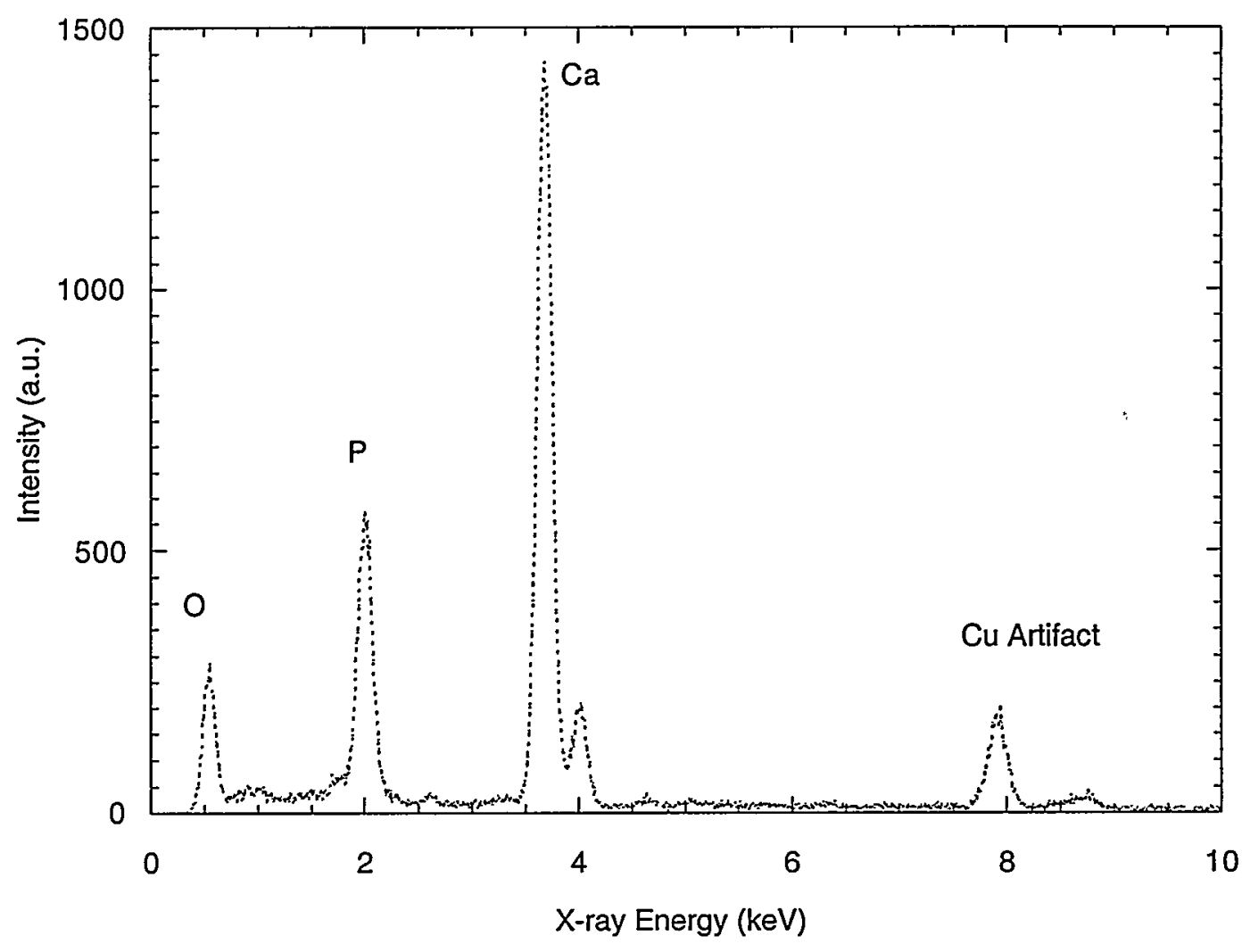

(c)

Fig. 54. Contd. 


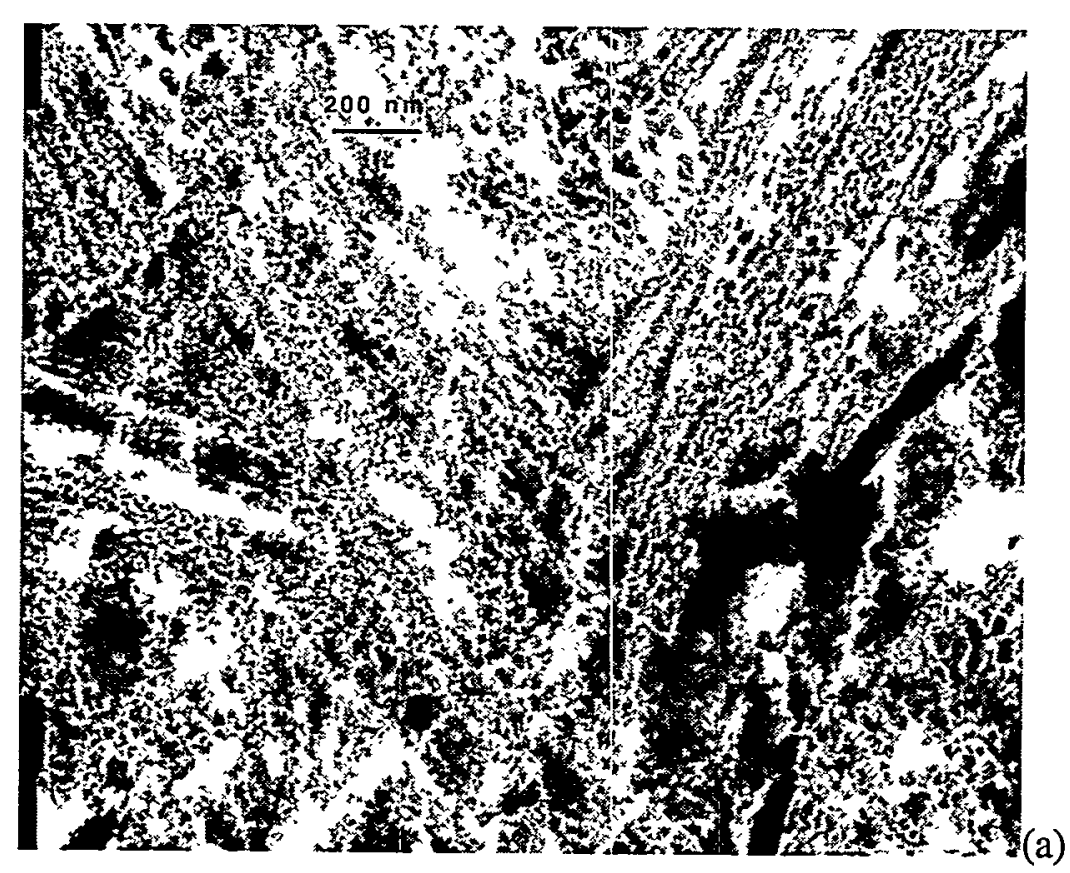

(b)

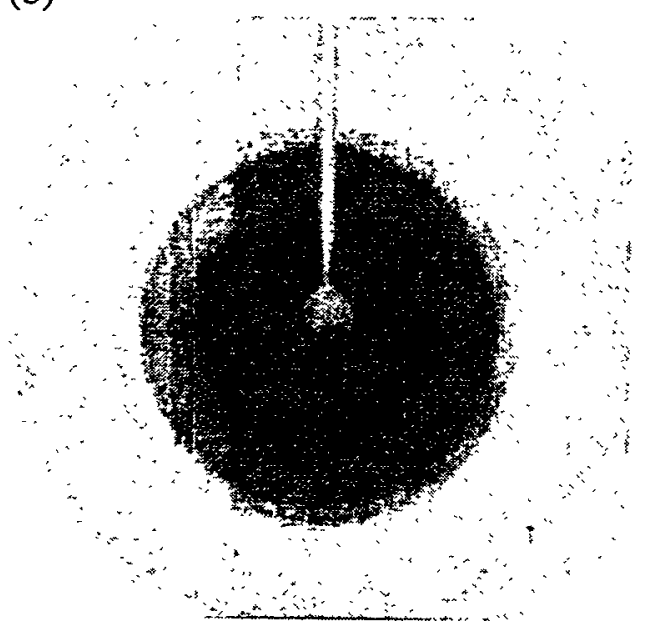

\begin{tabular}{ccc}
\hline $\begin{array}{c}\text { Measured } \\
\text { d-spacing }(\AA)\end{array}$ & $\begin{array}{c}\text { Geothite } \\
\text { JCPDS } 29-713\end{array}$ & hkl \\
\hline 4.26 & 4.18 & 110 \\
2.54 & 2.58 & 021 \\
2.25 & 2.25 & 121 \\
1.98 & 2.01 & 131 \\
1.74 & 1.72 & 221 \\
1.52 & 1.51 & 002 \\
1.47 & 1.47 & 320 \\
\hline
\end{tabular}

Fig. 55. Results of AEM analysis of red particle from surface of PNL 76-68 waste glass vapor reacted at $75^{\circ} \mathrm{C}$ and $95 \% \mathrm{RH}$ for seven years: (a) TEM image of the sectioned article shows a poorly crystalline material, (b) an electron diffraction pattern from this material and comparison of measured d-spacings with those of geothite, (c) EDS spectrum of the section phase. 
(c)

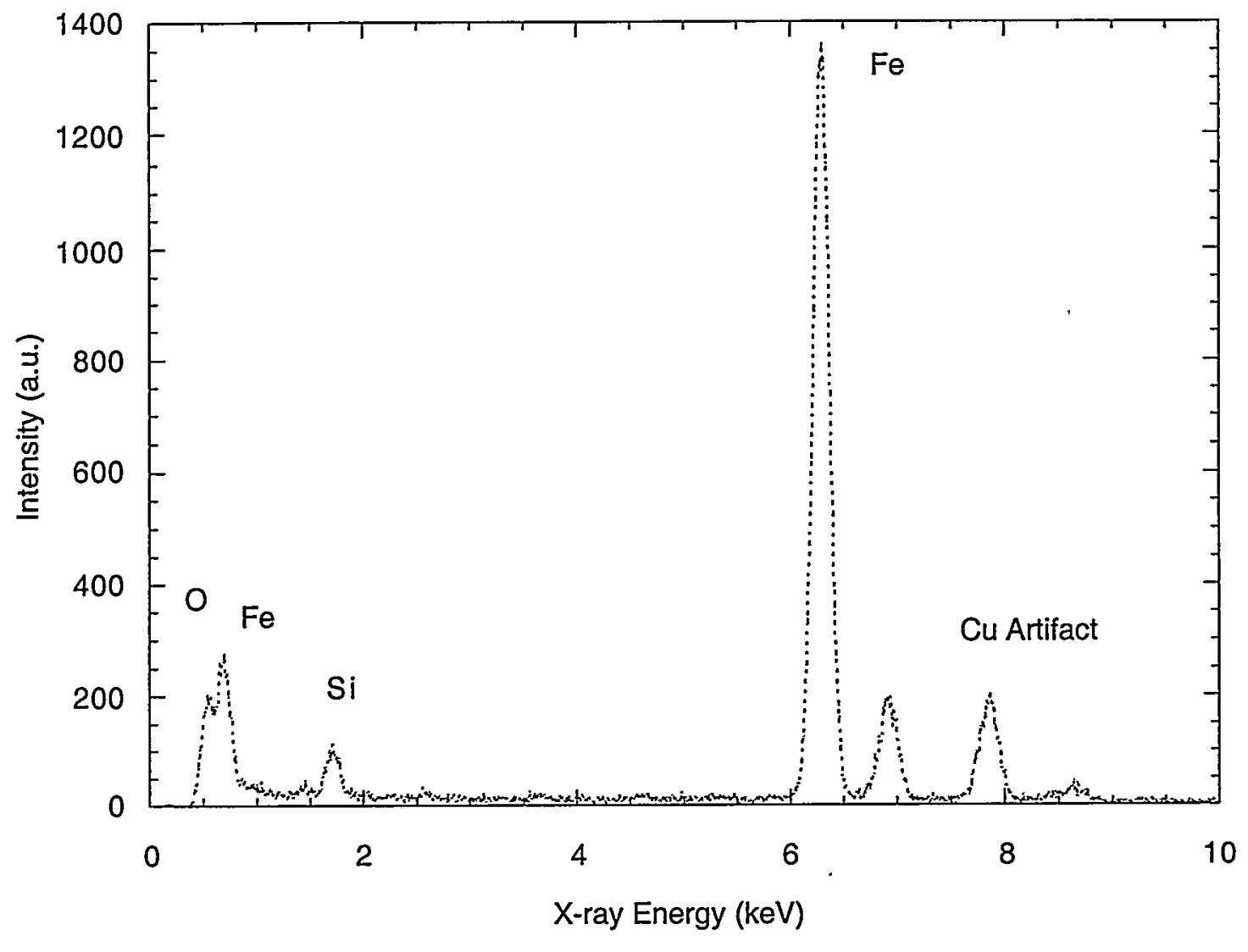

Fig. 55. Contd.

\subsection{Nine-Year Results}

This glass also formed a yellowish alteration layer (Fig. 56). In addition, white particles were also frequently seen under the optical microscope to have precipitated on the surface bottom. Examination of the surface with SEM showed a honeycombed layer of smectite like that on the glass reacted for seven years (Fig. 57a). In addition, a well-developed crystalline alteration phase was observed to have formed on the surface (Fig. 57b). Analysis of this precipitate by EDS revealed a composition that was rich in $\mathrm{Si}, \mathrm{Ba}$, and $\mathrm{S}$, an element absorbed from the environment (Fig. 57c). 

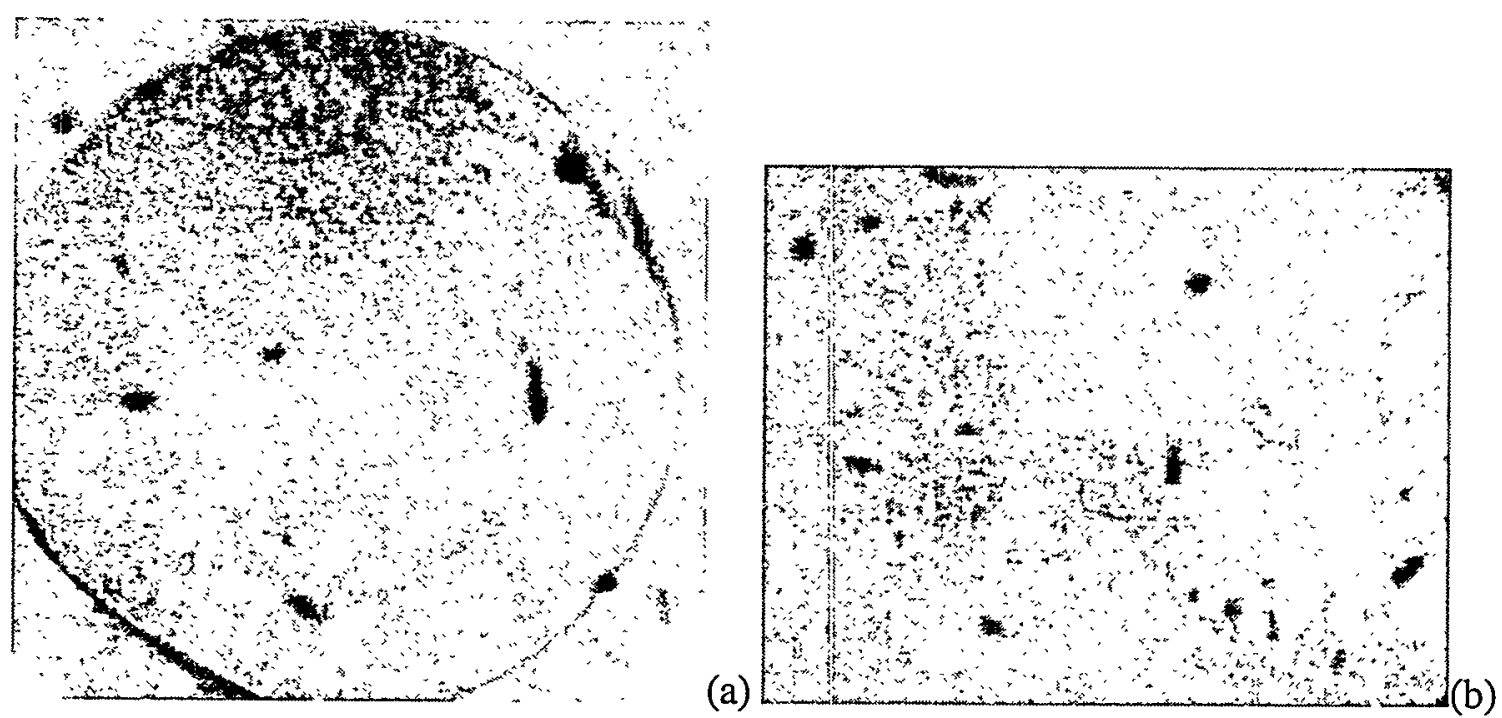

Fig. 56. Optical microscopy images of the PNL76-68 waste glass vapor reacted at $75^{\circ} \mathrm{C}$ in $95 \% \mathrm{RH}$ for nine years taken at (a) $6 \mathrm{X}$ and (b) $50 \mathrm{X}$. 

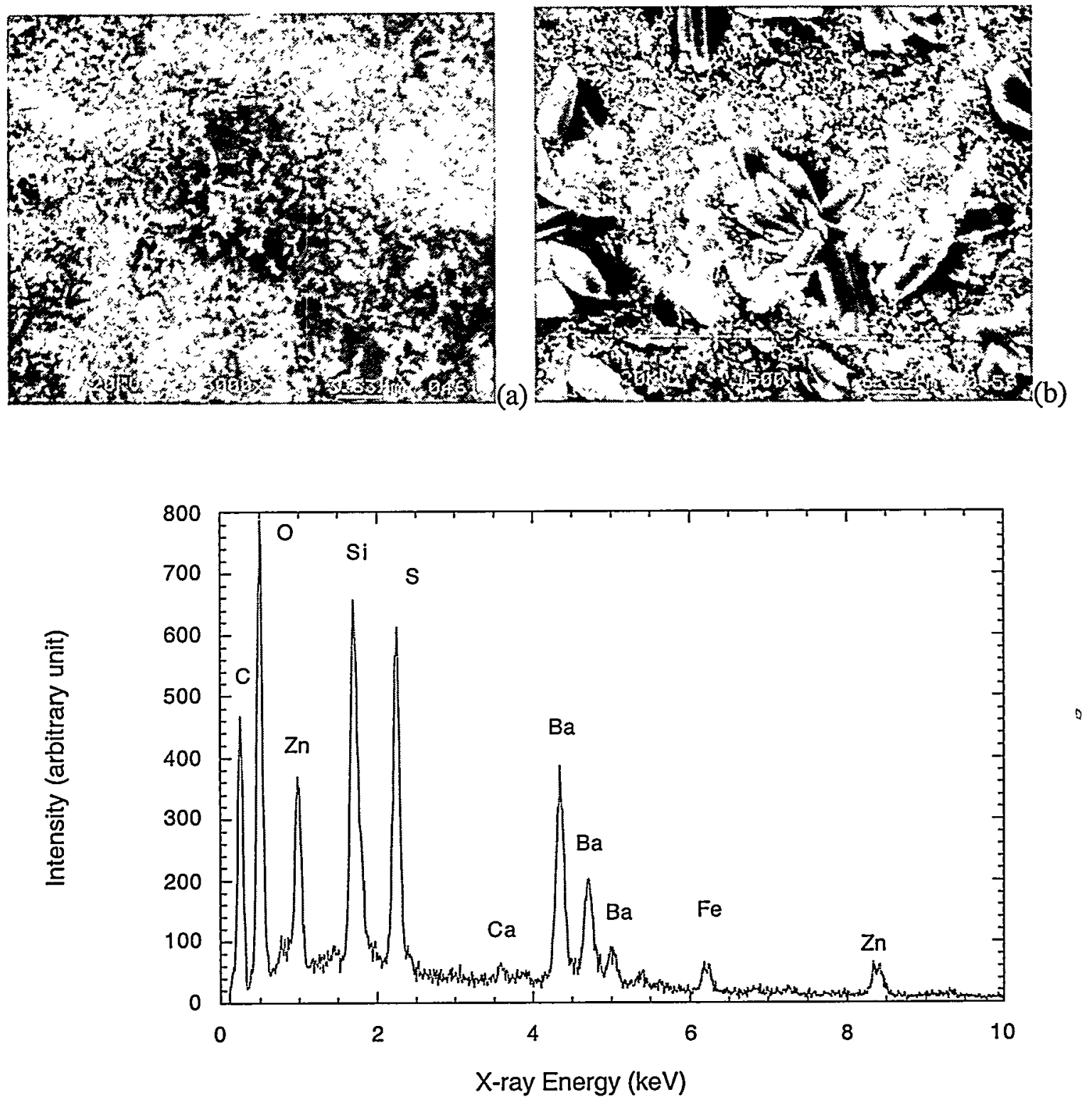

(c)

Fig.57. Layer formed on the surface of the PNL 76-68 glass vapor reacted at $75^{\circ} \mathrm{C}$ in $95 \%$ RH for nine years: (a) SEM image, (b) SEM image showing crystalline phase, and (c) EDS spectrum of crystalline phase.

Examination of the cross sections revealed a 5- $\mu \mathrm{m}$ alteration layer at the surface (Fig. 58a) that had a lamellar microstructure, a dense inner layer, and two relatively porous outer layers (Fig. 58b). The layer that was closest to the glass had a similar composition consisting mainly of $\mathrm{Na}, \mathrm{Si}, \mathrm{Fe}, \mathrm{Ti}$, and $\mathrm{Ca}$ plus a small amount of $\mathrm{Zn}$. The next layer had a similar composition but was nearly free of $\mathrm{Na}$. The outer layer contained similar elements as the layer underneath but was enriched in $\mathrm{Zn}$ (Fig. 58c). 
A small layer was removed from the surface and sectioned. Examination by AEM revealed the formation of a textured sauconite phase and an amorphous layer in inner areas (Fig. 59), similar to that observed in the seven-year sample. Analysis with EDS revealed enrichment of $\mathrm{Zn}$ at the outer layers and enrichment of $\mathrm{Ca}, \mathrm{Ti}$ and $\mathrm{Cl}$ in the inner areas. In addition to the layer, a white precipitate on the surface was removed and characterized. Examination by AEM revealed a mixture of a layered phase and several precipitates (Fig. 60). The layered phase was identified as sauconite. The diffraction pattern of the precipitate phase matched best with that of hannebachite, a calcium sulfite hydrate. Another precipitate observed was identified as rutile, a titanium oxide, with electron diffraction and EDS analysis. 

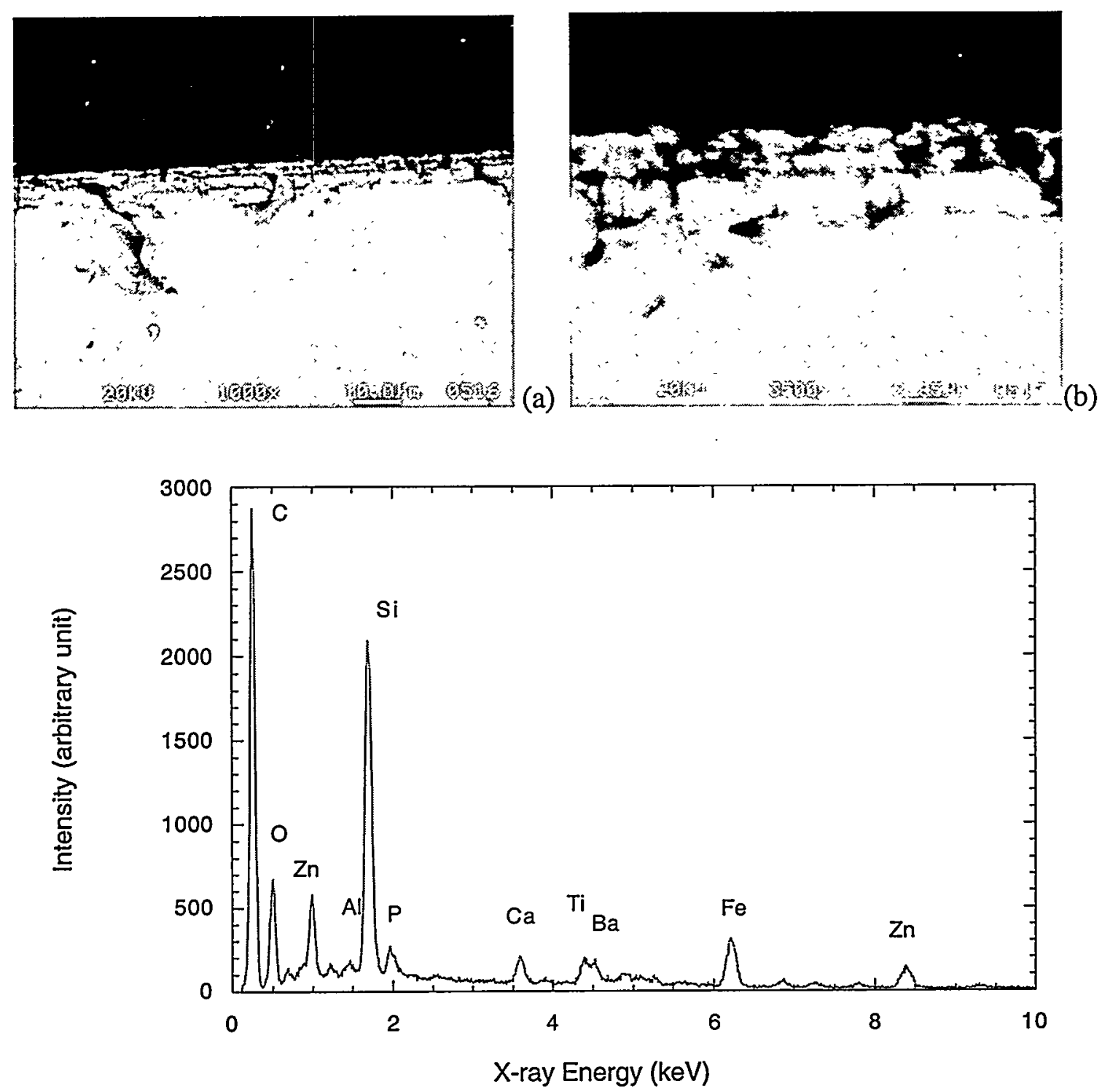

(c)

Fig. 58. Cross-sectional (a) and high-magnification cross-sectional (b) SEM images of the alteration layer formed on the surface of the PNL 76-68 glass reacted at $75^{\circ} \mathrm{C}$ in $95 \% \mathrm{RH}$ for nine years and (c) the EDS spectrum of the alteration layer. 


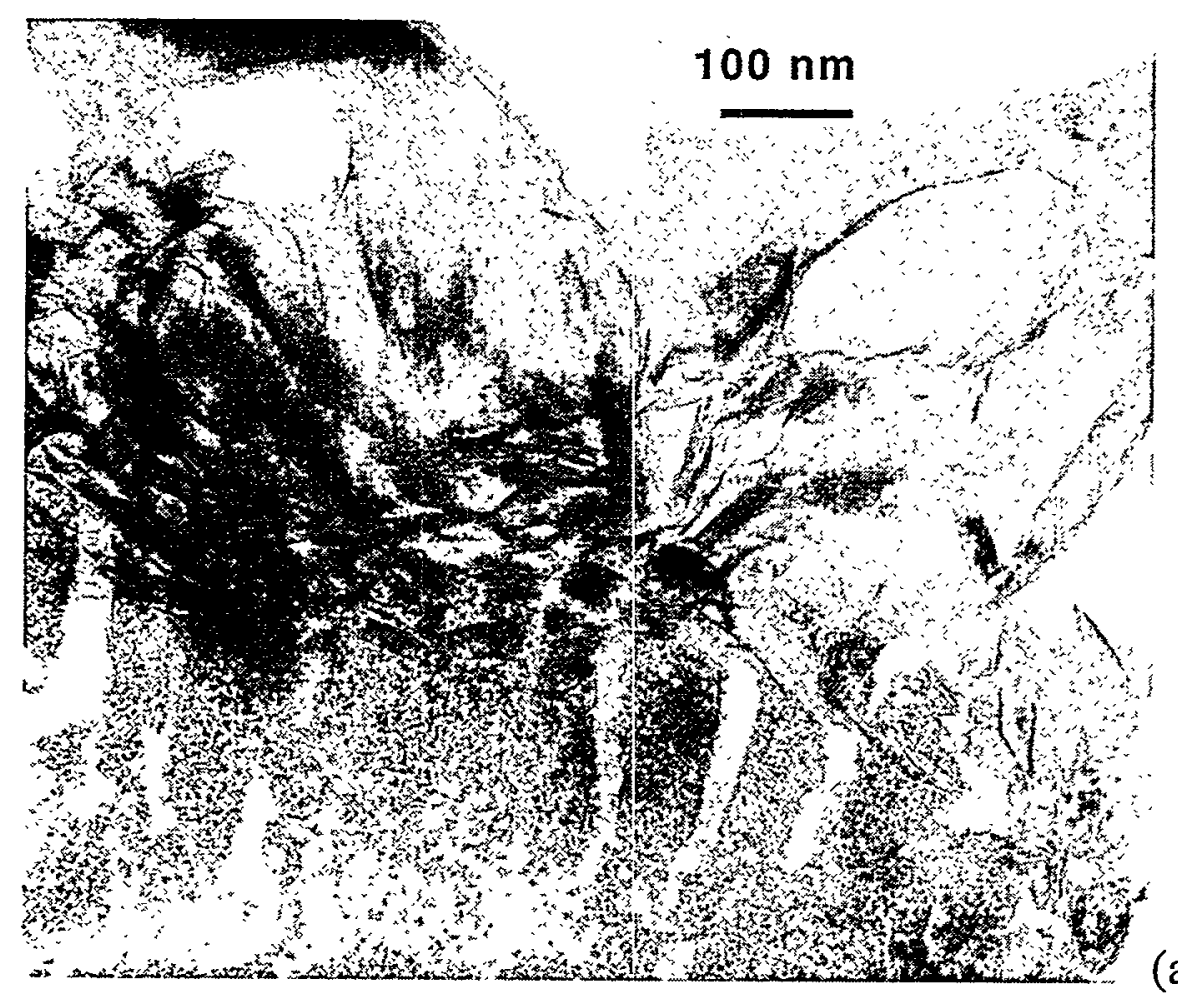

(a)

(b)

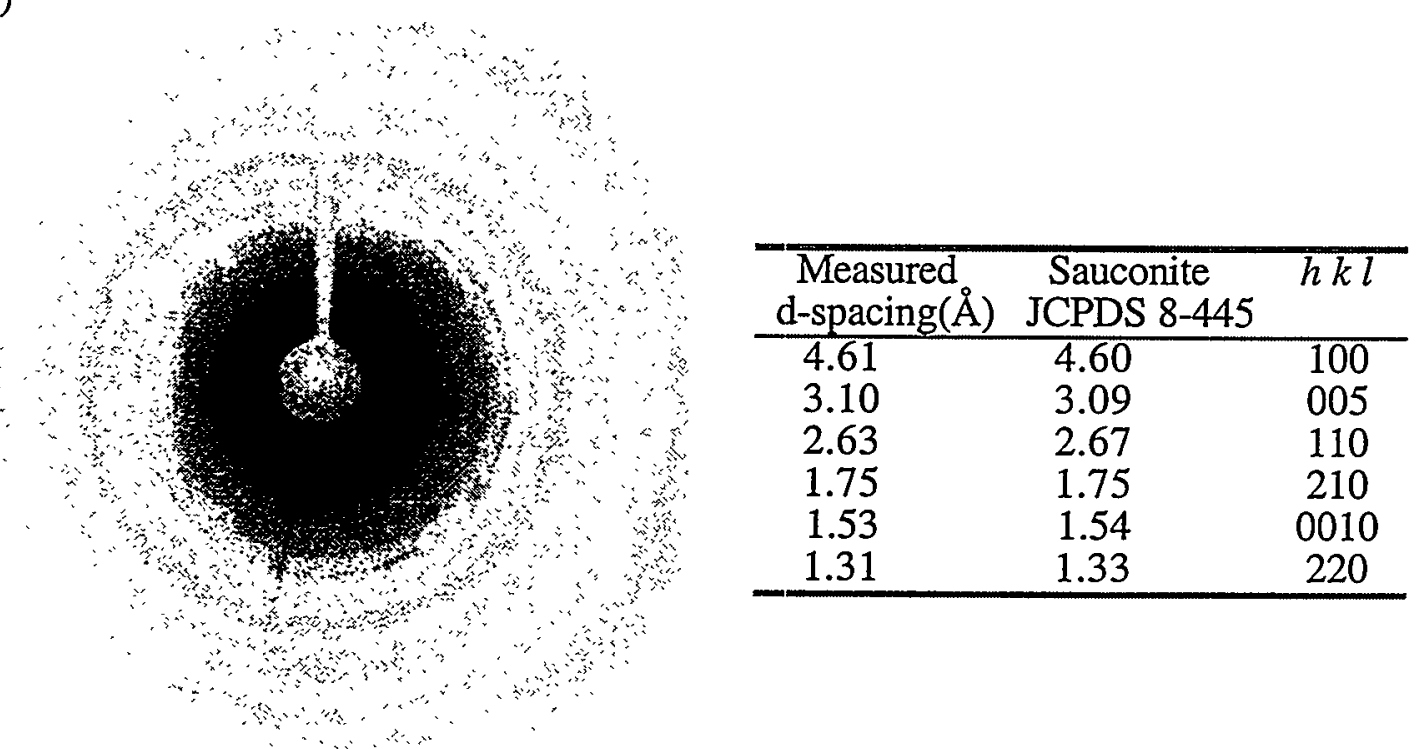

Fig. 59. Analysis by AEM: (a) TEM image of the sectioned feature showing the textured phase at outer surface, (b) electron diffraction pattern of outer layer and comparison of measured d-spacings with those of sauconite (identical diffraction pattern obtained for the inner layer) and (c) EDS spectra comparing both areas. 


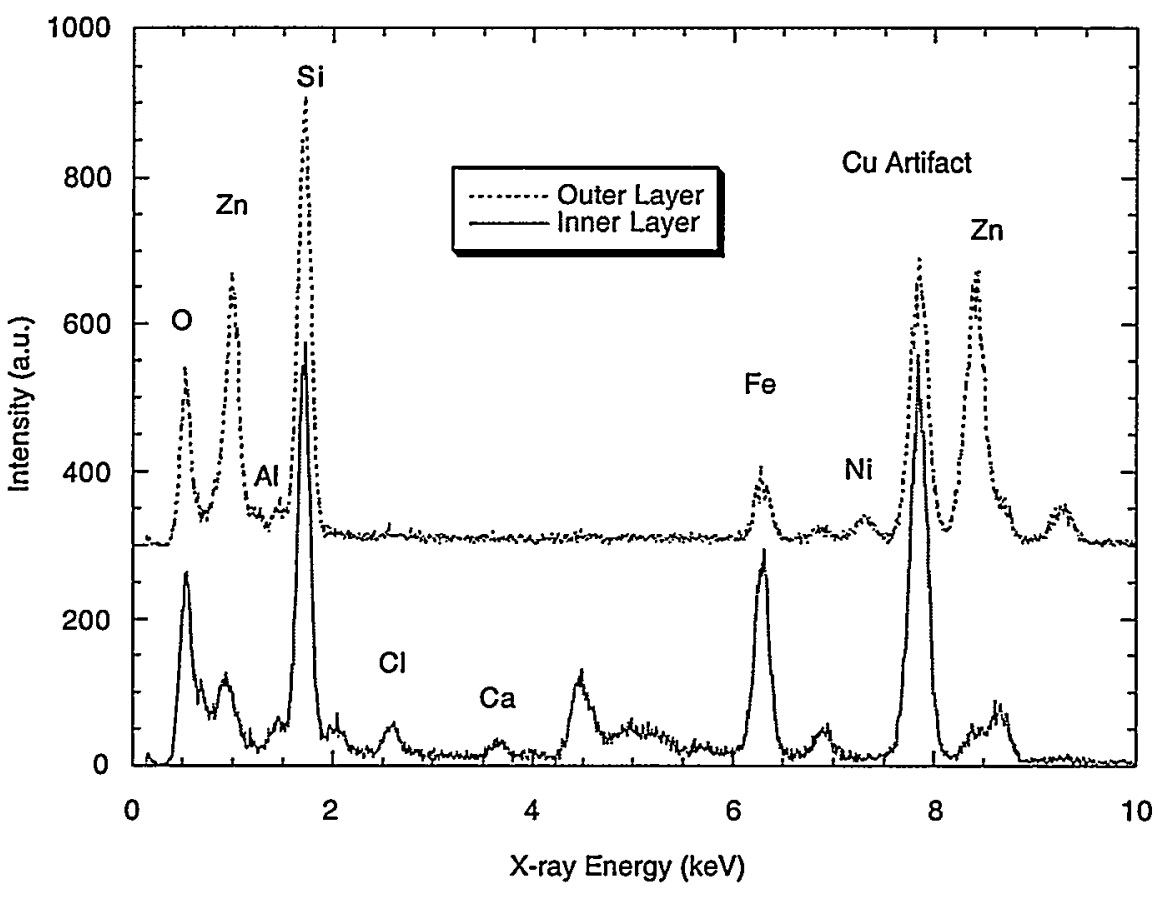

(c)

Fig. 59. Contd. 

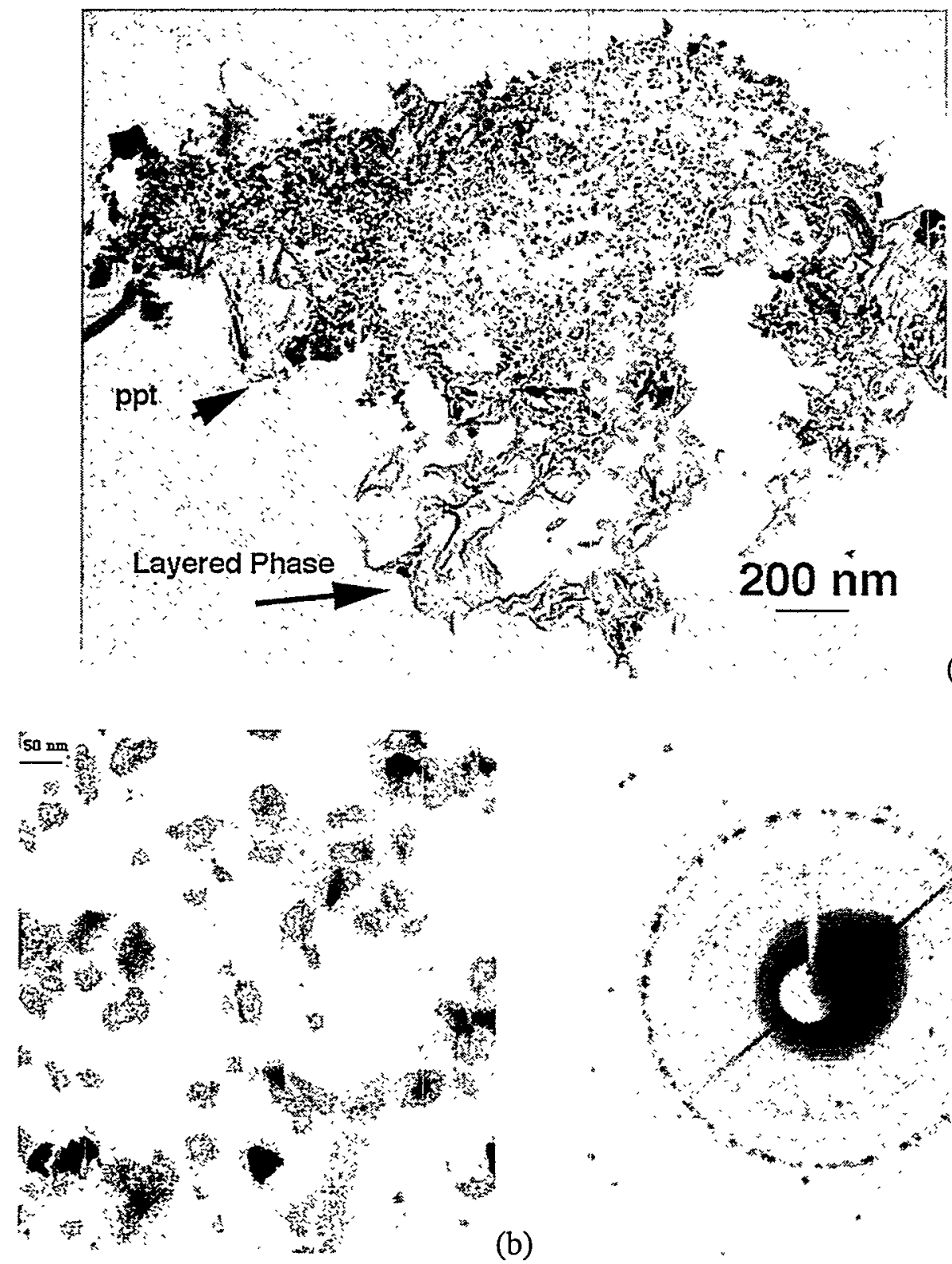

(a)

Fig. 60. Analysis by AEM of white precipitate from surface of PNL 76-68 waste glass vapor reacted at $75^{\circ} \mathrm{C}$ and $95 \% \mathrm{RH}$ for nine years: (a) TEM image of the sectioned particle showing a mixture of a layered material, identical to the sauconite and particles of a broken precipitate formed adjacent to the layered phase, (b-d) TEM image, electron diffraction pattern, and EDS spectrum of the precipitate, and (e) comparison of measured d-spacings with those of hannebachite, a calcium sulfite hydrate. 


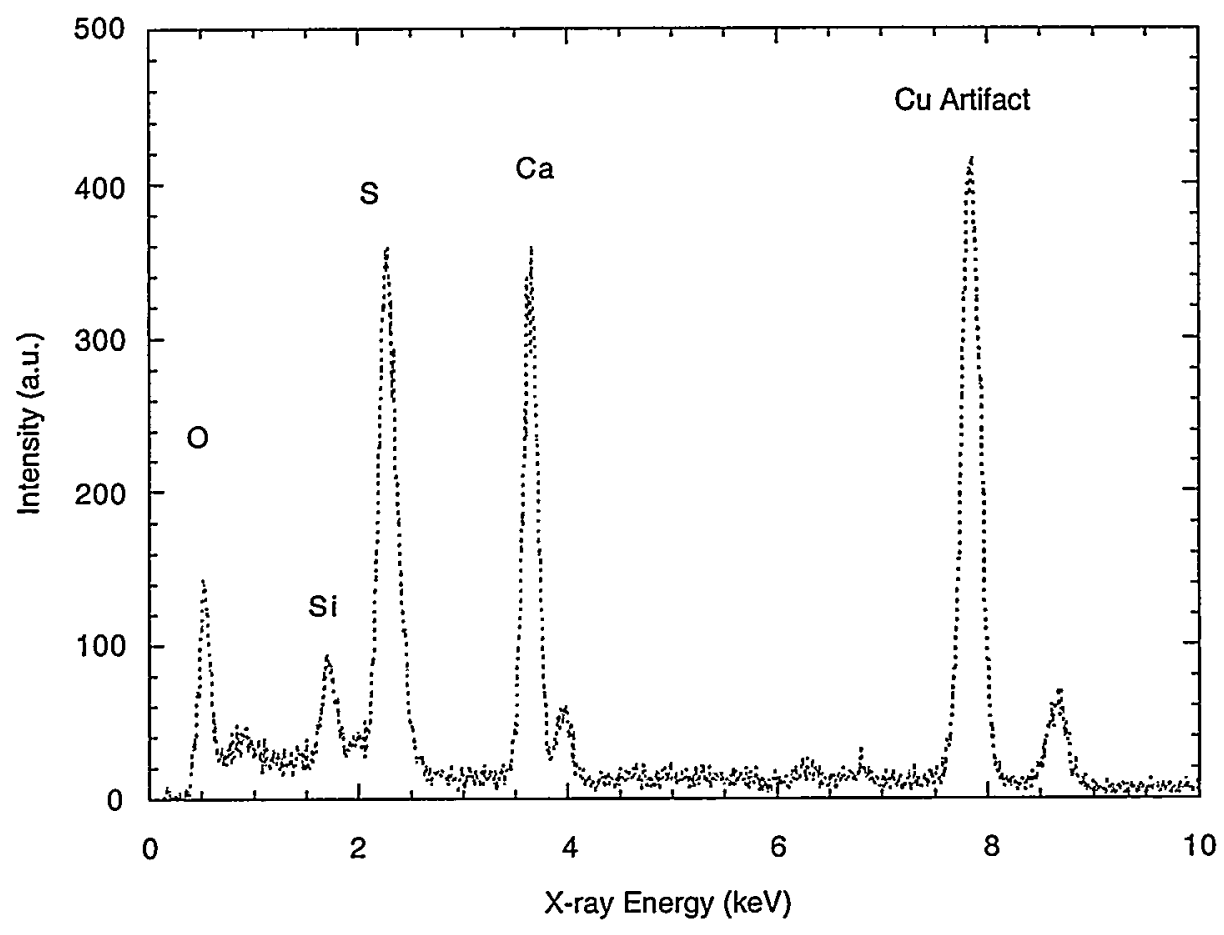

(d)

(e)

\begin{tabular}{ccc}
\hline $\begin{array}{l}\text { Measured } \\
\text { d-spacing }(\AA)\end{array}$ & \multicolumn{2}{c}{ Hannebachite } \\
JCPDS & 39-725 & \\
\hline 4.85 & 4.83 & 111 \\
3.17 & 3.16 & 221 \\
2.65 & 2.67 & 040 \\
2.47 & 2.45 & 400 \\
1.95 & 1.96 & 250 \\
1.86 & 1.85 & 511 \\
1.73 & 1.74 & 342 \\
\hline
\end{tabular}

Fig. 60. Contd. 


\subsubsection{Vapor Reaction at $75^{\circ} \mathrm{C}$ and in $100 \% \mathrm{RH}$}

A grayish layer formed on the surface (Fig. 61).

Examination with SEM showed a honeycombed surface, characteristic of smectite clay, plus a scattering of 5- $\mu \mathrm{m}$ white particles (Fig. 62). The smectite formed in this sample seemed more crystallized, as the surface features were sharper and clearer than with the samples reacted at 95\% RH (see Fig. 51b, 57a). The mat surface had a sauconite composition, which is characterized by the presence of $\mathrm{Si}, \mathrm{Ca}, \mathrm{Ti}$, and $\mathrm{Zn}$. The white particles observed on the surface also contained $\mathrm{Si}, \mathrm{Fe}, \mathrm{Ca}$, and $\mathrm{Zn}$. However, the content of $\mathrm{Ca}$ in this phase was much higher than that in smecitite clay (Fig. 63). This phase could not be identified by either SEM or EDS. Examination of the cross section showed the formation of an uniform alteration layer of about $5 \mu \mathrm{m}$ on the surface (Fig. 64a), which was enriched in $\mathrm{Zn}$ and $\mathrm{Fe}$ and depleted in Na, compared with unreacted glass (Fig. 64b).

A thin wedge from the surface was picked up and sectioned.

The sectioned sample contained both unreacted glass and the alteration layer. Examination by AEM revealed the formation of an amorphous layer on the glass surface followed by a textured layered phase at the outer surface (Fig. 65), which was identified as sauconite. Analysis with EDS also revealed enrichment of $\mathrm{Zn}$ in sauconite and enrichment of $\mathrm{Ca}, \mathrm{Ti}$, and $\mathrm{Cl}$ in the amorphous area. A alteration particle was also removed from surface and was identified as tobermorite, a calcium silicate, with AEM (Fig. 66). This phase may be the same white phase that was observed in SEM.

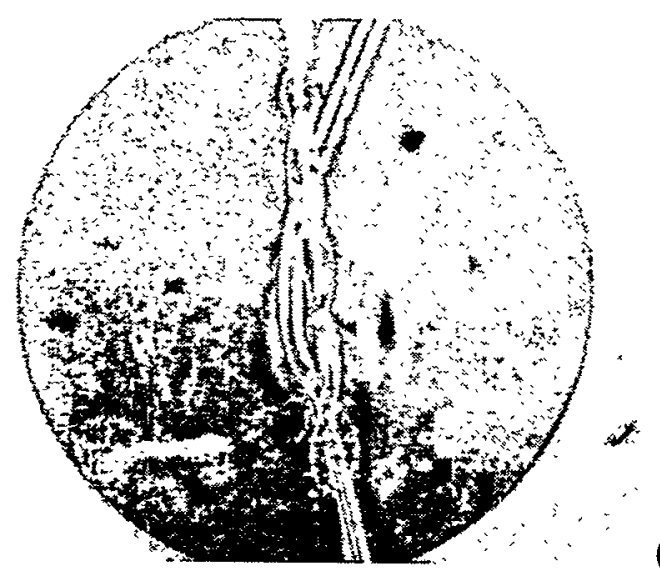

(a)

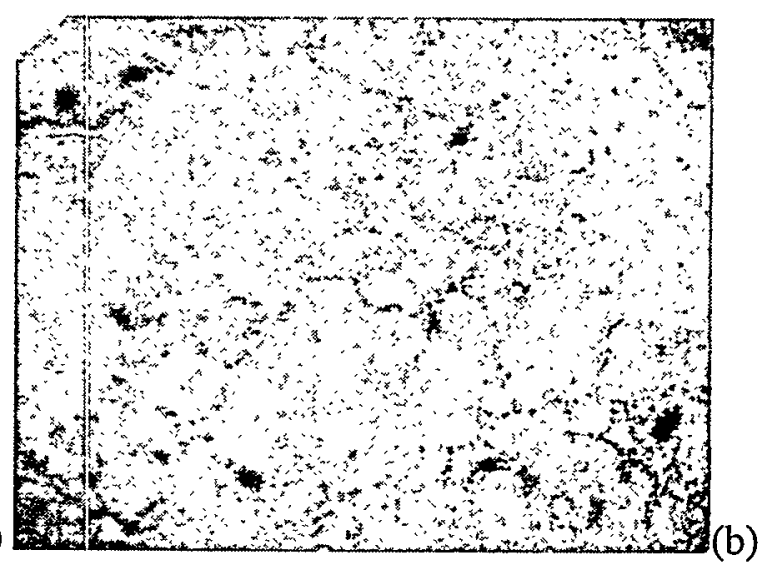

Fig. 61. Optical microscopy images of the PNL 76-68 waste glass vapor reacted at $75^{\circ} \mathrm{C}$ in $100 \% \mathrm{RH}$ for seven years taken at (a) $6 \mathrm{X}$ and (b) $50 \mathrm{X}$. 


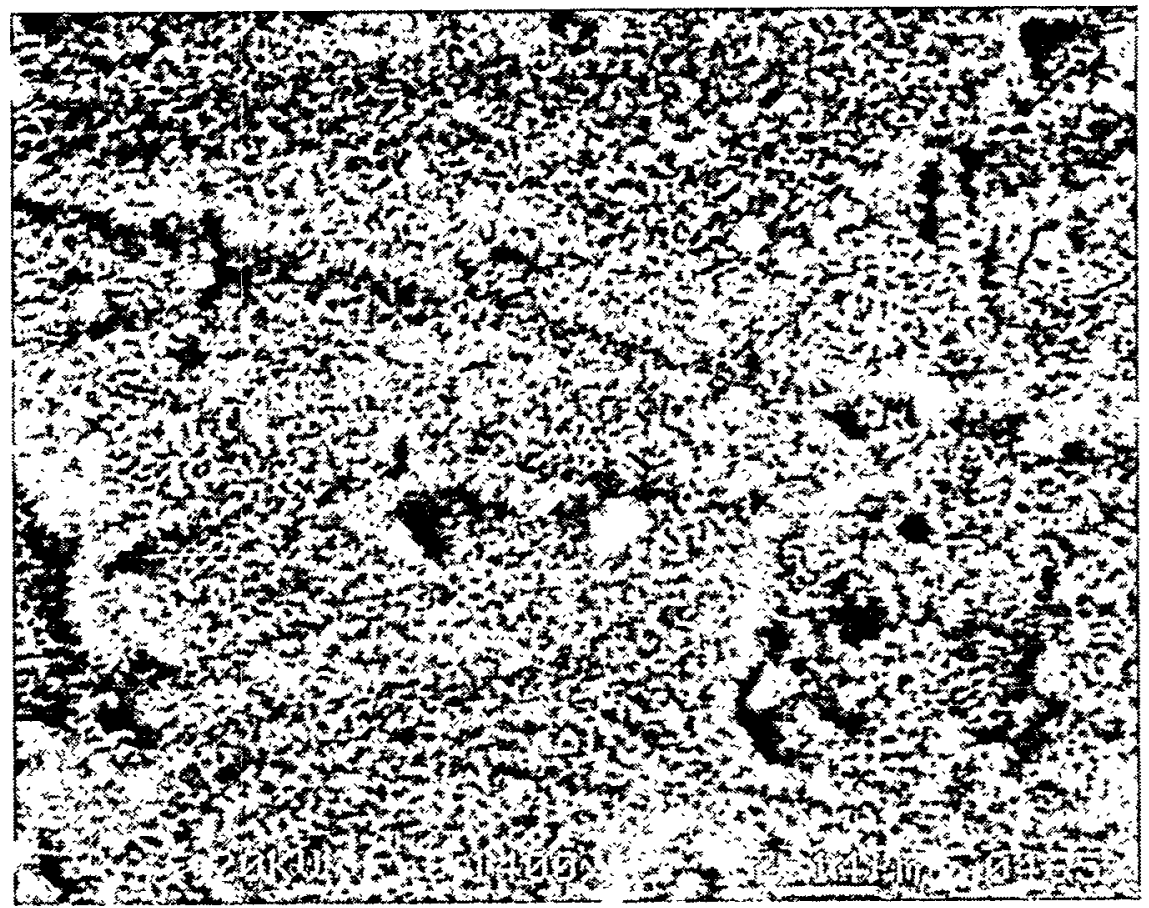

Fig. 62. An SEM image of the alteration layer formed on the surface of the PNL 76-68 glass vapor reacted at $75^{\circ} \mathrm{C}$ and $100 \% \mathrm{RH}$ for seven years.

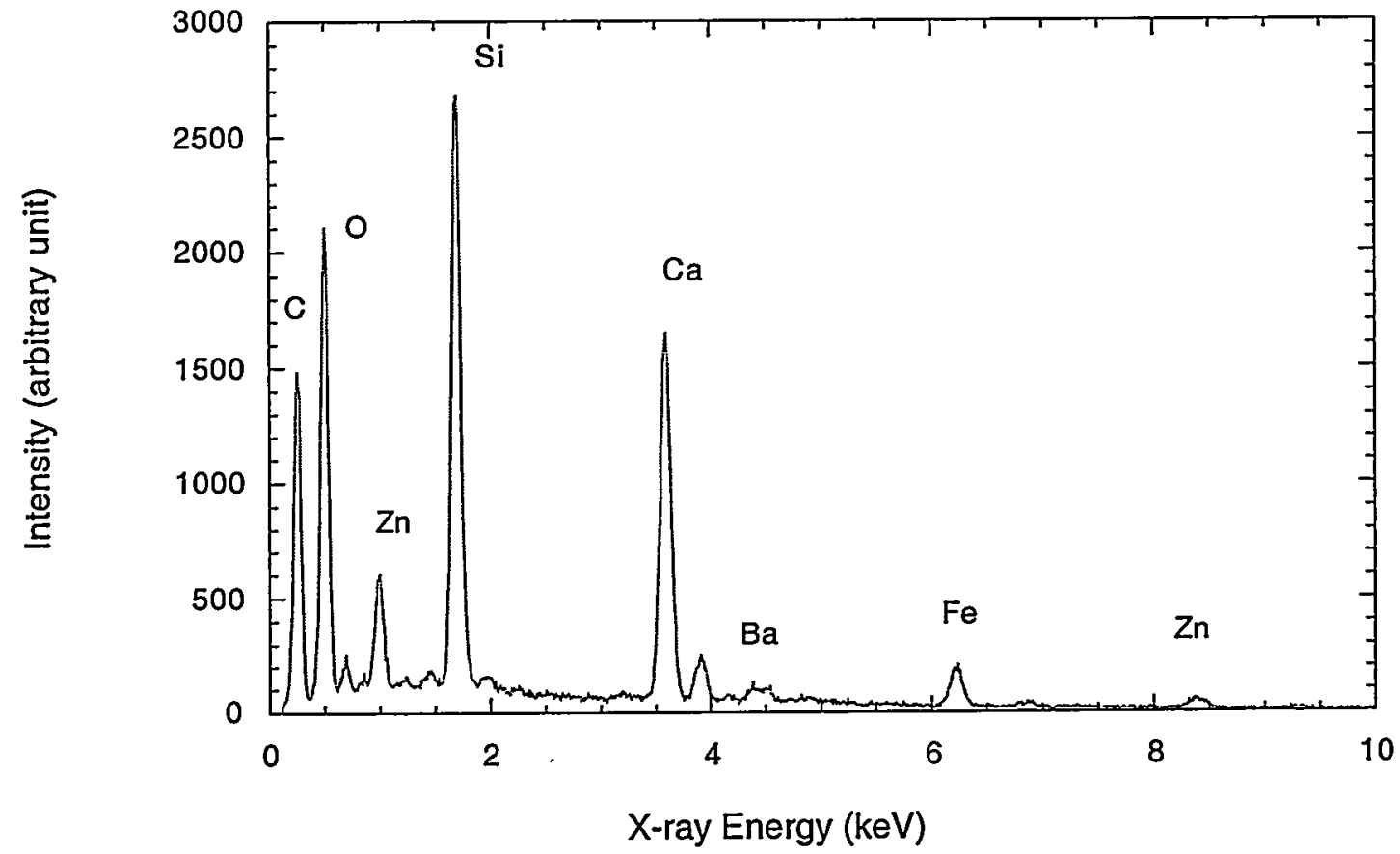

Fig. 63. An EDS spectrum of the white precipitate from the surface of the PNL 76-68. waste glass vapor reacted at $75^{\circ} \mathrm{C}$ for seven years. 

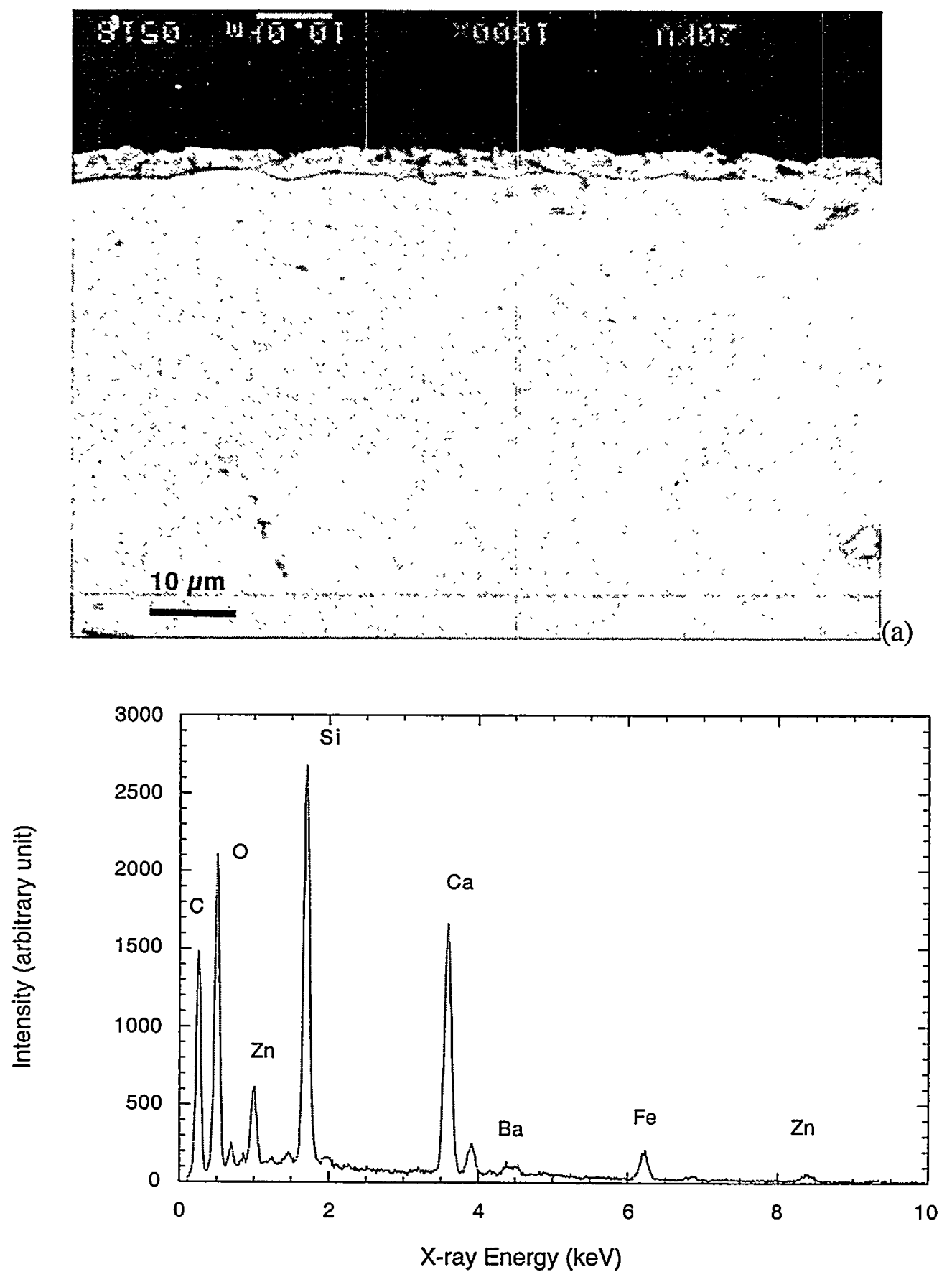

(b)

Fig. 64. (a) Cross-sectional SEM image of the alteration layer formed on the surface of the PNL 76-68 waste glass vapor reacted at $75^{\circ} \mathrm{C}$ and $100 \% \mathrm{RH}$ for seven years and (b) its EDS spectrum. 


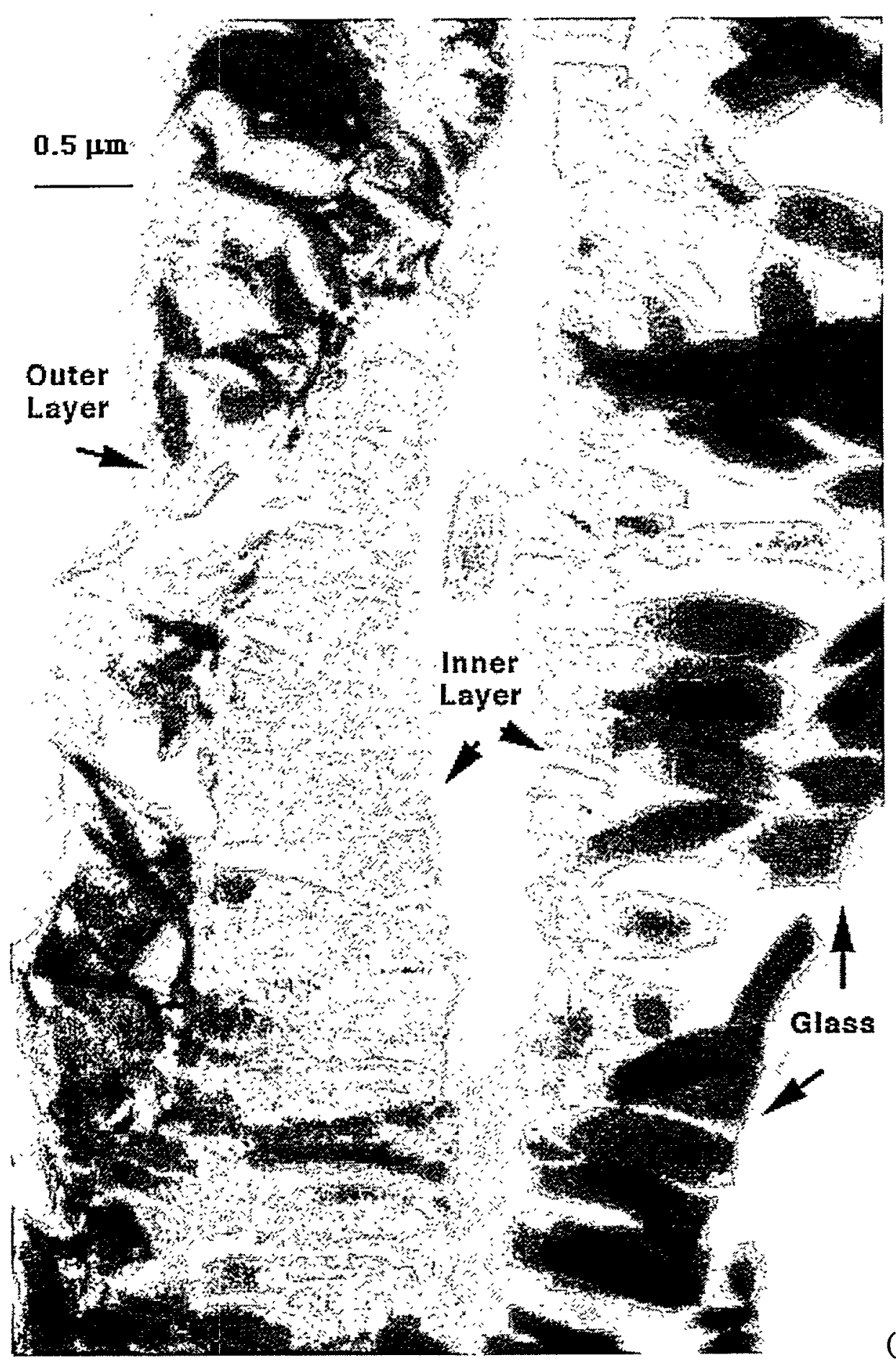

Fig. 65. Analysis by AEM of sample from surface of PNL 76-78 waste glass vapor reacted at $75^{\circ} \mathrm{C}$ and $100 \% \mathrm{RH}$ for seven years: (a) TEM image of the sectioned feature showing the alteration of glass into an amorphous gel layer with a textured phase at the outer surface, high-magnification TEM images of the interfaces of (b) outer/inner layers and (c) inner layer/glass, (d) electron diffraction pattern of the outer layers and comparison of measured d-spacings with those of sauconite, and (e) EDS spectra comparing alteration layers and unaltered glass. 

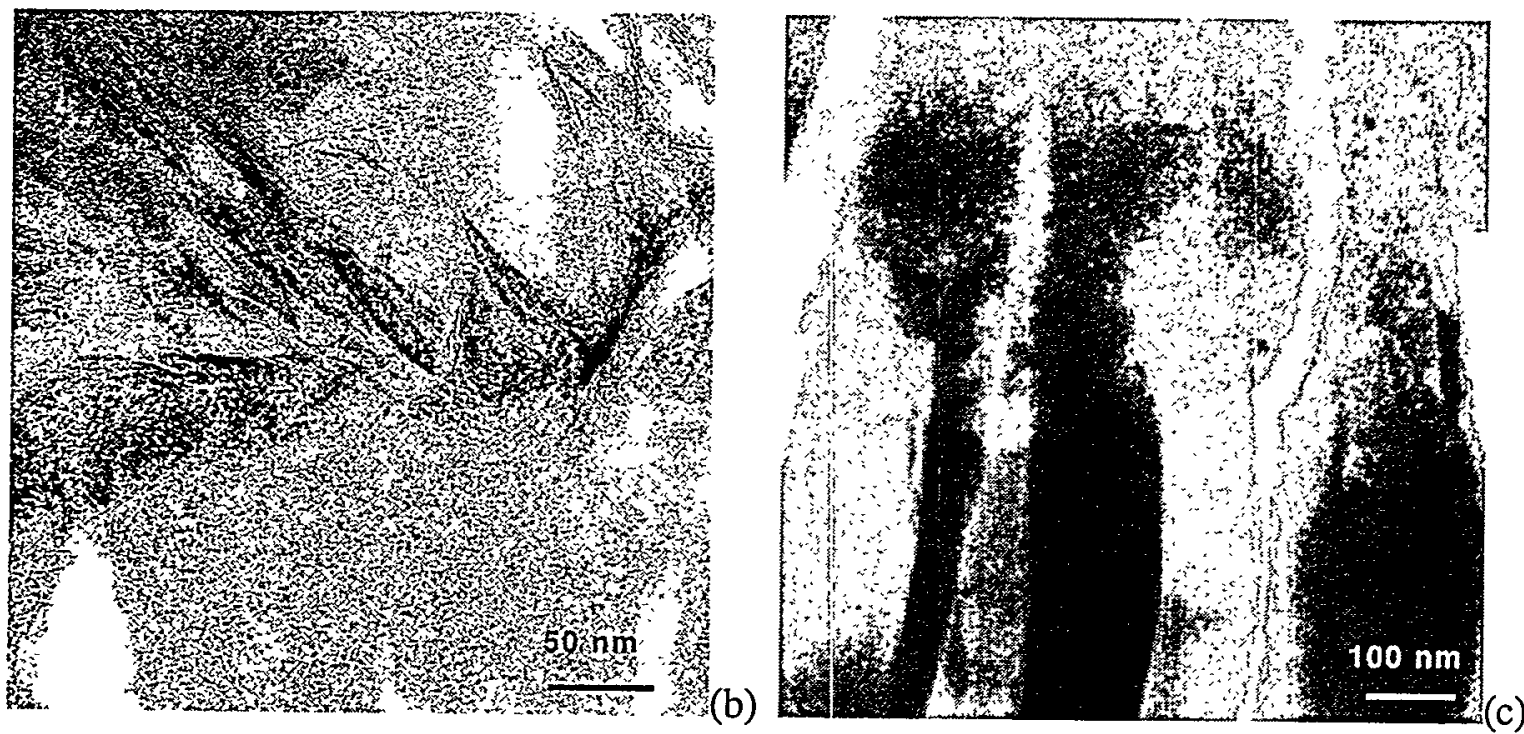

(d)

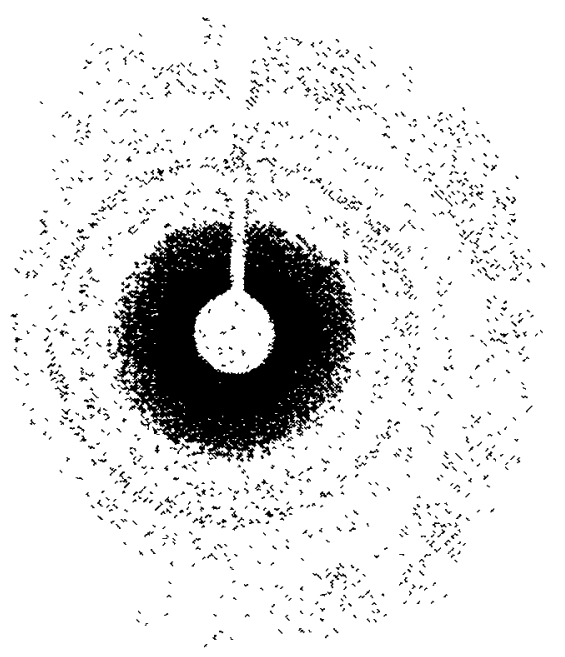

\begin{tabular}{ccc}
\hline $\begin{array}{c}\text { Measured } \\
\text { d-spacing( }(\AA)\end{array}$ & $\begin{array}{c}\text { Sauconite } \\
\text { JCPDS 8-445 }\end{array}$ & $h k l$ \\
\hline 4.61 & 4.60 & 100 \\
3.10 & 3.09 & 005 \\
2.63 & 2.67 & 110 \\
1.75 & 1.75 & 210 \\
1.53 & 1.54 & 0010 \\
1.31 & 1.33 & 220 \\
\hline
\end{tabular}

Fig. 65. Contd. 


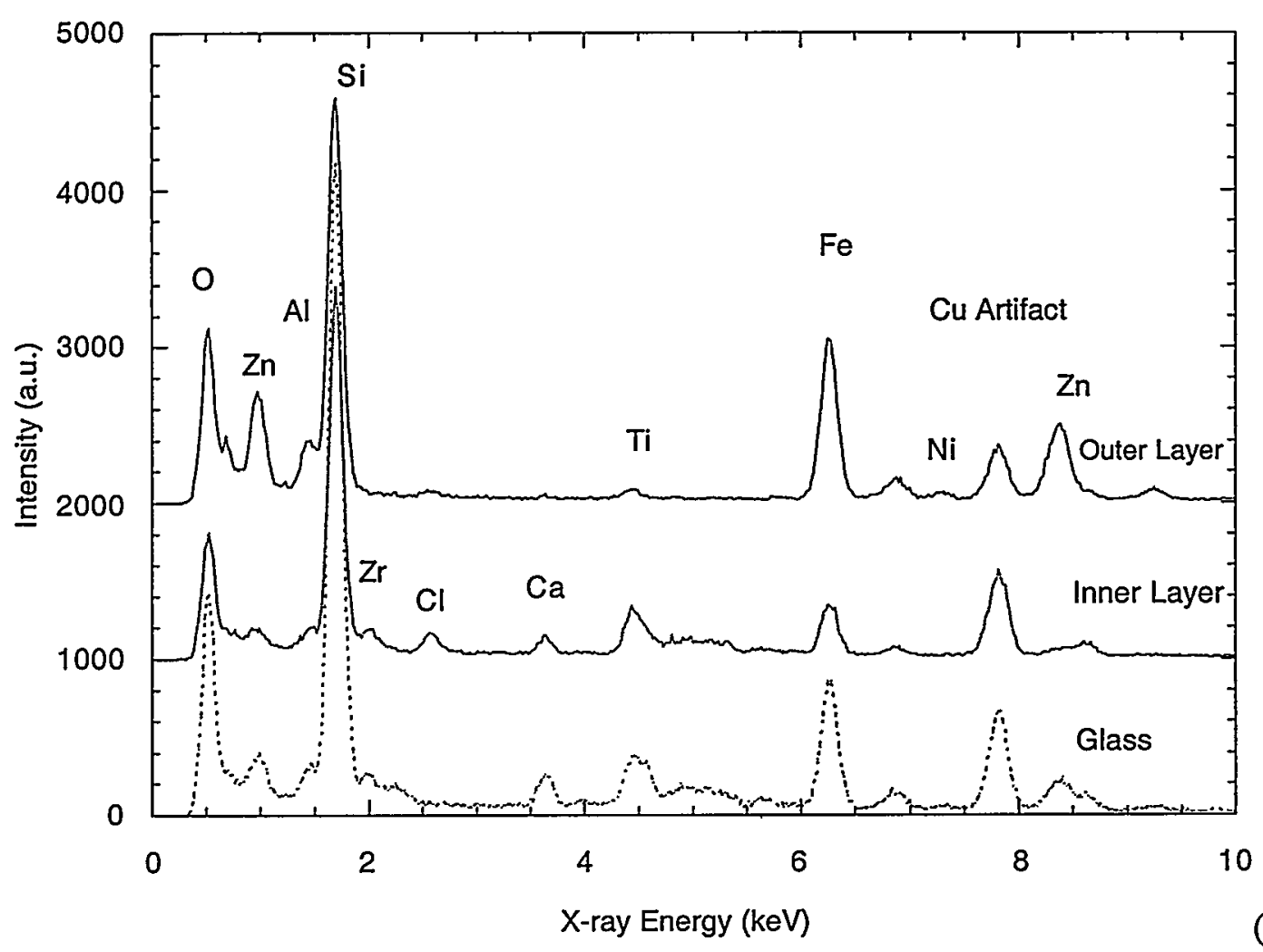

(e)

Fig. 65. Contd. 


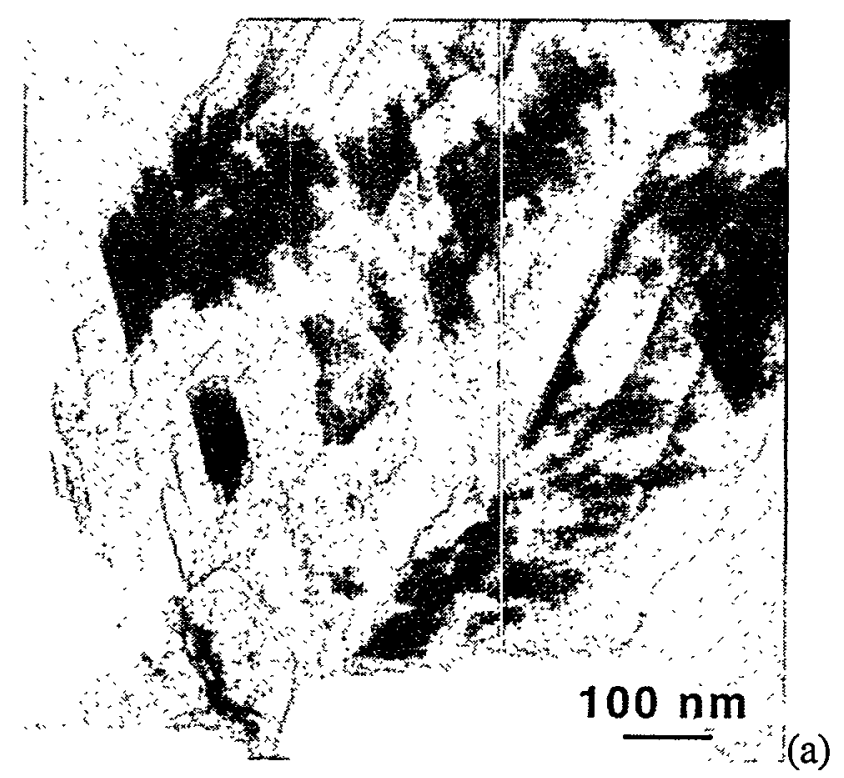

(b)

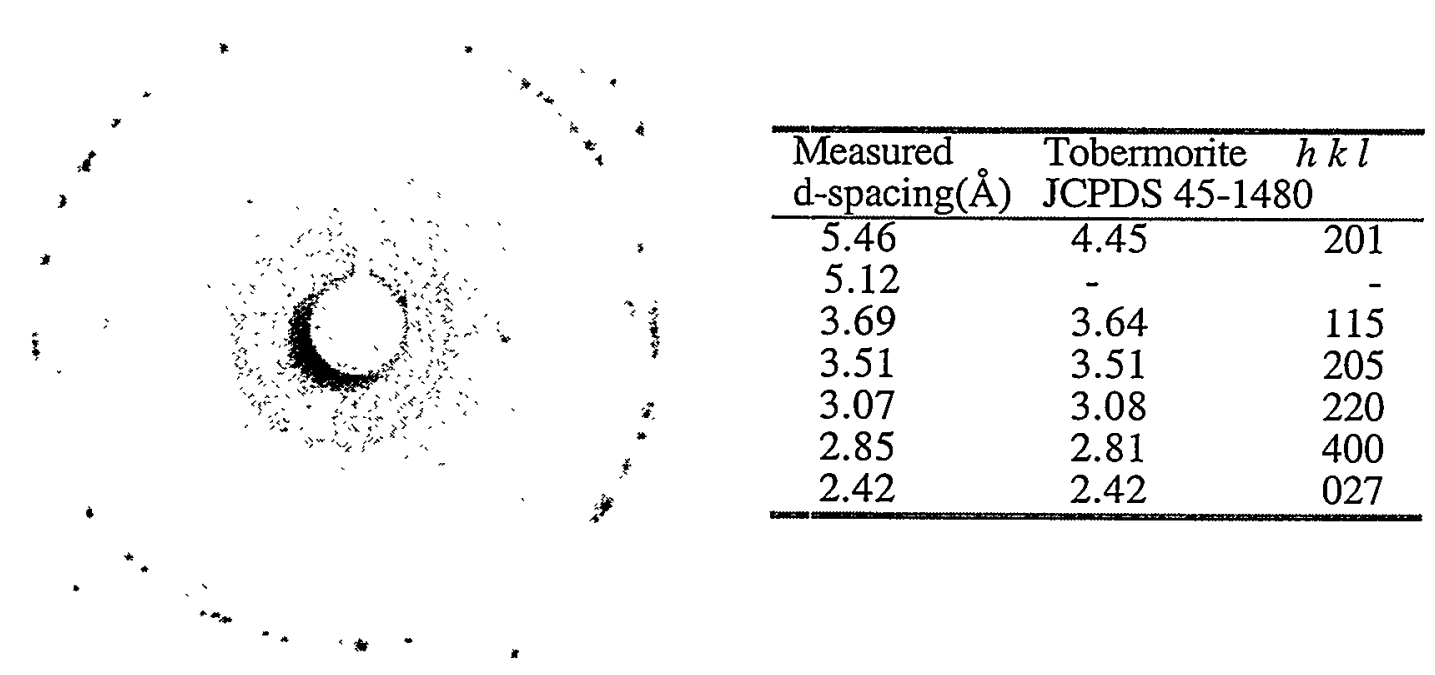

Fig. 66. Analysis by AEM of particle from surface of PNL 76-68 waste glass vapor reacted at $75^{\circ} \mathrm{C}$ and $100 \% \mathrm{RH}$ for seven years: (a) TEM image of the sectioned particle, (b) electron diffraction pattern and comparison of measured d-spacings with those of tobermorite, a calcium silicate, and (c) EDS spectrum of the sectioned phase. 


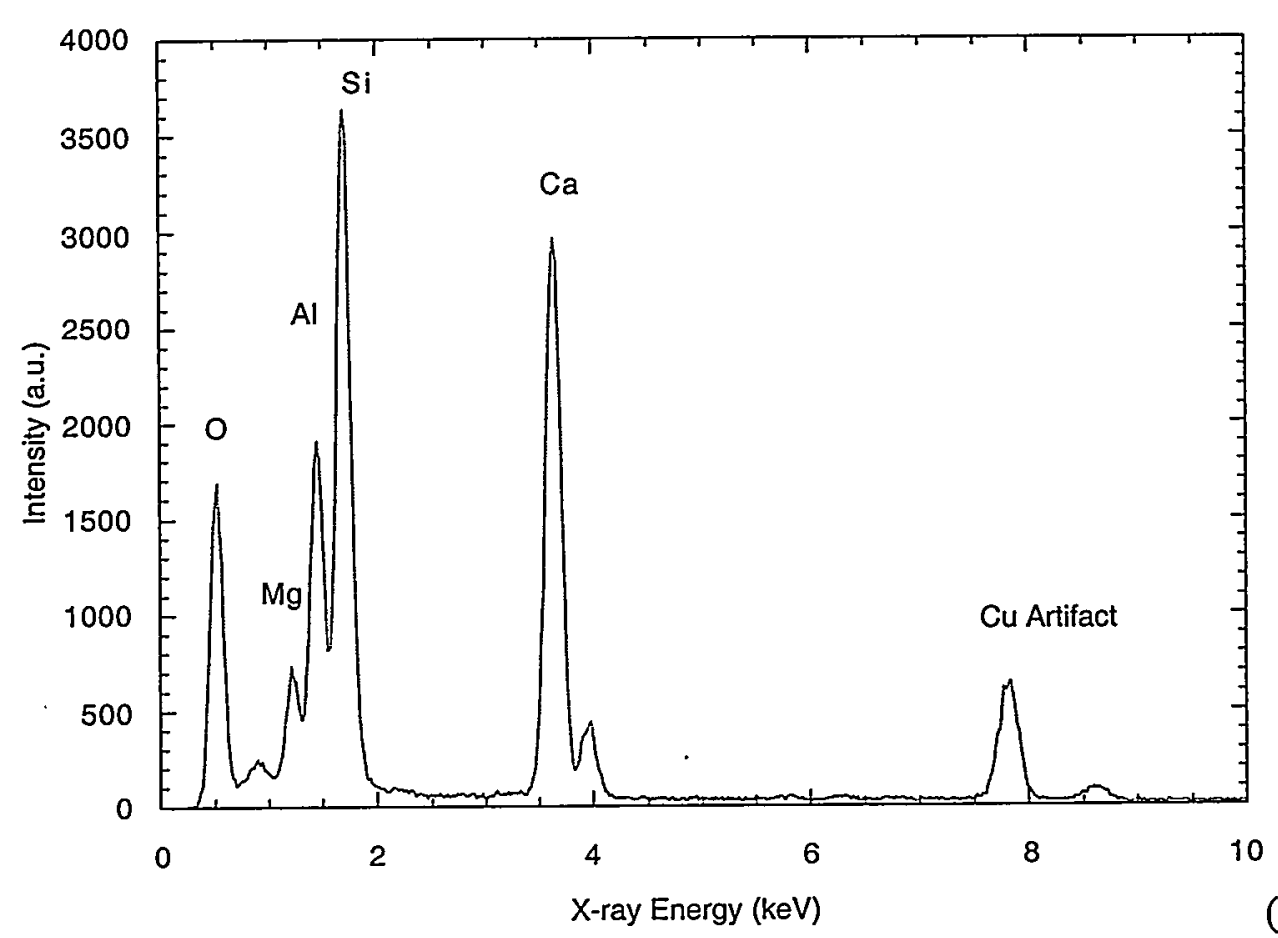

(c)

Fig. 66. Contd.

\subsubsection{Summary}

Alteration layers about $5 \mu \mathrm{m}$ thick were observed to have formed on the surface of the laboratory-reacted PNL 76-68 glass. The thickness of the alteration layer seemed not strongly affected by the values of $\mathrm{RH}$. The alteration layer consisted of an amorphous zone in contact with pricine glass and sauconite clay which was also characterized by fibrous microstructure. The amorphous zone contained $\mathrm{Na}, \mathrm{Si}, \mathrm{Fe}$, $\mathrm{Ti}$, and $\mathrm{Ca}$, whereas the outer layer was rich in $\mathrm{Zn}$ but often free of $\mathrm{Na}$. Secondary phases were occasionally observed on the outer surfaces of alteration layers. Major phases identified with AEM include hydroxyapatite, goethite, and tobermorite. 


\section{SUMMARY}

We compared the long-term alteration of natural glasses (obsidian and basalt) by natural processes and laboratory experiments. We compared these results with those of typical waste glasses that had been reacted under similar laboratory conditions to evaluate the effectiveness of laboratory vapor test methods in reproducing the reaction of glass in nature.

Snake River obsidian samples reacted at $75^{\circ} \mathrm{C}$ and at 95 and $100 \% \mathrm{RH}$ for up to nine years formed birefiregent layers on the surface. At $100 \% \mathrm{RH}$, the hydration rate at $75^{\circ} \mathrm{C}$ followed the same time dependence as those previously observed at highertemperatures. The extrapolations from high-temperature experiments with the Arrhenius relation were in good agreement with the $75^{\circ} \mathrm{C}$ vapor hydration results. Hydration at $95 \% \mathrm{RH}$ exhibited the same reaction kinetics as that at $100 \%$ with a nearly identical rate. These results indicate that hydration at $75^{\circ} \mathrm{C}$ is controlled by a water-diffusion process and is not very sensitive to the variation of relative humidity $(\mathrm{RH})$, at least in the range of 95 to $100 \% \mathrm{RH}$.

The palagonite formed on the surface of Hawaiian basaltic glasses has been characterized with SEM/EDS and AEM/EDS. It was found to consist mainly of geothite, an iron hydroxide, and several other crystalline precipitates: scarbroite $\left[\mathrm{Al}_{2}(\mathrm{OH})_{6} \mathrm{H}_{2} \mathrm{O}\right.$, kaolinite $\left[\mathrm{Si}_{2} \mathrm{Al}_{2} \mathrm{O}_{5}\left(\mathrm{OH}_{4}\right]\right.$, a septechlorite-montmorillonite-saponite mixture, magnetite $\left(\mathrm{Fe}_{3} \mathrm{O}_{4}\right), \alpha$-quartz $\left(\mathrm{SiO}_{2}\right)$, a Fe-Ca-Si-Mg containing phase, and an $\mathrm{Si}-\mathrm{Al}-\mathrm{Fe}$-rich amorphous phase. The formation of these phases can be explained by a progressive dissolution of glass with contemporaneous reprecipitation at the glass surface after the dissolved element reached its solubility limit. The formation of the identified phases were also consistent with the calculation made by [CROVISIER-1992] on the mineralogical sequences in basalt glass using the geochemical computer code DISSOL.

Our SEM/EDS studies also showed that the corrosion of basaltic glass was sensitive to local environment in the close vicinity of glass surface. The corrosion along cracks of the glass led to the formation of possible zeolite phases, which were not observed on the palagonite formed on the open glass surface. The formation of zeolites generally reflected the achievement of a saturated condition along the cracks where the rate of flow exchange is slow, whereas the phases formed on the surface palagonite corresponded to a reactivity low reaction progress due to its unsaturated conditions.

Synthetic basalt glass having the Hawaiian basalt composition was found to form an alteration layer at both 95 and $100 \% \mathrm{RH}$. The nature of the alteration layer depended strongly on the reaction conditions. At $95 \% \mathrm{RH}$ the glass first formed an amorphous gellayer, which then converted, most likely in situ, to saponite fibrous clay. The formation of a gel layer reflected the involvement of water-diffusion and ion-exchange processes. At $100 \% \mathrm{RH}$, however, no obvious gel layer was observed, and there was evidence of congruent dissolution at the surface. The alteration layer consisted mainly of saponite clay, which may have precipitated after it reached the solubility limit as the glass continued to dissolve.

Studies of waste glasses revealed that their alteration behavior depended on both the glass composition and reaction conditions. Silicon-poor glasses, such as SRL 131 and PNL 76-68 ( 43 wt\% $\left.\mathrm{SiO}_{2}\right)$, were less resistant to the corrosion of vapor. For these glasses, thick alteration layers $(>5 \mu \mathrm{m})$ were generally observed and the nature of the alteration layer seemed not strongly affected by RH. On the other hand, silicon-rich glass SRL $165\left(52 \mathrm{wt} \% \mathrm{SiO}_{2}\right)$ was found to be more resistive to water corrosion, and thinner layers $(<1 \mu \mathrm{m})$ were formed. Furthermore, the thickness of the alteration layer was smaller 
in glass reacted at $100 \% \mathrm{RH}$ than at $95 \%$. Analyses of the alteration layers showed an abundance of smectite clay, a phase also frequently observed in naturally reacted basalt. The presence of similar reaction products in both natural glass and waste glass suggests that similar processes occur during the corrosion of both types of glass. Our studies also indicate that the reaction kinetics of a particular glass may be significantly affected by the reaction conditions and the composition of the glass selected. 


\section{REFERENCES}

ABRAJANO-1989

Abrajano, T. A., J. K. Bates, et al. (1989). "Aqueous Corrosion of Natural and Nuclear Waste Glasses II. Mechanisms of Vapor Hydration of Nuclear Waste Glasses." Journal of Non-Crystalline Solids 108: 269-288.

BATES-1994

Bates, J. K., and E. C. Buck (1994). "Waste Glass Weathering." Materials Research Society Symposium Proceedings 333: 41-54.

BYERS-1987

Byers, C. D., M. J. Jercinovic, et al. (1987). A Study of Natural Glass Analogues as Applied to Alteration of Nuclear Waste Glass. Argonne National Laboratory Report ANL-86-46 (NUREG/CR-4842).

CROVISIER-1987

Crovisier, J. L., J. Honnorez, et al. (1987). "Dissolution of Basaltic Glass in Seawater: Mechanism and Rate." Geochim. Cosmochim. Acta 51: 2977-2990.

CROVISIER-1992

Crovisier, J. -L., J. Honnorez, et al. (1992). "Dissolution of Subglacial Volcanic Glasses from Iceland: Laboratory Study and Modeling." Applied Geochemistry Suppl. Issue No. 1: $55-81$.

CUNNANE-1994

Bates, J. K., C. R. Bradley, et al. (1994). "High-Level Waste Borosilicate Glass: A Compendium of Corrosion Characteristics." Vol. 1. Ed., J. C. Cunnane, DOE Reort No. DOE-EM-0177.

DEER-1992

Deer, W. A., R. A. Howie, and J. Zussman. (1992) in An Introduction to the Rockforming Minerals, Longman Scientific \& Technical, Essex, UK, p. 571.

DIEBOLD-1986

Diebold, F. E., and J. K. Bates (1986). "Glass-Water Vapor Interaction." Adv. Ceram. 20: $515-522$.

EBERT-1990

Ebert, W. L., and J. K. Bates (1990). "The Reaction of Synthetic Nuclear Waste Glass in Steam and Hydrothermal Solution." Materials Research Society Symposium Proceedings, 176, 339-346.

FRIEDMAN-1976

Friedman, I., and W. Long (1976). "Hydration Rate of Obsidian." Science 191: 347-352.

FRIEDMAN-1984

Friedman, I., and W. Long (1984). "Volcanic Glasses, Their Origins and Alteration Processes." J. Non-Crystalline Solids 67: 127-133.

FRIEDMAN-1994

Friedman, I., F. W. Trembour, et al. (1994). “Obsidian: The Dating Stone.” American Scientist 66: 44-51. 
GISLASON-1993

Gislason, S. R., D. R. Veblen, et al. (1993). "Experimental Meteoric Water-Basalt Interactions: Characterization and Interpretation of Alteration Products." Geochimica et Cosmochimica Acta 57: 1459-1471.

JERCINOVIC-1987

Jercinovic, M. J. and R. C. Ewing (1987). Basaltic Glasses from Iceland and the Deep Sea: Natural Analogues to Borosilicate Nuclear Waste-Form Glass. JSS Project Technical Reort 88-01.

MAZER-1992

Mazer, J. J., J. K. Bates, et al. (1992). "Water Diffusion in Tektites: An Example of the Use of Natural Analogues in Evaluating the Long-Term Reaction of Glass with Water." Journal of Nuclear Materials 190: 277-284.

MAZER-1991

Mazer, J. J., J. K. Bates, et al. (1991). "Alteration of Tektite to Form Weathering Products." Nature 357: 573-576.

MORGENSTEIN-1976

Morgenstein, M., and P. Rosendahl (1976). "Basaltic glass hydration dating in Hawaiian archaeology." Advances in Obsidian Glass Studies. Ed., R. E. Taylor. Noyes Press, Park Ridge, NJ. pp. 141-164.

\section{MURAKAMI}

Murakami, T., R. C. Ewing, and B. C. Bunker (1988), "Analytical Electron Microscopy of Leached Layered on Synthetic Basalt Glass." Materials Research Society Symposium Proceedings 112: 737-748.

SINGH-1995

Singh, B., and R. J. Gilkes (1995). "Application of Analytical Transmission Electron Microscopy to Indentify Intercrystal Variations in the Composition of Clay Minerals." Analyst 120: 1335-1339.

STANWORTH-1950

Stanworth, J. E., (1950) Physical Properties of Glass. Clarendon Press, Oxford, p. 224.

YAPER-1931

Yaper, W. A., and S. O. Morgan (1931). Journal of Physical Chemistry 35: 2026.

ZHOU-1989

Zhou, Z., and W. S. Fyfe (1989). "Palagonitization of Basaltic Glass from DSDP Site 355, Leg 37: Textures, Chemical Composition, and Mechanism of Formation." American Mineralogist 74: 1045-1053. 
Distribution for ANL-98/22

Internal:
A. J. Bakel
M. M. Goldberg
L. R. Morss
E. C. Buck
J. E. Harmon
L. Nuñez
D. B. Chamberlain
M. C. Hash
T. P. O'Holleran
J. C. Cunnane
J. E. Helt
R. A. Olson
W. L. Ebert (25)
S. Johnson
S.-W. Tam
R. E. Einziger
J. J. Laidler
S. F. Wolf
R. J. Finch
M. A. Lewis
P. A. Finn
J. S. Luo
J. Fortner
C. J. Mertz
V. N. Zyryanov
TIS Files

\section{External:}

DOE-OSTI (2)

ANL-E Library

ANL-W Library

A. Bindokas, DOE-CH

J. C. Haugen, DOE-CH

Chemical Technology Division Review Committee Members:

H. U. Anderson, University of Missouri-Rolla, Rolla, MO

E. R. Beaver, Monsanto Company, St. Louis, MO

A. L. Bement, Purdue University, West Lafayette, $\mathbb{N}$

M. V. Koch, University of Washington, Seattle, WA

R. A. Osteryoung, North Carolina State University, Raleigh, NC

V. P. Roan, University of Florida, Palm Beach Gardens, FL

G. R. St. Pierre, Ohio State University, Columbus, OH

T. A. Abrajano, Rensselaer Polytechnic Institute, Troy, NY

H. Adkins, TRW Environmental Safety Inc., Las Vegas, NV

T. Ahn, U.S. Nuclear Regulatory Commission, Washington, DC

D. H. Alexander, USDOE, Civilian Radioactive Waste Management, Washington, DC

M. K. Andrews, Westinghouse Savannah River Company, Aiken, SC

J. K. Bates, Plainfield, IL

R. W. Benedict, Idaho National Engineering and Environmental Laboratory, Idaho Falls, ID

H. A. Benton, Framatome Cogema Fuels, Las Vegas, NV

N. E. Bibler, Westinghouse Savannah River Company, Aiken, SC

W. L. Bourcier, Lawrence Livermore National Laboratory, Livermore, CA

N. R. Brown, USDOE, Richland Operations Office, Richland, WA

K. A. Chacey, USDOE, Office of Environmental Management, Germantown, MD

Y. Chen, Framatome Cogema Fuels, Las Vegas, NV

P. Cloke, Science Applications International Corp., Las Vegas, NV

R. C. Ewing, University of Michigan, Ann Arbor, MI

$\mathrm{X}$. Feng, Ferro Corp., Cleveland, $\mathrm{OH}$

K. M. Goff, Idaho National Engineering and Environmental Laboratory, Idaho Falls, ID 
S. E. Gomberg, USDOE, Office of Civilian Radioactive Waste Management, Washington, DC W. G. Halsey, Lawrence Livermore National Laboratory, Livermore, CA

J. Harbor, Westinghouse Savannah River Company, Aiken, SC

J. H. Holbrook, Pacific Northwest National Laboratory, Richland, WA

E. W. Holtzscheiter, Westinghouse Savannah River Company, Aiken, SC

P. R. Hrma, Pacific Northwest National Laboratory, Richland, WA

C. G. Interrante, U.S. Nuclear Regulatory Commission, Rockville, MD

W. S. Ketola, USDOE, West Valley Project Office, West Valley, NY

D. A. Knecht, Idaho National Engineering and Environmental Laboratory, Idaho Falls, ID

P. E. LaMont, USDOE, Richland Operations Office, Richland, WA

F. M. Mann, Lockheed Martin Hanford Company, Richland, WA

B. P. McGrail, Pacific Northwest National Laboratory, Richland, WA

G. B. Mellinger, Pacific Northwest National Laboratory, Richland, WA

R. Palmer, West Valley Nuclear Services, West Valley, NY

D. K. Peeler, Westinghouse Savannah River Company, Aiken, SC

I. L. Pegg, Vitreous State Laboratory, The Catholic University of America, Washington, DC

K. Picha, USDOE, Office of Environmental Management, Germantown, MD

G. F. Piepel, Pacific Northwest National Laboratory, Richland, WA

J. Plodinec, Mississippi State University, Mississippi State, MS

D. C. Sassani, Framatome Cogema Fuels, Las Vegas, NV

G. L. Smith, Pacific Northwest National Laboratory, Richland, WA

D. Stahl, Framatome Cogema Fuels, Las Vegas, NV

B. Staples, Lockheed Martin Idaho Technology Company, Idaho Falls, ID

C. Stockman, Framatome Cogema Fuels, Las Vegas, NV

R. B. Stout, Lawrence Livermore National Laboratory, Livermore, CA

D. M. Strachan, Pacific Northwest National Laboratory, Richland, WA

T. A. Thornton, Framatome Cogema Fuels, Las Vegas, NV

J. D. Vienna, Pacific Northwest National Laboratory, Richland, WA

G. G. Wicks, Westinghouse Savannah River Company, Aiken, SC

M. Aertsens, Centre d'Etude de LEnergie Nucleaire, Boeretang, BELGIUM

R. Baschwitz, Cogema, Velizy Cedex, FRANCE

E. Curti, Paul Scherrer Institute, Villigen, SWITZERLAND

B. Grambow, Kernforschungszentrum Karlsruhe Institut, Karlsruhe, GERMANY

L. Johnson, Atomic Energy of Canada, Ltd., Pinawa, Manitoba, CANADA

S. Luo, China Institute of Atomic Energy, Beijing, CHINA

P. Van Iseghem, Centre dEtude de LEnergie Nucleaire, Boeretang, BELGIUM

E. R. Vance, Australian Nuclear Science \& Technology Org., Lucas Heights, AUSTRALIA

E. Vernaz, Centre d'Etudes Nucleares de la Valle du Rhone, Marcoule, FRANCE

C. M. Veyer, Commissariat a L'Energie Atomique - SCD, Saint Waast La Vallee, FRANCE 